\title{
JOURNEYS THROUGH SHAPE AND TIME: \\ Palaeobiology of Cenozoic New Zealand \\ SPISSATELLA AND EUCRASSATELLA \\ (Bivalvia, Crassatellidae)
}

by

Katie Susanna Collins

\begin{abstract}
A thesis
submitted to the Victoria University of Wellington

in fulfillment of the requirements for the degree of

Doctor of Philosophy
\end{abstract}

Victoria University of Wellington

2013 





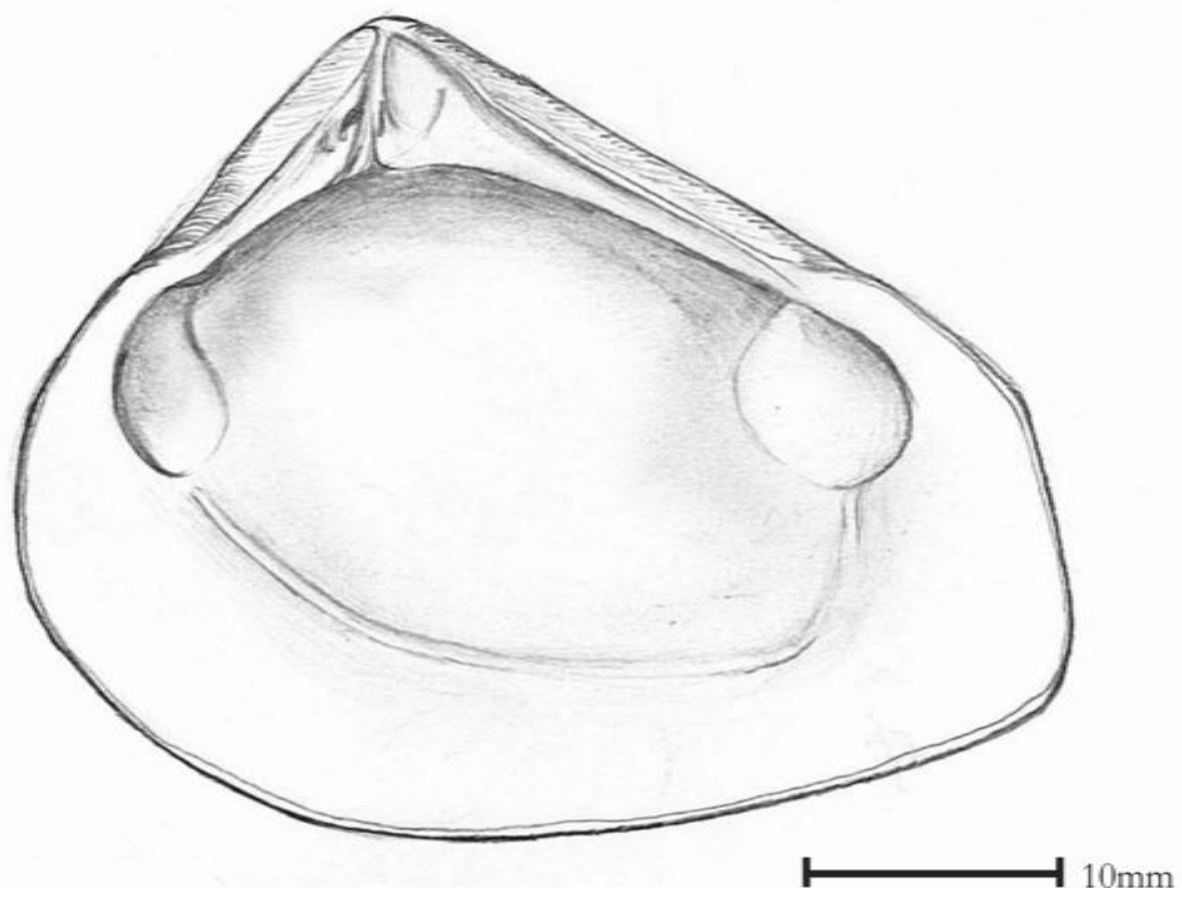

Spissatella trailli

(Lectotype TM2859 - Awamoa, Oamaru, New Zealand) 


\section{ABSTRACT}

A novel, highly-integrated approach combining morphometric, stratocladistic and sclerochronological methods has been applied to two genera of New Zealand Cenozoic crassatellid bivalve (Family Crassatellidae): Spissatella Finlay, 1926 and Eucrassatella Iredale, 1924. This study builds on previous work on Spissatella that demonstrated their amenability to shape analysis and provided a foundation for evolutionary studies of the group. The taxonomy of these crassatellids has been in need of revision; a number of changes to generic placement having been proposed in recent publications without redescription. These bivalves are character-depauperate and known only from fossil material within New Zealand, making them challenging subjects for the phylogenetic analysis that would, ideally, in form taxonomic revision.

Geometric morphometric methods have been used to characterise the morphological variation of the study group in terms of shape. Landmarks/semilandmarks that capture internal hard-part morphology and external shell shape, have been compared with internal landmarks only, outline shape semilandmarks only, and outline shape Fourier transform methods, and are shown to best combine comprehensive coverage of total shell form with high correct reassignment of individuals to taxa in multidimensional morphospace. Procrustessuperimposed landmark/semilandmark configurations have been ordinated using Principal Components Analysis (PCA), and PCA plots have been used to compare the shape variation of each species. The independance in morphospace of Spissatella n. sp. C from S. trailli and S. clifdenensis has been established. Covariation of internal morphology and shell-shape has been interpreted as supporting the interdependance of shell and body/mantle proposed by Stasek (1963).

PCA scores have been combined with traditional morphological characters and stratigraphic data to produce a phylogenetic tree using stratocladistics, a form of parsimony- 
based analysis which seeks to minimise combined morphological and stratigraphic debt. This technique also assesses the placement of taxa in ancestral positions on internal nodes of the tree. Combining discretised morphometric data with stratigraphic and morphological data in a single analysis has been shown to produce a more resolved tree than analyses based only on continuous morphometric data. The new analyses demonstrate paraphyly of both Eucrassatella and Spissatella as previously recognised.

A taxonomic revision of the studied taxa has been undertaken, incorporating information from both morphometric and phylogenetic studies. Spissatella subobesa and $S$. maudensis are referred to Eucrassatella. Spissatella discrepans is synonymised with S. acculta. Triplicitella n. gen. and S.maxwelli n. sp. are described.

Oxygen isotope analysis has been employed to show that shell-banding in these species is, on average, likely to have been laid down annually. Using this information, the longitudinal dataset of outlines from Crampton \& Maxwell (2000) has been recalibrated to use chronological age rather than size to compare shape across taxa, and investigate heterochrony in twelve pairs of species representing either ancestor-descendant, sister-group or lineage-segment relationships. All of the heterochronic processes sensu Gould (1977), namely progenesis, neoteny, acceleration and hypermorphosis, as well as proportioned dwarfism and proportioned gigantism, are identified as having affected evolution within this clade. 


\section{ACKNOWLEDGEMENTS}

To my supervisors, Mike Hannah and James Crampton: You've put up with a lot, from letting me burst into your offices and babble about taxonomic practice to answering late-night pleas for mathematical clarifications. Your advice, from the persuasive ("But with oxygen isotope data, you could talk about evolution. And you like talking about evolution!") to the practical ("Punch the computer if it won't do what you want,") has always been helpful. Thank you for all your hard work and all the support you've given me.

To my partner, Jamie: It's been four years of chaos and mess and accidentally treading on fossil whelks that, I acknowledge, should never have been left on the floor in the first place, but we've made it, and I couldn't have done it without you.

To my family: You encouraged me to keep studying the things I love and have supported me in so many ways during my many, many years at school, and there aren't enough ways to say thank you. I must also express gratitude for your forbearance in instances of "oh God, she's talking about pipis again".

To my friends and fellow postgrads: Matt 'George' Ryan, Sam 'Boots' Nowland, Rory 'Moonface' Mearns and Ignacio 'Nacho' Jara Parra, my officemates in Co305, "the Danger Zone", who taught me everything from why Comic Sans is evil to how to identify rimu pollen; Ben Hines and Bella Duncan, my co-tutors and ammonite hunters extraordinaire, who kept me sane; Caro Hall, my fellow coffee-junkie and frequent rescuer from the pit of my office; Michael Gazley, who edited things at very short notice and with great good humour; Alexa Van Eaton and Melissa Rotella for their comradeship and advice as fellow PhD students; Simon Barker, for his formatting expertise; and a special mention to Georgia Grant for donating "the specimen that changed everything" from Tarakohe Quarry. Thank you guys so much.

Finally, huge thanks are due to the people who let me into their collections, sent me photos, and supported my fieldwork or lab work: John Simes, Marianna Terezow and Alan Beu at GNS Science; Stewart Bush, Euan Smith and Julie Vry at VUW; Neville Hudson at Auckland University; Tom Trnski, Wilma Blom and Severine Hannam at Auckland War Memorial Museum; Bruce Marshall at Te Papa Tongarewa; Ewan Fordyce and the late Andrew Grebneff at Otago University; Norton Hiller at Canterbury Museum; Tom Darragh, Rohlf Schmidt and Thomas Watson at Museum Victoria. Especial thanks must go to Helen Neil and Peter (Chazz) Marriott at NIWA who not only taught me the use of the icromilling equipment and photographed specimens for me, but also analysed my micromilled samples for oxygen isotopes, without which there would be no Chapter Six. 
DEDICATION

FOR MY MOTHER

with much love 


\section{A NOTE ON THE EPIGRAPHS}

Each chapter of this thesis is prefaced with two stanzas from Lewis Carroll's epic nonsense poem The Hunting of the Snark. This may seem an odd choice, and deserves some explanation. The first presentation associated with this project was entitled 'Hunting the Morphospecies', and used the great quest described in the poem, hunting for the Snark and hoping you hadn't accidentally caught a Boojum instead, as a metaphor for taxonomic practice. As this study progressed, the poem continued to be a source of useful inspiration (and entertainment), and so relevant parts have been included, with apologies to Lewis Carroll.

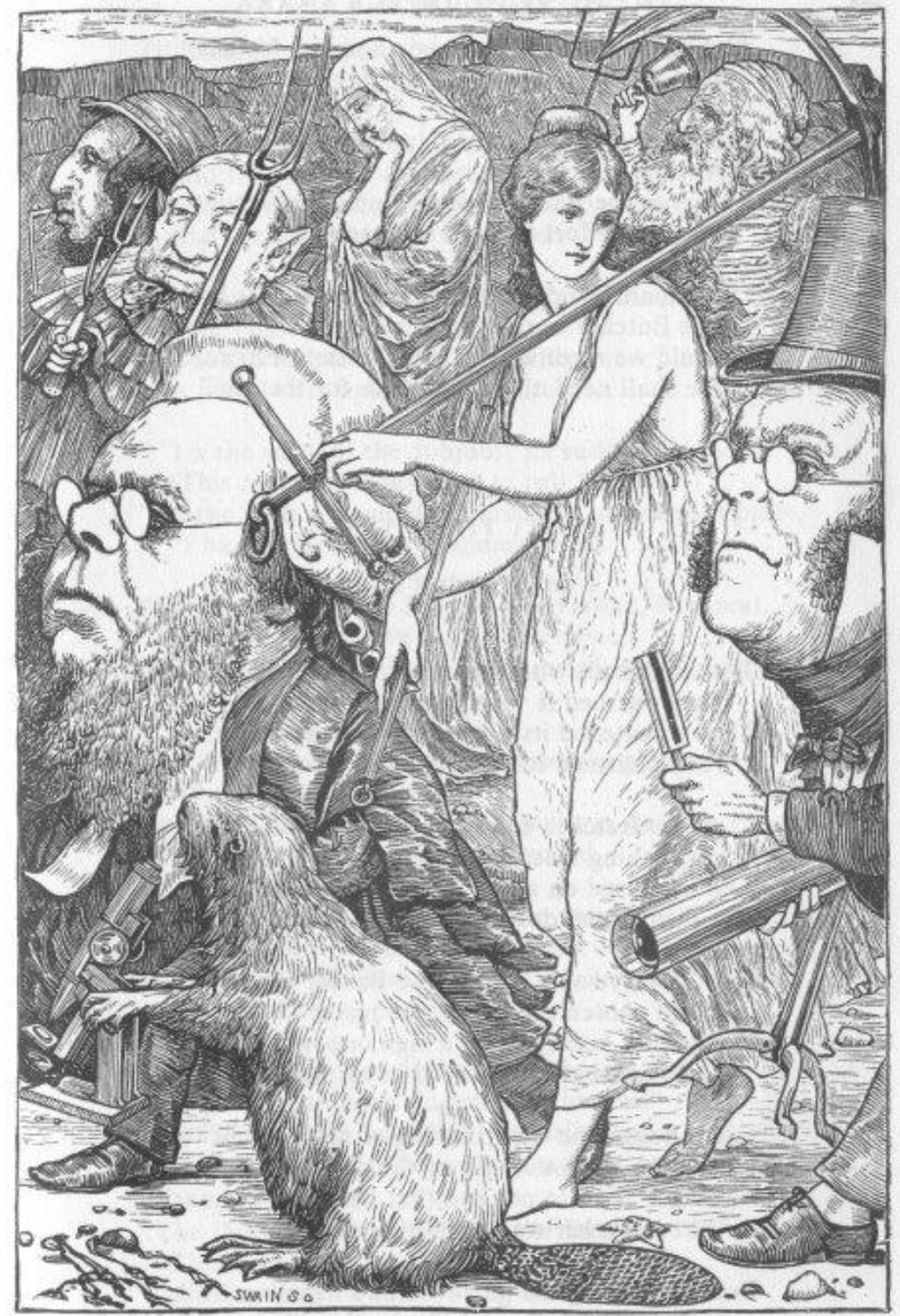

"To pursue it with forks and hope."

Illustration from The Hunting of the Snark: Fit the Fourth - The Hunting by Henry Holiday 


\section{TABLE OF CONTENTS}

Abstract $\quad$ iii

Acknowledgements $\mathrm{v}$

Dedication vii

Note on the Epigraphs $\quad$ ix

Table of Contents xi

List of Tables xii

List of Text Boxes xiii

List of Figures xiii

List of Plates xiv

$1 \quad$ Introduction 1

1.1 Aims 3

1.2 International context 3

1.3 Fossil bivalves as palaeobiological archives 4

1.4 Spissatella and Eucrassatella - a brief history 5

1.5 Phylogenetic taxonomy

$2 \quad$ Background 9

\begin{tabular}{llr}
\hline $2.1 \quad$ Methods overview & 11
\end{tabular}

2.2 Morphometrics 13

$\begin{array}{lll}2.3 & \text { Stratocladistics } & 14\end{array}$

$\begin{array}{lll}2.4 \text { Taxonomy } & 15\end{array}$

$\begin{array}{ll}2.5 & \text { Sclerochronology and heterochrony } \\ 2.6 & \text { Structure }\end{array}$

$\begin{array}{ll}2.6 & \text { Structure of the thesis } \\ & 17\end{array}$

$3 \quad$ Morphometrics 19

$\begin{array}{lll}3.1 \text { Abstract } & 21\end{array}$

3.2 Introduction 21

3.3 Methods and Material 29

3.4 Results and Discussion $\quad 34$

3.4.1 The 'Spissatella trailli' complex 38

3.4.2 Body and Shell/Mantle - Independance and Interaction $\quad 40$

3.5 Conclusions 43

$4 \quad$ Phylogenetics $\quad 45$

$\begin{array}{llr}4.1 & \text { Abstract } & 47\end{array}$

4.2 Introduction 47

4.2.1 Utility of morphometrics and continuous data in cladistics 48

4.2.2 Utility of stratigraphic data in cladistics 49

$\begin{array}{lll}4.3 & \text { Methods } & 51\end{array}$

4.4 Results 61

4.5 Discussion and Conclusions 63

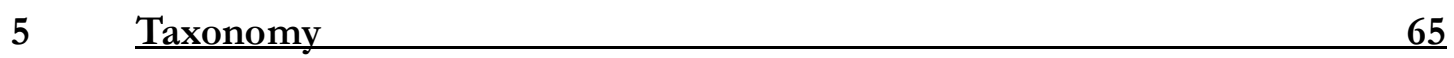

\begin{tabular}{lll}
\hline 5.1 & Abstract & 67
\end{tabular}

$\begin{array}{lll}5.2 & \text { Introduction } & 67\end{array}$

5.2 Morphometrics and phylogenetics contributing to this revision 69

$\begin{array}{ll}5.3 \text { Abbreviations and conventions adopted } & 70\end{array}$

$\begin{array}{lll}5.4 & \text { Systematic taxonomy } & 73\end{array}$

$\begin{array}{ll}\text { Eucrassatella } & 73\end{array}$

Spissatella $\quad 84$

$6 \quad$ Heterochrony 111 
6.1 Abstract 113

$\begin{array}{lll}6.2 & \text { Introduction } & 113\end{array}$

$\begin{array}{lll}6.3 \text { Methods } & 117\end{array}$

$\begin{array}{lll}6.4 & \text { Results } & 127\end{array}$

6.5 Discussion 133

6.6 Conclusions 136

$7 \quad$ Synthesis 137

$\begin{array}{lll}7.1 & \text { Conclusions } & 139\end{array}$

7.2 Functional morphological context and interpretation 140

7.3 Evolution of the larger Crassatellidae in New Zealand 144

$\begin{array}{lll}7.4 & \text { Directions for future work } & 145\end{array}$

$\begin{array}{ll}\text { References } & 147\end{array}$

\begin{tabular}{ll} 
Appendix One - Morphometrics & 159 \\
\hline
\end{tabular}

A1.1 Comparing methods for shape analysis of fossil bivalves 161

A1.1.1 Methods 161

A1.1.2 Results 162

A1.1.3 Summary 165

$\begin{array}{ll}\text { A1.2 Left vs. right valves } & 167\end{array}$

A.1.2.1 Summary 168

\begin{tabular}{lr} 
Appendix Two - Phylogenetics & 169 \\
\hline
\end{tabular}

A2.1 Cladistic solution using continuous morphometric data 171

Appendix Three - Estimating age (by E.G. C. Smith) 173

A3.1 Estimating age jointly from band and isotope data 175

Appendix Four - Specimen and locality data Disc

Appendix Five - Procrustes-superimposed coordinates $\quad$ Disc

\section{LIST OF TABLES}

\section{Chapter Three - Morphometrics}

$\begin{array}{lll}3.1 & \text { Description of landmarks and semilandmarks used } & 23\end{array}$

$\begin{array}{lll}3.2 & \text { Summary of collections used in this study } & 27\end{array}$

3.3 Characters used to compare populations, and their possible states 32

3.4 Tabulated character-state data for the 13 OTUs 33

$3.5 \%$ of variance explained along each PC axis 36

3.6 \% correct reassignment of specimens to groups - whole dataset 36

$3.7 \%$ correct reassignment of specimens to groups - 'S. trailli' complex. $\quad 40$

\section{Chapter Four - Phylogenetics}

$\begin{array}{lll} & \text { Full character matrix } & 58\end{array}$

4.2 Morphological character states $\quad 59$

4.3 Retention Indices and the data used to calculate them 61

Chapter Six - Heterochrony

$\begin{array}{lll}\text { 6.1 Specimens sampled for oxygen isotopes in this study } & 118\end{array}$

$\begin{array}{ll}\text { 6.2 Clock model data } & 124\end{array}$

$\begin{array}{ll}\text { 6.3 Species pairs investigated } & 125\end{array}$

Appendix One - Morphometrics

A1.1 \% correct reassignment of specimens to OTUs - semilandmark datasets 164

A1.2 \% correct reassignment of specimens to OTUs - all methods $\quad 164$

$\begin{array}{lll}\text { A1.3 Left vs right valve MANOVA results } & 167\end{array}$ 


\section{LIST OF TEXT BOXES}

Chapter Three - Morphometrics

$\begin{array}{lll}\text { Text Box } 1 & \text { Morphometrics overview } & 21\end{array}$

Text Box 2 Landmarks and semilandmarks 30

Text Box 3 Superimposition methods 34

Text Box $4 \quad$ Statistical ordinations (PCA, CVA) 35

Chapter Four - Phylogenetics

$\begin{array}{lll}\text { Text Box } 5 \quad \text { Cladistics and stratocladistics } & 49\end{array}$

Text Box $6 \quad$ Boxplot coding 56

Text Box $7 \quad$ The Retention Index 57

Chapter Six - Heterochrony

$\begin{array}{lll}\text { Text Box } 8 & \text { Heterochrony definitions } & 115\end{array}$

\section{LIST OF FIGURES}

Frontispiece - Spissatella trailli lectotype i

Illustration from The Hunting of the Snark by Henry Holiday ix

Chapter Three - Morphometrics

3.1 The landmark/semilandmark configuration used in this study. 22

3.2 Species included in this study 25

3.3 New Zealand geological timescale, species range-chart 26

$\begin{array}{lll}3.4 & \text { PCA plots and deformation grids } & 37\end{array}$

3.5 PCA and CVA of Spissatella trailli complex 39

Chapter Four - Phylogenetics

4.1 Species included in this study 52

4.2 States of characters 1-4 54

4.3 States of characters 5-9 55

4.4 Barchart of shell heights (Character 10) 56

4.5 Boxplots of PC scores along eight PC axes for the dataset 59

4.6 New Zealand geological timescale, species range-chart 60

4.7 Phylogeny for species of Spissatella and Eucrassatella 62

Chapter Five - Taxonomy

5.1 Phylogeny of the species of larger Crassatellidae from New Zealand 71

5.2 PCA plot of $95 \%$ confidence ellipses on the means of the revised genera $\quad 72$

5.3 PCA plot of $95 \%$ confidence ellipses on the means of Eucrassatella species $\quad 75$

$\begin{array}{lll}5.4 & \text { Crassatellid bivalve collection localities } & 76\end{array}$

5.5 PCA plot of 95\% confidence ellipses on the means of Spissatella species 87

Chapter Six - Heterochrony

$\begin{array}{lll}6.1 & \text { Species included in this study } & 114\end{array}$

6.2 Phylogeny of the species of larger Crassatellidae from New Zealand 119

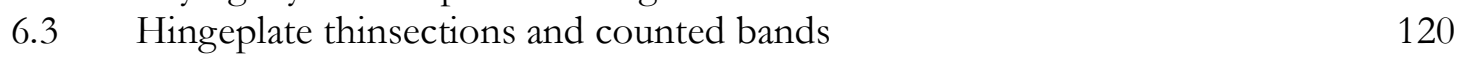

6.4a Relation of milled transects to oxygen isotope curves 122

6.4b Oxygen isotope curves plotted over shell transects 123

6.5 PCA plot with synthetic outlines from Crampton \& Maxwell (2000) 124

$\begin{array}{ll}\text { 6.6 Clock models - explanation and examples } & 126\end{array}$

6.7a-d Clock models and ontogenetic trajectory plots for the crassatellid dataset 127

6.7e-h Clock models and ontogenetic trajectory plots for the crassatellid dataset 129

6.7i-1 Clock models and ontogenetic trajectory plots for the crassatellid dataset 131 
6.8 Distribution of modes of heterochrony over phylogeny of study group

Chapter Seven - Synthesis

7.1 Qualitative morphospace of posterior shape vs. sculptural extent

Appendix One - Morphometrics

AF1.1 Diagrams of morphometric datasets tested

AF1.2 Stacked DFA histograms comparing datasets

AF1.3 Left vs. right valve DFA histograms

AF1.4 Mean left and right valve shapes for OTU 10

Appendix Two - Phylogenetics

AF2.1 Cladogram including continuous measurement data

LIST OF PLATES

Plate 1

Eucrassatella

105

E. marshalli

a-f

E. ampla

g-h

E. scopalveus

i-m

E. subobesa

$\mathrm{n}-\mathrm{q}$

E. maudensis

$\mathrm{r}-\mathrm{u}$

Plate 2 Spissatella

107

S. clifdenensis

a-d

S. trailli

e-g

S. maxwelli $\mathrm{n}$. sp.

h-o

S. acculta

p-s

S. poroleda

t-w

S. media

$\mathrm{X}-\mathrm{Z}$

Plate 3

Triplicitella n. gen.

109

T. australis

a-k 


\section{1 \\ Introduction}

'"Just the place for a Snark!! the Bellman cried,

As be landed his crew with care;

Supporting each man on the top of the tide

By a finger entwined in his hair.

'Just the place for a Snark!! I have said it twice:

That alone should encourage the crew.

Just the place for a Snark!! I have said it thrice:

What I tell you three times is true."

- The Hunting of the Snark: Fit the First - The Landing 


\subsection{Aims}

The aims of this study are threefold:

1 - To establish an integrated morphometric and stratocladistic procedure for studying fossil bivalve phylogenetics, and apply it to the larger New Zealand Crassatellidae;

2 - To apply sclerochronological techniques to investigate heterochrony as a mechanism of speciation in the larger New Zealand Crassatellidae.

3 - To revise the taxonomy of the larger Crassatellidae of New Zealand.

\subsection{International context}

The genera Spissatella and Eucrassatella are geographically restricted to New Zealand and Australia, but the Crassatellidae is a world-wide fossil group with sparsely-distributed extant members. They are united with the Carditidae and Astartiidae in the unranked clade Archiheterodonta, which is considered to be a sister clade to all other heterodonts (which are united as the Euheterodonta) (Taylor et al., 2007; Giribet, 2008), and the earliest known genus assigned to the Archiheterodonta is the Devonian crassatellid Eodon Hall 1877 in Miller (Carter et al., 2000; Taylor et al., 2007).

This study represents a contribution to overall knowledge of the Crassatellidae, which are an understudied group with only sparse literature on any aspect of their biology or palaeobiology, by providing a detailed phylogenetic and taxonomic examination of two genera out of an estimated 15 total worldwide (as listed in the Treatise on Invertebrate Palaeontology: I am unable to find any more recent estimate of the global diversity of the group). It also stands as a contribution to the study of fossil bivalves in general, by applying morphometric, sclerochronological, and heterochronic method s to a particularly character-depauperate group in a cohesive way that could be used on other taxa. 


\subsection{Fossil bivalves as palaeobiological archives}

Fossil bivalve molluscs, due to their readily-preserved calcareous shells and aquatic habitat, are amongst the most commonly preserved macrofossil taxa, and for this reason are often used in 'big picture' macroevolutionary and macroecological studies (e.g. Jablonski, 1986; Raup \& Jablonski, 1993; Jablonski \& Raup, 1995; Goldberg et al., 2005). Furthermore, bivalves are useful for biostratigraphy in New Zealand (e.g. Beu, 1995; Meesook \& Grant-Mackie, 1995; Crampton et al., 2001; Beu, 2006) and palaeoecology (e.g. Bradshaw \& McCartan, 1991; Hautman \& Nützel, 2005; Schatz, 2005), due to their long time-range as a class (Cambrian - Recent; Spencer et al., 2009) and their abundance in marine deposits. Bivalves form a major part of many marine communities, providing prey for predators such as crabs, starfish, octopi and gastropods, acting as the substrate for colonial animals, and as host for symbiotic algae (Beesley et al., 1998). They are found in a variety of marine and freshwater habitats, including lakes, estuaries, shallow- and deepwater oceanic settings, and geothermal seeps. Furthermore, wild bivalves are exploited as a food source by humans the world over, and some species are farmed for meat, shell material, or pearls, making them economically important to humans (Giribet, 2008).

The manner of bivalve shell growth, by secretion of calcium carbonate along the shell margin in chemical equilibrium with the surrounding water (Lutz \& Rhoads, 1970), means that they are suitable subjects for sclerochronology and geochemical investigation of palaeoclimate (e.g., Jones et al., 1984; Richardson, 2001). Bivalves can form a valuable palaeoenvironmental archive in the same manner as tree rings and speleothems, sometimes providing monthly or even daily resolution over a number of years. Furthermore, the periodic, accretionary nature of their growth allows reconstruction of earlier growth-stages and thus longitudinal ontogenetic data can be collected from any population of bivalves. These qualities make bivalves valuable for both geological and palaeobiological research. 


\subsection{Spissatella and Eucrassatella - a brief history}

Spissatella Finlay, 1926 and Eucrassatella Iredale, 1924 are mid-Cenozoic bivalve genera of the family Crassatellidae Férussac, 1822, order Carditoida Dall, 1889, subclass Heterodonta Neumayr, 1884. Nine species of Spissatella and five species of Eucrassatella from New Zealand are listed by Maxwell in Spencer et al. (2009), ranging in age from the late Eocene to the middle Miocene. Additionally, an undescribed species (Spissatella n. sp. C) is mentioned in Cenozoic Mollusca of New Zealand (Beu \& Maxwell, 1990), and included in Crampton and Maxwell's morphometric analyses (2000). One species, S. maudensis, is known from Australia (Darragh, 1965), and one species, S. byelli, is known from Patagonia (Griffin \& Nielsen, 2008). A further South American Tertiary species, Crassatella longior, may be referrable to Spissatella (Beu, 1997).

Spissatella and Eucrassatella contain the largest species of crassatellids known from New Zealand. Other crassatellid genera (Salaputium, Chattonia, Talabrica) present in New Zealand are smaller ( 5-15 mm high). For this reason, Spissatella and Eucrassatella will be referred to as the 'larger' crassatellids in this thesis, as a convenient shorthand.

Most species now referred to Eucrassatella from New Zealand were originally described as either Crassatella or Crassatellites (Zittel, 1864; Hutton, 1873; Suter, 1914; Marshall \& Murdoch, 1919; Laws, 1935). Spissatella was erected in 1926 by Finlay to contain any smooth-margined crassatellid that he considered too small to belong in Eucrassatella:

"... Eucrasssatella Iredale (loc. cit., p. 202) is available only for the large forms such as amplus (Zittel) and attenuatus (Hutton). The 'trailli' series, to which belong subobesus M\&M., Astarte australis Hutton, and all the forms here described, differs from Eucrassatella in size, character of initial ornament, hinge and muscle scars ... the members of the four genera above mentioned [Talabrica, Salaputium, Eucrassatella, 
Spissatella] all have smooth margins, while the genotype of Crassatellites itself ( $C$. sinuatus Krueger $=$ C. gibbosa Lk.) has finely corrugated margins ..."

(Finlay, 1926; p.256)

Several species assigned by Finlay to Spissatella were transferred to Eucrassatella by Beu and Maxwell (1990) on the basis of "size, shape, and sculptural characters" (e.g. " $S$ ". australis) and by Crampton and Maxwell (2000) on the basis of "sculpture, shape, ontogenetic development and shell thickness (unpublished data)" (e.g. " $S$ ". scopalveus and "S". concisa). As presently defined by Crampton and Maxwell (2000), Spissatella differs from Eucrassatella in having a smaller, thinner shell with a proportionally smaller hingeplate, and having commarginal sculpture over the entire shell.

It has been suggested that Spissatella was derived from an unknown Australian Eucrassatella, which is presumed to have colonised New Zealand during the Eocene and given rise to Spissatella (Crampton \& Maxwell, 2000). However, the larger crassatellids have a longer confirmed range in New Zealand than in Australia, thus making this relationship unlikely. The oldest confirmed member of the group from either country is Eucrassatella australis (Heretaungan - Runangan (mid-late Eocene); Waimate, Canterbury; pers. comms. A. Beu, 2012). Although Darragh (1965) lists a possible Eocene occurrence for Eucrassatella in Australia, it consists of a single specimen that has not been convincingly assigned to a species.

The larger crassatellids in New Zealand have not been well-studied. They are common in a number of Oligocene and Miocene sections, and moderately speciose, but have not received detailed attention beyond appearing in faunal lists. This study aims to improve this state of affairs, revise the taxonomy of the group, contribute evolutionary hypotheses, and test and extend morphometric and phylogenetic methods for use with fossil bivalves. 


\section{5 - Phylogenetic taxonomy}

In order for any group of organisms to be used in biostratigraphy, palaeoecological and palaeoenvironmental studies, or palaeoclimatology, taxonomy is required (Wilson, 2004) as assumptions of appearance and extinction dates, preferred habitats, and shell chemistry are implicit in identifications. Taxonomy should reflect evolutionary understanding of the group under study, and be phylogenetically informed.

Fossil bivalves are depauperate in terms of the kind of discrete characters that are traditionally considered admissible in phylogenetic (cladistic) analyses (Skelton et al., 1990), e.g., presence/absence of features, or characteristics that vary in discrete, non-overlapping ('red' or 'yellow' or 'blue') ways. It is a requirement of the cladistic method that in order to group or discriminate between taxa, there must be more characters than taxa in the analysis. Due to this paucity of characters, fossil bivalves have been considered unsuitable for generic-and specific-level cladistic analysis (Davis, 1982; Schneider, 2001). However, there are other attributes of fossil bivalves that could be used phylogenetically.

First, bivalves are highly variable in their shape. Bivalve shape is strongly influenced by the habitat of the organism, and thus is likely to be under strong selection pressure (Seilacher, 1984). This would make shape an ideal source of data for phylogenetic analysis if it could be brought into the cladistic framework, but discussion is ongoing as to both the admissibility of quantitative morphometric data on shape, and methods for achieving this (see Systematics Association Special Volume 64, 'Morphology, Shape and Phylogeny' (2002) for thorough coverage of this topic).

Secondly, bivalves have an excellent fossil record. The order of their appearance and disappearance in the stratigraphic record could be used as a character, and a method stratocladistics - exists to do just that. Stratocladistics has been shown to improve the power of cladistic analyses in studies with reliable stratigraphic control (Fisher, 2008), although, as with the inclusion of morphometric data, its theoretical admissibility is still 
debated (e.g. Smith, 2000; Adrain \& Westrop, 2001; Fisher et al., 2002). In this study, a pragmatic approach is adopted, utilising both morphometric and stratigraphic data. 
2

\section{Background}

"He had bought a large map representing the sea,

Without the least vestige of land:

And the crew were much pleased when they found it to be

A map they could all understand.

'What's the good of Mercator's North Poles and Equators,

Tropics, Zones and Meridian Lines?'

So the Bellman would cry: and the crew would reply

'They are merely conventional signs!"'

- The Hunting of the Snark: Fit the Second - The Bellman's Speech 


\subsection{Methods overview}

To achieve the aims as set out in Chapter One, this study employs a number of disparate methods for describing the fossilised bivalve shell, from quantifying its shape and morphological variation to using geochemical techniques in order to understand its growth and development. These methods are combined in various ways to address the taxonomic, phylogenetic and ontogenetic aims of the work.

Traditionally, bivalve morphology is described qualitatively (e.g. many works including Finlay, 1926; Boreham, 1965; Beu, 2006), and species are defined and assigned to genera. Evolutionary inferences may then be made between species on the basis of the se descriptions, often taking into account stratigraphic order (e.g. many instances in Beu \& Maxwell, 1990). The development of phylogenetic methods has allowed qualitative descriptions to be used as data for cladistics, which produces hypotheses of sister-taxon relationships between species. These relationships become the basis of phylogeneticallyinformed taxonomy.

However, morphological variation is not always easily described qualitatively; continuous or nearly-continuous variation of a feature is harder to frame in words than simple presence or absence. Morphometrics allows mathematical comparisons of shape between individuals or between taxa. Using principal components analysis (PCA) and multivariate analysis of variance (MANOVA), shape differences can be visualised and tested statistically in a manner that has taxonomic utility (Zelditch et al., 2004).

Furthermore, morphometrics provides data that can be used in phylogenetics (MacLeod, 2002); either as continuous data (e.g. Goloboff et al., 2006) or divided into character-states by one of a number of coding methods (e.g. Almeida \& Bisby, 1984; Swiderski et al., 1998). The use of morphometrics to inform taxonomy and phylogenetics brings repeatability and rigour to these disciplines. It has also been shown (Bodenbender \& Fisher, 2001; Fisher, 2008), despite some objections on theoretical grounds (Smith, 2000; 
Adrain \& Westrop, 2001), that the addition of stratigraphic data to cladistic analyses improves resolution of phylogeny in instances where stratigraphy is well-resolved. For this reason stratigraphic data have been used here to inform phylogenetic analyses.

Phylogenetics produces hypotheses of relationships between taxa, but the evolutionary nature of those relationships and the speciation events that produced them require further data. Changes in developmental timing (heterochrony), i.e., the timing of growth and somatic development relative to sexual maturation, are a major source of evolutionary novelties which can produce phyletic change and/or speciation events (Gould, 1977). Bivalves offer the opportunity to examine both shape-change through phylogeny (between related taxa), and shape-change through ontogeny (between growth-stages of the same specimen), as the accretionary nature of shell material along a single growth margin allows reconstruction of past shapes (Crampton \& Maxwell, 2000). Sclerochronology, using oxygen isotope analysis can provide information on ontogenetic age and growthrates. High-resolution sampling of shell material for oxygen isotope data reveals annual couplets of winter-high - summer-low values of $\delta^{18} \mathrm{O}$ (e.g., Ivany et al., 2003). Counting couplets over a transect of known distance will give estimates of shell length relative to years lived, which will allow species to be compared at a common growth-stage rather than a common size. Combining measurements of shape and size, sclerochronologically-derived estimates of age-at-size, and phylogenetic hypotheses of relationships, we can examine species' size, form and age at a standardised growth stage and identify the heterochronic processes that differentiate an ancestral species from its descendant or a species from its sister - relative acceleration and retardation of growth relative to age, through evolutionary time (Jones \& Gould, 1999). 


\subsection{Morphometrics}

Traditional morphometrics involves discrete measurements, e.g., length and height, examined either singly or in bi-or multivariate analyses. These measurements are more often selected for ease of collection than any biological meaning and often ignore areas of significant shape variation such as curved margins (Scott, 1980). Geometric morphometrics, in contrast, deals with configurations of measurements describing whole shapes (Zelditch et al., 2004; Webster \& Sheets, 2010). Geometric morphometrics is subdivided into landmark-based methods, which examine shapes recorded as configurations of discrete two- or three-dimensional Cartesian coordinates (e.g. Bookstein, 1997; Perez et al., 2006; Aguirre et al., 2006), and outline-based methods, which use Fourier (e.g., Kaesler \& Waters, 1972; Rohlf \& Archie, 1984; Foote, 1989; Crampton and Maxwell, 2000; Haines and Crampton, 2000), eigenshape or other curve-based approaches (e.g. Gevirtz, 1976; Lohman, 1983; MacLeod, 1991; MacLeod, 1999; Innes \& Bates, 1999; Sholz \& Hartman, 2007). Webster and Sheets (2010) note that these two methods (together with 'traditional' morphometrics) "share much in terms of underlying analytical machinery ... [and] the divide between styles is bridged by morphometric approaches such as Euclidean distance matrix analysis ... and analysis of semilandmarks".

As landmark and outline analyses cover different aspects of the morphology of an organism, they should not be regarded as competing, but as complementary, at least in some instances. In a landmark-based analysis, corresponding points on different specimens refer to a biologically homologous locus which is identifiable across all specimens in the study (Zelditch et al., 2004). Landmark-based methods are therefore powerful tools that allow the use of anatomical homologies in tracing relatedness between groups, but as originally formulated they are limited in that they cannot capture shape changes along margins that lack discrete homologies. A relatively recent adaptation of the method allows for the inclusion of 'semilandmarks' around homologous curves, such that individual 
points are not strictly homologous but the overall curve is. In this study, a configuration of 45 landmarks and semilandmarks has been used. This configuration summarises the internal anatomy, including the pallial line, and the outline shape. Data generated have been used to discriminate taxa, gather data for stratocladistic use, and examine the shape change and covariance of internal and external shapes.

A set of adult and reconstructed younger growth-stage outlines, captured using Fourier methods by Crampton and Maxwell (2000), is used in conjunction with sclerochronological data in order to address questions of heterochrony and speciation mechanisms. Chapter Three outlines the landmark/semilandmark methodology and the anatomical and taxonomic outcomes of this study; the confirmation of Spissatella n. sp. C as morphologically separate from $S$. trailli, and a reconsideration of the Concept of Independant Entities proposed by Yonge (1953) and debated by Stasek (1963) and Stanley (1970). Morphometric data are utilised also in Chapter Four (in the form of the PCA scores from the landmark/semilandmark dataset of Chapter Three) and Chapter Six (in the form of Fourier outlines from Crampton and Maxwell's (2000) study).

\subsection{Stratocladistics}

Stratocladistics is a parsimony-based phylogenetic method that seeks shared patterns of character-state distributions amongst taxa. In this it is similar to its parent method, cladistics. However, it uses an altered parsimony criterion that includes 'stratigraphic parsimony' - it tries to minimise ad hoc appeals to non-preservation as well as minimising ad hoc appeals to convergence or reversal of character states, and thus to find the shortest tree that reconciles the observed pattern of fossil occurrences with the pattern of morphological variation.

Debate over stratocladistics has continued since its proposal by Fisher (1994).

There have been objections to temporal data entirely on a variety of theoretical grounds 
(summarised in Adrain \& Westrop, 2001), and doubts about stratigraphic binning methodologies (Smith, 2000). These concerns have been addressed by a number of authors (Fisher et al., 2002; Wagner, 2002), and tests on stratocladistic and cladistic methodologies (e.g. Fox et al., 1999; Bodenbender \& Fisher, 2001) have shown that stratocladistics performs better in terms of resolving phylogenies than cladistics in studies where the stratigraphic data are reliable.

The incompleteness of the fossil record has also been raised as a potential objection to strato-methods in phylogenetics (Smith, 2000; Adrain \& Westrop, 2001). The New Zealand Cenozoic mollusc record is considered the most complete in the Southern Hemisphere, with the per-interval sampling probability at the specific level estimated at 20 48\% (Crampton et al., 2006). Whereas the fossil record is most certainly incomplete, it still contributes to our knowledge of the order of appearance of taxa, and as such it is still better to use stratigraphic data than to ignore them. Chapter Four discusses the stratocladistic methodology employed in this study and presents a new phylogeny for Spissatella and the New Zealand species of Eucrassatella.

\subsection{Taxonomy}

Identifications and higher-level taxonomy and systematics represent hypotheses of descent and relatedness, and as such should be phylogenetically informed. Monophyly of groups at the genus level and above is paramount; any group should be made up of all the descendants of one common ancestor. Prior to this study, no phylogeny for the larger Crassatellidae in New Zealand has ever been attempted, and the current taxonomy is in need of revision. The phylogeny presented in Chapter Four highlights several inconsistencies in current generic assignments, and the morphometrics presented in Chapter Three confirm the separate identity of Spissatella n. sp. C from S. trailli and S. clifdenensis. Chapter Five comprises a thorough revision of all species of Spissatella and 
Eucrassatella from New Zealand. All species are fully redescribed and illustrated, with reference to the phylogeny from Chapter Four, and appropriate morphometric plots drawn from the dataset of Chapter Three.

\subsection{Sclerochronology and heterochrony}

Having brought together a comprehensive dataset on the form and descent of this group of molluscs, the logical application of it is to questions of evolutionary mechanisms. For this, however, there is one further piece of information required; chronological age, and the lifespan of individuals in a species. Bivalves preserve this information, growing as they do by accretion of shell material (calcium carbonate) along their margin, generally commarginally. The calcium carbonate may be in the form of calcite or aragonite, and is typically deposited in equilibrium with the surrounding water, meaning that the $\delta^{18} \mathrm{O}$ content of the shell varies seasonally as the $\delta^{18} \mathrm{O}$ content of the water changes, showing enriched values during winter and depleted values in summer. These temporal data form the basis of sclerochronological analyses. The best-known application of sclerochronology is to climate records (e.g., in corals; Lough \& Barnes, 1990; Lazier et al., 1999; Noé et al., 2008; in bivalves; Schöne et al., 2005; Hallmann et al., 2008; Schöne \& Fiebig, 2009). The same techniques can, however, be applied to the understanding of development, aging and growth (e.g. Jones et al., 1984; Jones \& Gould, 1999).

Using oxygen-isotope analysis, we can age shells and derive growth-rates for taxa by counting annual peaks in $\delta^{18} \mathrm{O}$ over transects of known length and using this to estimate the number of years the shell grew. Combining this with shape information captured from several growth stages of an individual, changes in developmental timing (heterochrony) can be investigated, and thus we can examine shape-change through ontogeny - how does the shape of a juvenile specimen compare to the shape of an adult, and how does this pattern 
change through evolutionary time? How abrupt are changes in shape between age-classes? Where does the shape change?

Heterochrony as a process operates by either acceleration or retardation of somatic growth relative to reproductive features (Gould, 1977) - in terms of fossil bivalves, heterochronic change will involve comparison of juvenile shape to adult shape. The number of years it takes to attain a certain shape is expected to vary between taxa. Crampton and Maxwell (2000) compared 'juvenile', 'immature' and 'adult' shapes, but calibrated shape to body size, rather than the life-span of the individual specimen, for which they lacked data. Their results were therefore in the form of allometric heterochrony - shape change relative to size - not true chronological heterochrony. With the addition of true age data rather than size as a proxy for age, we can recover true chronological heterochrony. Chapter Six contains sclerochronological data collected for a small suite of specimens, and clock models of heterochronic change (after Gould, 1977) constructed using these data, the outline dataset of Crampton and Maxwell (2000), and the ancestordescendant relationships proposed by phylogenetic analysis in Chapter Four. Heterochrony as a mechanism of speciation in the New Zealand Crassatellidae is discussed.

\subsection{Structure of the thesis}

This thesis comprises seven chapters. The first two are introductory and include the relevant background literature and summaries of methodological groundwork. The third and fourth chapters present methodological contributions to morphometrics and phylogenetics respectively; the fifth chapter is a taxonomic revision of the species and genera studied herein based on new evidence of affinities between species brought to light by the morphometric and phylogenetic investigations in Chapters Three and Four. The sixth chapter adds sclerochronologically-derived age information and draws on the data and results presented in the previous three chapters to examine the evolution of the group and 
possible mechanisms of speciation in terms of heterochrony. Chapters Three - Six have been prepared for submission to journals and are structured accordingly. In places, text boxes have been inserted into the text to contain supplementary or explanatory material which would not ordinarily have been included in a paper for publication.

The seventh chapter concludes by summarising the findings of the preceding four chapters and discussing them in terms of functional morphology and evolutionary trends. 


\section{3}

\section{Morphometrics}

'"Two added to one - if that could but be done,'

It said, 'with one's fingers and thumbs!'

Recollecting with tears how, in earlier years,

It had taken no pains with its sums.

'The thing can be done,' said the Butcher, 'I think.

The thing must be done, I am sure.

The thing shall be done! Bring me paper and ink,

The best there is time to procure."'

- The Hunting of the Snark: Fit the Fifth - The Beaver's Lesson 


\section{Identification and independence: Morphometrics of Cenozoic New Zealand Spissatella and Eucrassatella (Bivalvia, Crassatellidae)}

\subsection{Abstract}

Fossil bivalve shells are well-suited for landmark/semilandmark morphometric analysis as they preserve both traces of the internal anatomy and the whole shell outline, including an ontogenetic series of outline shape. Utilising landmarks and semilandmarks, we have characterised internal and external shape variation in a monophyletic clade of Cenozoic New Zealand crassatellid bivalves, to test the contiguity in morphospace of species-level taxa, and to examine covariation between the internal and external shapes in order to assess the applicability of the "Concept of Independant Entities" of Yonge (1953) to this group. Spissatella n. sp. C is confirmed as forming a contiguous group separate to $S$. trailli and S. clifdenensis. Shell outline and internal anatomy are found to covary in shape, refuting the "Concept of Independant Entities" in the study group.

\subsection{Introduction}

Geometric morphometric methods (Text Box 1) quantify biological shape using mathematical tools (e.g. Zelditch et al., 2004; Webster \& Sheets, 2010). Many studies have applied geometric morphometrics to a wide spectrum of organisms with a range of goals; including the investigation of allometry and ontogeny (Zelditch et al., 1992; Fink \& Zelditch, 1995, Zelditch et al., 2000; Monteiro et al., 2005), and phylogenetics
Text Box 1: Morphometrics is the branch of mathematics that deals with the measurement of shape. In biology, morphometrics has been used to describe both simple measurements of specimen dimensions e.g. length, width, height (traditional morphometrics), and the more complex multivariate methods known as geometric morphometrics, which are divided into landmark methods (Text Box 2; used in this chapter) and outline methods (used in Chapter Six).

(Klingenberg \& Gidaszewski, 2010, Clouse et al., 2009, de Bivort et al., 2010). 


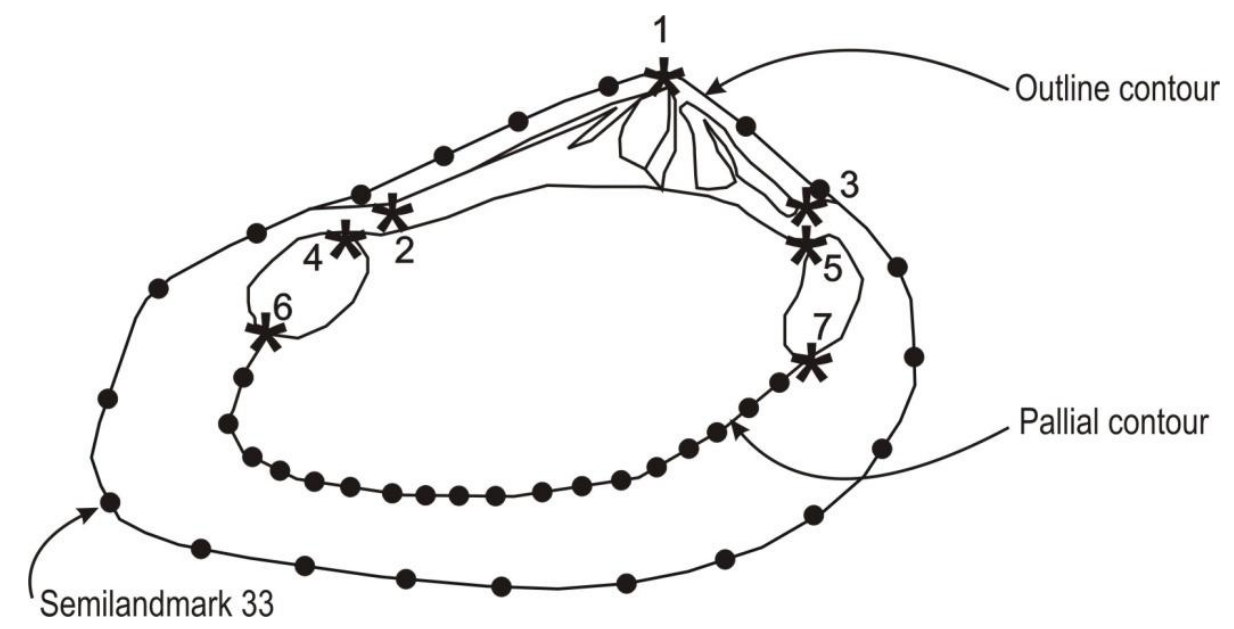

Figure 3.1: The landmark/semilandmark configuration used in this study. Asterisks indicate landmarks (which are numbered) and circles indicate semilandmarks. See Table 3.1 for descriptions and classifications of landmarks.

This study utilises a configuration of landmarks and semilandmarks (e.g. Bookstein, 1991; Bookstein, 1997; Zelditch et al., 2004; Perez et al., 2006; Webster \& Sheets, 2010) to characterise comprehensively the internal anatomy and the overall shape of the crassatellid bivalve shell. Landmark/semilandmarks are discrete Cartesian coordinates which capture points on the specimen that are inferred to be anatomically homologous with each other or to delineate homologous curves such as the pallial line (Zelditch et. al. 2004). Figure 3.1 summarises the landmark/semilandmark configuration used in this study.

Landmarks were classified into three types by Bookstein (1991):

Type 1 landmarks are optimal, locally-defined points such as juxtapositions of tissues (e.g., Landmark 6, the junction of the pallial line and posterior adductor muscle scar);

Type 2 landmarks are local minima and maxima (e.g., Landmark 2, the distal end of the posterior lateral tooth or socket);

Type 3 landmarks are globally-defined extremes. Semilandmarks are considered Type 3 points (Gunz et al. 2005). The configuration of landmarks/semilandmarks used includes seven landmarks and two curves delineated by semilandmarks - the internal 
contour of the pallial line, anchored by two landmarks, and the external shape of the shell, which is a closed contour anchored on one landmark (Table 3.1; Figure 3.1).

\begin{tabular}{|c|c|c|}
\hline$\#$ & Description & Type \\
\hline 1 & Tip of beak & 1 \\
\hline 2 & Distal end of posterior lateral tooth/socket & 2 \\
\hline 3 & Distal end of anterior lateral tooth/socket & 2 \\
\hline 4 & $\begin{array}{l}\text { Junction of hingeplate and posterior adductor } \\
\text { muscle scar }\end{array}$ & 1 \\
\hline 5 & $\begin{array}{l}\text { Junction of hingeplate and anterior adductor } \\
\text { muscle scar }\end{array}$ & 1 \\
\hline 6 & $\begin{array}{l}\text { Junction of posterior adductor muscle scar } \\
\text { and pallial line }\end{array}$ & 1 \\
\hline 7 & $\begin{array}{l}\text { Junction of anterior adductor muscle scar and } \\
\text { pallial line }\end{array}$ & 1 \\
\hline $8-25$ & Pallial line & 3 \\
\hline $26-45$ & Outline & 3 \\
\hline
\end{tabular}

Table 3.1: Landmarks (1-7) and semilandmarks (8-45). 'Type' refers to the landmark classification scheme of Bookstein (1991) (see text).

Crassatellids are non-siphonate, infaunal filter-feeders (Beesley et al., 1998). Their depth of burial is constrained by their lack of siphons - they must remain close enough to the sediment surface so that their inhalant and exhalant currents, which are required for feeding, excretion and respiration, can access water. Therefore, the posterior margin of the shell must intercept the sediment surface. This makes them vulnerable to disinterrment by waves, currents or predators. Anteriorly, the species studied here are uniformly prosogyrous (having anteriorly-directed beaks) with a flattened lunule (the anterior area between the beaks), a form that is a fundamental adaptation of burrowing bivalves (Stanley, 1975) which allows them to resist being pulled out of the burrow they are digging by their own see-sawing, reciprocal burrowing action. Non-siphonate bivalves commonly have either flattened posterior margins that in life-position are oriented parallel to the sediment/water interface, or rostrate posteriors, in which case the long axis of the shell will be oriented almost vertically in life position (Stanley, 1970). Both of these characteristic shapes are observed in the study group, along with a third type with a broadly-rounded posterior. Shell 
outline-shape and size were shown to be correlated by Crampton and Maxwell (2000), contrary to the conclusion of Stanley and Yang (1987) that size and shape in bivalves act independently during evolution.

The larger fossil crassatellid bivalves of New Zealand, Spissatella Finlay (1926) and Eucrassatella Iredale (1924) (Figure 3.2), are a group in which the majority of morphological differences reside in overall shape. The hinge configuration, sculpture, muscle-scars, and pallial line are all conservative with regard to features that may be described in terms of multiple, discrete character states (number of teeth, nature of sculpture, shape of scars, etc.) both within and between the genera. Within-taxon shape variation is high in the majority of species under study. For example, several collections previously identified as Spissatella trailli are in open nomenclature (Crampton \& Maxwell, 2000) as a potential new species (Spissatella n. sp. C). The relationship of this putative taxon to other taxa in a landmark/semilandmark morphospace will allow a confident assessment of it as either as a new group or part of the variation of an already named species.

The purpose of the study is to examine relative changes in shape between the overall shell outline and the internal anatomical configuration, with two aims. The first is to reassess the "Concept of Independant Entities" of Yonge (1953), which suggests that there is a disconnect between the internal and external morphologies; e.g., rotation of shell/mantle relative to body in the Tridacnidae, resulting in an 'upside-down' shell compared to other heterodonts. This independance of internal and external morphologies from one another was rejected by Stasek (1963) and Stanley (1970) on the basis that the shell/mantle system is inextricably linked to the body. Stasek (1963) also argued that the shell/mantle and body share points of homology, although he did not describe them. The second aim is to investigate the relative taxonomic utility of both internal and external components of shape described using morphometrics. This information will provide both 
a quantitative basis for comparison of these taxa, and data for the phylogenetic analysis and taxonomic descriptions of Chapters Four and Five.

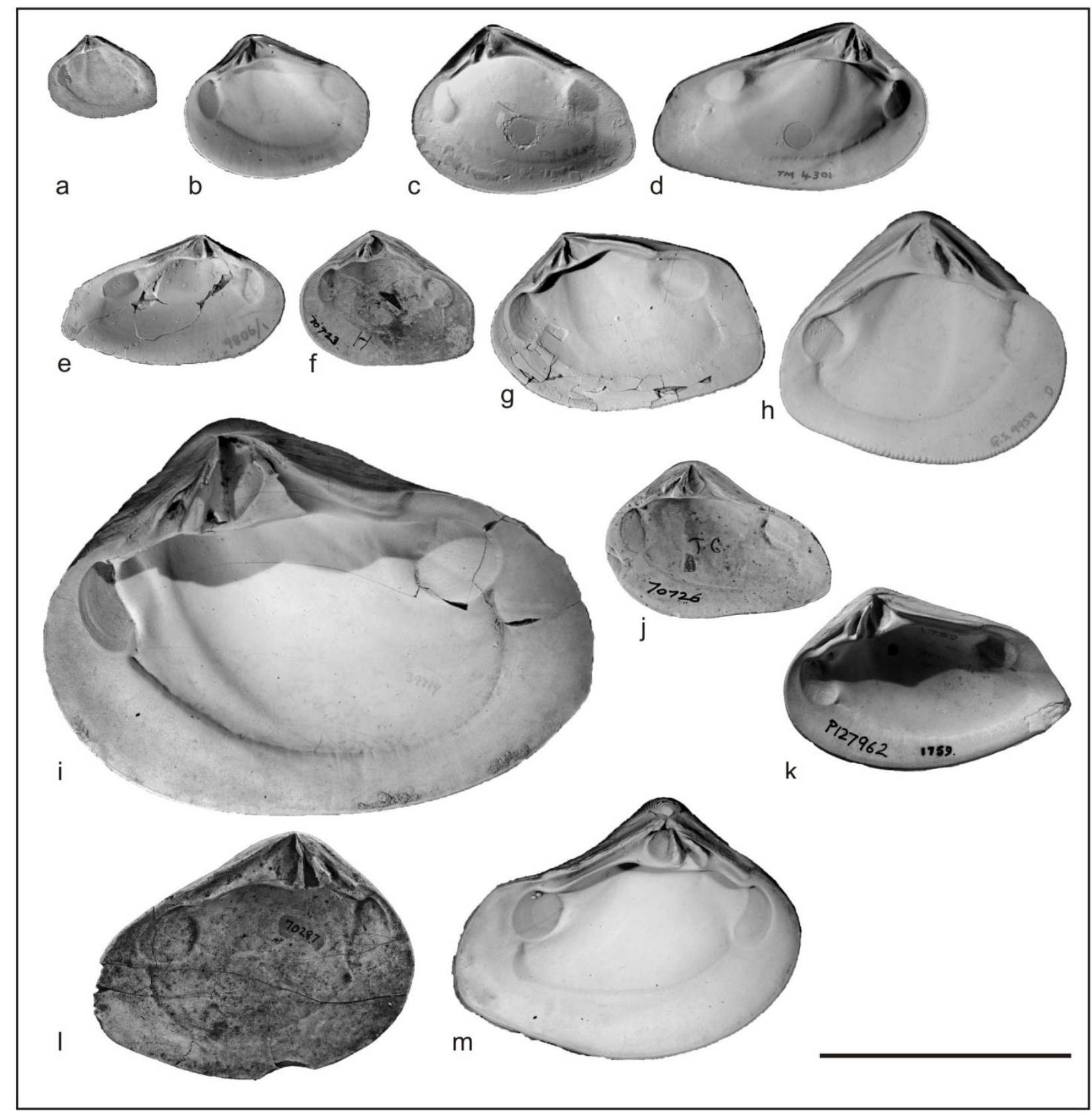

Figure 3.2: Species included in this study: (a) Spissatella media (OU8648); (b) Spissatella n. sp. C (GS4901); (c) Spissatella trailli (TM2859); (d) Spissatella subobesa (TM4301); (e) Spissatella poroleda (GS9806); (f) Spissatella clifdenensis (AK70723); (g) Spissatella acculta (TM7845); (h) Eucrassatella australis (GS9959); (i) Eucrassatella ampla (AK39719); (j) Eucrassatella scopalveus (AK70726); (k) Spissatella maudensis (P127962); (l) Eucrassatella marshalli (GS1101); (m) Eucrassatella kingicola (AK50183). Scale bar $=50 \mathrm{~mm}$. 


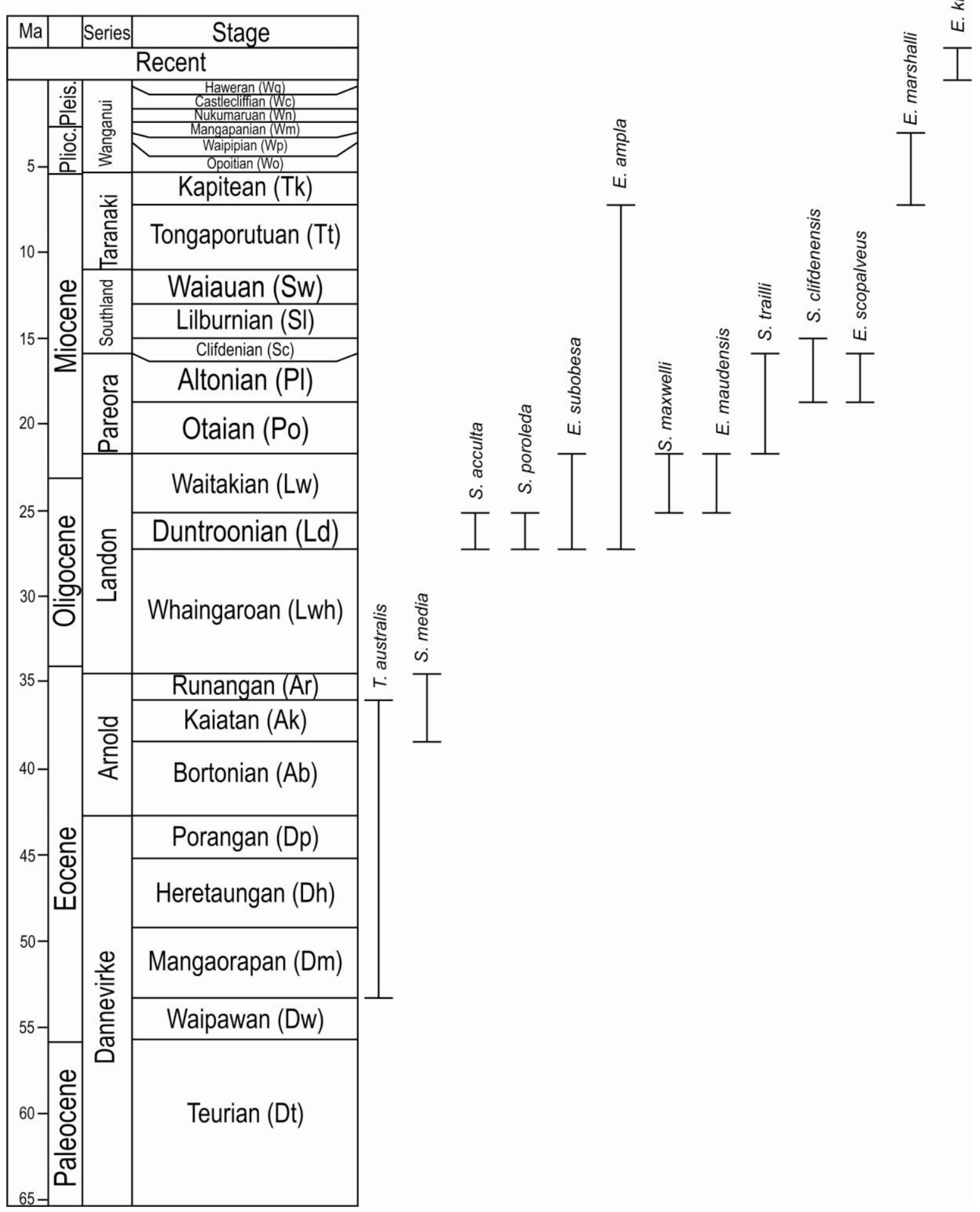

Figure 3.3: New Zealand geological timescale correlated to international stages, and rangechart for species included in this study (after Hollis, 2010). Stratigraphic ranges from Spencer et al., (2009). In the text, New Zealand stages will be used first, followed by their international correlates. 


\begin{tabular}{|c|c|c|c|c|c|c|}
\hline Collections* & FRF\# & OTU & Localities $\ddagger$ & Species & Age $\int$ & \# specimens \\
\hline GS11214, 9481, OU8648, PAM-A, B, TM4299; & $\begin{array}{l}\text { J42/f0126, } \\
\text { I40/f7551, } \\
\text { J41/f8460, } \\
\text { J40/f8721 }\end{array}$ & 01 & $\begin{array}{l}\text { Lorne, Bridge Point and } \\
\text { McCullough's Bridge }\end{array}$ & S. media & Ak-Ar & 2 \\
\hline $\begin{array}{l}\text { AK105795, 135326, 51854, 62228; AU1501, 20017, 2951; } \\
\text { GS1473, 7166; KC-HQ, L1079, 3510; M027618, 14912, 17838, } \\
\text { 18036, 290285, 290517, 292050, 292051, 292055, 292057, } \\
\text { 292058, 292068, 866; SCIP?; TM7846; }\end{array}$ & $\begin{array}{l}\mathrm{I} 40 / \mathrm{f} 7578 \\
\mathrm{I} 40 / \mathrm{f} 9519 \\
\mathrm{I} 40 / \mathrm{f} 0188 \mathrm{~B}\end{array}$ & 02 & $\begin{array}{l}\text { Archer's Crossing, Bluestone } \\
\text { Creek, Brother's Stream, } \\
\text { Sister's Creek, Haugh's } \\
\text { Quarry, Trig Z, Otiake }\end{array}$ & S. n. sp. C & $\mathrm{Lw}$ & 144 \\
\hline $\begin{array}{l}\text { AK51855, 64983, 64985, 105786, 105802, 105819, 132274, } \\
\text { 132293, 39715, 39721, 62226, 65758, 65765, 65771, 65772, } \\
\text { 65788, 65790, 65801, 65808; GS11283, 4795, 9570, 9571, 1160, } \\
\text { 9521, 9685; L1061-6, 8, 1072; AU1391, 1392, 20012, 8024; } \\
\text { M290054, 292059, 297290, 027616, 111688, 16164, 16275, } \\
\text { 2141-2143, 215, 288228, 288468, 290276; TM7847, TM2859; }\end{array}$ & $\begin{array}{l}\text { J41/f9634, } \\
\text { J41/f8568, } \\
\text { J39/f7500C, } \\
\text { J41/f8030, } \\
\text { I38/f7749, } \\
\text { I38/f7750, } \\
\text { J41/f9499, } \\
\text { J41/f9499B }\end{array}$ & 03 & $\begin{array}{l}\text { Otaio River, Tengawai River, } \\
\text { Blue Cliffs, Awamoa, } \\
\text { Ardgowan, Mt. Harris, All } \\
\text { Day Bay, Elephant Hill, } \\
\text { Pukeuri, Beach Road }\end{array}$ & S. trailli & Po-Pl & 178 \\
\hline $\begin{array}{l}\text { AK105763, 39714, 65811; AU20011, 20014; GS10837, 1821, } \\
\text { 476; L1076; M011713, 027621, 111583, 289715, 289748; } \\
\text { TM4300, 4301; }\end{array}$ & $\begin{array}{l}\text { I } 40 / \text { f0109, } \\
\text { I } 40 / \text { f } 6493 \\
\text { I } 40 / \text { f0035, } \\
\text { I } 40 / \text { f6495 }\end{array}$ & 04 & Wharekuri, Waitaki Valley & S. subobesa & Ld-Lw & 30 \\
\hline AK39717, 70725; AU20007; GS9806; & $\mathrm{F} 45 / \mathrm{f} 9668$ & 05 & Shell Gully, Chatton & S. poroleda & $\mathrm{Ld}$ & 7 \\
\hline $\begin{array}{l}\text { AK105779, 105787, 110599, 39724, 65789, 65794, 65809, } \\
\text { 70723; AU20018, 2956; GS10344, 10365, 11182, 2948; L1074; } \\
\text { M027609, 027611, 14422, 288805, 289618, 292054; TM7848; }\end{array}$ & $\begin{array}{l}\text { D45/f8637, } \\
\text { D45/f8819, } \\
\text { D45/f8485, } \\
\text { D45/f8598 }\end{array}$ & 06 & Clifden Section & S. clifdenensis & $\mathrm{Pl}-\mathrm{Sc}$ & 30 \\
\hline AK70722; GS11195; & - & 07 & Lake Waitaki & S. acculta & $\mathrm{Ld}$ & 8 \\
\hline GS9959; M289605, 289605, 292056; & $\mathrm{J} 40 / \mathrm{f} 6610$ & 08 & $\begin{array}{l}\text { Pentland Hills, Waimate, } \\
\text { Waihao River }\end{array}$ & E. australis & $\mathrm{Dm}-\mathrm{Ak}$ & 16 \\
\hline
\end{tabular}


AK105769, 105784, 105785, 12244, 132123, 39716, 39720 , 39723, 51856, 53089, 62227, 65756, 65793, 65805, 70726, 70727, 80419, 86774; GS11154, 11180, 951, 952; L1057, 1070, 1071, 1077-8; M027615, 16209, 289979; SCIP; TM7850;

GS1101;

$\mathrm{J} 39 / \mathrm{f} 0026$

$\mathrm{J} 40 / \mathrm{f} 0069$,

$\mathrm{J} 41 /$ f 8025

Q22/f7303

11

Dyer's Run, Target Gully, junction of Porter and

E. scopalvens,

E. s. concisa,

$\mathrm{Pl}$

91

Thomas River, Pareora River

Q22/f7303, Waipipi Beach,

Waverly. $1 \mathrm{ml} \mathrm{N}$ of Wairoa

Stream

MUGD1758, 1759;

NA

12

Spring Creek - Australia

S. maudensis

Equiv.

Lw

Rec

AK30181, 50183, 52562; AM7166, 7167, 7169, 7173; GS30181, NA

New South Wales, Tasmania, King Island - Australia

\section{Table 3.2: Summary of collections used in this study.}

* With the exception of MUGD collections (Museum Victoria), all collections are housed in New Zealand. AK: Auckland War Memorial Museum; AM:

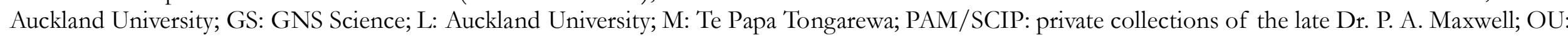

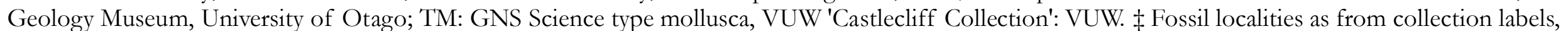
corroborated where possible by records in the Fossil Record Electronic Database (FRED), a national database administered by the Geological Society of

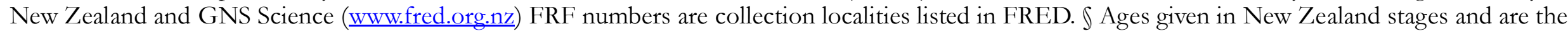
total known range of the species (see Fig. 3). 


\subsection{Methods and Material}

The landmark/semilandmark configuration (Fig. 3.1; Text Box 2) used here combines the greatest coverage of the total anatomy of the bivalve with high recovery of group assignments (as tested using jackknife reassignment tests in canonical variates analysis (CVA) (Zelditch et al., 2004) (Appendix Tables 1.1, 1.2)). Higher recovery of group assignments can be achieved using a configuration of landmarks/semilandmarks that covers only the internal features (Appendix Table 1.2), but this is a very reduced subset of the total anatomy and misses vital information related to the outline shape, which is both functionally significant to the organism (Stanley, 1975) and taxonomically informative in this group (Darragh, 1965; Crampton \& Maxwell, 2000). We prefer to use as comprehensive a coverage of anatomy as possible as this study, and subsequent investigations which will utilise the data included here, are aimed at addressing evolutionary and phylogenetic questions, for which this information may well be important.

The shell outline and the pallial line are included in this study in order to capture as fully as possible the entire shape of the shell. In addition, these two curves represent key aspects of shape that the eye uses in subjective taxonomy (Scott, 1980). The pallial line, which marks the attachment of the mantle to the shell, and the major portion of the shell outline, are each composed of a single growth margin, both of which are discrete and homologous features (Stanley, 1970). However, the shell outline does not correspond exactly to the growth margin, and thus strict homology of this contour is difficult to establish. Despite this, an advantage of using the entire outline is that the breadth and projection of the umbonal region gives an impression of overall shell inflation, and thereby the analysis incorporates some (albeit, grossly simplified) information about the third dimension of shape. 
The dataset is based on a new suite of digital photographs of 537 specimens from every Spissatella and Eucrassatella species known from New Zealand and represented in collections, and two from Australia, showing the internal anatomy. These specimens have been loaned from all of the major collections in New

Zealand, and some photographs of

Australian specimens have been supplied by Museum Victoria (Table 3.2).

Photographs were taken at GNS Science using a Nikon D100 digital SLR with an AF Micro Nikkor 60mm 1:2:8 D lens, attached to an adjustable camera stand. Specimens were bedded into black sand with their sagittal planes perpendicular to the camera lens (i.e., flat) and their adductor muscle scars aligned along the horizontal axis of the picture. Any discrepancies in the rotation of shells were corrected by the rotational step included in partial Procrustes superimposition.

Diffuse, multi-angle lighting was used and adjusted to show up the internal features of interest (muscle scars, pallial line, and
Text Box 2: Landmarks, in morphometrics, are two- or threedimensional Cartesian coordinates that describe a locus of anatomical interest which is homologous between specimens, i.e. a biological landmark.

Any given shape is described by a configuration of landmarks.

Semilandmarks are likewise two- or three-dimensional Cartesian coordinates, but rather than locating unique points, they are used to describe curves of biological interest that are homologous between specimens but do not contain discrete loci that can be consistently identified as landmark points. Twodimensional semilandmarks are fixed in one dimension during superimposition and only allowed to move in the other. Semilandmarks can then be 'slid' along the contour to minimise differences caused by arbitrary placesment of points on the contour. Partial Procrustes superimposition (Text Box 3) can then proceed as if all points are landmarks. However, due to their being fixed in one dimension, semilandmarks have only one degree of freedom in statistical terms. 
hinge teeth) as clearly as possible. A fifty $\mathrm{mm}$ scale was included on every picture.

Specimens studied here were first grouped into "populations" (in the sense of Newell [1956]) made up of specimens collected by one palaeontologist from one horizon at one locality. Populations were examined for multimodal distributions and outliers using principal components analysis (PCA). If discrete groups within populations had been detected, those populations would have been subdivided and the resulting subpopulations treated as separate subsequently; however, no such discrete subpopulations were detected during analyses.

In order to combine populations into meaningful groups for further analysis and for practical purposes, populations were initially scored using a matrix of fifteen discrete morphological characters (Table 3.3), including qualitative characters pertaining to overall shape. Those populations that exhibited less than five character differences (i.e., less than a third) were grouped for initial analysis, the resulting groups then being scored as multistate for the characters that vary within any group. Characters that were considered diagnostic at the specific level by previous authors were not allowed to be multistate (Table 3.3). This method mirrors the standard practice of taxonomic discrimination by visual comparison of morphology. Existing taxonomic placement was ignored at this stage. Specimens that plotted as strong outliers in initial morphometric analyses were re-examined and either excluded from further analysis or reassigned to a more appropriate group. This initial grouping procedure resulted in 13 operational taxonomic units (OTUs) comprising two Australian and $11 \mathrm{New}$ Zealand groups (Table 3.4).

Most specimens in this study are single valves. Prior to analysis, right valve photographs were mirrored digitally in order to remove the effects of primitive bilateral symmetry. Crampton \& Maxwell (2000) note that left and right valves of equivalve individuals plot together in morphospace and appear essentially identical during statistical analysis. To confirm this, left and right valves of the six groups with $\mathrm{n}>15$ were subjected 
to multivariate analysis of variance (MANOVA), grouping on valve type (left or right).

None showed significant differences between left and right valves, with the exception of

OTU 10, which displays a subtle, trivial valve inequality (see Appendix 1; Table 1 and Figs.

1 and 2) that has no impact on interpretations presented here.

The dataset was analysed largely according to the methods outlined in Zelditch et al. (2004) and Webster \& Sheets (2010), using the tpsDig software of Rohlf

(http://life.bio.sunysb.edu/morph/) and the Integrated Morphometrics Package (IMP)

software of Sheets (http://www3.canisius.edu/ sheets/morphsoft.html). Configurations

of landmarks/semilandmarks were captured in tpsDig. The outline and pallial line contours were captured using an arbitrary number of closely-spaced points and then subsampled to a standardised number of points using tpsDig's "resample curve" function. The number of points in each curve was determined by visual assessment of how well a given number of points approximated the true contour.

\begin{tabular}{llllll}
\hline & Character & State 1 & State 2 & State 3 & Invariant? \\
\hline 1 & Adductor muscle scar & Deep & Shallow & NA & No \\
2 & Posterior shape & Rounded & Square & Pointed & No \\
3 & Posterior 'corners' & Round & Sharp & NA & Yes \\
4 & Resilifer impression & Deep & Shallow & NA & No \\
5 & Edge texture & Crenulate & Smooth & NA & Yes \\
6 & Pallial line extent & Past scar & Not past scar & NA & No \\
7 & Thick under hingeplate? & Yes & No & NA & No \\
8 & Posterior lateral & Concave & Straight & Convex & No \\
9 & Anterior lateral & Concave & Straight & Convex & No \\
10 & Hingeplate border & Even & Shallow curve & Deep curve & No \\
11 & Pallial line shape & Evenly curved & Pointed & Round & No \\
12 & Anterior hingeplate & Smooth & Small hook & Deep hook & No \\
13 & Max. height & $<20$ mm & 20-50mm & $>50 m m$ & No \\
14 & Lateral teeth & Smooth & Striate & NA & No \\
15 & Thickness & Thin & Moderate & Thick & Yes \\
\hline
\end{tabular}

Table 3.3: Characters used to compare populations and identify OTUs, and their possible states. 'Invariant' characters are those that are not allowed to be polymorphic for taxonomic reasons (see text). These are not strictly cladistic characters, although some of them are included in modified form in the stratocladistic analyses of Chapter Four. 


\begin{tabular}{cccccccccccccccc}
\hline OTU & \multicolumn{1}{c}{ Characters } \\
\hline & 1 & 2 & 3 & 4 & 5 & 6 & 7 & 8 & 9 & 10 & 11 & 12 & 13 & 14 & 15 \\
\hline 1 & 2 & 2 & 1 & $?$ & 2 & 12 & 2 & 2 & 12 & 2 & 13 & 1 & 1 & 1 & 1 \\
2 & 12 & 2 & 1 & 12 & 2 & 2 & 12 & 123 & 12 & 12 & 123 & 12 & 2 & 12 & 2 \\
3 & 12 & 23 & 1 & 12 & 2 & 12 & 12 & 123 & 12 & 12 & 123 & 12 & 2 & 12 & 2 \\
4 & 12 & 23 & 1 & 12 & 2 & 1 & 12 & 12 & 2 & 12 & 23 & 12 & 2 & 12 & 2 \\
5 & 12 & 23 & 2 & 2 & 2 & 12 & 2 & 2 & 2 & 12 & 12 & 12 & 2 & 12 & 1 \\
6 & 12 & 2 & 1 & 12 & 2 & 2 & 12 & 123 & 12 & 12 & 13 & 12 & 2 & 12 & 2 \\
7 & 2 & 2 & 1 & 2 & 2 & 2 & 2 & 3 & 2 & 12 & 3 & 1 & 2 & 1 & 1 \\
8 & 12 & 123 & 1 & 12 & 1 & 2 & 12 & 2 & 2 & 12 & 12 & 12 & 23 & 12 & 3 \\
9 & 1 & 1 & 1 & 1 & 2 & 2 & 12 & 123 & 123 & 23 & 1 & 23 & 3 & 12 & 3 \\
10 & 12 & 123 & 1 & 12 & 2 & 12 & 12 & 123 & 123 & 123 & 123 & 12 & 2 & 12 & 3 \\
11 & 1 & 1 & 1 & 1 & 2 & 2 & 1 & 1 & 2 & 23 & 1 & 1 & 3 & 12 & 3 \\
12 & 1 & 23 & 2 & 12 & 2 & 1 & 2 & 2 & 3 & 2 & 2 & 12 & 2 & 12 & 2 \\
13 & 1 & 123 & 1 & 12 & 2 & 2 & 12 & 12 & 12 & 23 & 13 & 12 & 23 & 12 & 3 \\
\hline
\end{tabular}

Table 3.4: Tabulated character-state data for the thirteen OTUs of this study. Characters and states are explained in Table 3.1. ? indicates a feature that is present but the state of which could not be determined. Multiple character states ("123") are coded for taxa which are polymorphic for that particular feature.

Configurations were then normalised for size using a centroid size of 1 (centroid size is defined as the square root of the sum of the squared distances of the landmarks from the centroid), and aligned in IMP using partial Procrustes superimposition (Text Box 3), and then projected into tangent space for statistical analysis, using a mean configuration as the tangent point in order to minimise distortions involved in the transition from curved shape space to planar tangent space. The resulting Procrustes-aligned landmark coordinates were then used as input for standard multivariate ordination techniques such as PCA and CVA (Text Box 4). Semilandmarks, which are not homologous points but evenlyspaced points that delineate a homologous curve, must be 'slid' to minimise the effect of variation due to arbitrary placement around the curves defined by the pallial line and shell outline. This is done by fixing these points in one dimension but allowing movement in the other, to minimise the effect of original point placement upon the resulting configuration. Sliding was achieved here using the IMP program Semiland6 to minimise Procrustes distances (see Zelditch et al. 2004). 
PCA and CVA (Text Box 4) were

undertaken in R (functions 'prcomp' and 'lda' respectively, R Development Core Team, 2012). PCA and CVA both reduce the dimensionality of the dataset, making it easier to visualise relationships between specimens and groups within shape-space. In addition, CVA also allows explicit testing of group assignments and differences between group means using standard non-parametric tests such as jackknife crossvalidation and permutation tests, respectively (Zelditch et al., 2004). Non-parametric approaches are used here because the use of semilandmarks introduces uncertainties in the degrees-of-freedom associated with statistical tests (Webster \& Sheets 2010).

\subsection{Results and Discussion}

The variance explained along each is presented in Table 3.5. PCA results for the first three axes (totalling 63\% of the variance) are presented in Figure $3.4 \mathrm{a}$ in the form of $95 \%$ confidence ellipses on group means. Axes are scaled in units of standard deviation from the mean. Deformed grid and vector plots summarise shape-change along each axis in
Text Box 3: Superimposition is the operation by which configurations of landmarks and semilandmarks are scaled and rotated to a uniform size and position in order to remove any effects of rotation, scaling and translation accrued during image-capture. Two superimposition methods are used in this study. Partial Procrustes $\underline{\text { superimposition involves scaling }}$ configurations to a common centroid size of 1 and anchoring them at their centroids. Configurations are then rotated until the distances between any given landmark and the same landmark on all other configurations in the set is minimised. Variance is thus distributed evenly between all landmarks. This is the method used in preparation for all statistical operations and ordinations herein. Bookstein or baseline registration is used in this study for display purposes only, and involves selecting two landmarks that lie along some biological axis of interest and pinning the configurations to this 'baseline' by making the selected landmarks invariant. Variance is thus distributed amongst the free landmarks relative to this fixed baseline. 
order to aid visualisation (Fig. 3.4b). These plots are displayed in Bookstein baseline registration (Zelditch et al., 2004), anchored on landmark 1 and semilandmark 33 for the following reason: Landmark 1 marks the beak, which is the origin of growth - all other landmarks must move relative to it. Semilandmark 33 marks roughly the furthest point on the shell from the beak. They mark the endpoints of a distance known as the 'axial length' (Crampton \& Maxwell, 2000), which is the axis of maximum shell growth. As all

Text Box 4: Display and interpretation of morphometric data in this project is achieved primarily using two ordination methods. Ordinations seek to reduce dimensionality of multivariate datasetts by identifying a small number of axes that are combinations of variables and that explain much of the variance in the dataset. Principal Components Analysis (PCA) is the most frequently-used ordination in this project, providing visualisations of morphospace and data for phylogenetic analysis. PCA seeks the dimension of greatest variance within the dataset and reordinates the cloud of datapoints so as to make that dimension the first principal component axis. The second principal component axis is orthogonal to the first, and describes the dimension of second-greatest variance within the dataset, and so on. Canonical Variates Analysis (CVA) is a related technique that operates in much the same manner, save that input to CVA must include some form of group assignment, which could be species, ecological group, sex, habitat etc., for each specimen. CVA will then seek the dimension with the greatest separation between a priori groups and reordinate the data points in order to make that dimension the first canonical variate axis and then likewise for subsequent axes. The total number of axes will be one fewer than the number of groups. CVA can be used to test the a priori group assignments it is given using Mahalanobis distance, which is the distance between a specimen and its assigned group mean. Using a jacknife resampling method, in which specimens are excluded, one-by-one, from the dataset so that the specimen having its assignment tested is not contributing to the positioning of group means, CVA will examine the Mahalanobis distances of all specimens to all group means and then assign the specimen of interest, a posteriori, to the group with the closest mean. The CVA can then be made to report the differences between a priori and a posteriori group assignments, which shows whether or not the designated groups are reliably able to be recovered using morphometrics. 
configurations have been scaled to a centroid size of one, pinning them along this axis allows shape change in terms of relative growth in different areas of the shell to be visualised in a standardised manner. This manipulation is purely for display purposes - all statistics and ordinations are performed on Prucrustes-aligned coordinates.

\begin{tabular}{lrc}
\hline PC axis & $\begin{array}{l}\text { Proportion of } \\
\text { variance }\end{array}$ & \% cumulative \\
\hline PC1 & 0.332 & 33 \\
PC2 & 0.189 & 52 \\
PC3 & 0.109 & 63 \\
PC4 & 0.088 & 72 \\
PC5 & 0.056 & 77 \\
PC6 & 0.047 & 82 \\
PC7 & 0.030 & 85 \\
PC8 & 0.025 & 88 \\
\hline
\end{tabular}

Table 3.5: \% variance explained along each PC axis

\begin{tabular}{lc}
\hline OTU & $\%$ correct \\
\hline 2 & 83 \\
3 & 83 \\
4 & 73 \\
5 & 86 \\
6 & 80 \\
7 & 88 \\
8 & 81 \\
9 & 82 \\
10 & 71 \\
11 & 50 \\
13 & 100 \\
\hline Average \% correct & 80 \\
\hline
\end{tabular}

Table 3.6: \% correct reassignment of specimens to a priori groups by jackknifed reassignment test in CVA

CVA jackknife cross-validation group assignment test results are summarised in Table 3.6. Groups 1 and 12, which comprise fewer than three specimens, were omitted from the CVA. Recovery of correct group assignments (Table 3.6, column 2) using this method is very high (average correct assignment is $80 \%$ ). Using PCA plots, CVA reassignment tests, and morphological characteristics such as sculpture, we conclude that all of the OTUs comprise discrete taxa. 

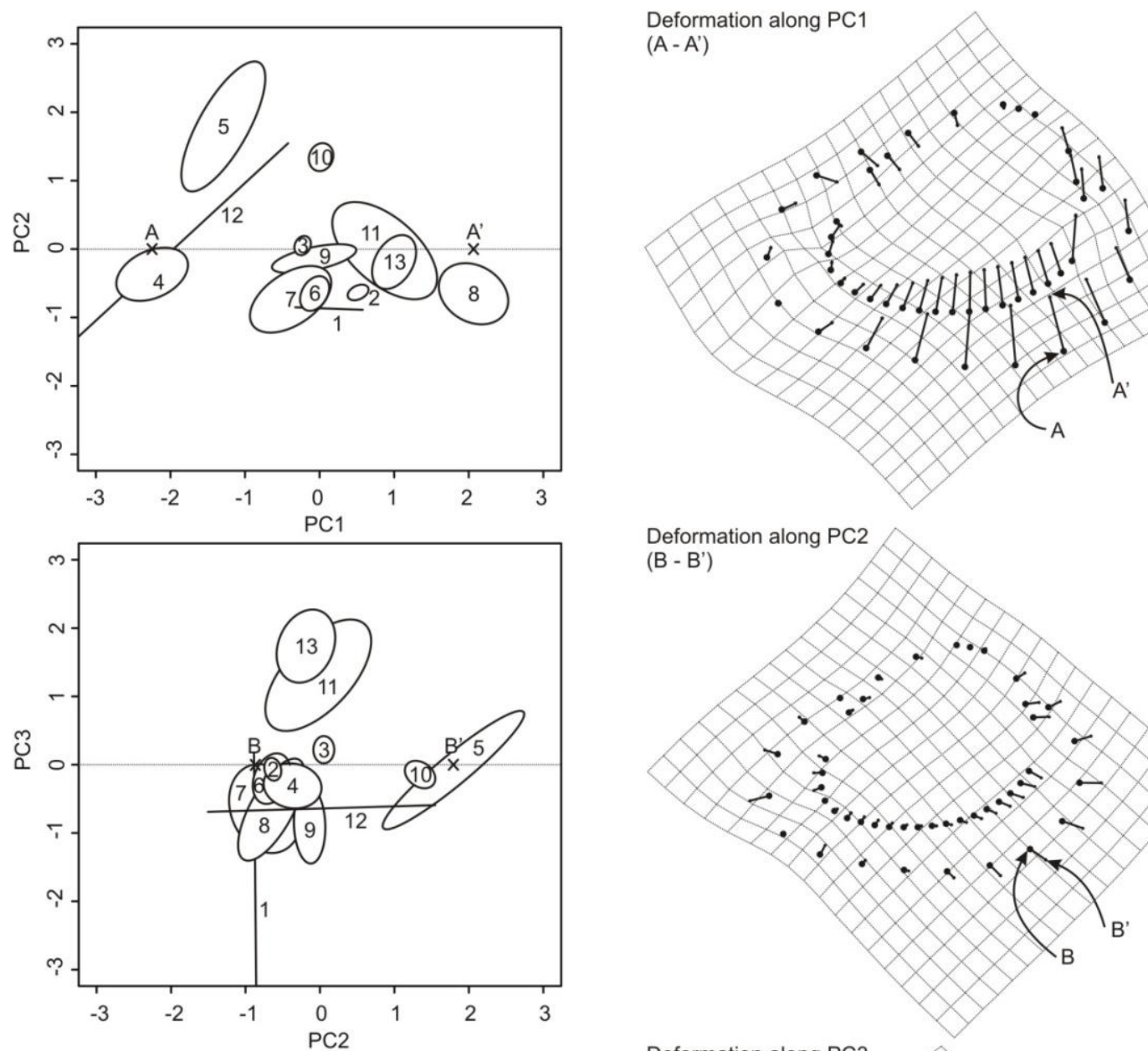

Deformation along PC2
(B - B')
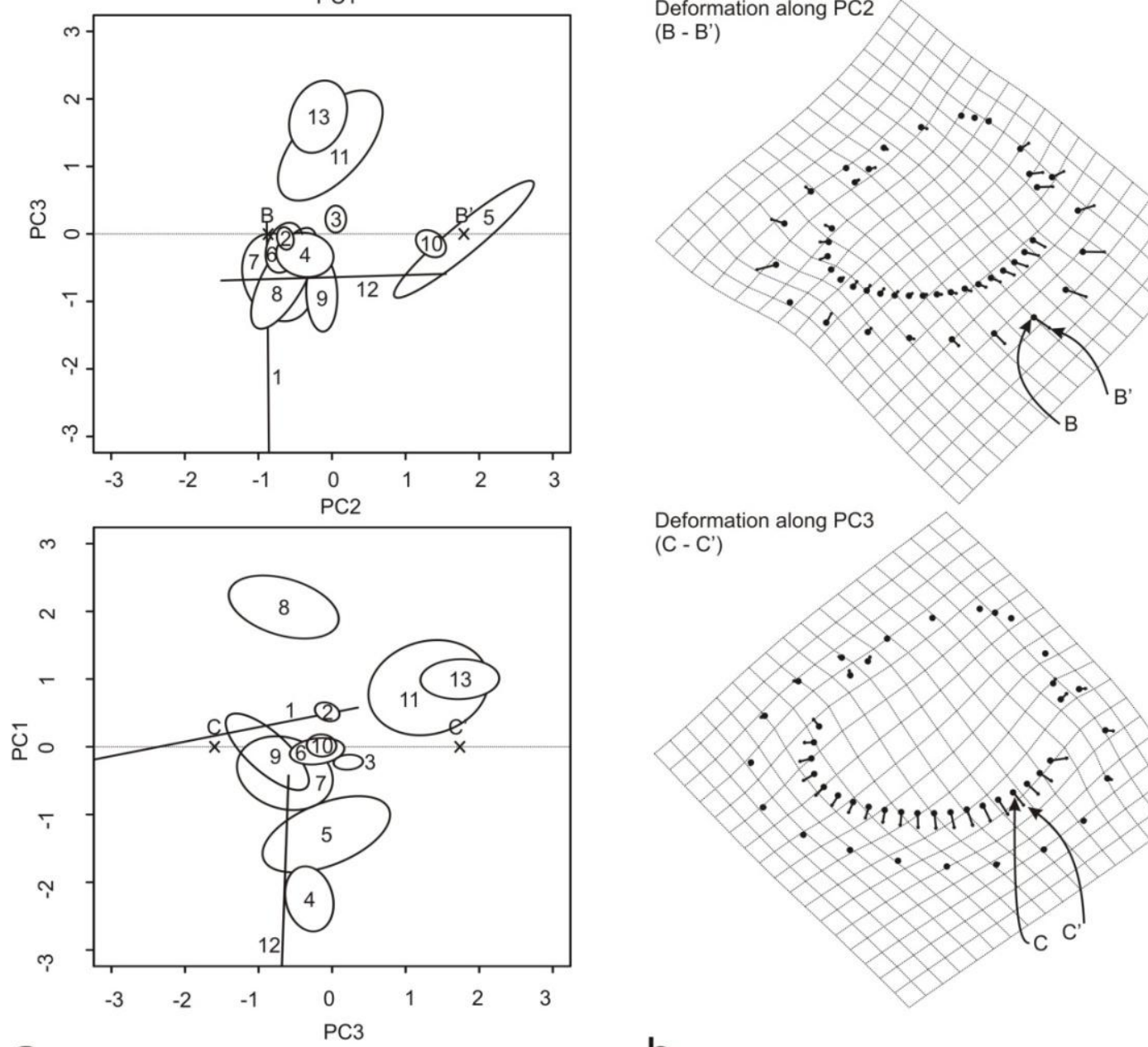

Deformation along PC
(C - C')

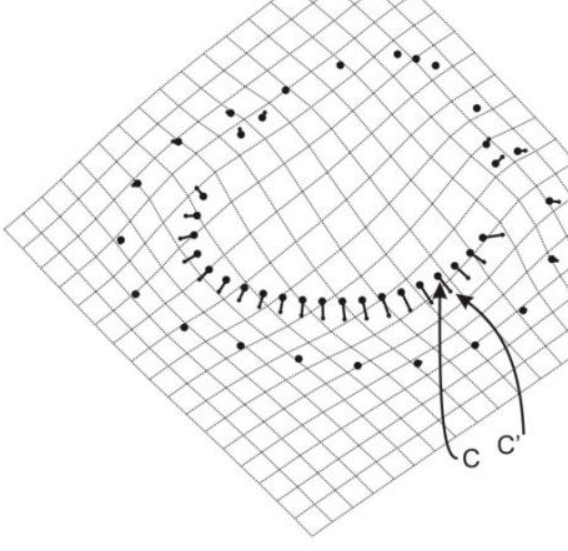

b

Figure 3.4: (a) PCA plots of the first three PC axes for the dataset. Ellipses represent 95\% confidence levels on OTU means. Points A-A', B-B' etc represent minima - maxima of group means along each axis. The vectorplots in (b) represent the deformation between the synthetic shapes that would plot at these points. Vectorplots on deformation grids are displayed in Bookstein/baseline registration (see text), the baseline being anchored at Landmark 1 and Semilandmark 33 (see Figure 3.1), which corresponds to the axial length or axis of maximum growth. Direction and magnitude of shape-change is implied by vectors on landmarks and by deformation of the grid. 


\subsubsection{The 'Spissatella trailli' complex}

Spissatella trailli Finlay (1926) (Otaian-Altonian - early Miocene; Figure 3.3) (Fig. 3.2c) is the type species of the genus Spissatella, and is of average size ( $\sim 40 \mathrm{~mm}$ maximum valve length), moderately elongate for its height, and carrying the same simple ribbed sculpture as the rest of the genus. Morphologically, it is close to the overall average for all taxa studied here. It is similar to Spissatella clifdenensis Finlay (1926) (Clifdenian-Lillburnian middle Miocene) (Fig. 3.2f), which it is postulated to have given rise to cladogenetically at some point in the Miocene (Crampton \& Maxwell, 2000). Some authors (Beu \& Maxwell, 1990; Crampton \& Maxwell, 2000) and some collectors have recognised an undescribed species closely similar to $S$. trailli - known as $S$. n. sp. C (Fig. 3.2b) - within the variation previously assigned entirely to S. trailli. Spissatella. n. sp. C is known from the Waitakian (late Oligocene- early Miocene) limestones of the South Island of New Zealand.

PCA, which seeks to identify and rank independent dimensions of overall variance in the dataset, clearly illustrates the problem of differentiating these taxa by shape alone. The more specimens in any given analysis, the more bewildering the array of shape variation becomes, and unless there is some very strong morphological disjunction that can be used to separate groups taxonomically, specimens intermediate between typologicallydefined taxa are common. However, CVA can take an a priori grouping scheme, in this case the OTUs based on the matrix of traditional characters in Table 3.3, and seek the axis of greatest variance between group means, relative to within-group variance (Webster \& Sheets, 2010). Specimens that are very different in shape to the other specimens in their group will plot as outliers from the group scatter, and the cross-validation rate obtained by jackknifed reassignment tests for a group with aberrant specimens will be comparatively low.

If Spissatella trailli encompasses $S$. n. sp. C, we would expect a PCA plot of the groups to show this, with the ellipses for each group overlapping. We would also expect the 
reassignment test within a CVA to return low values of correct reassignment for one or both groups, compared to values of correct reassigment for either group to $S$. clifdenensis. To test this, PCA and CVA were run on the individual locality collections of $S$. trailli, $S$. clifdenensis and S. n. sp. C. By assigning groups based on individual localities rather than on postulated taxonomic identification, we are not forcing the analysis to seek an axis of discrimination between groups that may not exist. A CVA was then run on the same dataset but grouped by postulated taxonomic ID, to assess reassignment rates of specimens to taxa.

Figure 3.5a shows a plot of PCs 1 vs 2, displaying 95\% confidence ellipses on the means for each locality group. Each species occupies a distinct region of the plot. Figure 3.5b shows the CVA plot of the same dataset, which emphasises the close relationship between $S$. trailli and $S$. n. sp. C, and separates out $S$. clifdenensis on the second axis. Neither plot shows any great degree of overlap between locality collections assigned to different species.
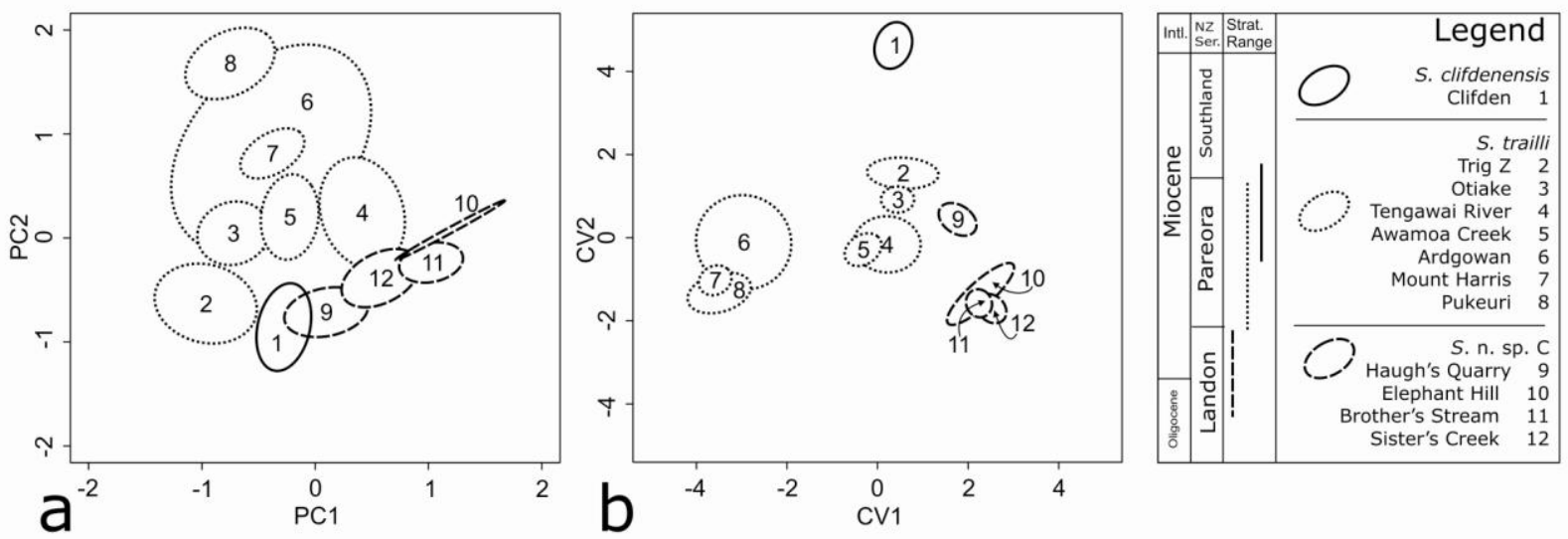

Figure 3.5: (a) PCA plot and (b) CVA plot of Spissatella trailli, S. n. sp. C, and S. clifdenensis. Ellipses are 95\% confidence ellipses on locality collection means. Each species occupies a separate, contiguous region of the PCA space even when broken down into constituent collections. CVA demonstrates that $S$. trailli and $S$. n. sp. C vary continuously along CV1 (but are separable along that axis) and that $S$. clifdenensis is discrete along CV2.

Table 3.7 shows \% correct reassignment scores from jackknifed cross-validation tests on the current taxonomic IDs. Reassignment rates are consistently high. On the basis 
of these tests we support the taxonomic separation of $S$. trailli from $S$. n. sp. C and $S$. clifdenensis.

\begin{tabular}{lc}
\hline Species & $\%$ Correct Reassignments \\
\hline S. clifdenensis & 86 \\
S. $n$. sp. $C$ & 82 \\
S. trailli & 84
\end{tabular}

Table 3.7: Percentage correct reassignment rate of specimens to putative species within the 'Spissatella trailli' complex.

The range chart in Figure 3.2 includes the three species discussed in this section. Taking their respective ages into account, we suggest that the pattern is consistent with an anagenetic relationship between $S$. trailli and $S$. n. sp. C, and support the cladogenetic relationship between S. trailli and S. clifdenensis proposed by Crampton \& Maxwell (2000).

\subsubsection{Body and Shell/Mantle - Independance and Interaction}

The Bivalvia is a class of organisms for which the overall shape is produced by a single generating margin, the mantle, which is homologous. In addition, this overall shape is vital to the animal's ability to survive in its environment, providing the ability to dig and also to remain buried. Internal anatomy is also important to the functioning of the animal. These two parts of the bivalve anatomy are closely related and interact with each other as part of a whole organism (Stasek, 1963). Both aspects of bivalve shape are included in this study and combined into the 45-point landmark/semilandmark configuration - the shell outline and the space occupied by the visceral mass as delineated by the mantle's attachment to the shell (pallial line). For the purposes of this discussion, we follow Yonge (1953), Stasek (1963) and Stanley (1970), who regard the mantle and shell as a single united system, separate from the visceral mass or 'body'. In terms of the configuration used in this study, landmarks 1-7 describe the positioning of the hinge and the traces of the adductor muscle scars, semilandmarks 8-25 delineate the pallial line, and together these points define the gross shape and positioning of the body within the space available inside 
the shell as described by semilandmarks $26-45$. However, it is important to note that the configuration does not show actual positioning of individual organs within the body. This dataset is two-dimensional and can be thought of as lying on, or having been projected onto, the sagittal plane of the organism.

Crassatellids, as a group, are highly constrained in their shell-shape. Because they are non-siphonate, they can only be shallow-burrowers, and thus their shape must allow for reburial in the event of disinterment and promote stability within sediment subjected to wave or current action (Stanley, 1970). However, it is also the case that a bivalve that is buried close to the sediment/water interface is vulnerable to predation. Damage that only affects the shell and/or mantle may not kill the animal, as demonstrated by marginal damage to shells that has been subsequently overgrown (Vermeij, 1983; Savazzi, 1990), but damage to the body organs may be fatal. There is likely to be pressure to restrict the organs (i.e., the body) to the anterior-most regions of the shell to keep them as far as possible from potential predators, but the shell must reach the sediment/water interface. There is therefore the possibility that these competing pressures may cause internal and external shapes to covary.

Yonge (1953) and Stasek (1963) have both addressed the relationship between the body (i.e., the visceral mass) and the shell/mantle of the Bivalvia, and their arguments are summarised in Stanley (1970). To the best of our knowledge, this topic has received little attention since Stanley, but in the course of this study it has become apparent that geometric morphometrics may shed further light on the question. Yonge (1953) argued that the body and the mantle/shell of a bivalve are independent of each other, and using two sets of geometrical axes, showed that they can become offset from each other. This has become known as the Concept of Independant Entities. Stasek (1963) argued instead that the body and mantle/shell are inseparable and used deformation coordinates (Thomson, 1942), which are visually similar (but not mathematically equivalent) to the deformation 
grids used here in Fig. 3.4b, to show that body form and shell/mantle form change as a single system. Stanley (1970) concluded that Stasek's (1963) argument is the better supported and more logically defensible of the two, as Yonge's (1953) axes have little biological significance and, furthermore, there are few grounds for a clear anatomical disjunction between body and shell/mantle. The mantle is attached to the body of the animal and secretes the shell - it is the interface between the shell and the body.

Using vector plots and deformed grids summarising the deformation between two taxa, the magnitude and direction of change in relative positions of all landmarks and semilandmarks can be visualised. Figure $3.4 \mathrm{~b}$ presents deformation grids and vector plots that summarise deformation along the first three PC axes. This method of display is very similar to that used by Stasek (1963), but as it is based on landmarks and semilandmarks, it is founded on a much stronger basis of biological comparability than Stasek's original diagrams, which incorporate no landmarks at all and were drawn using visual comparisons of specimens.

Taking the deformation along PC1 as an example, these plots show no disjunction in the 'direction' of shape change between internal and outline shapes. If, in one taxon compared to another, the ventral margin is displaced dorsally, then the pallial line does likewise - if the anterior portion of the outline is displaced inwards then the landmark at the junction of the hingeplate and the anterior adductor muscle scar do the same. In the plot summarising the deformation along PC2, the vectors along the pallial line 'twist', changing direction at the point of flexure, and the ventral margin can be seen to do so also. We see no evidence of potential shell elongation with reduction of the area occupied by the internal anatomy, nor of adductor muscle scars shifting in different directions to the shell outline. Based on this, we support the position of Stasek (1963) and Stanley (1970) that the shell and the mantle/body of crassatellids are interdependant and covary in terms of shape, and reject the "Concept of Independant Entities" of Yonge (1953). 


\subsection{Conclusions}

- The most comprehensive coverage of shape is provided by landmarks and semilandmarks, and in light of this, we suggest that for bivalves, a landmark/semilandmark approach that covers both internal and external aspects is the most appropriate method of characterising overall shape.

- Utilising this method, we have examined the relative shape-changes of the shell outline and the body organs and conclude that they covary in a meaningful way, rejecting the "Concept of Independant Entities" of Yonge (1953).

- Using PCA and CVA plots and jackknifed reassignment tests of specimen identification, we have confirmed that Spissatella $\mathrm{n} . \mathrm{sp} . \mathrm{C}$ is a separate taxon from both Spissatella trailli, which it gave rise to anagenetically, and Spissatella clifdenensis, which split cladogenetically from S. trailli, as suggested in Crampton \& Maxwell (2000) 


\section{4 \\ Phylogenetics}

"You may seek it with thimbles - and seek, it with care;

You may bunt it with forks and with hope;

You may threaten its life with a railway-share;

You may charm it with smiles and soap -!

('That's exactly the method,' the Bellman bold

In a basty parenthesis cried,

'That's exactly the way I have always been told

That the capture of Snarks should be tried!')"

- The Hunting of the Snark: Fit the Third - The Baker's Tale 


\section{Shapes of Things to Come - Phylogeny of character-poor Spissatella and Eucrassatella (Bivalvia, Crassatellidae) using morphometrics and stratocladistics}

\subsection{Abstract}

Fossil bivalves are considered, by some workers, to be unsuitable for cladistic analysis at the specific level, due to the low number of discrete morphological characters that can be derived from the shell alone (Davis, 1983). To study fossil bivalves phylogenetically, other sources of data must be investigated, including their stratigraphic context. We use stratocladistics combined with morphometric data to produce a phylogeny of two genera of New Zealand crassatellid bivalves - Spissatella Finlay, 1926, and Eucrassatella Iredale, 1924. We find that New Zealand taxa currently included in the genus Eucrassatella do not form a monophyletic group. Eucrassatella australis (Hutton) occupies a basal position with regards to the rest of the dataset, and the remaining species of Eucrassatella, including the type species E. kingicola, form a derived group which is sister to Spissatella. Spissatella subobesa and S. maudensis are moved to Eucrassatella on the basis of phylogenetic relationships and shell characters.

\subsection{Introduction}

Bivalves are amongst the most common animals preserved in the marine fossil record. They are known from as far back as the Cambrian and today are a major component of the global aquatic fauna, occurring worldwide in marine, estuarine and freshwater habitats, and are, both wild and cultured, an important source of food for humans (Giribet, 2008). The outline shape of bivalves is considered to be a key morphological and phylogenetic character (Crampton and Maxwell, 2000), as it is strongly controlled by, and thus reflects, life habit and function (Stanley, 1970). The internal features of bivalve shells, e.g. muscle scars, pallial line, and hinge, are also important taxonomic characters. Fossil bivalves, however, or lineages with a fossil component, have been the 
subject of few species-level cladistic analyses due to the degree of gross morphological similarity between the shells of closely-related species (Davis, 1983; Skelton et al., 1990; Schneider, 2001). This is the first phylogenetic analysis of taxa within the Crassatellidae that we are aware of.

Adrain and Westrop (2001) suggested that if a group lacks sufficient morphological data, then we should resign ourselves to never being able to reconstruct its phylogeny. If, however, our goal is to reconstruct the history of life on Earth, then we must find methods that can deal with inconvenient groups and utilise whatever data are at our disposal. To this end, here we combine traditional morphological characters with binned morphometric data and stratigraphic information in a single character matrix. In the literature there has been extensive debate about the validity, or not, of including morphometric and stratigraphic characters into the cladistic framework. We summarise these arguments below.

\subsubsection{Utility of morphometrics and other continuous data in cladistics}

Discussions on the inclusion of continuous data in phylogenetic analysis, including simple measurements, has centred on methods of binning them (e.g., Almeida \& Bisby, 1984; Thorpe, 1984; Archie, 1985; Humphries, 2002) or not (e.g., Goloboff et al., 2006; Hendrixson \& Bond, 2009; Clouse et al., 2009; de Bivort et al., 2010; Clouse et al., 2011). Regarding morphometric data specifically, debate has concentrated on what constitutes an appropriate measure of shape for cladistic analysis (e.g., Pimental \& Riggins, 1987; Swiderski et al., 2002; MacLeod, 2002). In general, whereas various authors debate methodologies, the consensus, which we support, appears to be that morphometric data have value for phylogenetic analysis and are admissible into a cladistic framework.

In this study, both outline and internal features have been captured in a single configuration using landmarks and semilandmarks (Webster and Sheets, 2010), and summarised using Principal Components Analysis (PCA) on Procrustes shape coordinates 
(Procrustes-PCA), which is equivalent to a

relative warps analysis (Rohlf, 1999).

Morphometric variables such as PCA scores

may be used as characters for cladistic

analysis, as they satisfy the definition of a

systematic character as "a collection of

mutually exclusive states" (MacLeod, 2002).

\subsubsection{Utility of stratigraphic data in cladistics}

Stratocladistics (Text Box 5) is a

modification of the cladistic method to

include stratigraphic information. In New

Zealand, Spissatella and Eucrassatella have a

long fossil record in the shallow-marine rocks

of the South Island and in parts of the North

Island (Beu \& Maxwell, 1990). The

stratigraphy in these areas is well-known and

well-dated, and thus is ideal for stratocladistic

use. Stratocladistics modifies standard

cladistic parsimony, which seeks minimisation

of homoplasy, by adding a stratigraphic

parsimony criterion which seeks minimisation

of ad hoc appeals to non-preservation. Studies have shown that the addition of a

stratigraphic character improves explanatory power as measured using retention indices

(Clyde \& Fisher, 1997), and that stratocladistics outperforms cladistics in simulations (Fox

et al., 1999). Bodenbender and Fisher (2001), using real data for blastoids, found that the 
phylogeny produced by stratocladistics was better resolved than that produced by standard cladistics. Similarly, Bloch et al. (2001), using real data for carpolestids, found that with a well-sampled fossil record and congruent character data, stratocladistics and cladistics produced the same cladogram.

Opponents of stratocladistics suggest a number of reasons why stratigraphic data should be regarded as inadmissible for cladistic use (e.g, Smith, 2000; Adrain \& Westrop, 2001). First, they argue that stratigraphic data are extrinsic to organisms, and should not be combined with intrinsic data such as anatomical features. Fisher (2008) acknowledged this concern, but argued also that temporal order is part of the process of descent with modification. Secondly, it has been suggested that stratigraphic data are infinitely subdividable and therefore able to be binned in order to produce whichever result the investigator desires. Alroy (2002) countered that, in practice, this is not the case, because temporal data are typically expressed in terms of stratigraphic stages, which are discrete units and are, therefore, not infinitely divisible. A final objection is that if stratigraphy is used to inform phylogenetics, then the resulting phylogenies cannot be used to investigate character evolution. Fisher et al. (2002) argued in response that the apparent circularity of this is an illusion, caused by the use of the word 'taxa' to indicate both units of analysis (used to construct the tree) and units of descent (constructed from the tree). Given the demonstrated utility of stratigraphic data (Fox et al., 1999; Bodenbender \& Fisher, 2001; Bloch et al., 2001) and the nature of the dataset under study here, we have included stratigraphic level as a single character.

This paper is not intended to test stratocladistic methodology against cladistic methodology. That topic has been well-addressed in previous studies and summarised above. This is a fossil dataset, and so the strict cladistic assumption that all included taxa are coeval is violated, and any cladogram produced for this dataset would be meaningless unless it were interpreted in the context of stratigraphic order. Thus we prefer to include 
the stratigraphic information at the outset, rather than introduce it at a later stage. In order to include the stratigraphic data we have binned the continuous data. If stratigraphic data is removed and continuous data analysed as such in Tree Analysis using New Technology (TNT), the result is a tree that recovers many of the same relationships between terminal taxa as the stratocladistic tree, but with a number of unresolved polytomies, and with a deeper structure that is incompatible with stratigraphic order (Appendix 2, Figure 2).

\subsection{Methods}

Fourteen species are included in the dataset; thirteen crassatellids from the two genera Spissatella Finlay 1926 and Eucrassatella Iredale 1924 (Fig. 4.1a-m), and one carditiid outgroup, Purpurocardia purpurata (Deshayes, 1854) (Fig. 4.1n). This includes all New Zealand species of Spissatella, the sole Australian species S. maudensis (Pritchard, 1903), all species of Eucrassatella from New Zealand, and the (Australian) type species of Eucrassatella; E. kingicola (Lamarck, 1805). Purpurocardia purpurata was selected as outgroup because wellpreserved specimens are common in collections, it has many gross morphological similarities to the species of Spissatella and Eucrassatella, and because of the close phylogenetic relationship indicated by authors such as Giribet (2008) between the Crassatellidae and Carditiidae.

Ten traditional morphological characters were scored for each species (Table 4.1, characters 1-10). These were selected to capture aspects of the morphology that are distinct from overall shape, and mostly comprise details of the internal shell anatomy and sculpture. The states of these characters are summarised in Table 4.2 and Figures 4.2, 4.3 and 4.4, and detailed descriptions follow. These characters were treated as unordered between states, because it is not evident that there should necessarily be a linear transition between states for any of them. 


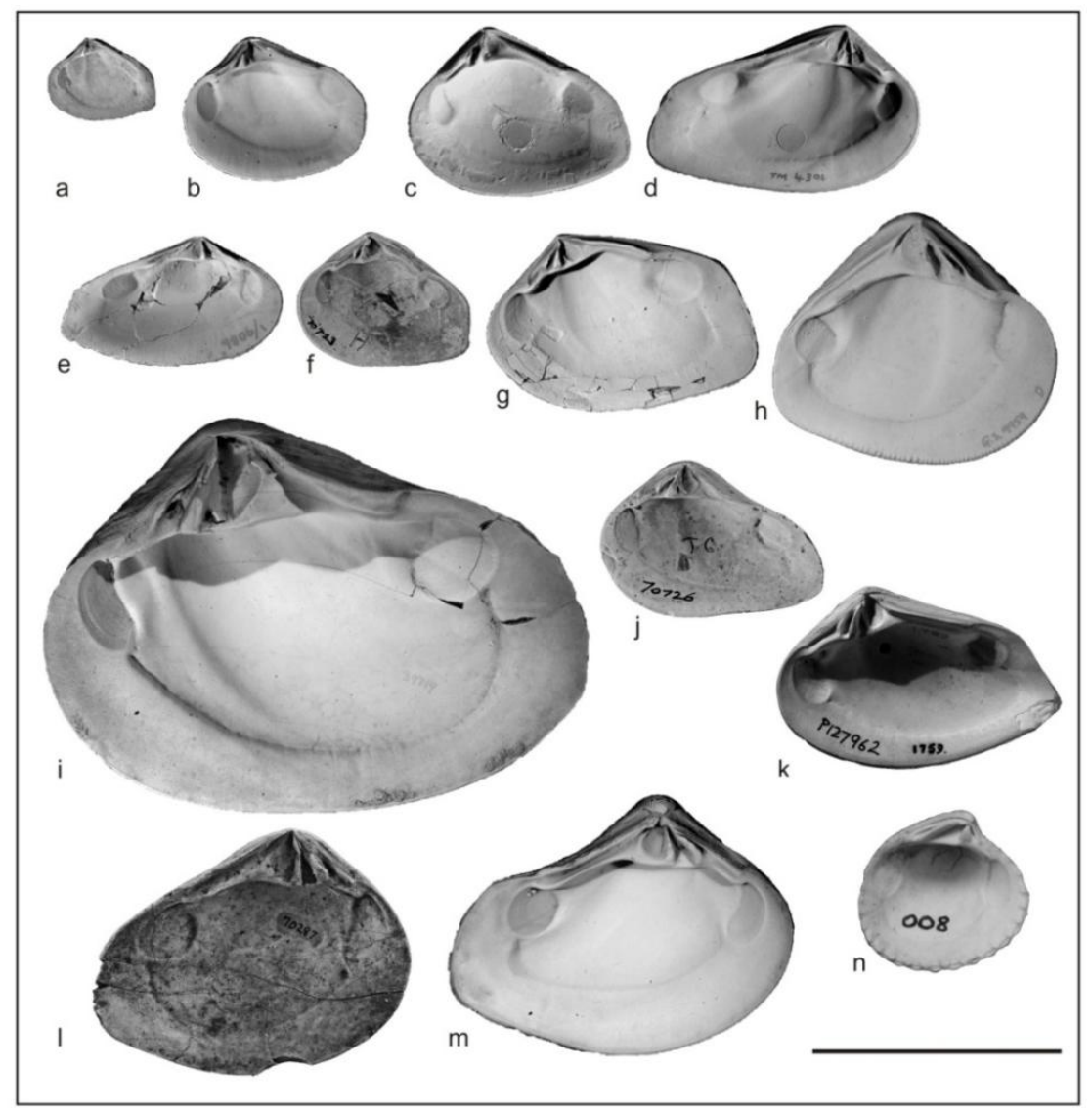

Figure 4.1: Species included in this study: (a) Spissatella media (OU8648); (b) Spissatella n. sp. C (GS4901); (c) Spissatella trailli (TM2859); (d) Spissatella subobesa (TM4301); (e) Spissatella poroleda (GS9806); (f) Spissatella clifdenensis (AK70723); (g) Spissatella acculta (TM7845); (h) Eucrassatella australis (GS9959); (i) Eucrassatella ampla (AK39719); (j) Eucrassatella scopalveus (AK70726); (k) Spissatella maudensis (P127962); (l) Eucrassatella marshalli (GS1101); (m) Eucrassatella kingicola (AK50183); (n) Purpurocardia purpurata (VUW bulk) Scale bar $=50 \mathrm{~mm}$.

\section{Morphological character states}

1: Adductor muscle scar impression. States: (0) deep (1) shallow (Fig. 4.2a, b). The impression of the adductor muscle scars is often deepened in heavy-shelled species by build-up of surrounding shell material. In other species the scars are differentiated by a change in shell texture and an incised border, but not by this cushion-like thickening of the surrounding shell.

2: Resilifer impression: (0) deep (1) shallow (Fig. 4.2c, d). In some species the resilifer is clearly demarcated from the rest of the hingeplate by a depression, in others it is faint or only differentiated by a thin border. 
3: Margin texture: (0) crenulate (1) smooth (Fig. 4.2e, f). This has been considered a diagnostic genus-level taxonomic character within the Crassatellidae by Laws (1935) an interpretation disputed by others (notably Beu \& Maxwell, 1990).

4: Shell under hingeplate: (0) thickened (1) not thickened (Fig. 4.2g, h). Some species display a pronounced build-up of shell material underneath the hingeplate, whereas others are well-excavated.

5: Hingeplate margin: (0) arched (1) shallowly sinuous (2) deeply sinuous (Fig. 4.3a, b, c). The dorsal margin of the hingeplate varies between smoothly arched and strongly reflexed, with some species showing an intermediate, slightly reflexed morphology.

6: Pallial line: (0) evenly curved (1) pointed (2) round-cornered (Fig. 4.3d, e, f). The curvature of the pallial line generally (but not universally) follows the curvature of the ventral margin of the shell. Crassatellids and carditiids are integripalliate, meaning they have no pallial sinus, but they still display some variation in the nature of the curve of their pallial line.

7: Anterior end of hingeplate: (0) smooth (1) small-hooked (2) deeply-hooked (Fig. $4.3 \mathrm{~g}, \mathrm{~h}, \mathrm{i})$. The inflation of the shell combined with the thickness of the hingeplate may produce a 'hook' or protuberance at the anterior end of the hingeplate, dorsal to the anterior adductor muscle scar.

8: Maximum height: (0) <20mm (1) 20-50mm (2) $>50 \mathrm{~mm}$ (Fig. 4.4).

9: Lateral teeth: (0) smooth (1) striate. In some species, the lateral teeth display striate or rugose textures. (Fig. 4.3j, k).

10: Shell thickness: (0) thin (1) moderate (2) thick. 'Thin' and 'thick' are relative terms. Thickness was assessed qualitatively relative to overall shell size. 'Moderate' shells are those that would not normally be considered particularly thick but which display some thickening of shell material around muscle scars or the pallial line. 
(State 0)

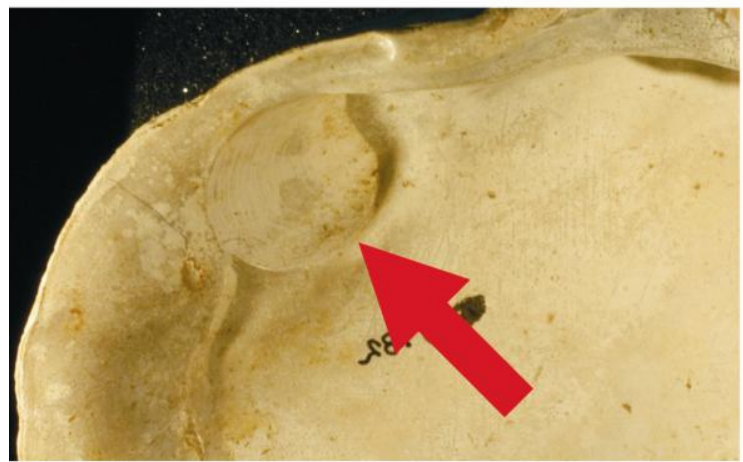

a

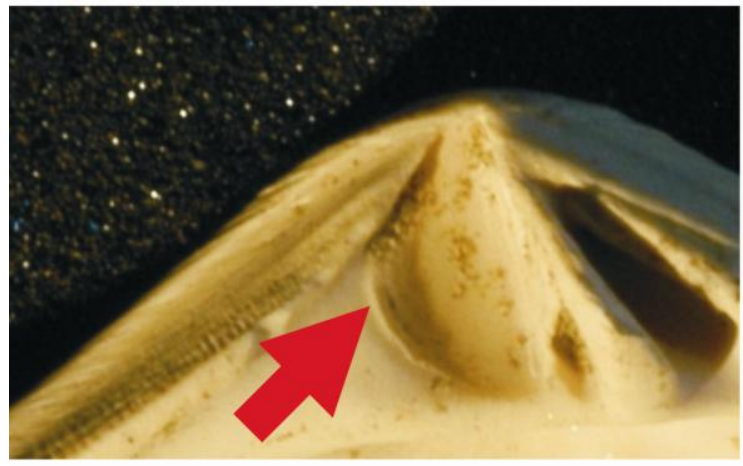

C

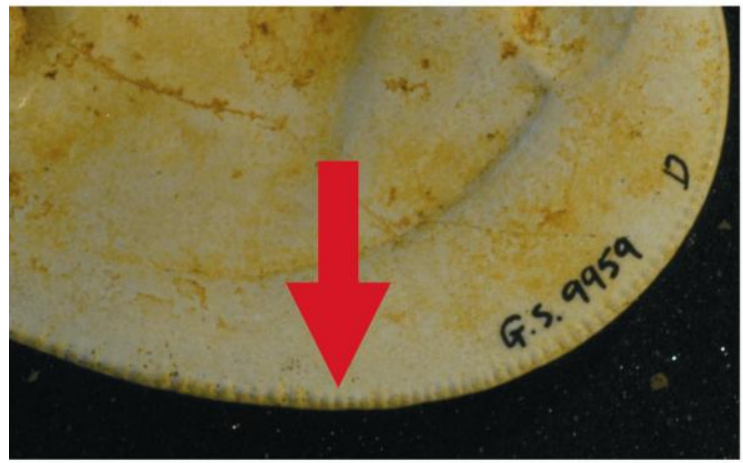

e

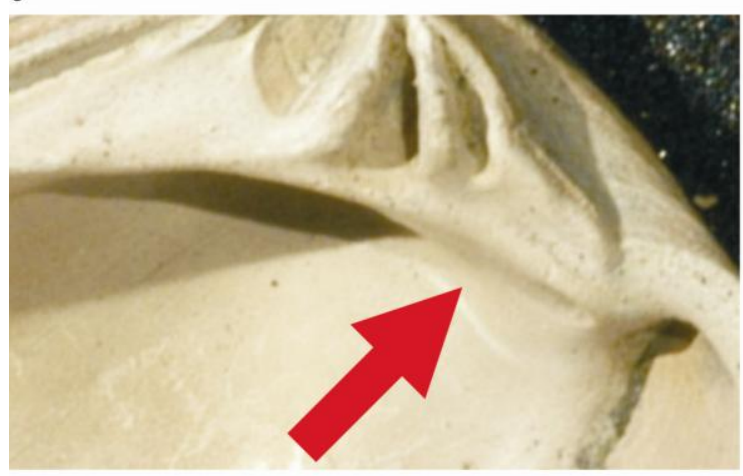

g
(State 1)

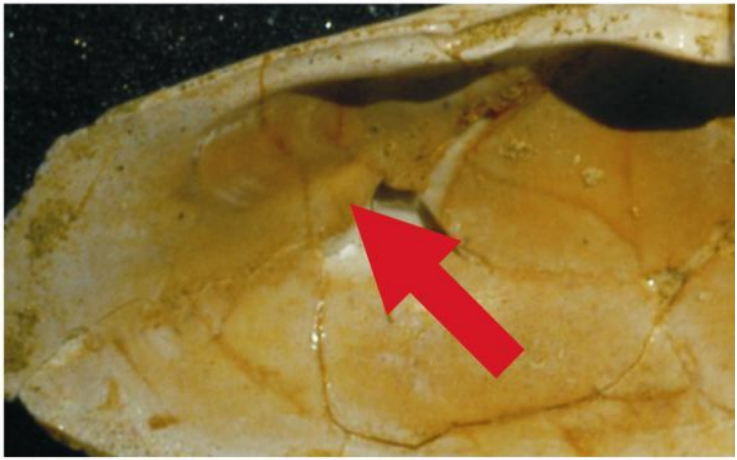

b

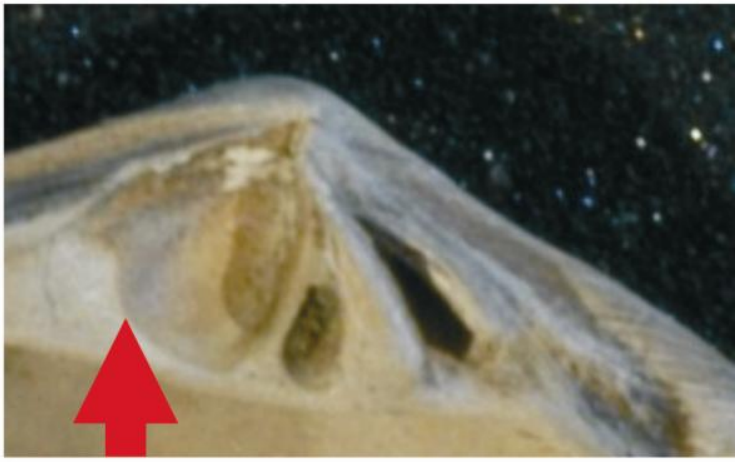

d

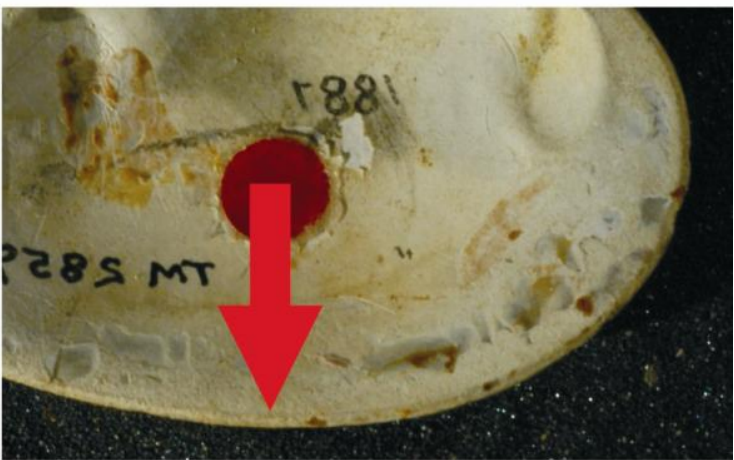

f

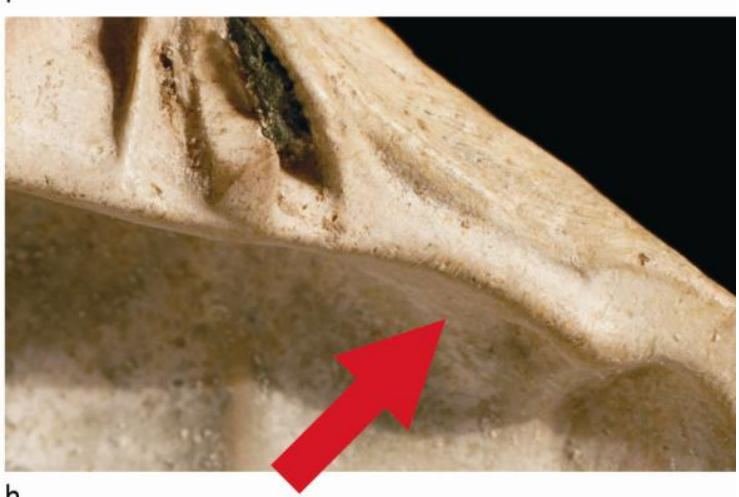

Figure 4.2: (a) Character 1, State 0: Eucrassatella ampla (AK105782) (b) Character 1, State 1: Spissatella poroleda (GS9806) (c) Character 2, State 0: E. scopalvens (M027615) (d) Character 2, State 1: S. acculta (TM7845) (e) Character 3, State 0: E. australis (GS9959) (f) Character 3, State 1: S. trailli (TM2859) (g) Character 4, State 0: S. subobesa (GS10837) (h) Character 4, State 1: S. maudensis (P127961). 
(State 0)

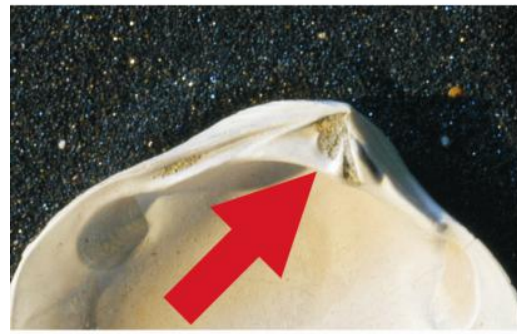

a

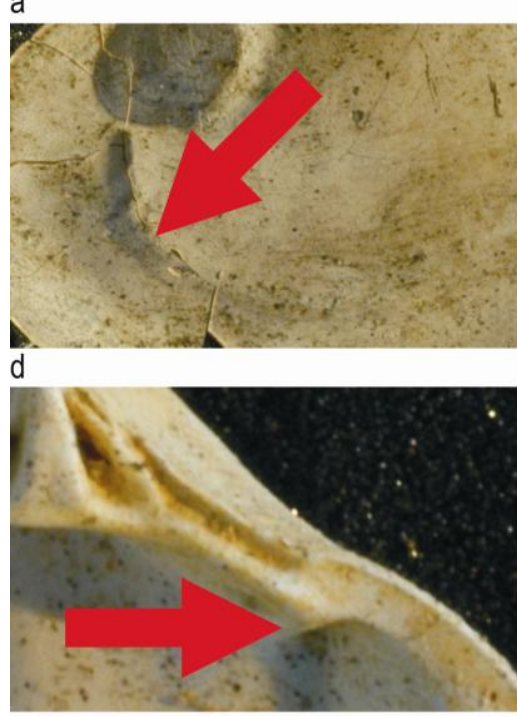

g

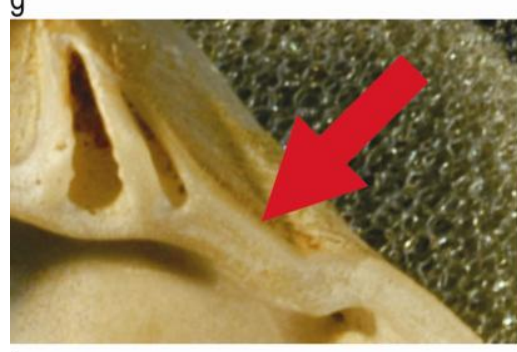

(State 1)

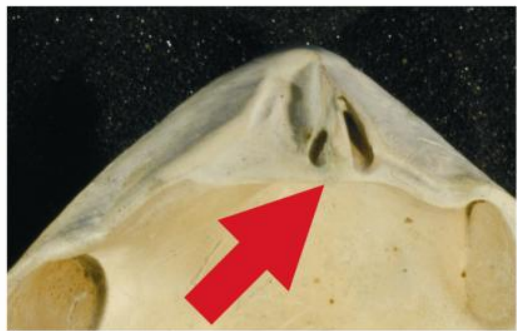

b

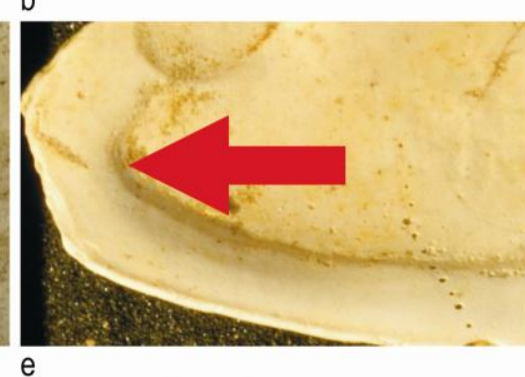

e

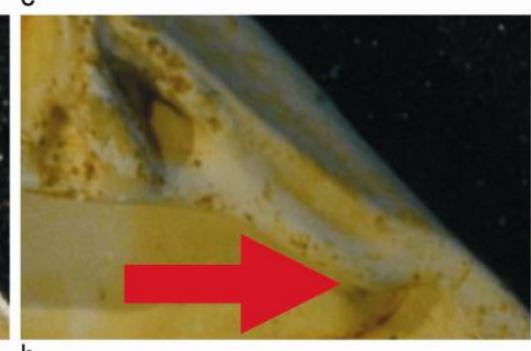

h
(State 2)

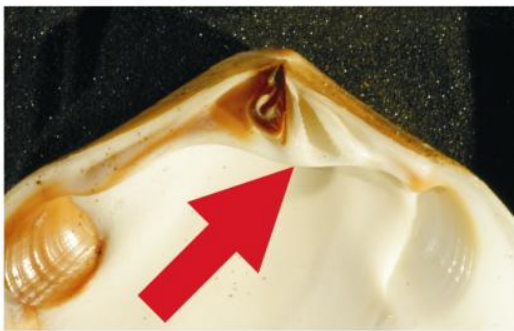

C
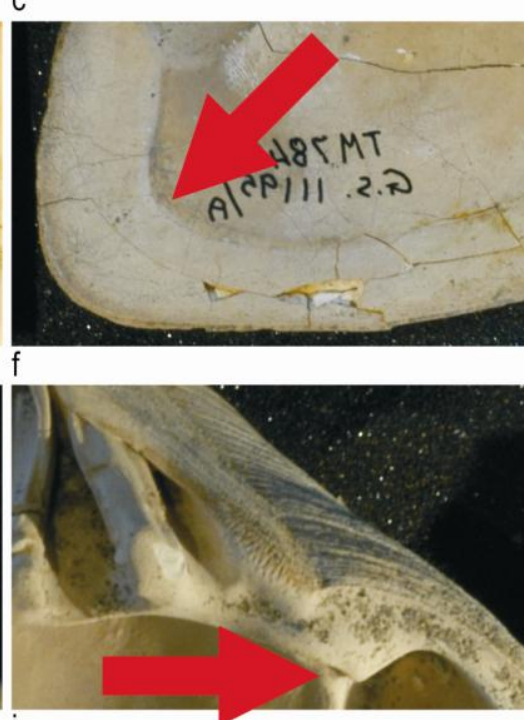

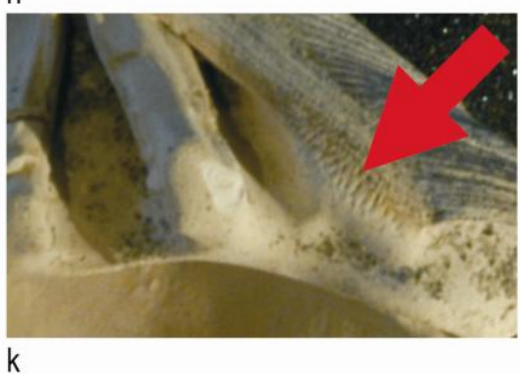

i

j

Figure 4.3: (a) Character 5, State 0: Spissatella maxwelli (M292068) (b) Character 5, State 1: S. clifdenensis (AK65794) (c) Character 5, State 2: Eucrassatella kingicola (M203440) (d) Character 6, State 0: E. marshalli (GS1101) (e) Character 6, State 1: E. scopalveus (M027615) (f) Character 6, State 2: S. acculta (TM7845) (g) Character 7, State 0: S. maxwelli (M292055) (h) Character 7, State 1: E. australis (GS9959) (i) Character 7, State 2: E. ampla (TM7849) (j) Character 9, State 0: Spissatella clifdenensis (AK65809) (k) Character 9, State 1: Eucrassatella ampla (TM7849).

\section{Principal Component (PC) scores from PCA of Procrustes}

landmark/semilandmark configurations were inclued in the analysis in order to capture information on shape. Using a broken-stick model (Jackson, 1993; see page 37), eight PCs, summarising $88 \%$ of the total variance, were found to be statistically significant. In order to include these continuous data in a stratocladistic analysis, PC scores were binned using the boxplot method of Almeida and Bisby (1984) (Text Box 6; Fig. 4.5), which yielded a further eight ordered characters (Table 4.1, characters 11-18) with 22 states overall. 


\section{Maximum heights}

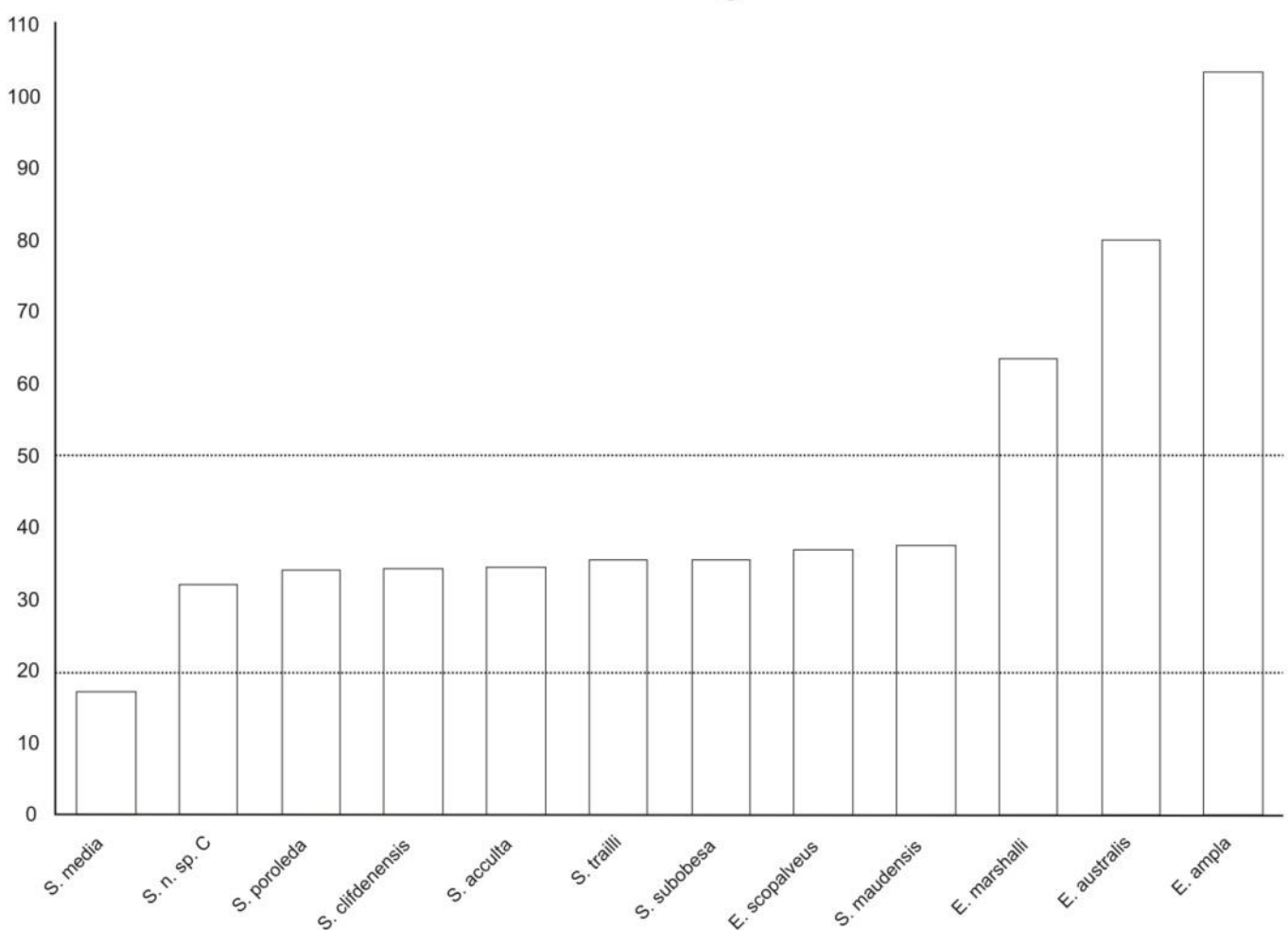

Figure 4.4: Bar chart of maximum heights for Spissatella and Eucrassatella species in this study, showing delineated size classes used as states of Character 8.

Stratigraphic data are binned according to units of the New Zealand geological timescale (Figure 4.6). The bins chosen were New Zealand series rather than stages, in order to minimise the required number of states. Age data for Australian species, given in terms of Australian local stages by Darragh (1965), were correlated to the New Zealand local timescale (Cooper et al., 2004) using data from Young and Laurie (1996). Stratigraphic

Text Box 6: Almeida and Bisby's (1984) boxplot method of coding discrete character states from continuous data is a semi-quantitative, non-automated method that allows examination of the structure of the data to guide the drawing of character state boundaries, and is analogous to the traditional qualitative coding of character states by observation of morphology. Characters are coded for a state if their interquartile range (the central $25 \%-75 \%$ of the data, shown as the solid central rectangular portion of the boxplot), lies within it (Figure 4.2). This prevents outliers from skewing the coding of character states. State boundaries are drawn so as to avoid crossing interquartile ranges as far as possible, although often this will be unavoidable. The advantage of using a semi-quantitative method such as this is that it combines subjective judgement gained from experience with the taxa at hand with a transparent and repeatable methodology. 
information provided one character (Table 4.1, character 19), coded as 'stratigraphic', which has eight states. Figure 4.6 presents a range-chart for the species included in this analysis together with the boundaries of the bins used.

Initial analysis was conducted in StrataPhy (Marcot \& Fox, 2008), using an exhaustive search over 100 search replicates and five ancestral-assignment search replicates. The maximum number of trees saved to file was set at 1000. The outgroup was Purpurocardia purpurata. All characters were treated as equally-weighted. For this dataset, StrataPhy recovered two trees of treelength $=143$. The data matrix (Table 4.1) and the treefile output by StrataPhy were then analysed further in MacClade (Maddison \& Maddison, 2005). The tree with the highest Retention Index (RI) (=0.58) was subjected to manual branchswapping and ancestral state assignments in order to search for a shorter tree, and to output tree statistics such as treelength, steps, minimum and maximum steps, and character RIs. The pooled RI for the morphological and morphometric characters, the RI of the stratigraphic character alone (which MacClade cannot output), and the pooled RI for the tree as a whole were calculated using output from MacClade, following the method of Clyde \& Fisher (1997).

Text Box 7: The Retention Index is calculated from the minimum and maximum possible steps for each character over the tree:

$$
R I=\left(\sum M_{i}-\sum S_{i}\right) \div\left(\sum M_{i}-\sum m_{i}\right)
$$

where $\mathrm{M}_{\mathrm{i}}=$ maximum number of steps

$$
\begin{array}{ll}
\mathrm{m}_{\mathrm{i}}=\quad \begin{array}{l}
\text { minimum number of steps } \\
\text { for character } i
\end{array} \\
\mathrm{~S}_{\mathrm{i}}=\quad \begin{array}{l}
\text { steps for character } i \text { in } \\
\text { current solution }
\end{array}
\end{array}
$$

'Steps' are changes in character state. Calculation of $\mathrm{M}_{\mathrm{i}}$ and $\mathrm{m}_{\mathrm{i}}$ is dependant on the type of character (unordered, ordered, stratigraphic etc) as the number of possible changes is dependant on whether or not reversions are allowed. $\mathrm{M}_{\mathrm{i}}, \mathrm{m}_{\mathrm{i}}$ and $\mathrm{S}_{\mathrm{i}}$ are all output by MacClade.

The Retention Index can be thought of as a measure of how well a given tree fits the raw data it was constructed from. A higher value of RI indicates better fit of tree to data. Retention indices can be calculated for characters individually, allowing the comparison of the summed RIs of the morphological data and the RI of the stratigraphic data to the RI of the entire tree, as has been undertaken in this study. 


\begin{tabular}{|c|c|c|c|c|c|c|c|c|c|c|c|c|c|c|c|c|c|c|c|}
\hline & naract & & & & & & & & & & & & & & & & & & \\
\hline Species & 1 & 2 & 3 & 4 & 5 & 6 & 7 & 8 & 9 & 10 & 11 & 12 & 13 & 14 & 15 & 16 & 17 & 18 & 19 \\
\hline S. media & 1 & $?$ & 1 & 1 & 1 & $(02)$ & 0 & 0 & 0 & 0 & 2 & 1 & 0 & 0 & (012) & 0 & 2 & 1 & 1 \\
\hline S. n. sp. C & (01) & (01) & 1 & (01) & (01) & (012) & (01) & 1 & (01) & 1 & (12) & 1 & 1 & 0 & (12) & 1 & (12) & (01) & 2 \\
\hline S. trailli & (01) & (01) & 1 & (01) & (01) & (012) & (01) & 1 & (01) & 1 & 2 & 1 & 1 & (01) & $(12)$ & 1 & (12) & 0 & 3 \\
\hline S. subobesa & (01) & (01) & 1 & (01) & (01) & $(12)$ & (01) & 1 & (01) & 1 & 3 & 1 & (01) & (01) & 1 & (01) & (12) & 0 & 2 \\
\hline S. poroleda & (01) & 1 & 1 & 1 & (01) & $(01)$ & (01) & 1 & (01) & 0 & 3 & 0 & 1 & 1 & 2 & 1 & 1 & 1 & 2 \\
\hline S. clifdenensis & (01) & (01) & 1 & (01) & (01) & $(02)$ & (01) & 1 & (01) & 1 & 2 & 1 & 1 & 0 & 1 & 1 & 1 & 0 & 3 \\
\hline S. acculta & 1 & 1 & 1 & 1 & (01) & 2 & 0 & 1 & 0 & 0 & 2 & 1 & (01) & 1 & 2 & 1 & 2 & (01) & 2 \\
\hline S. maudensis & 0 & (01) & 1 & 1 & 1 & 1 & (01) & 1 & (01) & 1 & 3 & 1 & 1 & 0 & 1 & (01) & 2 & 2 & 2 \\
\hline E. australis & (01) & (01) & 0 & (01) & (01) & (01) & (01) & (12) & (01) & 2 & 0 & 1 & (01) & 0 & 1 & (01) & 2 & (01) & (01) \\
\hline E. ampla & 0 & 0 & 1 & (01) & (12) & 0 & (12) & 2 & (01) & 2 & (12) & 1 & (01) & (01) & 1 & 0 & (12) & 1 & $(2345)$ \\
\hline E. scopalvens & (01) & (01) & 1 & (01) & (012) & (012) & (01) & 1 & (01) & 2 & 2 & 0 & 1 & (01) & 1 & 1 & 1 & (01) & 3 \\
\hline E. marshalli & 0 & 0 & 1 & 0 & 1 & 0 & 0 & 2 & (01) & 2 & 1 & 1 & 2 & 1 & 0 & (01) & 1 & 0 & $(56)$ \\
\hline E. kingicola & 0 & (01) & 1 & (01) & $(12)$ & $(02)$ & (01) & (12) & (01) & 2 & 1 & 1 & 2 & 1 & 0 & 1 & 2 & 1 & $(67)$ \\
\hline P. purpurpata & 0 & - & 0 & 1 & 1 & 0 & 0 & 1 & 0 & 1 & 0 & 2 & 1 & 1 & 1 & 1 & 0 & 1 & $(67)$ \\
\hline
\end{tabular}

Table 4.1: Full character matrix. States of characters 1-10 are summarised in Table 4.2. States of characters 11-18 are presented in Figure 4.5. States of character 19 are presented in Figure 4.6. ? indicates missing data, - indicates 'inapplicable'. 

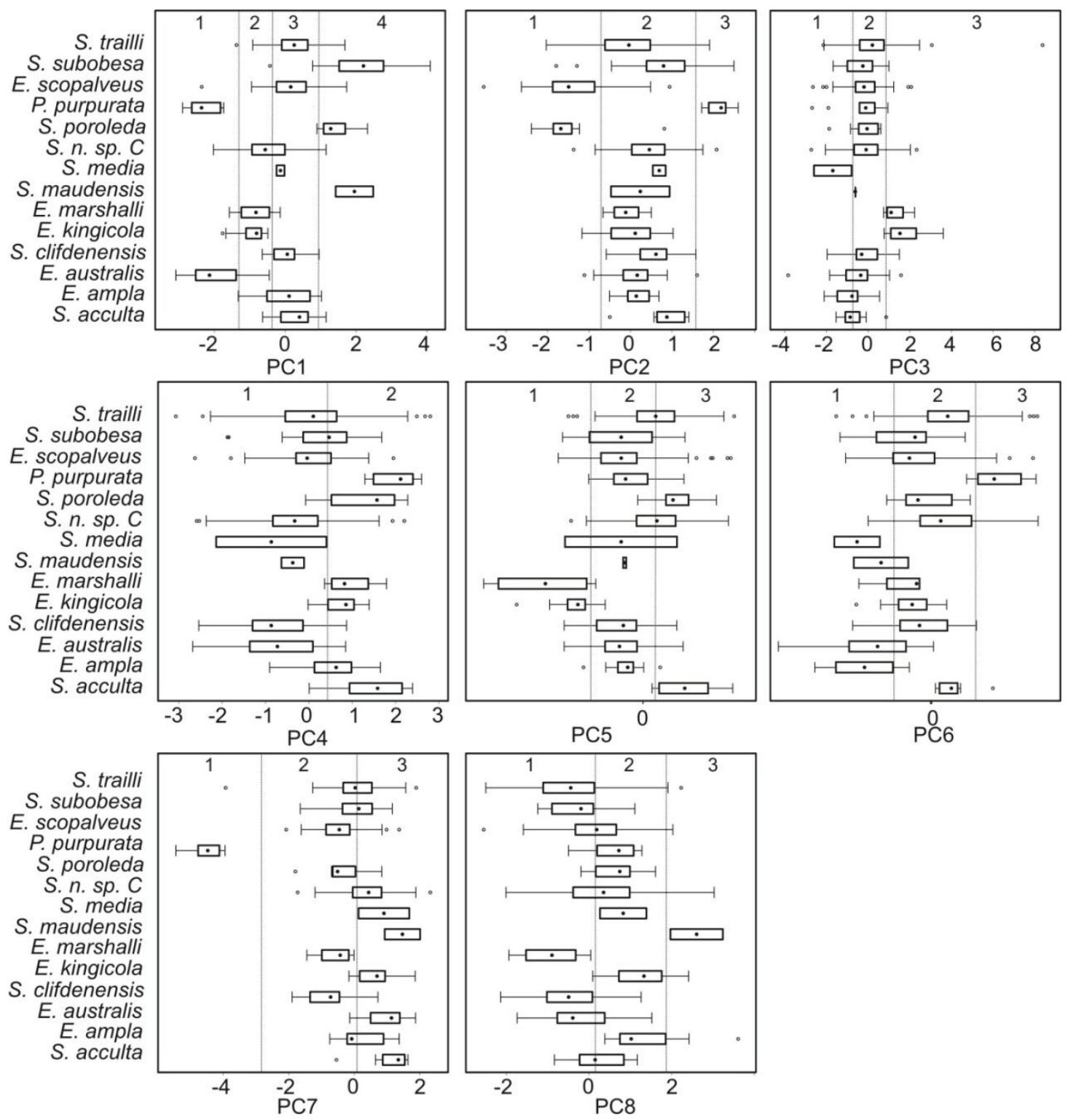

Figure 4.5: Boxplots of PC scores along eight PC axes for the dataset. Dotted lines delineate character states (numbered at the top of each plot) identified using Almeida and Bisby's (1984) method.

\begin{tabular}{rllll}
\hline \# & Name & State 0 & State 1 & State 2 \\
\hline 1 & Adductor muscle scar impression & Deep & Shallow & - \\
2 & Resilifer impression & Deep & Shallow & - \\
3 & Margin texture & Crenulate & Smooth & - \\
4 & Shell under hingeplate & Thickened & Not thickened & - \\
5 & Hingeplate margin & Arched & Shallowly-sinuous & Deeply-sinuous \\
6 & Pallial line & Evenly curved & Pointed & Round-cornered \\
7 & Anterior end of hingeplate & Smooth & Small-hooked & Deeply-hooked \\
8 & Maximum height & $<20 \mathrm{~mm}$ & 20-50mm & $>50 \mathrm{~mm}$ \\
9 & Lateral teeth & Smooth & Striate & - \\
10 & Shell thickness & Thin & Moderate & Thick \\
\hline
\end{tabular}

Table 4.2: Morphological character states. 


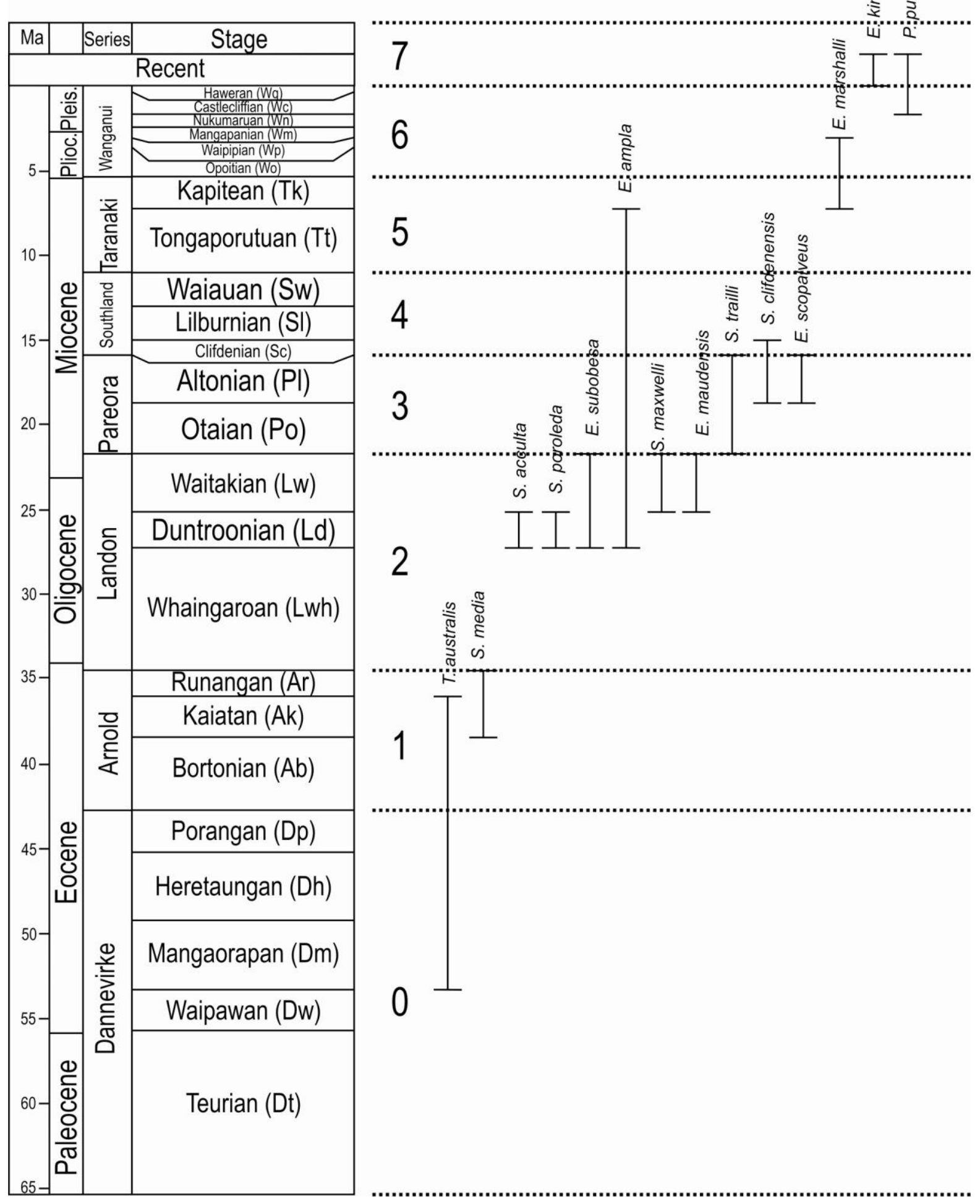

Figure 4.6: New Zealand geological timescale correlated to international stages (after Hollis et al., 2010), and range-chart for the species included in this study. Time-bins used for the stratigraphic character correspond to New Zealand series and are delineated by dotted lines and numbered along the right-hand side of the timescale. 


\subsection{Results}

The final tree for the dataset (treelength 137, RI 0.75) is presented in Figure 4.7.

There are two distinct sister clades, one of which includes mostly species currently assigned to Eucrassatella, and one of which includes species currently assigned to Spissatella. The tree is well-resolved, with no polytomies. Retention indices and the data used to calculate them for this tree are presented in Table 4.3. Retention indices measure goodness-of-fit of tree to data, with higher numbers indicating better fit. Retention index values of $\sim 0.7$ were described as 'high' by Clyde and Fisher (1997). All RIs for this tree are $>0.7$, and, comparing the RI of the morphological characters only to the RI of the tree as a whole, it can be seen that the inclusion of the stratigraphic character has improved the congruence of the data with the tree. Furthermore, the morphological and stratigraphic RI values reported for this tree are similar (within 0.6 of each other), indicating correlation between these two sources of data (Clyde \& Fisher, 1997).

\begin{tabular}{|c|c|c|c|c|c|c|c|}
\hline Character & Type & Weight & States & Steps & Minsteps & Maxsteps & RI \\
\hline 1 & unordered & 1 & 2 & 8 & 8 & 9 & 1 \\
\hline 2 & unordered & 1 & 2 & 8 & 8 & 10 & 2 \\
\hline 3 & unordered & 1 & 2 & 1 & 1 & 2 & 1 \\
\hline 4 & unordered & 1 & 2 & 8 & 8 & 9 & 0 \\
\hline 5 & unordered & 1 & 3 & 11 & 11 & 11 & 0 \\
\hline 6 & unordered & 1 & 3 & 14 & 14 & 15 & 1 \\
\hline 7 & unordered & 1 & 3 & 11 & 11 & 11 & 0 \\
\hline 8 & unordered & 1 & 3 & 4 & 4 & 5 & 1 \\
\hline 9 & unordered & 1 & 2 & 11 & 11 & 11 & 0 \\
\hline 10 & unordered & 1 & 3 & 4 & 2 & 8 & 0.67 \\
\hline 11 & ordered & 1 & 4 & 7 & 5 & 11 & 0.67 \\
\hline 12 & ordered & 1 & 3 & 4 & 2 & 3 & 0 \\
\hline 13 & ordered & 1 & 3 & 6 & 6 & 7 & 1 \\
\hline 14 & ordered & 1 & 2 & 6 & 5 & 9 & 0.75 \\
\hline 15 & ordered & 1 & 3 & 6 & 6 & 8 & 1 \\
\hline 16 & ordered & 1 & 2 & 6 & 5 & 6 & 0 \\
\hline 17 & ordered & 1 & 2 & 7 & 5 & 8 & 0.33 \\
\hline 18 & ordered & 1 & 3 & 7 & 6 & 10 & 0.75 \\
\hline 19 & stratigraphic & 1 & 8 & 8 & 0 & 39 & 0.79 \\
\hline Morphological RI & & & & & & & 0.71 \\
\hline Stratigraphic RI & & & & & & & 0.79 \\
\hline Tree RI & & & & & & & 0.75 \\
\hline
\end{tabular}

Table 4.3: Retention Indices and the data used to calculate them. 


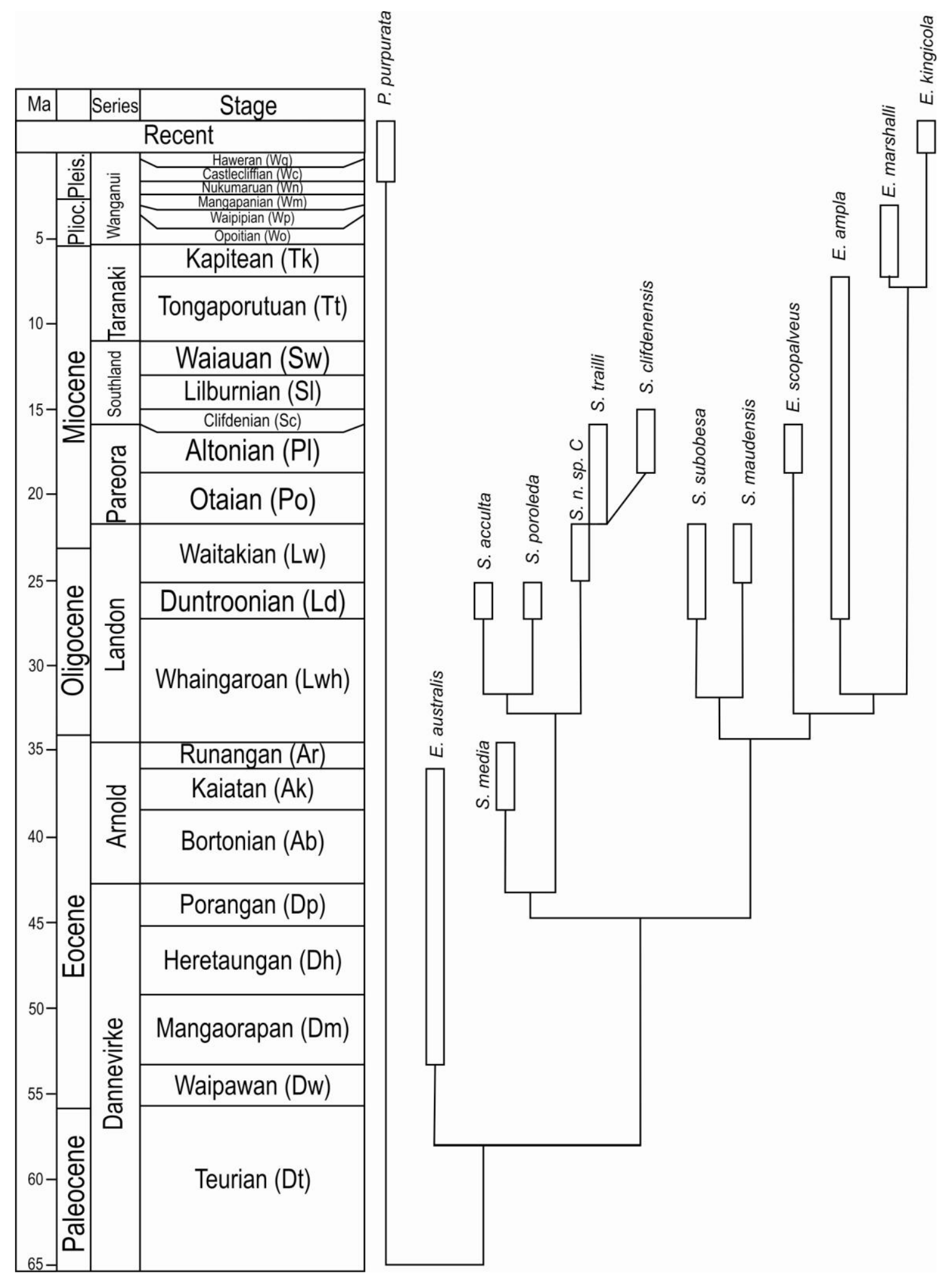

Figure 4.7: Phylogeny for species of Spissatella and Eucrassatella. Separation of E. australis from younger Eucrassatella and of S. subobesa and S. maudensis from other Spissatella renders both genera paraphyletic as currently defined. Thick bars indicate stratigraphic ranges thin lines represent phylogenetic relationships. Branching points are not indicative of age of lineage splitting. 


\subsection{Discussion and Conclusions}

The tree presented in Figure 4.7 shows that the current taxonomy of the larger New Zealand Crassatellidae requires revision. Most notably, Eucrassatella as currently defined is paraphyletic; if "E." australis is truly a Eucrassatella, then the species currently assigned to Spissatella must also be placed in Eucrassatella. However, "E." australis is not typical of Eucrassatella; it is very equilateral in shape, where other Eucrassatella are elongate, and it has a crenulate margin, a character which is explicitly excluded from Eucrassatella by Darragh (1965). Add to this the history of disagreement over its generic placement - it was assigned to Astarte by Hutton (1873), Spissatella by Finlay (1926), Crassatellites by Laws (1935) and Eucrassatella by Beu and Maxwell (1990) - and we suggest that this species should be placed within its own genus. In order to maintain monophyly of Eucrassatella and Spissatella, the two species S. subobesa and S. maudensis should be reassigned to Eucrassatella. Like E. scopalveus, which they resemble, they are small for Eucrassatella, but thick-shelled and elongate. These reassignments, it should be noted, require no alteration of the diagnoses of either genus (Finlay, 1926; Darragh, 1965).

StrataPhy allows positioning of taxa at internal nodes of the tree in instances where doing so does not add to the combined parsimony debt. The solution presented here places Spissatella n. sp. C as the ancestor of S. trailli, a relationship first suggested by Crampton and Maxwell (2000) and which we have accepted here.

Combining morphological, morphometric and stratigraphic characters has produced a well-resolved tree that fits both stratigraphic order and morphological observations well. This method is novel and will require refinement - ideally, the development of software that can accept both continuous and stratigraphic data - but contributes to recovery of the phylogenies of taxa that would previously have been considered unsuitable for study using cladistic methodologies. 


\section{5}

\section{Taxonomy}

"'... It next will be right

To describe each particular batch:

Distinguishing those that have feathers, and bite

From those that have whiskers, and scratch.

For, although common Snarks do no manner of harm,

Yet, I feel it my duty to say,

Some are Boojums -' The Bellman broke off in alarm,

For the Baker had fainted away."

- The Hunting of the Snark: Fit the Second - The Bellman's Speech 


\section{A Revision of New Zealand species of Spissatella and Eucrassatella (Bivalvia, Crassatellidae)}

\subsection{Abstract}

The genera and species of larger Crassatellidae in New Zealand have not hitherto been studied collectively, although some species have been individually redescribed in previous publications, and generic reassignments have taken place without justification. In the current redescription, two species ("Spissatella" subobesa and the Australian "S." maudensis) are transferred to the genus Eucrassatella; the genus Spissatella is redescribed and the species assigned to it are reviewed. A new species, Spissatella maxwelli, is described, and the new genus Triplicitella is proposed for the oldest New Zealand species of crassatellid, "Eucrassatella" australis.

\subsection{Introduction}

Spissatella Finlay 1926, and Eucrassatella Iredale 1924, are Cenozoic bivalve genera of the family Crassatellidae Férussac, 1822. Nine species of Spissatella and five species of Eucrassatella from New Zealand are listed by Maxwell in Spencer et al. (2009), ranging in age from the late Eocene to the middle Miocene. Additionally, an undescribed species (Spissatella n. sp. C) is mentioned in Cenozoic Mollusca of New Zealand (Beu \& Maxwell, 1990), and included in Crampton and Maxwell's morphometric analyses (2000). One species, Spissatella maudensis (Pritchard 1903), is known from Australia (Darragh, 1965), and one species, S. lyelli (Sowerby 1846), is known from Patagonia (Griffin \& Nielsen, 2008). A further South American Tertiary species, Crassatella longior Von Ihering, 1897, may be referrable to Spissatella (Beu et al., 1997).

Most species now referred to Eucrassatella from New Zealand were originally assigned to either Crassatella or Crassatellites (Zittel, 1864; Hutton, 1873; Suter, 1914; Marshall \& Murdoch, 1919; Laws, 1935). The genus Spissatella was erected in 1926 by Finlay 
to contain any smooth-margined crassatellid that he considered too small to belong in Eucrassatella. "Spissatella" australis was transferred to Eucrassatella by Beu and Maxwell (1990) on the basis of "size, shape, and sculptural characters", and "S." scopalveus and "S." concisa were likewise transferred to Eucrassatella by Crampton and Maxwell (2000) on the basis of "sculpture, shape, ontogenetic development and shell thickness (unpublished data)". As defined by Crampton and Maxwell (2000), Spissatella differs from Eucrassatella in having a smaller, thinner shell with a proportionally smaller hingeplate, and having commarginal sculpture over the entire shell.

It has been suggested that Spissatella was derived from an unknown Australian Eucrassatella, which is presumed to have colonised New Zealand during the Eocene and given rise to Spissatella (Crampton \& Maxwell, 2000). However, the larger crassatellids have a longer confirmed range in New Zealand than in Australia, thus making this relationship unlikely. The oldest confirmed member of the group from either country is Eucrassatella australis (Heretaungan - Kaiatan (mid-late Eocene); Waimate, Canterbury). Although Darragh (1965) lists a possible Eocene occurrence for Eucrassatella in Australia, it consists of a single specimen that has not been convincingly assigned to a species.

Spissatella and Eucrassatella in New Zealand have not been well-studied. They are common in a number of Oligocene and Miocene sections, and moderately speciose, but have not received detailed attention beyond appearing in faunal lists. This study aims to improve this state of affairs by revising their taxonomy in a phylogenetic context. 


\subsection{Morphometrics and phylogenetics contributing to this revision}

This revision has been undertaken with reference to morphometric and phylogenetic work previously undertaken (Collins et al., in submission; Collins et al., in prep). The relevant phylogenetic tree is shown in Figure 5.1. Where appropriate, morphometric plots have been included to illustrate generic and species relationships in morphospace. The data presented in these plots is derived from principal components analysis (PCA) of landmark and semilandmark shape analysis (Collins et al., in submission; Webster \& Sheets, 2010). In all plots presented here, higher values of principal component (PC) 1 correspond to a general increase in shell elongation (L) and higher values of PC2 correspond to low umbonal angles $\left(\sim 90^{\circ}\right)$ and short anterior regions. Figure 5.2 illustrates the relative positions of the three genera in this morphospace. It can be seen that the means of Spissatella and Eucrassatella are united along PC1 here, but that the means of Triplicitella n. gen. and Spissatella are united on PC2. The means of Triplicitella and Eucrassatella are separated along both axes. There is partial overlap between the probability ellipses of all groups. Referring back to the phylogeny presented in Figure 5.1, the inference can be made that Spissatella species are derived from Triplicitella or Triplicitella-like ancestors by means of an expansion into a 'more -elongate' region of morphospace, and that Eucrassatella is a further expansion into 'deeper-shelled' morphospace. 


\subsection{Abbreviations and conventions adopted}

\section{Abbreviations:}

J40/f6610 NZ Fossil Record File (www.fred.org.nz) number; NZ map sheet number ("J40") followed by locality number within that sheet ("f6610"'")

AK Specimen registration number, Auckland War Memorial Museum

AU Bulk locality number, University of Auckland

GS Bulk locality number, GNS Science

L Specimen registration number, University of Auckland

M Specimen lot registration number, Te Papa Tongarewa

MUGD Specimen registration number, Melbourne Museum

NHMW Specimen registration number, Naturhistorisches Museum Wein

OU Bulk locality number, University of Otago

TM Type Mollusca specimen registration number, GNS Science

Annotations on synonymies: (Following Matthews, 1973)

* Indicates type material

v "vidimus" - we have seen and checked the material attached to this reference

v* Type material has been seen and checked by the authors

1889 Italicised date: Indicates a reference that contributes no new information (e.g. a checklist entry)

We accept responsibility for attaching this reference to this species

\section{Dimensions:}

Specimen dimensions are given in millimetres, in the consistent order $\mathrm{L}$ (= length), $\mathrm{H}$ (= height). The dimensions of the largest specimen examined are given for each species described. 


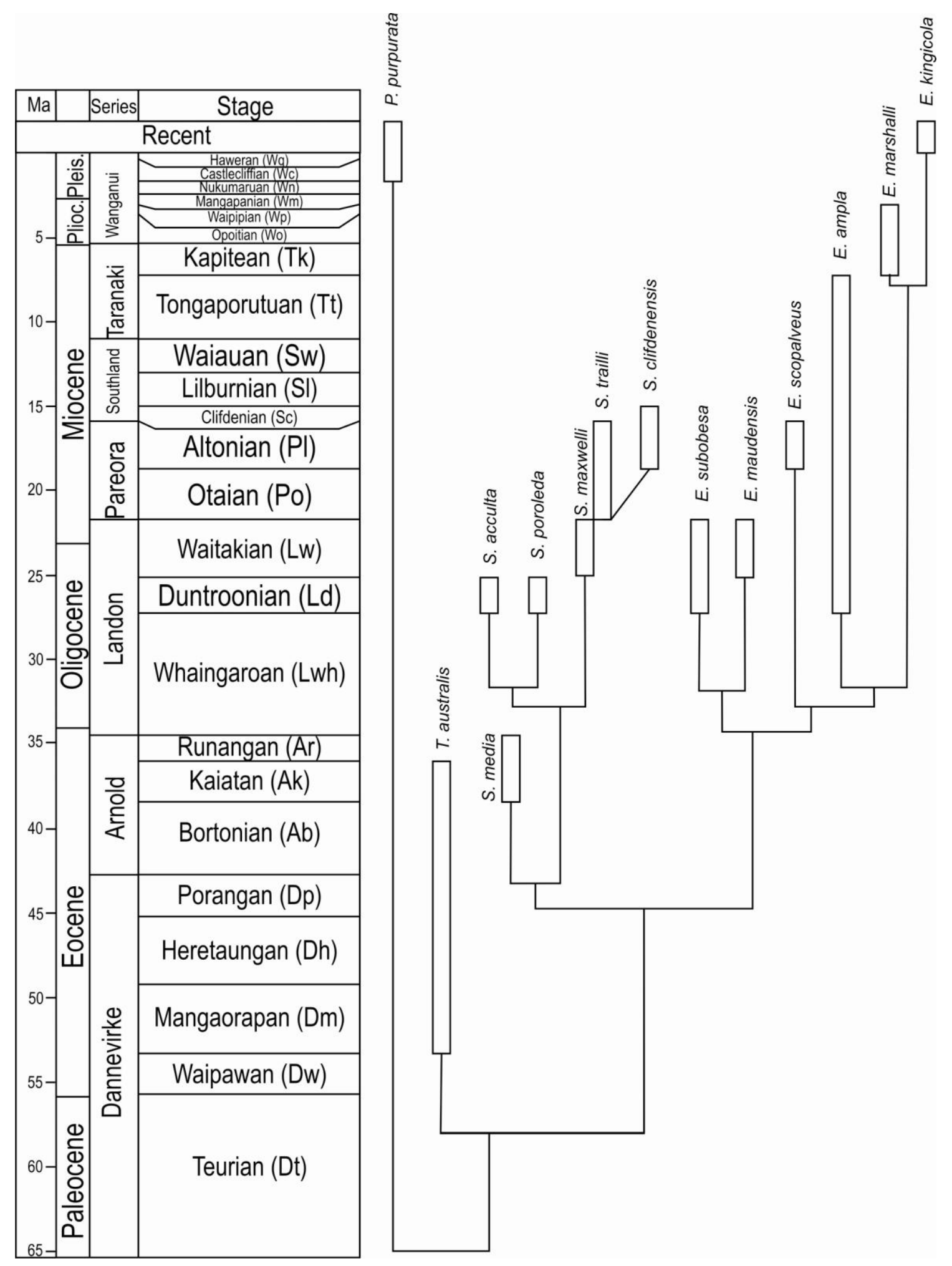

Figure 5.1: Phylogeny of the species included in this study. NB: The outgroup,

Purpurocardia purpurata, and Eucrassatella kingicola (which is not found in New Zealand) are not included in this taxonomic revision. Thick bars indicate stratigraphic ranges (from Spencer et al., 2009) and thin lines show phylogenetic relationships. 


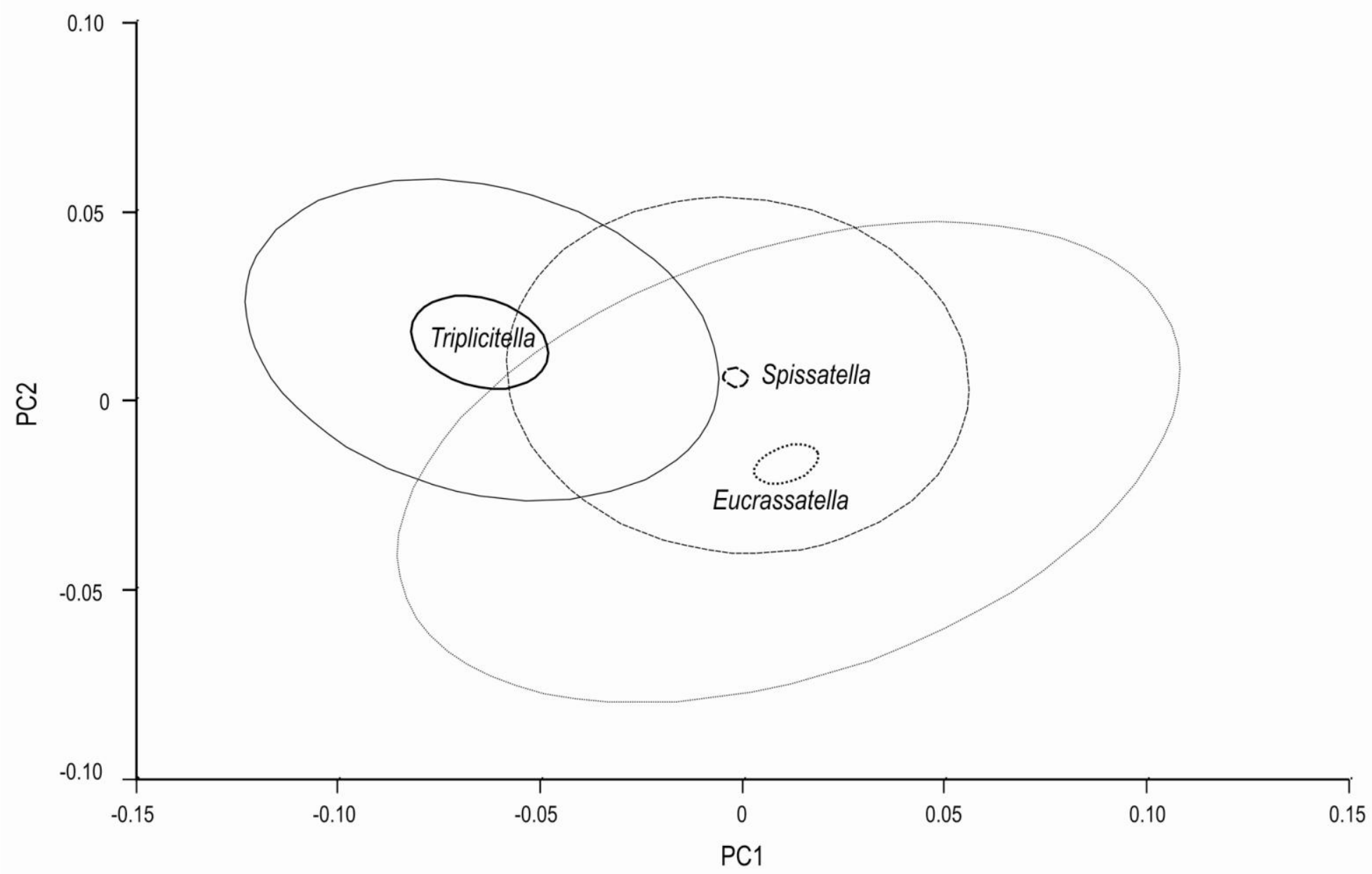

Figure 5.2: Principal components analysis of 7 landmark/38 semilandmark configuration of Triplicitella $\mathrm{n}$. gen. $(\mathrm{n}=16)$, Spissatella $(\mathrm{n}=370)$ and Eucrassatella $(\mathrm{n}=152)$. Small ellipses are 95\% confidence ellipses on group means, larger ellipses are 95\% probability ellipses on groups. PC1 explains $33.1 \%$ and PC2 explains $18.9 \%$ of the total variance in the dataset. 


\title{
5.5 Systematic taxonomy
}

\author{
Phylum: MOLLUSCA \\ Class: BIVALVIA Linnaeus, 1758 \\ Subclass: HETERODONTA Neumayr, 1884 \\ Order: CARDITOIDA Dall, 1889 \\ Superfamily: CRASSATELLOIDEA Férussac, 1822 \\ Family: CRASSATELLIDAE Férussac, 1822
}

Genus: EUCRASSATELLA Iredale, 1924

Eucrassatella Iredale 2924, p. 202. Type species (by original designation): Crassatella kingicola Lamarck, 1805. Recent, southern Australia.

DiAGNOSIS: Thick-shelled, elongate crassatellids with well-developed triangular cardinal teeth, deeply impressed adductor muscle scars, ribbed commarginal sculpture, and smooth valve margins.

DesCRIPTION: From Darragh (1965, p.98): "Shell thick, heavy, equivalve, ovate to suboblong, occasionally subquadrate. Umbo prosogyral. Siphonal ridge [= posterior ridge] present. Lunule and escutcheon deeply impressed. Ornament consisting of concentric ribs usually confined to the umbonal region, occasionally entirely absent or extending to the ventral border of the valve. Hinge plate short and with a large triangular resilifer extending from under the beak to the ventral edge of the hinge plate. Ligament pit narrow, posterior to the resilifer. Tooth formula

\begin{tabular}{ccrr}
$3 a$ & $3 b$ & $5 b$ & LPI \\
\hline LAII & 2 & $4 b$
\end{tabular}

Laterals are variable and are poorly developed in most cases being an extension of the valve margin. 3b [= right median cardinal] is strongly developed and has its sides grooved, $3 \mathrm{a}$ [= right anterior cardinal $]$ and $5 \mathrm{~b}$ [= right posterior cardinal $]$ usually not well developed, 5b has no corresponding socket in the left valve. Pallial line simple and impressed. Pedal 
impression deep beneath the hinge plate and just behind the anterior muscle scar. Muscle scars large sub-equal deeply impressed, the anterior scar a little elongated dorso-ventrally, the posterior scar sub-circular. Interior of shell porcellaneous. Ventral margin of the valves smooth without crenulations."

DistRiBution: Upper Oligocene to Recent, Australia and New Zealand.

REMARKS: We repeat the excellent description of this genus provided by Darragh (1965) for the sake of completeness, seeing no need to amend it. However, generic reassignments herein necessitate that it be explicitly noted that Eucrassatella may include small, but still heavy-shelled and elongate, taxa that might previously have been assigned to Spissatella primarily on the basis of their size, following Finlay (1926). The genus Eucrassatella is moderately speciose, comprising four extant Australian species and a further nine fossil Australian species and four fossil New Zealand species. It also occurs in the fossil record in New Guinea and Japan (Darragh, 1965). It is not extant in New Zealand. The species of Eucrassatella are variable in size but are united by having thick, elongate, smooth-margined shells which have a deep hingeplate. Figure 5.3 shows the relationships between species of Eucrassatella in morphospace. Taking taxa in stratigraphic order from the oldest, E. subobesa is elongate, with a short anterior region and low umbonal angles. Eucrassatella evolution progressively produces less elongate taxa with higher umbonal angles and more extended anterior regions - i.e., more rounded and less inequilateral over all. This is associated with a general thickening of the shell, and reduction in the extent of sculpture over the shell disc. 
Species referred herein to this genus are:

Eucrassatella ampla (Zittel, 1865)

Eucrassatella marshalli Powell, 1931

Eucrassatella scopalveus (Finlay, 1926)

Eucrassatella subobesa (Marshall and Murdoch, 1919) (comb. nov.)

Eucrassatella maudensis (Pritchard, 1903) (comb. nov.)

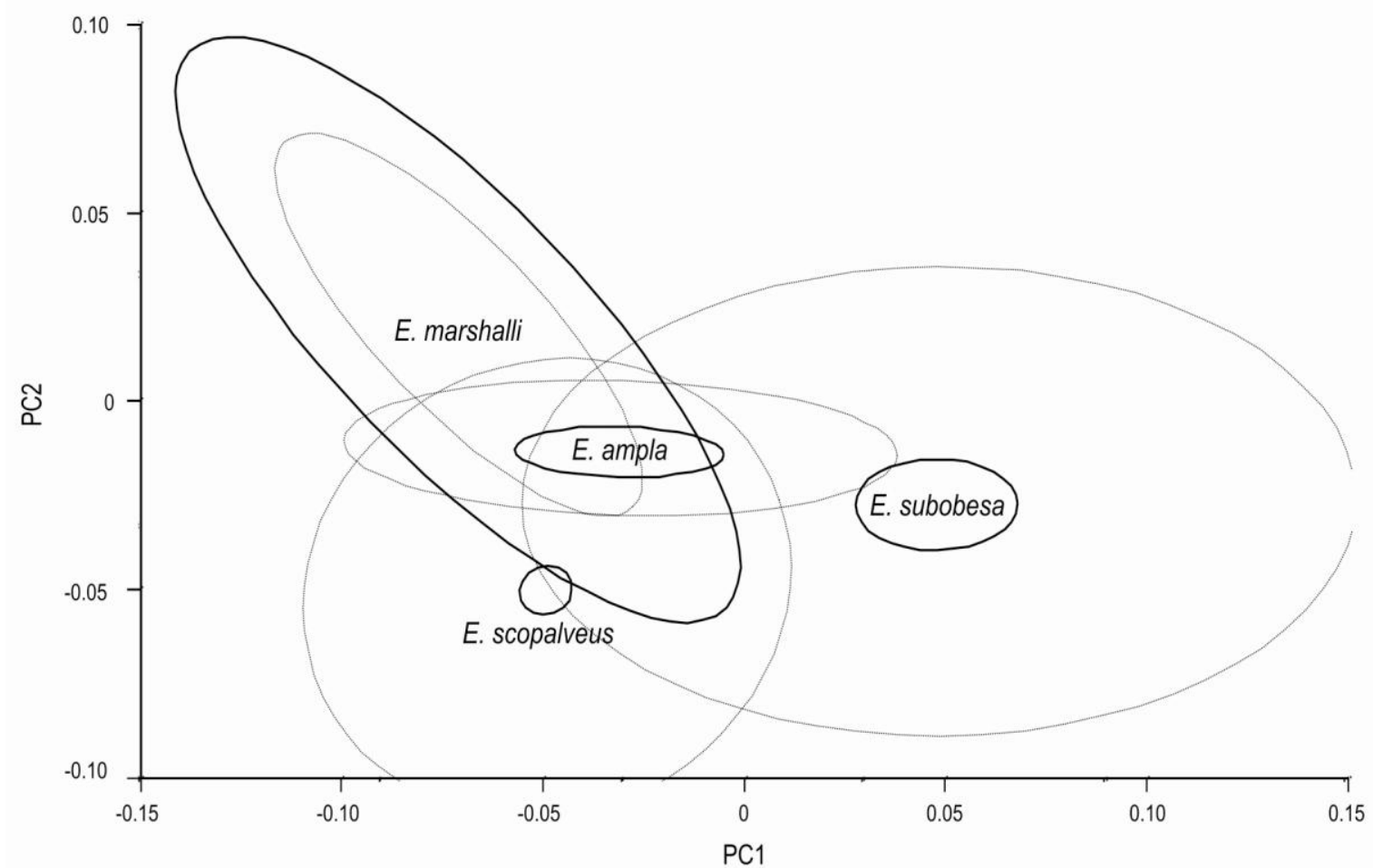

Figure 5.3: Principal components analysis of 7 landmark/38 semilandmark configuration of the species of Eucrassatella; E. ampla $(\mathrm{n}=11)$; E. marshalli $(\mathrm{n}=4)$; E. scopalveus $(\mathrm{n}=91)$; E. subobesa $(\mathrm{n}=30)$. Thick ellipses are $95 \%$ confidence levels on group means; thin ellipses are $95 \%$ probability on groups. PC1 explains $50.3 \%$ and PC2 explains $19.2 \%$ of the total variance in the dataset. NB: E. maudensis is not included on this plot due to low number of specimens in the dataset $(\mathrm{n}=2)$ and E. kingicola is not included on this plot as it is not included in this revision, although both were included in the morphometric analysis. 


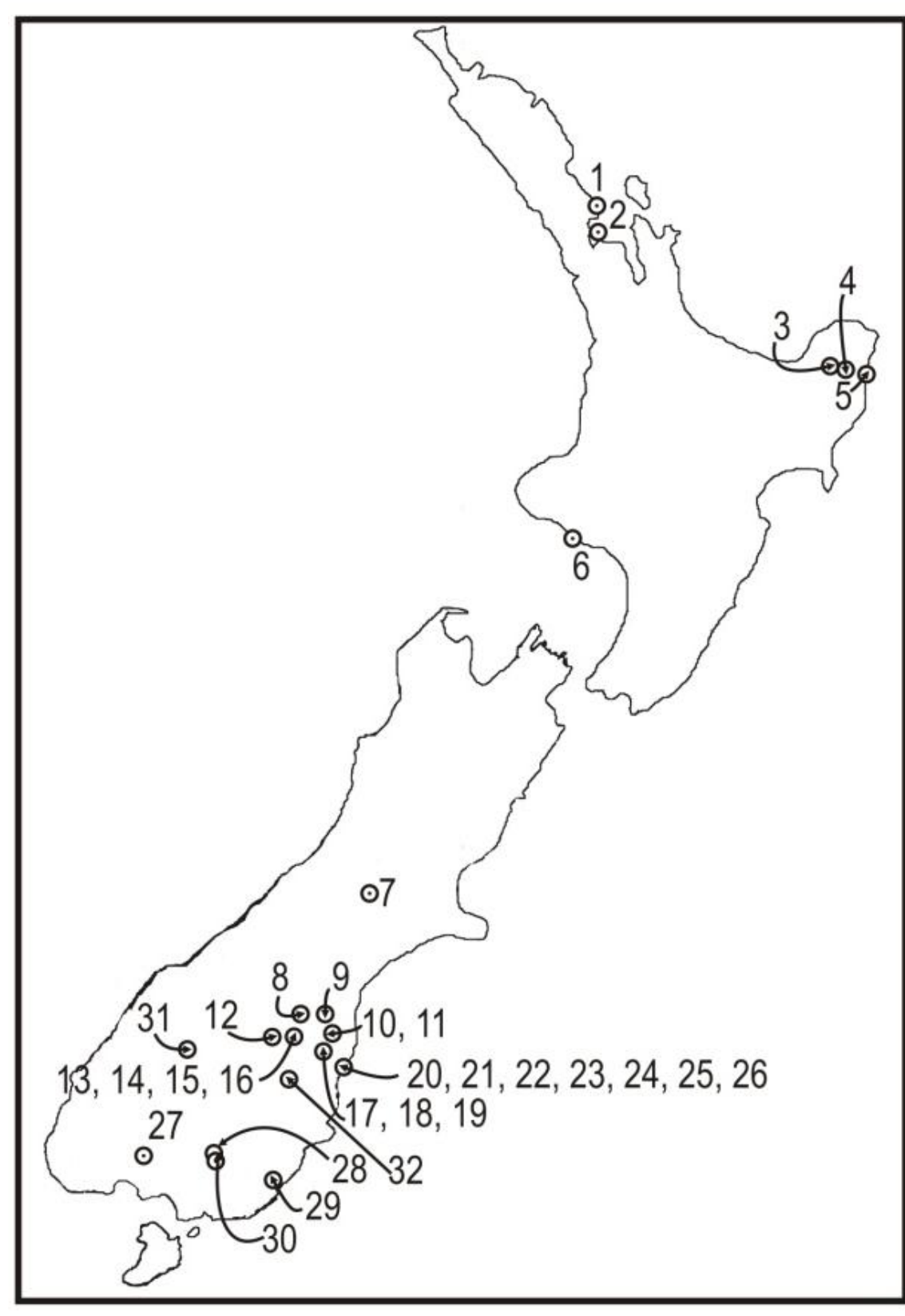

1 Matheson's Bay

2 Church Bay

3 Muddy Creek

4 Pangopango Stream

5 Marau Point

6 Waipipi

7 Broken River

8 Tengawai River

9 Kakahu River

10 Mount Horrible

11 Otaio River

12 Lake Waitaki, Wharekuri

13 Sister's Creek

14 Brother's Stream

15 Haugh's Quarry

16 Bluestone Creek

17 Pentland Hills

18 Elephant Hill

19 Lower Waihao Valley

20 Lorne

21 Pukeuri

22 Ardgowan

23 Target Gully

24 Awamoa Creek

25 Beach Road

26 All Day Bay

27 Clifden

28 Chatton

29 Castle Hill

30 Mataura River

31 Lake Whakatipu

32 Archer's Crossing

Figure 5.4: Crassatellid bivalve collection localities. 
Eucrassatella ampla (Zittel, 1865)

(Plate 1; Figures g, h)

1863 Crassatella ampla ZITTEL, p. 158 (nomen nudum)

1865 Crassatella ampla ZITTEL, pl.14, fig 3a, b

1873b Crassatella ampla Zittel; HUTTON, p. 24

v* $1873 \mathrm{~b}$ Crassatella attenuata HUTTON, p. 24

1886 Crassatella ampla Zittel; HeCTOR, p. 51, fig. 9.8

1886 Crassatella attenuata Hutton; HeCTOR, p. 54, fig. 15.6

1897 Crassatellites amplus Zittel; HARRIS, p. 365

1897 Crassatellites attentuatus Hutton; HARRIS, p. 365

1905 Crassatellites amplus Zittel; CLARKE, p. 418

1914 Crassatellites amplus (Zittel); SUTER, p.47, 48, pl. 12, fig. 1a, b

1914 Eucrassatella attenuata (Hutton); SUTER, p.47, 48, pl. 12, fig. 3

1926 Eucrassatella ampla (Zittel); FINLAY, p.256

1926 Eucrassatella attenuata (Hutton); FINLAY, p.256

1929 Eucrassatella attenuata (Hutton); POWELL \& BARTRUM, p.402, fig. 107

1931 Eucrassatella attenuata (Hutton); MARWICK, p. 66, pl. 5, fig. 79

v 1931 Eucrassatella spp. MARWICK, p. 67, pl. 5, figs. 84, 85

1938 Eucrassatella ampla (Zittel); POWELL, p. 366, pl. 38, fig. 1-3

v 1965 Eucrassatella ampla (Zittel); BOREHAM, p. 49 pl.14, fig.1

1966 Eucrassatella ampla (Zittel); FLEMING, p. 24, fig. 260

1966 Eucrassatella spp. FLEMING, p. 24 figs. 261, 262

1972 Eucrassatella ampla (Zittel); KEYES, p. 65

1972 Eucrassatella n. sp. KEYES, p. 65

1990 Eucrassatella ampla (Zittel); BEU \& MAXWELL, p. 146, pl. 12d, e

v 2000 Eucrassatella ampla (Zittel); CRAMPTON \& MAXwell, p. 400. Fig. 2j

2009 Eucrassatella ampla (Zittel); SPENCER et al., p. 237

2009 Eucrassatella ampla (Zittel); BEU \& RAINE, p. BM137

2012 Eucrassatella ampla (Zittel); BEU et al., p. 42, figs. 6a, b; 17b, c, f; $18 \mathrm{a}$

DiAGNOSIS: The largest and most massive species of Eucrassatella, variably elongate with a broadly rounded posterior, massive hingeplate, very thick cardinal teeth and rugose lateral teeth. 
DESCRIPTION: (L: 141.3; H: 103.5) Oblong, subtrigonal, with rounded margins. Umbones between half and anterior third of length, degree of elongation variable. Lunule and escutcheon deeply impressed, lanceolate. Posterior end broadly rounded. Dorsal margins of most specimens straight or slightly concave. Sculpture of broad commarginal ribs present only on tips of beaks, shell otherwise smooth. Posterior ridge broad, straight or shallowly concave relative to posterior margin, not well-defined. Posterior area flattened. Hingeplate massive and thick, ventral border of hingeplate of most specimens sinuous. Resilifer triangular, extending to hingeplate border. Hinge teeth massive. Right valve with short, thick rugose anterior lateral, partially fused to lunule border; very wide triangular median cardinal; posterior lateral formed by escutcheon margin. Left valve with rugose anterior lateral formed by edge of lunule; thick anterior cardinal; thinner, longer median cardinal; posterior cardinal thin, partially coalescent with escutcheon margin; posterior lateral socket wide, finely rugose. Adductor muscle scars deeply impressed, shell thickened on interior edges; anterior adductor muscle scar elongate, posterior subcircular. Pallial line similarly impressed and bordered by thickened shell material.

Type Material: Syntypes NHMW 1865/XXVII/145/1-2, from Matheson's Bay, Auckland (Fig. 5.4 \#1). Held by the Naturhistorisches Museum, Wien. These syntypes were recently refigured by Beu et al. (2012, figs. 17c, 18a). TM2858 (holotype of Eucrassatella attenuata), upper beds, Broken River, Canterbury (Fig. 5.4 \#7).

Other Material Examined:; AK105782, AK39719, Clifden band 7a, Southland (Fig. 5.4 \#27); AK39718, Target Gully, Oamaru (Fig. 5.4 \#23); AU6871, Church Bay, Auckland (Fig. 5.4 \#2) ; GS11174, Fallon's Shellbed, Ardgowan, Oamaru (Fig. 5.4 \#22); GS3600, TM7849, Mataura River, Southland (Fig. 5.4 \#30); TM4302, Pangopango Stream, Gisborne (Fig. 5.4 \#4); TM4305, Marau Point, Gisborne (Fig. 5.4 \#5). 
DisTRIBUTION: Duntroonian - Tongaporutuan (late Oligocene - late Miocene), throughout New Zealand.

REMARKS: This species is long-ranging and very distinctive, and is the most massive New Zealand crassatellid.

Eucrassatella marshalli Powell, 1931

(Plate 1; Figures a-f)

$\begin{array}{lll} & 1931 & \text { Eucrassatella marshalli POWELL, p. 93, pl. 12, fig. 21, } 22 \\ & 1990 & \text { Eucrassatella marshalli Powell; BEU \& MAXWELL, p. } 398 \\ \text { v } & 2000 & \text { Eucrassatella marshalli Powell; CRAMPTON \& MAXWELL, p. } 400 \\ & 2009 & \text { Eucrassatella marshalli Powell; SPENCER et al., p. } 237\end{array}$

DiAGNOSIS: Smaller and less massive than E. ampla; posterior, anterior and umbonal regions all very rounded, impression of lunule and escutcheon forming distinctively concave dorsal margins.

DESCRIPTION: (L: 81; H: 63.3) Thick-shelled, ovate. Umbones at anterior third of length, shell very rounded overall. Escutcheon, lunule deeply impressed, dorsal margins of shell concave. Sculpture almost completely absent, except for few commarginal ridges on beaks. Hingeplate thick, slightly curved along the ventral margin. Right valve with short, strong anterior lateral, partially fused to lunule border; triangular median cardinal; posterior lateral formed by escutcheon margin. Left valve with anterior lateral formed by edge of lunule; thick anterior cardinal; thin, high median cardinal; posterior cardinal very low, narrow, partially coalescent with escutcheon margin; posterior lateral socket shallow and wide. Adductor muscle scars, resilifer, pallial line as in Eucrassatella ampla. 
TYPe MATERIAL: Syntypes AK70287, two valves; one left, one right (not a matched pair but of similar size), from Waipipi coast, $1.2 \mathrm{~km}$ west of the mouth of Wairoa Stream, Whanganui (Fig. 5.4 \#6). Held by Auckland War Memorial Museum.

Other MATERIAl ExAmINED: GS1101, Waipipi Beach, Waverly, 1 mile north of Wairoa Stream, Whanganui (Fig. 5.4 \#6).

DistRiBUTIOn: Kapitean - Waipipian (late Miocene - early Pliocene), North Island, New Zealand.

REMARKs: This is the youngest member of the genus present in New Zealand. It more closely resembles the extant Australian members of the genus in overall shape (particularly in the rounded posterior end and deeply recurved lower hingeplate border) than it does Eucrassatella ampla. This is reflected in the phylogenetic grouping of E. marshalli with E. kingicola (the Australian type species of the genus), as shown in Figure 5.1. It appears to be a representative of the Australian lineage of the genus that crossed the Tasman, rather than being a descendant of other New Zealand species of Eucrassatella.

Eucrassatella maudensis (Pritchard, 1903)

(Plate 1; Figures r-u)

* 1903 Crassatellites maudensis PRITCHARD, p. 93, pl. 14, fig. 2, 3

1965 Spissatella maudensis (Pritchard); DARRAGH, p. 110, pl. 12 fig. 1, pl. 13 fig. 11, pl. 14 fig. 22

DiAGNOSIs: A small but thick-shelled Eucrassatella with a squarely truncated posterior, straight dorsal margins, and coarse, low ribbed commarginal sculpture that fades out over the posterior area. 
DesCription: (L: 53.7; H: 37.6) This species is described in detail by Darragh (1965, p.110) and is not redescribed here.

Type Material: Holotype MUGD1759, Spring Creek, Victoria, Australia. Held by Museum Victoria. Paratype MUGD1758, Spring Creek, Victoria, Australia. Held by Museum Victoria.

DistRIBUTION: Janjukian (late Oligocene - early Miocene), Victoria, Australia.

REMARKS: Museum Victoria kindly supplied high-resolution photographs of the holotype and paratype, but we have been unable to examine any material of this species in detail. It closely resembles Eucrassatella subobesa in elongation, thickness, and hinge characters, and based on these observations and upon its placement in phylogenetic analyses we include it, with E. subobesa, in Eucrassatella. The smaller members of the genus then are E. subobesa, E. scopalveus and E. maudensis, which are united by being elongate and thick-shelled for their size, with a curved axial ridge. These species are the earliest members of the genus and represent the transition from a thinner-shelled, shorter Spissatella morphology to the typical large, thick-shelled, elongate Eucrassatella.

Eucrassatella scopalveus (H. J. Finlay, 1926)

(Plate 1; Figures i-m)

v* 1926 Spissatella scopalveus FINLAY, p. 258, pl. 60, fig. 7, 8

v* 1926 Spissatella scopalveus concisa FINLAY, p. 258, pl. 59, fig. 12

1990 Spissatella scopalveus Finlay; BEU \& MAXwELL, p. 398

1990 Spissatella concisa Finlay; BEU \& MAXWELL, p. 398

v 2000 Eucrassatella scopalveus (Finlay); CRAMPTON \& MAXWELL, p.400, fig. 2, m

v 2000 Eucrassatella concisa (Finlay); CRAMPTON \& MAXWELL, p.400

2009 Eucrassatella scopalveus (Finlay); SPENCER et al., p. 237

2009 Eucrassatella concisa (Finlay); SPENCER et al., p. 237 
DiAGNOSIs: Small, thick-shelled Eucrassatella with distinctive pointed posterior, sculpture almost entirely absent.

DESCRIPTION: (L: 53.2; H: 36.8) Umbones at anterior third. Lunule and escutcheon lanceloate, impressed, posterodorsal margin strongly concave. Anterior margin evenly rounded, posterior comes to a rounded point due to steep upcurve of ventral margin. Posterior ridge strongly curved towards posterior. Umbones bearing fine commarginal ridges, remainder of shell surface smooth. Hingeplate strong, thick, with a straight ventral margin. Dentition, resilifer, adductor muscle scars and pallial line as in Eucrassatella marshalli.

Type MATERIAL: Holotype of E. scopalveus: AK70726, Target Gully Shellbed, Oamaru (Fig. 5.4 \#23). Held by Auckland War Memorial Museum. Holotype of E. scopalveus concisa: AK70727, Target Gully Shellbed, Oamaru (Fig. 5.4 \#23).

Other Material Examined: AK105784, AK105785, AK12244, AK132123, AK39720, AK39723, AK53089, AK62227, AK65793, AK65805, AK80419, GS951, L1057, L1077, L1078, M027615, M16209, M289979, Target Gully, shellbed and greensand, Oamaru (Fig. 5.4 \#23); AK39716, GS11180, L1070, L1071, Dyer's Run, Lower Waihao Valley, Canterbury (Fig. 5.4 \#19); GS11154, Mount Horrible, Pareora River, South Canterbury (Fig. $5.4 \# 10)$.

DistRiBution: Otaian-Altonian (middle Miocene), South Canterbury.

REMARKs: Finlay erected the subspecies Spissatella scopalveus concisa (Plate 1; Figures k, l) for an extremely short form of the species. It co-occurs with S. scopalveus s.s. in the Target Gully Shellbed and at Dyer's Run, where it is uncommon. It was elevated to specific rank 
by Beu \& Maxwell (1990) and listed as a separate species by Crampton \& Maxwell (2000) and Spencer et al. (2009). However, it is the opinion of the authors that the concisa form is part of the natural variation in shape of scopalveus and that therefore elevation to specific rank is unwarranted. Finlay's original diagnosis stated that $S$. scopalveus concisa "[d]iffers only in being very short while of same height, and having posterior dorsal area and truncation considerably narrower." This species is notably plastic in outline shape; an aberrant specimen labelled "Spissatella repanda" (Plate 1; Figure m) from 'Junction of Porter and Thomas Rivers', Castle Hill Basin, Canterbury (GS3188), is a variant of S. scopalveus of the opposite extreme, with an extremely narrow and upcurved posterior area.

Eucrassatella subobesa (Marshall and Murdoch, 1919)

(Plate 1; Figures n-q)

v* 1919 Crassatellites subobesus MARshall \& Murdoch, p.257 pl. 19, fig. 2, 3

v 1990 Spissatella subobesa (Marshall \& Murdoch); BEU \& MAXWELL, p. 398

v 2000 Spissatella subobesa (Marshall \& Murdoch); CRAMPTON \& MAXWELL, p.400 Fig. 2, e.

2009 Spissatella subobesa (Marshall \& Murdoch); SPENCER et al., p. 237

DiAGNOSIS: Small, thick-shelled Eucrassatella, extremely elongate, sculpture persisting over entire shell but weakening on posterior area, and with strong axial ridge curved towards the posterior area.

DESCRIPTION: (L: 53.7; H: 35.6) Elongate, with umbones at anterior third to anterior quarter, posterior truncated squarely or roundly. Posterior ridge well-rounded and curved concavely relative to posterior dorsal margin. Sculpture of commarginal ribs, fine for genus, fading out on posterior area. Escutcheon long and lanceolate, impressed; lunule broader and shorter. Hingeplate strong, smoothly arched. Dentition, resilifer, adductor muscle scars and pallial line as in Eucrassatella marshalli. 
Type Material: Holotype TM4300, Wharekuri, Waitaki Valley, Otago(Fig. 5.4 \#12). Held by GNS Science; Paratype TM4301, Wharekuri, Waitaki Valley, Otago (Fig. 5.4 \#12). Held by GNS Science.

Other Material Examined: AK105763, AK39714, AK65811, AU20011, AU20014, GS10837, GS1821, GS476, L1076, M011713, M027621, M111583, M289715, M289748, various localities around Wharekuri and head of Lake Waitaki, Waitaki Valley, Otago (Fig. $5.4 \# 12)$.

DiSTRIBUTIOn: Duntroonian-Waitakian (Upper Oligocene - Lower Miocene), Waitaki.

REMARKS: This species is referred to Eucrassatella by its placement in phylogenetic analysis. This is supported morphologically by the relative thickness of its shell and the degree of elongation, which are more typical of Eucrassatella than Spissatella. Figure 3 shows that E. subobesa occupies an area of morphospace somewhat separated from that of other species of Eucrassatella on PC1, but is united with E. scopalveus and E. ampla on PC2.

Genus: SPISSATELLA Finlay 1926

Spissatella Finlay, 1926 p. 256. Type species (by original designation): Crassatella trailli Hutton 1873; Upper Oligocene, New Zealand

DiAGNOSIS: Small (to 40mm height), moderately thin-shelled, smooth-margined crassatellids, most with a square or roundly-truncated posterior margin, and fine, ribbed commarginal sculpture persisting over much of the shell.

DESCRIPTION: A genus of Crassatellidae, small $(10-40 \mathrm{~mm}$ high), inequilateral, with umbones generally at anterior third. Most species trapezoidal in shape, anterior consistently 
rounded, posterior squarely truncated. Shell thin to moderately thick, well-excavated under hingeplate. Sculpture of commarginal ribs, variable in strength and extent, although extending to ventral margin at least on the anteriormost portions of shell in most species; some have sculpture obsolete posteriorly. Pallial line entire. Margins smooth, bevelled. Darragh (1965) gave the tooth formula of Spissatella as:

\begin{tabular}{cccr}
$3 a$ & $3 b$ & $5 b$ & LPI \\
\hline LAII & 2 & $4 b$
\end{tabular}

On hinge of right valve; anterior cardinal partially coalescent with lunule margin; median cardinal high, narrowly triangular; posterior cardinal much reduced, following anterior border of resilifer; strong, narrow posterior lateral formed by escutcheonal margin. On hinge of left valve; anterior lateral narrow, formed by edge of lunule; anterior cardinal strong and narrow; median cardinal small and narrow; posterior cardinal very much reduced, partially coalescent with escutcheonal margin. Lunule and escutcheon generally lanceolate, lunule bordered by thin groove, escutcheon marked by slight depression and sculptural change. Resilifer triangular and extending nearly to hingeplate margin.

Distribution: Kaiatan - Clifdenian (late Eocene - mid-Miocene), Southland, Otago, less common elsewhere in the South Island and the North Island.

REMARKS: Spissatella is the most speciose genus of the Crassatellidae in New Zealand, with six species included here and two others questionably included. The genus is recorded in the Tertiary of Patagonia (Spissatella lyelli (Sowerby, 1846); Griffin \& Nielsen, 2008). The morphometric plot presented in Figure 5.5 shows that one of the earliest members of the genus, $S$. poroleda (S. media is omitted due to lack of specimens; see Fig. 5.5 caption) scores higher on PC1 than younger species, being more elongate for its size. S. acculta, the sister species to $S$.poroleda (Figure 5.1) is more equilateral, occupying much the same region of morphospace as $S$. trailli and overlapping with $S$. clifdenensis, and resembling the much 
smaller ancestral $S$. media very closely in shape. The shortest, most equilateral species is $S$. maxwelli. With the exception of $S$. poroleda, all species of Spissatella plot near 0 on PC2. In evolutionary terms, it would appear that there are two separate expansions into different regions of morphospace within the Spissatella lineage. S.poroleda represents an extension of Spissatella morphology into the more elongate, Eucrassatella-like region of morphospace. $S$. maxwelli is the opposite, a more rounded, more equilateral shape, the descendants of which encroached back into the broad, short, inequilateral space occupied by early members of the genus.

Species referred herein to this genus are:

Spissatella acculta Finlay, 1926

Spissatella clifdenensis Finlay, 1926

Spissatella? cordiformis (Suter, 1917)

Spissatella? luteophila Marwick, 1931

Spissatella media Marwick 1926

Spissatella poroleda Finlay 1926

Spissatella trailli (Hutton, 1873)

Spissatella maxwelli $\mathbf{n} . \mathbf{s p}$. 


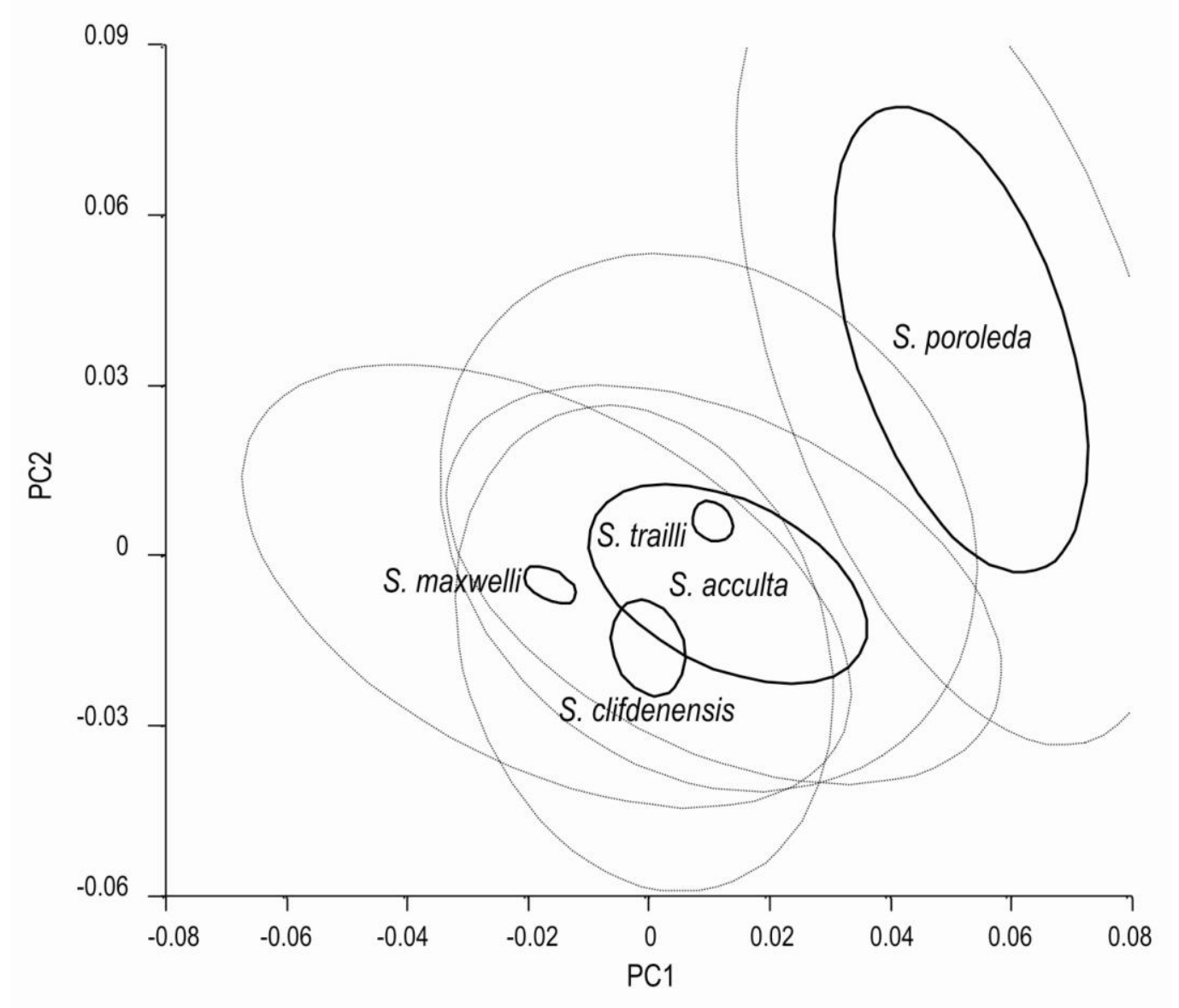

Figure 5.5: Principal components analysis of 7 landmark/38 semilandmark configuration of the species of Spissatella; $S$. acculta $(\mathrm{n}=8) ;$. clifdenensis $(\mathrm{n}=30) ;$. maxwelli $\mathrm{n}$. $\mathrm{sp} .(\mathrm{n}=$ 144); S. poroleda $(\mathrm{n}=7) ; S$. trailli $(\mathrm{n}=179)$. Thick ellipses are $95 \%$ confidence levels on group means; thin ellipses are $95 \%$ probability on groups. PC1 explains $23.9 \%$ and PC2 explains $17.2 \%$ of the total variance in the dataset. NB: $S$. media is not included on this plot due to lack of specimens $(\mathrm{n}=2)$ but was included in the study. S? luteophila and $S$ ? cordiformis were not included in the morphometric analysis.

Spissatella acculta Finlay, 1926

(Plate 2; Figures p-s)

v* 1926 Spissatella acculta FINLAY, p. 257

$\mathrm{v}^{*} 1926$ Spissatella discrepans FINLAY, p.256, pl. 59, fig. 10

1990 Spissatella acculta Finlay; BEU \& MAXWELL, p. 398

1990 Spissatella discrepans Finlay; BEU \& MAXWELL, p. 398

v 2000 Spissatella acculta Finlay; CrAmpton \& MAXWELl, p.400. Fig. 2, d

2009 Spissatella acculta Finlay; SPENCER et al., p. 237

2009 Spissatella discrepans Finlay; SPENCER et al., p. 237 
DiAGNOSIS: A very thin-shelled, broad, angular species of Spissatella, with fine sculpture over the entire shell.

DESCRIPTION: (L: 49.6; H:34.5) Trapezoidal, umbones at anterior third, posterior end squarely truncated. Dorsal margins straight. Sculpture of commarginal ribs, variable in strength but consistently finer than those of other Spissatella species, covering entire shell. Posterior ridge broadly rounded and straight. Lunule and escutcheon, dentition, adductor muscle scars and pallial line as in other Spissatella species.

Type Material: Holotype of Spissatella acculta: AK70722, Wharekuri, (Fig. 5.4 \#12). Held by Auckland War Memorial Museum. Holotype of S. discrepans: AK70724, Lake Whakatipu, Southland (Fig. 5.4 \#31). Held by Auckland War Memorial Museum.

Other Material Examined: GS11195, Lentipecten Bed, Lake Waitaki (Fig. 5.4, \#12).

DistRiBution: Duntroonian (Late Oligocene), Wharekuri, Waitaki, Oamaru.

REMARKS: Spissatella acculta and Spissatella discrepans were both described by Finlay (1926), and he noted that they are similar, describing $S$. acculta with close reference to $S$. discrepans. Having examined his types, we can find no reason to separate them; aside from the coarseness of the sculpture, the differences Finlay mentioned (production of anterior end, length of posterior end, posterior angulation) are all related to the fact that the holotype of S. acculta is larger and higher in relation to its length than the holotype of S. discrepans. Degree of elongation in this manner is known to be variable in other species of Spissatella and Eucrassatella (e.g. S. trailli, E. ampla, E. scopalveus). Furthermore, while S. acculta has been recollected, it became apparent in the course of examining material for this study that no 
collection in the country holds material identified as $S$. discrepans other than the holotype at the Auckland War Memorial Museum, and only specimens doubtfully referred to the species appear in faunal lists in the Fossil Record Electronic Database. As first revisers, we select $S$. acculta as the valid name for the species named both $S$. acculta and $S$. discrepans by Finlay (1926).

This species is one of the most thin-shelled species of Spissatella, and is grouped phylogenetically with $S$. poroleda, which is much narrower dorsoventrally but otherwise similar in shape, with markedly square posterior truncation, flattened ventral and straight or slightly concave dorsal margins. Spissatella acculta is considerably larger than, but suggestively similar in shape to, the late Eocene species $S$. media, which occupies an ancestral position according to phylogenetic analysis (Figure 5.1).

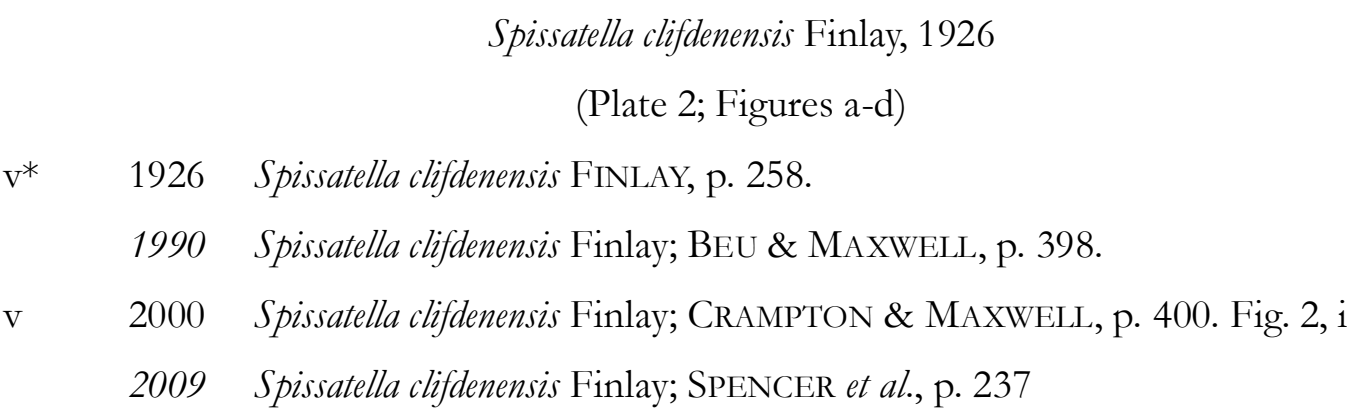

DiAGNOSIS: Short, triangular, thick-shelled Spissatella with straight or convex dorsal margins and deep hingeplate.

DeSCRIPTION: (L: 44.3; H: 34.3) Short, inequilateral; umbones at anterior third.

Posterodorsal margin straight or slightly convex in a few specimens. Posterior ridge straight or convex following posterodorsal margin.Posterior truncated very broadly and squarely for genus. Sculpture of fine commarginal ribs, extending to ventral margin, becoming markedly less prominent or obsolete on posterior area. Hingeplate strong, deep, with a reflexed 
ventral margin. Lunule and escutcheon, dentition, adductor muscle scars and pallial line as in other Spissatella species.

Type Material: Holotype AK70723, Clifden band 4b, Southland (Fig. 5.4 \#27). Held by Auckland War Memorial Museum.

Other Material ExAmined: AK65794, AK65809, GS10365, GS11182, L1074, M027609, M027611, Clifden (undifferentiated); AK110599, GS2948, Clifden band 4; M14422, AK105779, AK105787, AK65789, Clifden band 6b; M289618, M292054, TM7848, AU20018, Clifden, Long Beach; AU2956, GS10344, Clifden, Calamity Point (all Fig. 5.4 \#27).

Distribution: Altonian - Clifdenian (early-mid Miocene), Southland.

REMARKS: This is the youngest and most massive species of Spissatella, with the strongest and deepest hinge. Crampton and Maxwell (2000) hypothesised that S. clifdenensis was descended from S. trailli, and subsequent phylogenetic work based on morphological, morphometric and stratigraphic data has supported this inference, showing a cladogenetic relationship between $S$. trailli and S. clifdenensis (Fig. 5.1). The two species co-occur in the Clifden section.

\footnotetext{
Spissatella (?) cordiformis (Suter, 1917)

v* 1917 Crassatellites cordiformis SUTER, p.72, pl.13, fig. 3

2009 Spissatella (?) cordiformis (Suter); SPENCER et al., p. 237
}

DESCRIPTION: The specimen is a small, worn cast. No details of the hinge, sculpture, or internal structures are preserved. The affinities of this taxon are thus uncertain. 
Type Material: Holotype TM4307, Lower tuffs, Broken River, Trelissick Basin, Canterbury (Fig. 5.4 \#7), Miocene (?Duntroonian). Held by GNS Science.

OTHER MATERIAl ExAMINED: No other material available.

DistRIBUTION: Miocene, Canterbury.

REMARKS: The holotype is the only specimen of this taxon that has yet been recovered. Its generic placement is uncertain. The last published reference to it is in the list of Cenozoic Mollusca by P.A. Maxwell, published in Spencer et al. (2009), as Spissatella? cordiformis, but the specimen itself has been relabelled Talabrica? cordiformis in the collections of GNS Science. It is probable that its affinities may never be known. No further material referrable to this species has been collected in ninety-five years, and we therefore declare it a nomen dubium.

Spissatella? luteophila Marwick, 1931

v* 1931 Spissatella luteophila MARWICK, p.67, pl. V, fig. 73

1990 Spissatella luteophila Marwick; BEU \& MAXwELL, p. 398

2009 Spissatella luteophila Marwick; SPENCER et al., p. 237

DESCRIPTION: A small, juvenile right valve, well-preserved, attached to a block of finegrained matrix. Umbones at anterir third, anterior and posterior dorsal margins straight; rounded anterior and squarely truncated posterior. Long, narrow lunule and escutcheon. Strong ribbed commarginal sculpture. Internal characters obscured by matrix.

Type Material: Holotype TM4298, Muddy Creek, Gisborne (Fig. 5.4 \#3).

OTHER MATERIAL ExAMINED: No other material of this taxon is available. 
Distribution: Clifdenian (middle Miocene), Gisborne.

REMARKs: This species was described by Marwick (1931) from the Ihungia Series, Gisborne District (GS1237, Y16/f7491). No further specimens have been identified in any collection around the country. The holotype is a juvenile specimen and the internal characters are not visible. Thus, it cannot be either confirmed as a separate species or synonymised with any other known species of crassatellid. We tentatively retain it within Spissatella, following the checklist of Maxwell (in Spencer et al., 2009).

Spissatella media (J. Marwick, 1926)

(Plate 2; Figures $\mathrm{x}-\mathrm{z}$ )

v* 1926 Eucrassatella media MARWICK, p. 311, pl. 72, fig. 6

v. 1960 Spissatella aff. australis (Hutton); MARWICK, p. 12, pl. 1, fig. 3

1990 Spissatella media (Marwick); BEU \& MAXWELL, p. 398

v 2000 Spissatella media (Marwick); CRAMPTON \& MAXwell, p. 400. Fig. 2, a

2009 Spissatella media (Marwick); SPENCER et al., p. 237

DiAGNOSIs: Small, inequilateral, strongly sculptured Spissatella with weak, straight posterior ridge.

DESCRIPTION: (L: 22.3; H: 17.2) Umbones at anterior third, dorsoventral height almost equivalent to antero-posterior length. Sculpture of coarse commarginal ribs, posterior ridge straight and not as well developed as in larger taxa. Hingeplate ventral border smoothly arched. Lunule and escutcheon, dentition, adductor muscle scars and pallial line as in other species of Spissatella.

Type Material: Holotype TM4299, Lorne, near Weston, North Otago (Fig. 5.4 \#20). Held by GNS Science. 
Other Material Examined: GS11214, GS9481, OU8648, Lorne (Fig. 5.4 \#20) and McCullough's Bridge, lower Waihao Valley (Fig. 5.4 \#19).

DistRiBution: Heretaungan - Runangan (Mid-Late Eocene), North Otago.

REMARKS: This species is uncommon and small. Most specimens that are available in national collections are damaged, decalcified, or poor moulds. It is small enough to be mistaken for a juvenile of some other Spissatella species, but the prominent sculpture, inequilateral shape, and consistent maximum size of those specimens that have been collected indicate that it is instead a true, albeit small, species. A small specimen identified as "Spissatella aff. australis" by Marwick (1960) is assigned to this species on the basis of its strongly inequilateral shape and distinctive, ribbed sculpture, which extends to the margins, much further than it would on Triplicitella australis (see below), in which the sculpture becomes obsolete on the very tips of the beaks if it is present at all.

Spissatella poroleda Finlay, 1926

(Plate 2; Figures t-w)

v* 1926 Spissatella poroleda FINLAY, p. 257, pl. 59, fig. 11

1990 Spissatella poroleda Finlay; BEU \& MAXWELL, p. 398

v 2000 Spissatella poroleda Finlay; CRAMPTON \& MAXWELl, p. 400. Fig. $2 \mathrm{f}$

2009 Spissatella poroleda Finlay; SPENCER et al., p. 237

DiAGNOSIs: Thin-shelled, elongate Spissatella with narrow hingeplate and squarelytruncated posterior.

DeSCRIPTION: (L: 54.9; L: 34.1) Elongate, thin-shelled. Umbones at anterior third.

Posterior truncated very squarely and narrowly due to extreme upward curve of ventral margin. Posterior ridge slightly convex relative to posterodorsal margin. Sculpture of fine, 
commarginal ribbing, becoming obsolete on posterior area. Hingeplate small with straight ventral margin. Lunule and escutcheon, dentition, adductor muscle scars and pallial line as in other Spissatella species. Shell margins smooth.

Type Material: AK70725, Shell Gully, Chatton (Fig. 5.4 \#28). Held by Auckland War Memorial Museum.

Other Material Examined: AK39717, AU20007, GS9806, Shell Gully, Chatton (Fig. 5.4 \#28).

DistribuTIOn: Duntroonian (Late Oligocene) Chatton Shellbed, Shell Gully, Chatton, Southland.

REMARKS: S. poroleda is the most elongate species of Spissatella, and has been supposed to be most closely related to other elongate forms such as subobesa, which is transferred here to Eucrassatella. However, $S$. poroleda is most closely associated phylogenetically with $S$. acculta, with which it shares a very thin, straight-margined shell, a relatively narrow hingeplate, and fine commarginal sculpture. The elongation of the shell in S.poroleda, rather than representing a synapomorphy between that species and the species of Eucrassatella, is a result of homoplasy, and evidence of convergence on a successful shell form by two separate lineages. 
Spissatella trailli (Hutton, 1873)

(Plate 2; Figures e-g)

v* 1873 Crassatella trailli HuTTON, p. 24

1897 Crassatellites trailli Hutton; HARRIS, p. 366

1905 Mactropsis trailli (Hutton); HuTTON, p. 65

v 1914 Crassatellites obesus (A. Adams); SuTER, p. 48, pl. 13, fig. 4 (not of A. Adams)

v 1926 Spissatella trailli (Hutton); FINLAY, p. 257, pl. 59, fig. 13, 14

v 1965 Spissatella trailli (Hutton); BOREHAM, p.53 pl.14, fig. 6, 7, 8

v 1990 Spissatella trailli (Hutton); BEU \& MAXWELL, p. 186, pl.18, i, k

v 2000 Spissatella trailli (Hutton); CRAMPTON \& MAXwELL, p. 400. Fig. $2 \mathrm{~h}$

2009 Spissatella trailli (Hutton); SPENCER et al., p. 237

DiAGNOSIS: Straight-margined Spissatella with rounded anterior, square posterior, and ribbed sculpture extending to ventral margins

DESCRIPTION: (L: 48.4; H: 35.5) Umbones at anterior third. Sculpture of coarse commarginal ribbing extending to ventral margin on anterior, dying out over posterior area. Posterior ridge strong, broadly rounded, straight or slightly curved concave relative to posterororsal margin. Hingeplate ventral border evenly curved. Lunule and escutcheon, dentition, adductor muscle scars and pallial line as in other Spissatella. Shell margins smooth.

Type Material: Lectotype TM2859, Awamoa Creek, Oamaru (Fig. 5.4 \#24). Held by GNS Science.

Other Material Examined: AK105786, AK132274, AU20012, M215, M290276, Awamoa Creek, Oamaru (Fig. 5.4 \#24); AK105802, AK39715, AU1392, AU8024, GS1160, GS9521, L1072, Ardgowan, Oamaru (Fig. 5.4 \#22); AK105819, AK39721, AK62226, AK65788, AK65790, AK65808, M027616, M111688, M2141, M2141, M2143, Mount Harris, Waihao (Fig. 5.4 \#19); AK65758, All Day Bay, Oamaru (Fig. 5.4 \#26); AK65771, 
Elephant Hill, Waihao (Fig. 5.4 \#18); AK65772, AK65801, AU1391,GS9685, M16275, TM7847, Pukeuri, Oamaru (Fig. 5.4 \#21); GS11283, Otaio River, Canterbury (Fig. 5.4 \#11); GS9570, GS9571, M290054, M297290, Tengawai River (Fig. 5.4 \#8); M288228, M288468, Beach Road Section, S of Awamoa Creek, Oamaru (Fig. 5.4 \#25), AU20018, AK65809, Clifden Section, Southland (Fig. 4 \#27).

Distribution: Otaian-Altonian (Early Miocene), Oamaru and South Canterbury.

REMARKs: Suter (1914) designated "Crassatellites obesus" of A. Adams (1854) as a valid name in his synonymy of trailli. However, Iredale (1924) pointed out that this species was never recollected from New Zealand and suggested that it may be an "obese juvenile aberration of the Moreton Bay shell" - i.e., Eucrassatella cumingi - and not from New Zealand at all. Thus, we follow Boreham (1965) and Beu and Maxwell (1990) in using Crassatella trailli Hutton, 1873 as the valid name for this species. Further, we include "Mactropsis trailli" Hutton, 1905 in synonymy, following Suter (1914). Hutton (1906), upon receipt of a specimen which appeared to have a pallial sinus, revised his generic placement of trailli and removed it to Mactropsis. Suter (1914) subsequently examined Hutton's "Mactropsis trailli" specimen and concluded that the appearance of a pallial sinus was due to "a roundish spot" where a sinus might be, but that the pallial line was in fact entire, and that the species was best retained within Crassatellites (=Spissatella).

\footnotetext{
Spissatella maxwelli $\mathrm{n} . \mathrm{sp}$.

(Plate 2; Figures h-o)

1990 Spissatella aff. trailli (Hutton); BEU \& MAXwELL, p. 186

v 2000 Spissatella n. sp. C; CRAMPTON \& MAXWELl, p. 400, fig. $2 \mathrm{~g}$
} 
DiAGNOSIS: Moderately thin-shelled Spissatella with rounded posterior and anterior, concave dorsal margins, and coarse ribbed sculpture becoming obsolete over the posterior and ventral shell areas.

DESCRIPTION: (L: 44.3; H: 32.2) Umbones between half and anterior third. Dorsal margins concave. Posterior roundly truncated. Posterior ridge broadly rounded, concavely curved relative to posterodorsal margin. Sculpture of fine commarginal ribs on umbones, variable in extent, becoming obsolete over posterior and ventral areas of shell. Growth lines prominent on many specimens. Hingeplate small, ventral border recurved. Lunule and escutcheon, dentition, adductor muscle scars and pallial line as in other Spissatella species.

ETYMOLOGY: This species is named in honour of the late Dr. P. A. Maxwell, who first recognised it as a separate species.

Type Material: GS4901, Sister's Creek, Hakataramea Valley, South Canterbury (Fig. 5.4 \#13). Held by GNS Science.

Other Material ExAmineD: AK105795, AK135326, AK51854, L1079, L3510, M027618, AU2951, GS1473, M14912, Otiake, Waitaki Valley (Fig. 5.4 \#12); AU1501, GS7166, M290285, M292050, M292068, M866, OU BULK, Brother's Stream, Hakataramea Valley, Oamaru (Fig. 5.4 \#14); AU20017, M18036, M290517, M292055, M292057, M292058, TM7846, Sister's Creek, Hakataramea Valley, Oamaru (Fig. 5.4 \#13); KC-HQ, OU BULK, Haugh's Quarry, Hakataramea Valley, Oamaru (Fig. 5.4 \#15); M17838, Cliffs near Archer's Crossing (Fig. 5.4 \#32); M292051, Bluestone Creek, Kurow (Fig. $5.4 \# 16)$. 
DisTRIBUTION: Waitakian (late Oligocene); Oamaru and South Canterbury.

REMARKS: This is the common Waitakian species of Spissatella that is abundant in various localities around Waitaki and Oamaru, particularly in the Hakataramea Valley. It is easily confused with the younger species, Spissatella trailli (Otaian-Altonian), differing chiefly from that species in its thinner, rounder, and slightly more equilateral shell, with more concave anterior and posterior dorsal margins. In addition, the sculpture of $S$. maxwelli becomes obsolete below the umbones, whereas it persists to the ventral margins in almost all specimens of S. trailli. Phylogenetic work based on morphological, morphometric and stratigraphic data suggests that $S$. maxwelli gave rise to $S$. trailli anagenetically in the early Miocene.

Genus: TRIPLICITELLA n. gen TYPE SPECIES: Astarte australis Hutton, 1873

DIAGNOSIS: Large, equilateral, subcircular or sub-trigonal Crassatellidae with narrow cardinal teeth and crenulate ventral margins.

DESCRIPTION: A genus of Crassatellidae, moderate to large (up to $90 \mathrm{~mm}$ high), equilateral, sub-trigonal to sub-circular, anterior-posterior length slightly exceeding height in many specimens. Sculpture of coarse commarginal ribs. Integripalliate, pallial line impressed, shell thickened between pallial line and commissure. Margin varies within one species; smooth, finely striate, or crenulate. Resilifer triangular, impressed, extending almost to border of hingeplate. Cardinal teeth narrow in most specimens, the median being most prominent in both hinges, and lateral teeth formed by borders of lunule and escutcheon. Right valve with weak anterior lateral tooth, anterior cardinal tooth coalescent with edge of lunule, median cardinal prominent and narrow. Edge of escutcheon forming strong posterior 
lateral in right valve, matched by faint socket in left valve. Left valve with narrow anterior cardinal separated from lunule by a groove; median cardinal narrow and prominent, posterior cardinal low and narrowly divergent from escutcheon margin.

ETyMology: The new name is constructed from the specific name of Crassatellites triplicter, a junior synonym of the type species.

DistRiBuTiOn: Heretaungan-Kaiatan, Otago.

Triplicitella australis (Hutton, 1873)

(Plate 3; Figures a-k)

v* 1873 Astarte australis HuTTON, p. 25

v 1914 Astarte australis HuTTON; Suter, p. 47, pl.13, fig. 5, pl.17, fig. 2

1926 Spissatella australis (Hutton); FINLAY p. 56; 256

1935 Crassatellites tripliciter LAWs, p. 23, pl. 4, fig. 1a

v. 1937 Spissatella cf. australis (Hutton); FINLAY \& MARWICK, p. 99, pl. 14, fig. 7

v. 1960 Spissatella aff. australis (Hutton); MARWICK, p. 12, pl. 1, fig. 5

v 1965 Spissatella australis (Hutton); BOREHAM, p. 53 pl.14, fig. 2, 3, 4, 5

v 1990 Eucrassatella australis (Hutton); BEU \& MAXWELL, p. 101, pl. 5f, i

v 2000 Eucrassatella australis (Hutton); CRAMPTON \& MAXWELL, p. 400

2009 Eucrassatella australis (Hutton); SPENCER et al., p. 237

v 2012 Eucrassatella australis (Hutton); BEU \& RAINE, p. BM49

DiagnOSIs: Weakly inflated Triplicitella with sculpture restricted to beaks, and crenulate margin.

DESCRIPTION: (L: 83.8; H:80.1) Equilateral, sub-trigonal to sub-circular, some specimens more produced posteriorly; posterior area in these specimens roundly truncated. Wellexcavated under hingeplate, but not a very inflated species. Hingeplate border smoothly arched. Commarginal ribbed sculpture generally restricted to beaks, present lower down on some young shells, more prominent anteriorly. Growth lines variable, eroded to form 
irregular grooves in some specimens. Adductor muscle scars large, impressed, subequal, anterior one reniform, posterior subcircular. Lunule and escutcheon elongate, strongly impressed. Pallial line impressed, shell thickened between pallial line and commissure.

TyPe MATERIAL: Astarte australis, holotype (TM2861) from "Kokohu" = Kakahu River, South Canterbury, New Zealand (Fig. 5.4 \#9). Boreham (1965) noted that the matrix matches that of collections GS164, 2096 and 3233, from Kakahu Bush. The specimen is poorly preserved - it comprises a hinge and part of the disc with some matrix adhering. Held by GNS Science.

Other Material Examined: TM2862 "Black Point, Waitaki River" (Fig. 5.4 \#12); TM2870 "Castle Hill shaft" (Fig. 5.4 \#29); GS9959 (J40/f6610) "South branch Waihao River, top shellbed, near 'Pentland Hills'" (Fig. 5.4 \#17); M289605 "Pentland Hills?" (Fig. 5.4 \#17); M292506 (J40/356105, 44²41.37'S, 17047.59'E) "W of Waimate, Kaiwarua Road, opposite Pentland Hills Station" (Fig. 5.4 \#17).

Distribution: Heretaungan-Kaiatan, Otago. Both Hutton and Laws's types are from Bortonian horizons.

REMARKS: The generic position of this species has changed more frequently than that of any other New Zealand crassatellid. Hutton proposed it as a new species of Astarte based on the hinge (1873), but in his redescription of Astarte australis, Suter remarked that "Hutton seems to have taken this valve to be the right; the hinge is much damaged, but there can be no doubt that it is the left valve of an Astarte" (Suter, 1914; p. 47). Boreham, in her subsequent redescription of the species (1965), made no comment but listed the 
specimen, as Hutton did, as a right valve. Upon inspection, we conclude that Suter was mistaken and that the specimen is indeed a right valve, Astarte or not.

Finlay (1926) transferred Astarte australis to Spissatella, along with Crassatella trailli and a suite of new species, which he united on the basis of "size, character of initial ornament, hinge and muscle scars", without giving details of how these differed from their equivalents in other genera. Laws described Crassatellites tripliciter (1935) as a new species in a separate genus largely (judging by his diagnosis and commentary) on the basis of the crenulate margin, although, as remarked upon by Finlay and Marwick (1937), this character on its own is not enough to separate the two on a specific level, let alone a generic one.

Finlay and Marwick (1937) illustrated a new species "Spissatella" cf. australis which differs only, from their description, on the size of the lunule and, in our opinion, is not sufficiently different in overall morphology to warrant separation from T. australis. Likewise the Otaio Gorge specimens illustrated as "S." aff. australis by Marwick (1960) are, as he notes, considerably variable in proportions and in our opinion, rather than being referrable to a new species, show admirably the range of variation (in terms of length/height, margin crenulation, and extent of sculpture) exhibited by T. australis.

Beu and Maxwell (1990) assigned "Spissatella" australis to Eucrassatella on the basis of 'size, shape, and sculptural characters'. In terms of shell dimensions, T. australis is indeed closer to the large (50-90mm high) New Zealand species of Eucrassatella (e.g. E. ampla, E. marshalli) than it is to the species of Spissatella (e.g. S. trailli, S. poroleda, S. acculta) which tend to be smaller (20-40mm high). The sculpture also agrees with Eucrassatella in that it becomes obsolete below the umbones (as opposed to the strong sculpture over the whole shell of most Spissatella species), but the narrow cardinal teeth and crenulate margin differentiate it from the larger Eucrassatella species, which have strongly triangular median cardinals and smooth margins. 
Morphometric plots separate Triplictella australis from both Spissatella and Eucrassatella, and T. australis is also separated from both genera phylogenetically; it occupies a basal position with regard to the clade formed by Spissatella+Eucrassatella, and for that reason should not be included in either genus. In addition, the overall equilateral shape and variably crenulate margin differentiate it sufficiently from both Eucrassatella and Spissatella, which are markedly inequilateral and have smooth margins, to justify separation into a new genus. 


\section{Plates}



a, b, d, e MA70287
E. marshalli Powell
syntypes, Waipipi, Whanganui
c, f GS1101
E. marshalli Powell
Waipipi, Whanganui
g, h AK39719
E. ampla (Hutton) Clifden, Southland
i,j MA70726
E. scopalveus (Finlay) holotype, Target Gully, Oamaru
k, $1 \quad$ MA70727
E. scopalveus (Finlay)
holotype 'E. concisa', Target Gully, Oamaru
m $\quad$ GS3188
E. scopalveus (Finlay)
'repanda' form, Porter River, Canterbury
n AU20011a
E. subobesa (Marsh. \& Murd.) Lake Waitaki, Otago
o $\quad$ TM4301
E. subobesa (Marsh. \& Murd.) paratype, Wharekuri, Otago
p $\quad$ AU20014
E. subobesa (Marsh. \& Murd.) Wharekuri, Otago
q TM4300
E. subobesa (Marsh. \& Murd.) holotype, Lake Waitaki, Otago
r, s P12762
E. maudensis (Pritchard)
holotype, Spring Creek, Victoria, Aus
t, u P12761
E. maudensis (Pritchard)
paratype, Spring Creek, Victoria, Aus

Scale bar $-50 \mathrm{~mm}$ 


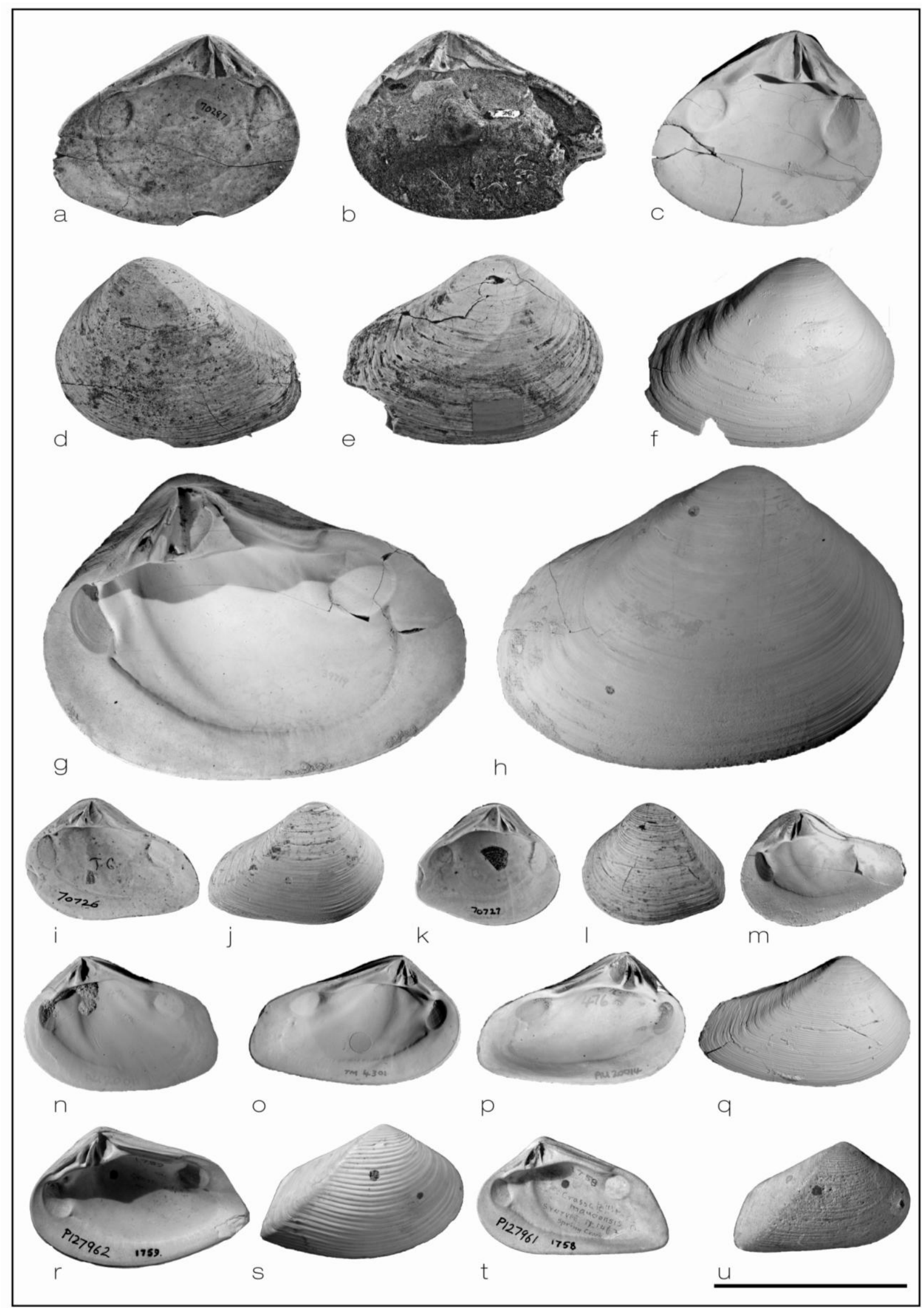

1 


$\begin{array}{llll}\text { a, b } & \text { MA70723 } & \text { S. clifdenensis Finlay } & \text { holotype, Clifden band 4b, Southland } \\ \text { c } & \text { L1074 } & \text { S. clifdenensis Finlay } & \text { Clifden, Southland (unlocalised) } \\ \text { d } & \text { AU2956 } & \text { S. clifdenensis Finlay } & \text { Calamity Point, Clifden, Southland } \\ \text { e, f } & \text { TM3859 } & \text { S. trailli } \text { (Hutton) } & \text { holotype, Awamoa Creek, Oamaru } \\ \text { g } & \text { M215 } & \text { S. trailli } \text { (Hutton) } & \text { Awamoa Creek, Oamaru } \\ \text { h, l } & \text { GS4901 } & \text { S. maxwelli } \text { n. sp. } & \text { holotype, Sister's Ck, Hakataramea Valley, Otago } \\ \text { i } & \text { GS4901 } & \text { S. maxwelli } \text { n. sp. } & \text { paratype, Sister's Ck, Hakataramea Valley, Otago } \\ \text { j } & \text { NA } & \text { S. maxwelli } \text { n. sp. } & \text { paratype, Haugh's Q, Hakataramea Valley, Otago } \\ \text { k, m, n, o GS7199 } & \text { S. maxwelli } \text { n. sp. } & \text { paratype, Brother's St, Hakataramea Valley, Otago } \\ \text { p, q } & \text { MA70722 } & \text { S. acculta } \text { Finlay } & \text { holotype, Wharekuri, Otago } \\ \text { r } & \text { MA70724 } & \text { S. acculta } \text { Finlay } & \text { holotype 'S. discrepans', Whakatipu, Southland } \\ \text { s } & \text { GS11195 } & \text { S. acculta } \text { Finlay } & \text { Lake Waitaki, Otago } \\ \text { t, u } & \text { MA70725 } & \text { S. poroleda } \text { Finlay } & \text { holotype, Chatton Shellbed, Southland } \\ \text { v, w } & \text { GS9806 } & \text { S. poroleda } \text { Finlay } & \text { Chatton Shellbed, Southland } \\ \text { x } & \text { TM4299 } & \text { S. media } \text { (Marwick) } & \text { holotype, Lorne, North Otago } \\ \text { y, z } & \text { OU8648 } & \text { S. media } \text { (Marwick) } & \text { Lorne/McCulloch's Bridge, North Otago }\end{array}$

Scale bar - $50 \mathrm{~mm}$ 


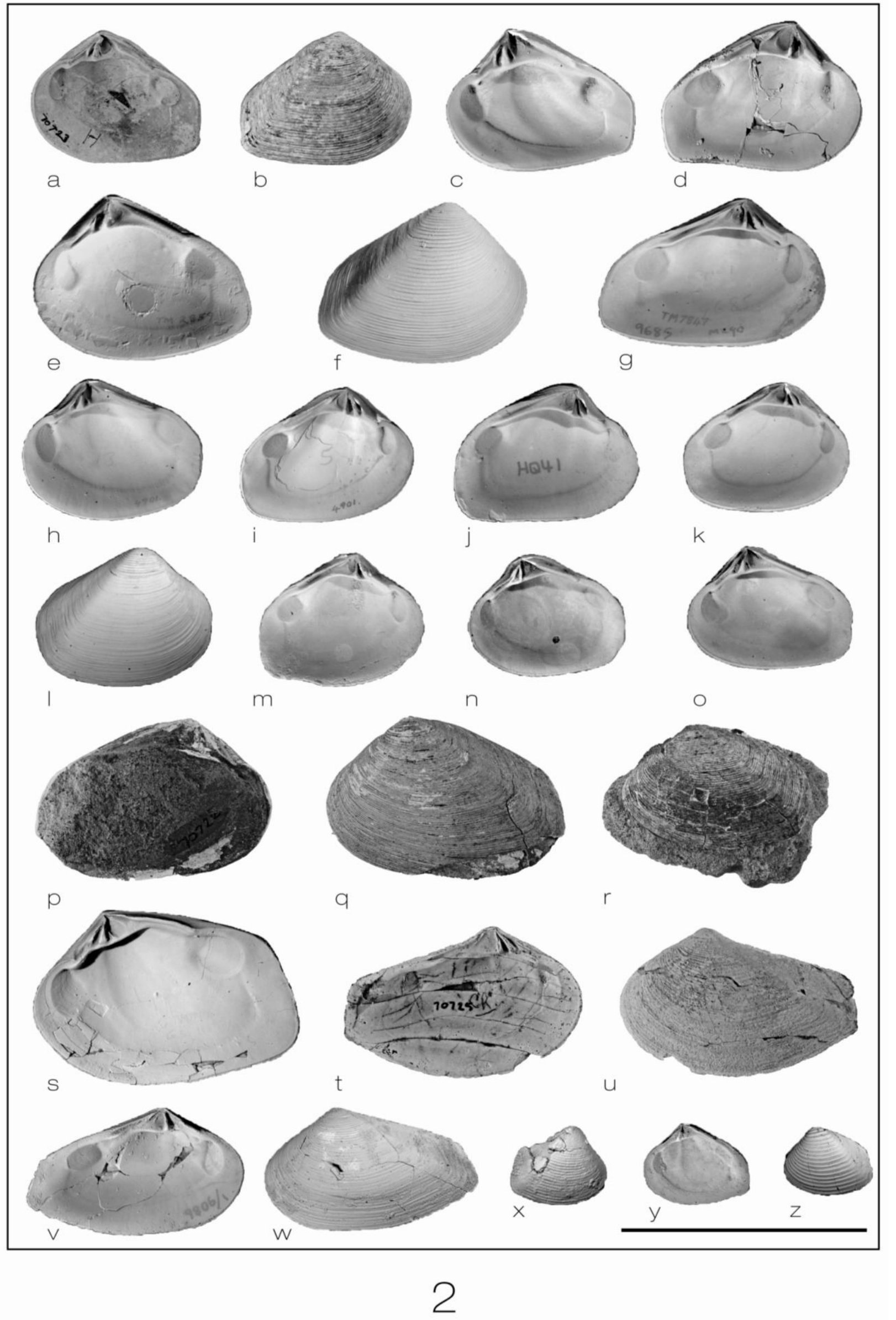



a, b TM2861 T. australis (Hutton) holotype, Kakahu R, South Canterbury
c, d MA72672 T. australis (Hutton) syntype 'Crassatellites tripliciter', Waihao, Canterbury
e, f MA70215 T. australis (Hutton) syntype 'Crassatellites tripliciter', Waihao, Canterbury
g OU bulk T. australis (Hutton) Pentland Hills, Waimate
h, i GS9959 T. australis (Hutton) Waihao River, Canterbury
j, k M289605 T. australis (Hutton) Pentland Hills, Waimate

Scale bar $-50 \mathrm{~mm}$ 


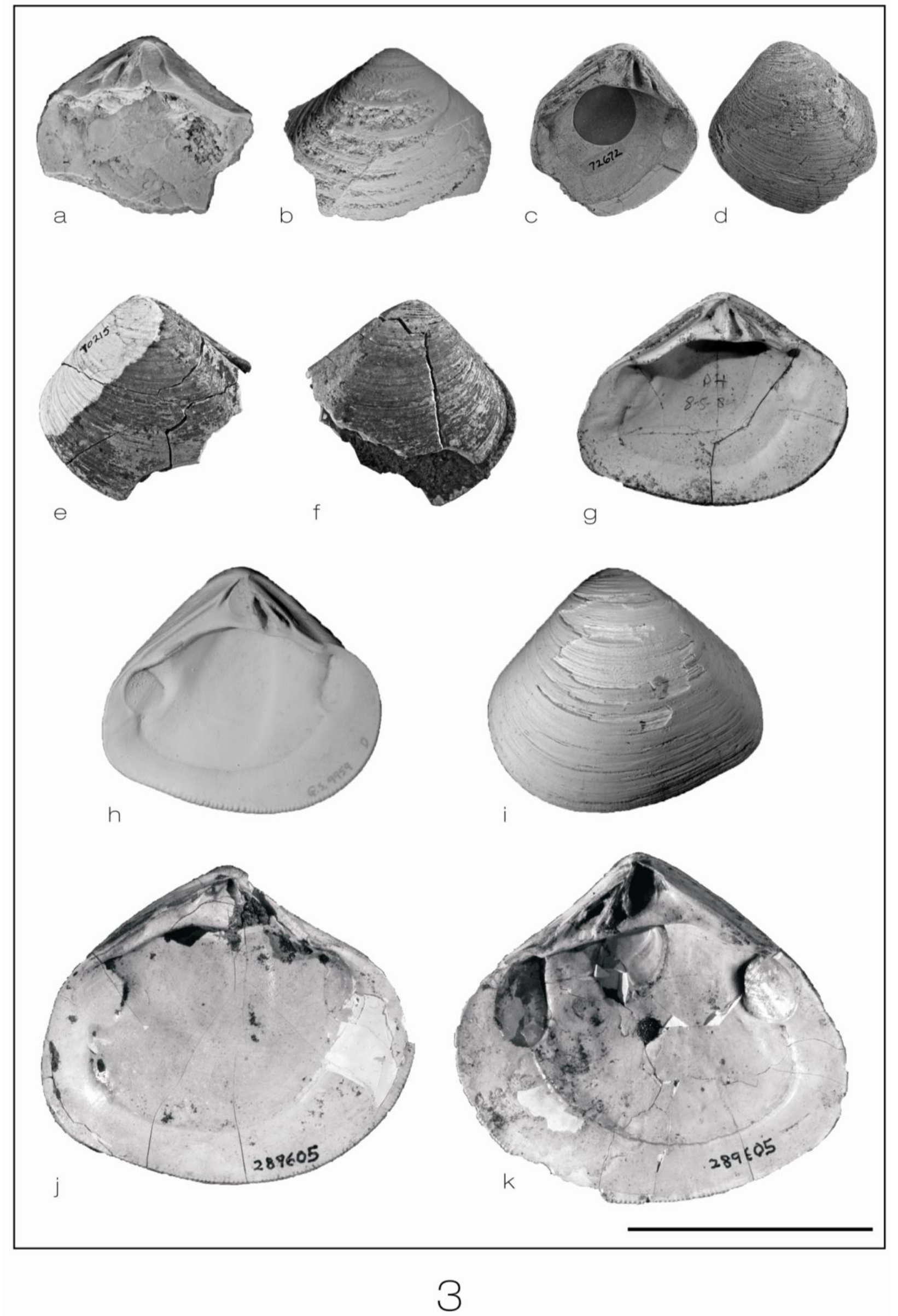




\section{6}

\section{Heterochrony}

"'In one moment I've seen what has hitherto been

Enveloped in absolute mystery,

And without extra charge I will give you at large

A Lesson in Natural History.'

In his genial way he proceeded to say

(Forgetting all laws of propriety,

And that giving instruction without introduction,

Would have caused quite a thrill in Society),"

- The Hunting of the Snark: Fit the Fifth - The Beaver's Lesson 


\section{Journeys through Shape and Time: Sclerochronology and heterochrony in Spissatella and Eucrassatella(Bivalvia, Crassatellidae)}

\subsection{Abstract}

New growth-rate estimates for nine species from three genera of larger New Zealand Crassatellidae, combined with shape and size data from Crampton\& Maxwell (2000) and recent phylogenetic work, reveal heterochronic processes in the evolution of these genera. Both paedomorphosis and peramorphosis occur within the clade, and all four categories of heterochrony as defined by Gould (1977), as well as gigantism and dwarfism, are identified. Stability in the substrate and predator avoidance, constrained by sluggish burrowing speed and inability to escape by deep burial, are suggested as key drivers of morphological change in these genera. Despite their conservative morphology, New Zealand crassatellids have responded to environmental pressure in a variety of ways using heterochronic mechanisms.

\subsection{Introduction}

Six genera of crassatellid bivalves are known from the Cenozoic of New Zealand, and three of these, Spissatella Finlay, 1926, Eucrassatella Iredale, 1924, and Triplicitella Collins et al., in prep (see Chapter 5) (Figure 6.1) are inferred to be closely related. Both are extinct in New Zealand, although Eucrassatella has extant representatives in Australia (Darragh, 1965). Bivalves, which preserve a record of their ontogeny via accretionary growth around a single margin, are amenable subjects for studies of heterochrony (e.g. Gryphaea, Jones \& Gould, 1999; Crassostrea, Kirby, 2001; Spisula, Ivanyet al., 2003). Heterochrony (Text Box 8) is the name given to "changes in the relative time of appearance and rate of development for characters already present in ancestors" (Gould, 1977: p. 482), and is considered to be a major mechanism of evolutionary change (Jaecks \& Carlson, 2001; Gould, 2002; McNamara \& McKinney, 2005). Heterochrony operates in terms of acceleration or 
retardation of growth of somatic features relative to reproductive organs (Gould, 1977).

The visible results of heterochrony are either peramorphosis, in which a descendant species has gone through the stages of its ancestor and developed further in some aspect, or paedomorphosis, in which the adult of the descendant species resembles a juvenile stage of its ancestor.

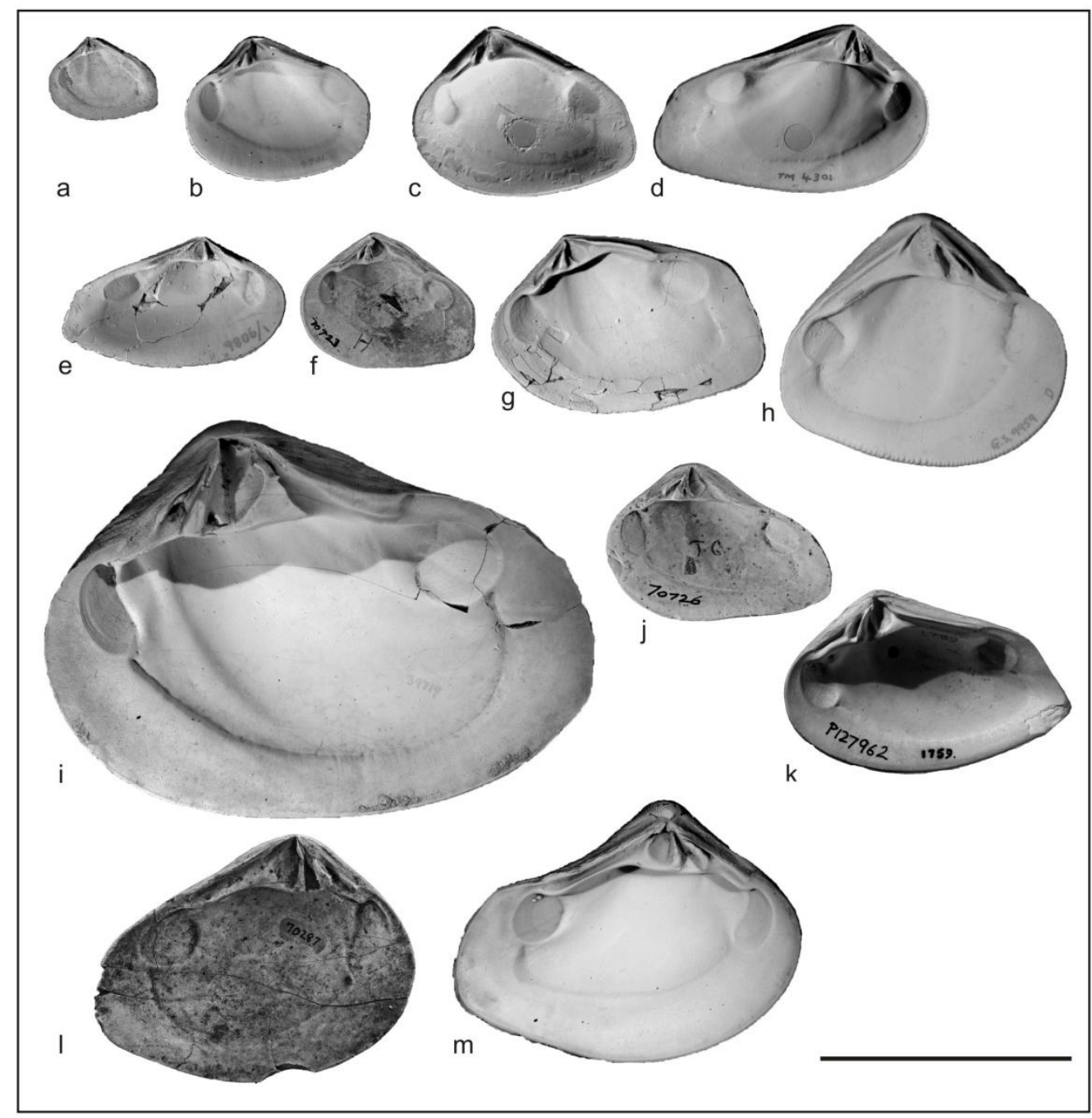

Figure 6.1: Species included in this study: (a) Spissatella media (OU8648); (b) Spissatella n. sp. C (GS4901); (c) Spissatella trailli (TM2859); (d) Spissatella subobesa (TM4301); (e) Spissatella poroleda (GS9806); (f) Spissatella clifdenensis (AK70723); (g) Spissatella acculta (TM7845); (h) Eucrassatella australis (GS9959); (i) Eucrassatella ampla (AK39719); (j) Eucrassatella scopalveus (AK70726); (k) Spissatella maudensis (P127962); (l) Eucrassatella marshalli (GS1101); (m) Eucrassatella kingicola (AK50183). Scale bar $=50 \mathrm{~mm}$. 
Text Box 8: Heterochrony is identified by comparing two species (generally an ancestor and a descendant) at a common developmental stage. Heterochrony involves two processes, which produce four results. The first process is the truncation or elongation of lifespan; the second process is the acceleration or retardation of growth, which can affect size, shape, or both.

Heterochrony occurs when lifespan, size and shape are offset relative to one another in ancestral and descendant species. 'Shape' is used here as a convenient shorthand for any morphological feature unrelated to absolute size or age. Taxa are compared at a stage of life, e.g. 'sexual maturity', rather than an absolute age - 'truncation' of lifespan is achieved by the descendant taxon attaining sexual maturity at a younger absolute age than the ancestral taxon.

\begin{tabular}{llll}
\hline Lifespan & Size and/or Shape & Resulting process & Resulting pattern \\
\hline Truncated & Arrested & Progenesis & Paedomorphosis \\
Extended & Increased & Hypermorphosis & Peramorphosis \\
Unchanged & Retarded & Neoteny & Paedomorphosis \\
Unchanged & Accelerated & Acceleration & Peramorphosis \\
\hline
\end{tabular}

(Related to heterochrony, but not considered forms of it, are proportioned dwarfism and proportioned gigantism, in which shape and size are coupled and either retarded or accelerated relative to lifespan.)

Heterochrony may affect the entire organism, in which case it is known as global heterochrony, or different heterochronic processes may act on individual organs, features, or character complexes of the organism. Furthermore, offsets between size, shape and age may not necessarily correspond perfectly to the four categories of true heterochrony described here.

Depending on the interplay between the timing of appearance of a morphological

feature, rate of growth, and length of lifespan, there are four broad categories of

heterochrony: acceleration, progenesis, neoteny and hypermorphosis (Text Box 8).

Investigations of heterochrony require size, shape and ontogenetic age data, and a

phylogenetic framework so that ancestor-descendant relationships can be identified;

furthermore, taxa must be compared at a standardised stage of development (Jaecks\&

Carlton, 2001). However, age data can be problematic to gather, particularly for extinct

species, and developmental stages can be difficult to identify or impractical to use Jones \&

Gould, 1999). Crampton and Maxwell (2000) investigated size-structured heterochrony in

the genera Spissatella and Eucrassatella, using size as an approximate proxy for ontogenetic

age. They compared shell shapes mathematically using Fourier analysis, which describes 
complex curves in terms of simpler sine and cosine harmonics. By reconstructing outlines from successively younger growth stages and using principal components analysis (PCA) to construct a morphospace, they were able to show shifts in average ontogenetic shape development between species. PCA takes multivariate shape data and reorients the dataset to find the dimension of maximum variance, designating this the first principal component (PC1), and the next-highest dimension of variance the second principal component (PC2) and so on. PC axes can be correlated to aspects of shape, making PCA plots useful for visualising and interpreting shape variation, and PC scores useful as a linear measure of originally-multivariate shape.

Plotting each size class for a given species on a set of PC axes and linking 'juvenile', 'immature' and 'adult' growth stages, Crampton and Maxwell (2000) were able to produce ontogenetic trajectories for each species, which allowed visual comparison of the degree of allometry displayed by each species. They concluded that heterochrony was the dominant evolutionary mechanism, on the basis of correspondence between the orientation of trajectories. However, their observations of heterochronic processes were limited by a lack of age data for their specimens, and they were thus unable to identify which heterochronic processes were involved.

Sclerochronology, the direct measurement of age data from shells, can provide a solution to this problem. In bivalves, shell is added incrementally around the valve margins (Seed, 1980). Because of this method of growth, in cross-section bivalve shells are often banded. Bands and lines in the bivalve shell may correspond to periodic shell-deposition (e.g. annual, monthly, daily; Lutz and Rhoads, 1980) or to interruptions to deposition (e.g., seasonal storm events; Richardson, 2001). Annual banding has been found in many bivalves, and is useful, as it provides information on total age at death and can be used to extrapolate growth-rates. Macroscopic banding in the Crassatellidae has been observed 
(Taylor et al., 1973) but its periodicity is not known. Identification of the periodicity of this banding is an aim of the present study.

The ratio of heavy ${ }^{18} \mathrm{O}$ to lighter ${ }^{16} \mathrm{O}$, known as $\delta^{18} \mathrm{O}$, varies seasonally in seawater in relation to temperature, meaning that oxygen isotope measurements from bivalve shells can show seasonal variations in the form of winter-high - summer-low couplets of $\delta^{18} \mathrm{O}$ (e.g. Jones \& Gould, 1999; Ivany et al., 2003; Jones et al., 2005). This allows (a) comparison of growth bands with oxygen curves to establish whether or not the bands are annual and (b) estimation of the ontogenetic age of the shell at death.

Using sclerochronology to provide age data that are independent of size, the most recent phylogeny (Chapter Three), and the shape and size data from Crampton and Maxwell (2000), we revisit the role of heterochrony in New Zealand crassatellid evolution.

\subsection{Methods}

It is hypothesised that the macroscopic shell bands visible in the species of Spissatella and Eucrassatella studied here are laid down annually. If the $\delta^{18} \mathrm{O}$ pattern corresponds with the banding pattern through the shell then this would support the inference that the bands are annual. This approach was used by Jones and Gould (1999) to establish chronological age in Gryphaea spp. for the purpose of studying heterochrony, and it will be emulated here.

Nine specimens, which represent the majority of species included in the recent phylogenetic analysis of this group, were donated by GNS Science from their New Zealand fossil reference collection (Table 6.1). Spissatella media, Eucrassatella marshalli, E. maudensis and E. kingicola were omitted due to lack of available specimens. Each specimen was embedded in epoxy resin and sectioned along its axial length using a slow saw. The axial length corresponds to the distance between the beak and the most distant point on the margin, a dimension marked in these species by a broadly-rounded ridge. This feature marks the axis 
of maximum growth. The smaller of the two remaining blocks was retained for preparation of thin-sections. The larger shell block was cut again, $5-10 \mathrm{~mm}$ anterior to the axial length, and the axial length face was polished to produce a smooth, flat surface.

\begin{tabular}{llcccccc}
\hline ID & Species & $\begin{array}{c}\text { Axial } \\
\text { length }\end{array}$ & $\begin{array}{c}\text { Bands } \\
(\mathrm{min})\end{array}$ & $\begin{array}{c}\text { Bands } \\
(\mathrm{max})\end{array}$ & $\begin{array}{c}\text { Couplets } \\
(\mathrm{min})\end{array}$ & $\begin{array}{c}\text { Couplets } \\
(\mathrm{max})\end{array}$ & $\begin{array}{c}\text { Growth rate } \\
\text { (L95CI - U95CI) }\end{array}$ \\
\hline GS9959 & T. australis & 42 & 27 & 35 & 17 & 30 & $1.61(1.39-1.86)$ \\
HQ-40 & S. maxwelli & 37 & 12 & 15 & 14 & 24 & $2.38(2.08-2.73)$ \\
GS11195 & S. acculta & 36 & 19 & 30 & - & - & $1.47(1.18-1.84$ \\
GS2946 & S. clifdenensis & 36 & 11 & 15 & 10 & 16 & $2.85(2.47-3.29)$ \\
GS2155 & E. ampla & 85 & 39 & 50 & - & - & $1.91(1.69-2.17)$ \\
GS475 & S. trailli & 30 & 9 & 15 & 12 & 16 & $2.4(2.02-2.85)$ \\
GS951 & E. scopalveus & 39 & - & - & 11 & 21 & $2.6(1.84-3.67)$ \\
GS9806 & S. poroleda & 33 & 14 & 23 & - & - & $1.8(1.42-2.28)$ \\
GS476 & E. subobesa & 53 & 21 & 30 & - & - & $2.08(1.75-2.48)$ \\
\hline
\end{tabular}

Table 6.1: Specimens used for oxygen isotope analysis and resulting growth-rate estimates. '95CI' means 95\% confidence interval.

Polished slabs were microsampled at the National Institute of Water and Atmospheric Research (NIWA) using a New Wave micromill with a $0.2 \mathrm{~mm}$ endmill. Each sample was milled from a path that followed, where possible, visible growth banding through the thickest part of the shell, avoiding the outer sculpture-bearing layer, the discontinuity that marks the pallial myostracum (where visible), and the flexure of the hingeplate where banding becomes thin and hard to discern (Figure 6.2). All shell material was visually assessed in thin-section for alteration - only GS2155 (Eucrassatellaampla) displayed any obvious recrystallisation, and this was only on the outer, sculpture-bearing layer of the shell, which was avoided for sampling purposes. Alteration of aragonite in scleractinian corals has been found to cause a negative shift in $\delta^{18} \mathrm{O}$ which results in increased temperature estimates, but with the seasonal cyclicity of the isotope curve preserved (McGregor and Gagan, 2003), meaning that even if the shell material has been slightly altered, the age information remains. 


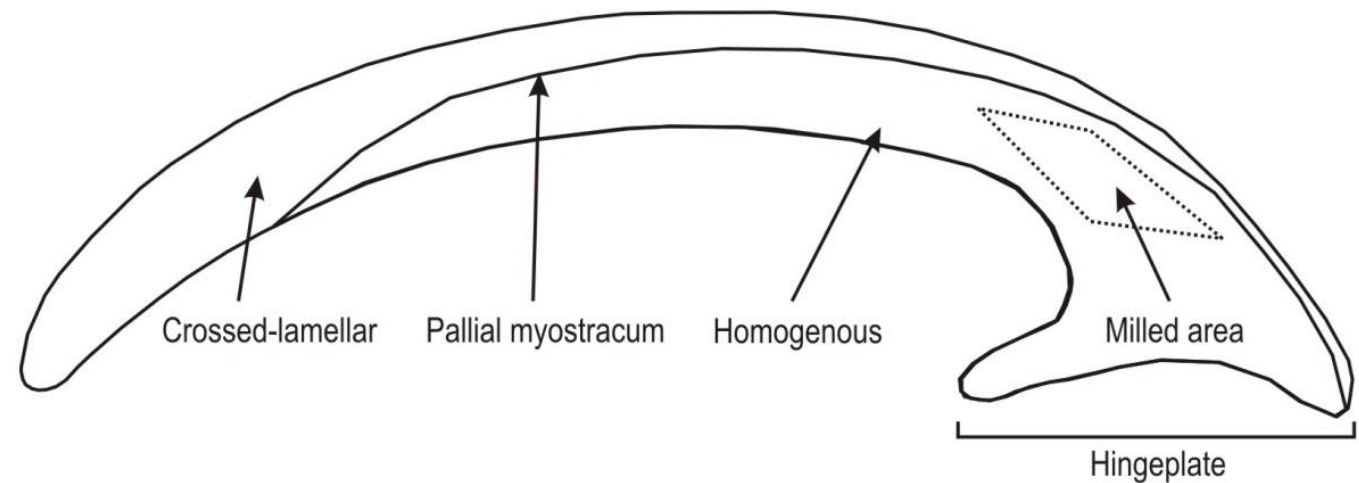

Figure 6.2: Diagram of the internal shell-structure of a generalised crassatellid bivalve, after Taylor et al., (1973). The crassatellid shell is aragonitic throughout, with crossed-lamellar structure exterior to, and homogenous structure interior to, the pallialmyostracum. The milled area was selected to cross the area of the shell with the widest, clearest bands and avoid discontinuities such as the trace of the pallialmyostracum. Thickness of the shell has been exaggerated for clarity.

Analysis of $\delta^{18} \mathrm{O}$ was undertaken at NIWA. Samples were reacted with three drops of $\mathrm{H}_{3} \mathrm{PO}_{4}$ at $75^{\circ} \mathrm{C}$ in an automated individual-carbonate reaction (Kiel III) device coupled to a Finnigan MAT252 mass spectrometer. All values reported relative to vPDB (Vienna Pee Dee Belemnite, an oxygen isotope standard), where $\delta^{18} \mathrm{O}$ has avalue of $-2.20 \%$ for NBS19 calcite. Internal precision of measurements is $0.02-0.08 \%$, external precision is $0.03 \%$ relative to vPDB.

In order to identify heterochrony in ancestor-descendant relationships, three pieces of information are required: chronological age, an anatomical feature of interest (in this case, shell-shape) and a measure of size. Sclerochronological methods provide the chronological age information. To test the hypothesis that the banding in these shells is laid down annually, two separate estimates of age for each specimen were established. First, using thin-sections, bands were counted in the hingeplate, which is typically the bestpreserved area of these shells and in which the banding is clearer and easier to count than in the main disc (Figure 6.3). These bands are sometimes so closely spaced that counting them even through the hingeplate becomes difficult - hence minimum and maximum estimates were both taken. Secondly, peaks in oxygen curves were counted, both conservatively (counting only the highest peaks) and comprehensively (counting every high 
point in the curve), to provide a minimum and maximum estimate. Due to damage and natural discontinuities in shell material, oxygen transects never spanned the entire thickness of the shell. If a shell was twice as thick as the length of the transect, the number of peaks was doubled to derive an estimate of the age of the shell at the time of death. This is considered conservative because, as bivalves age, the bands of shell material they lay down become thinner and more closely spaced (Richardson, 2001). Our transects were typically taken through the centre of the shells' thickest part where the bands are most widely spaced. Total estimates were then obtained by taking the number of peaks counted over a known shell thickness and scaling to obtain a minimum estimate of number of peaks for the total shell thickness.

Utilising the method detailed in Appendix Three (p. 173), ages (and their statistical uncertainties) can be estimated for shells of a given axial length using either the band count data or the isotope peak data. The scale factor between these two methods is close to 1 , which strongly suggests that they are equivalent - i.e. that the bands are annual.

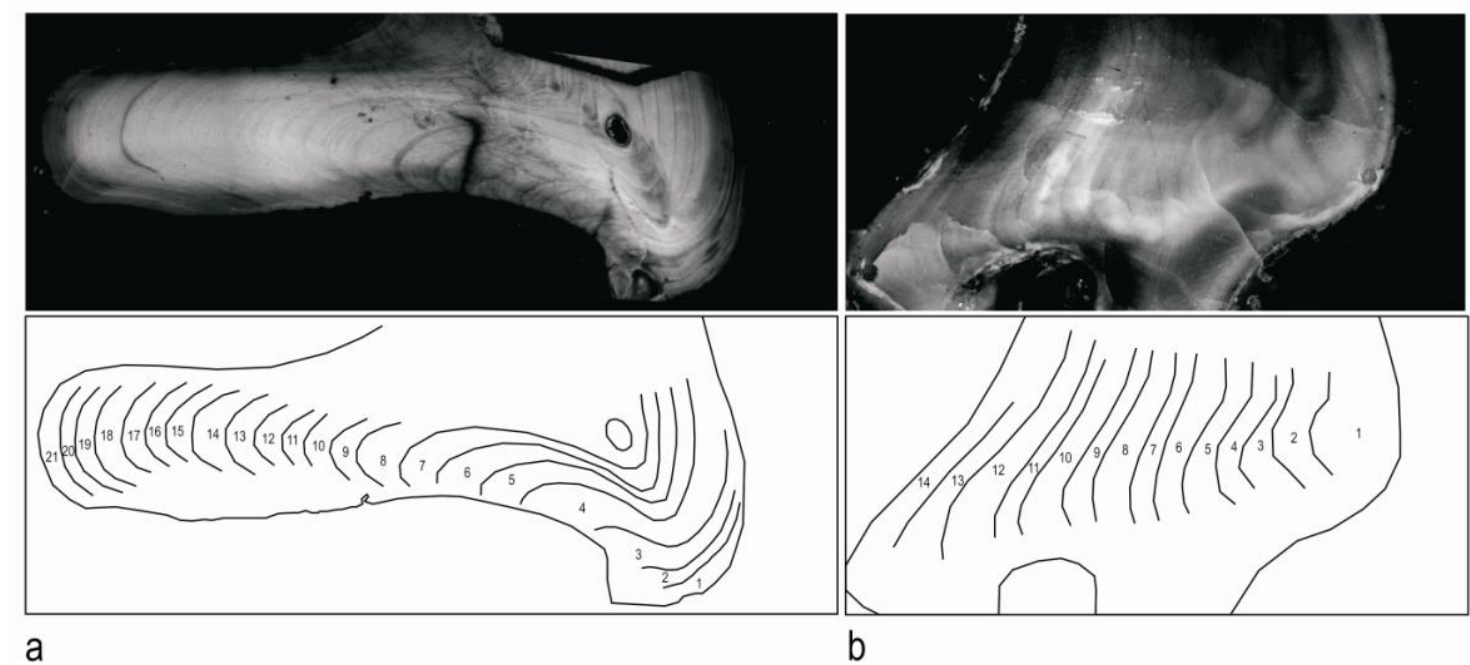

Figure 6.3: Examples of hingeplate thin-sections and band estimates diagrammed. (a) GS476 (Eucrassatella subobesa), with clear bands. (b) GS475 (Spissatella trailli), in which the bands are harder to interpret. 
Matching oxygen isotope curves and visually assessing correspondence of banding to isotope couplets, it can be seen that despite noise in the oxygen isotope signal, the largest specimens (E. ampla, T. australis, Fig. 6.4a) show do reasonable correspondence between high-low couplets in the oxygen curve and their bands, particularly in photos of the whole hingeplate where the banding is clearer than in close-ups. Smaller specimens $(E$. subobesa, E. scopalveus, S. maxwelli) with narrower, less clear bands (Fig. 6.4b) show more equivocal correspondence. Such banding as can be seen either is more closely-spaced than the micromill was capable of sampling, or is not well-delineated, but with colour changes that appear to correlate with high-low couplets in the oxygen isotope curves. The thinnest specimens (S. trailli, S. poroleda, S. acculta, S. clifdenensis; Fig. 6.4b) show closely-spaced banding that was too fine to enable effective sampling of every band with micro-mill techniques, and consequently there is little clear annual cyclicity preserved in the oxygen isotope curves, and such peaks and troughs as there are do not correspond closely to observed bands.

Clock models of heterochrony were compiled using average axial lengths in millimetres from the five largest specimens in the morphometric dataset to provide the size information. As the axial length corresponds to the axis of maximum growth, the axial length is a biologically-meaningful measure of size in the present context (c.f. centroid size, e.g. Kosniket al., 2006). Age estimates for these average axial lengths were calculated using the growth rates calculated for each species from the sclerochronological data (Table 6.2) (NB: the axial lengths used in the growth rate calculations are for the individual specimens involved in the oxygen isotope analysis, which were not included in the 'five largest specimens' subgroup, thus avoiding potential circularity). 

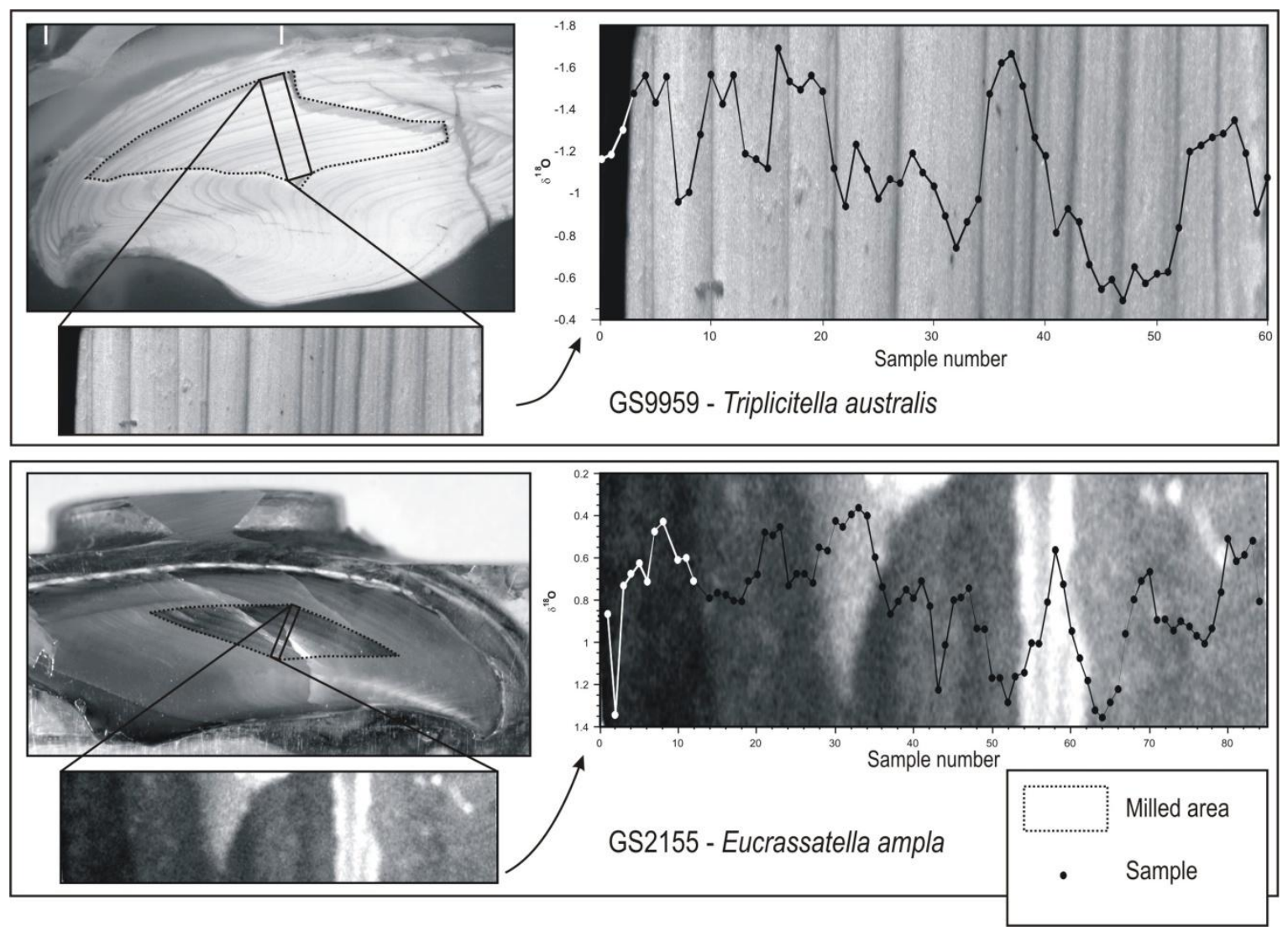

Figure 6.4a: Relation of milled transects to oxygen isotope curves, shown on Triplicitellaaustralis and Eucrassatellaampla. Close-ups are not as clearly banded as overview photos.

Scores for the first PC axis of all adult growth stages from the Cramton and Maxwell (2000) dataset were used as a summary of shape. PC1 explains $51 \%$ of total shape variation in the dataset (Crampton\& Maxwell, 2000) and corresponds in the main part to posterior elongation; individuals with low scores on PC1 have strongly inequilateral shapes with elongate, rostrate posterior margins; individuals with high scores on PC1 have more equilateral, truncated shapes. PC2, which does not contribute data to the heterochrony portion of this study, but which forms the $\mathrm{Y}$ axis of the ontogenetic plots in Figure 6.6, corresponds to anterior length, and projection and roundness of the umbo, with individuals scoring low on PC2 having extended anteriors and weakly inflated umbonal regions, and individuals scoring high on PC2 having short anterior regions with prominent umbones. 

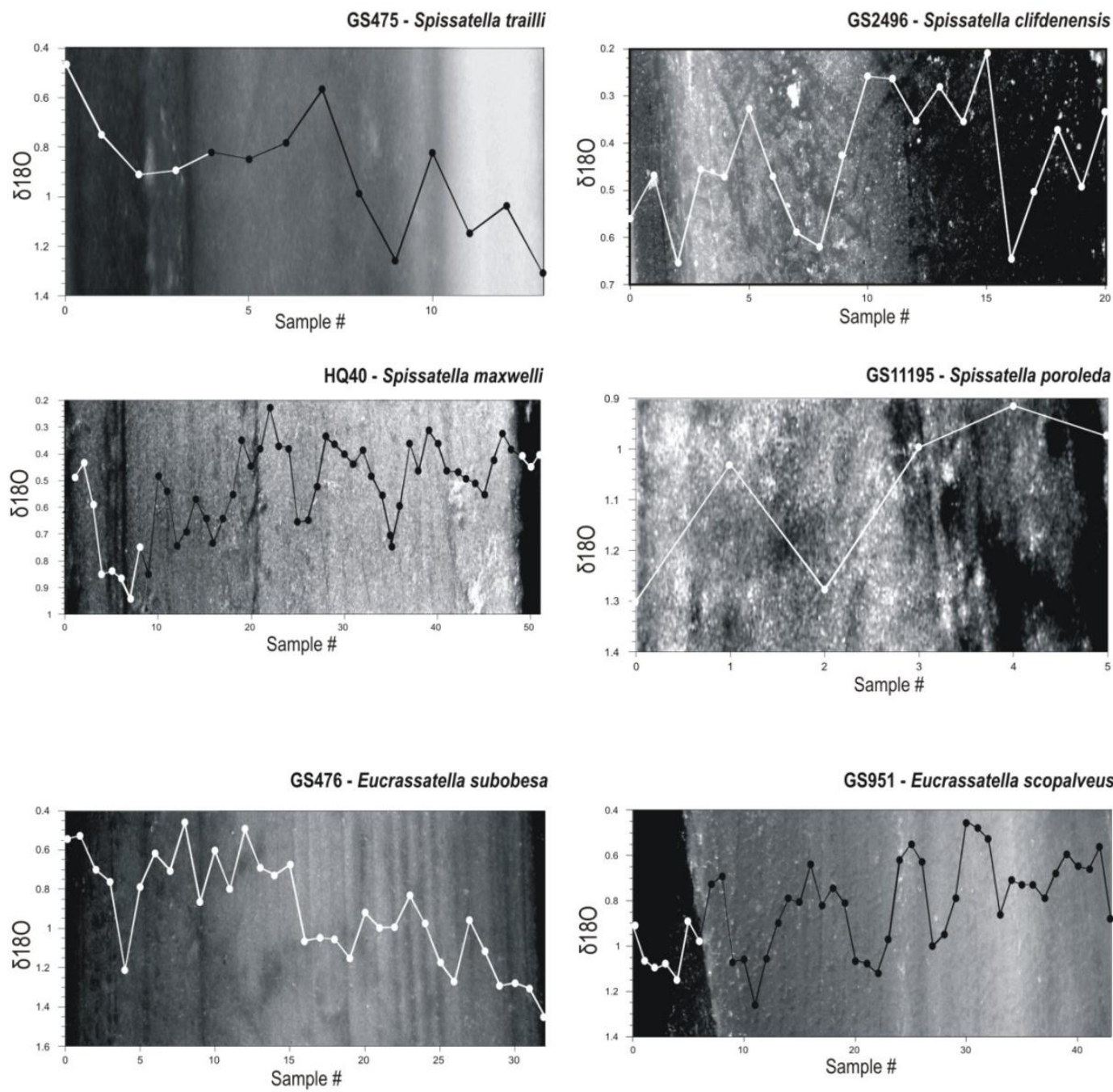

Figure 6.4b: Oxygen isotope curves over photographs of the milled area of shell they correspond to, showing the variety of banding patterns and degrees of correspondence to oxygen curves displayed in this group.

The shape and size map for this dataset from Crampton and Maxwell (2000) is presented, to aid interpretation of the ontogenetic PCA plots, in Figure 6.5. All age, size and shape data used in clock models are presented in Table 6.2. Pairs of species used and the type of phylogenetic relationship they represent are presented in Table 6.3. The positioning of the hands on a clock model shows the scores of the descendant species relative to the ancestor. To build a clock model, the age, size and shape data for the ancestral species are all set at the midpoints of their respective axes. Then the descendant species' data can be plotted on the model (Figure 6.6a). Hands pointing forward (clockwise) 
from the midpoint indicate acceleration of that aspect (size or shape), hands pointing backward (anticlockwise) from the midpoint indicate retardation. The age bar at the bottom shows graphically whether the lifespan of the descendant species has been lengthened (extending to the right of centre) or truncated (restricted to the left of centre) relative to that of the ancestral species. Gould (1977) showed theoretical clock models for 'pure' examples of each class of heterochrony; these are reproduced in Figure 6.6b to aid in interpretation of the clocks we have built from our crassatellid data.

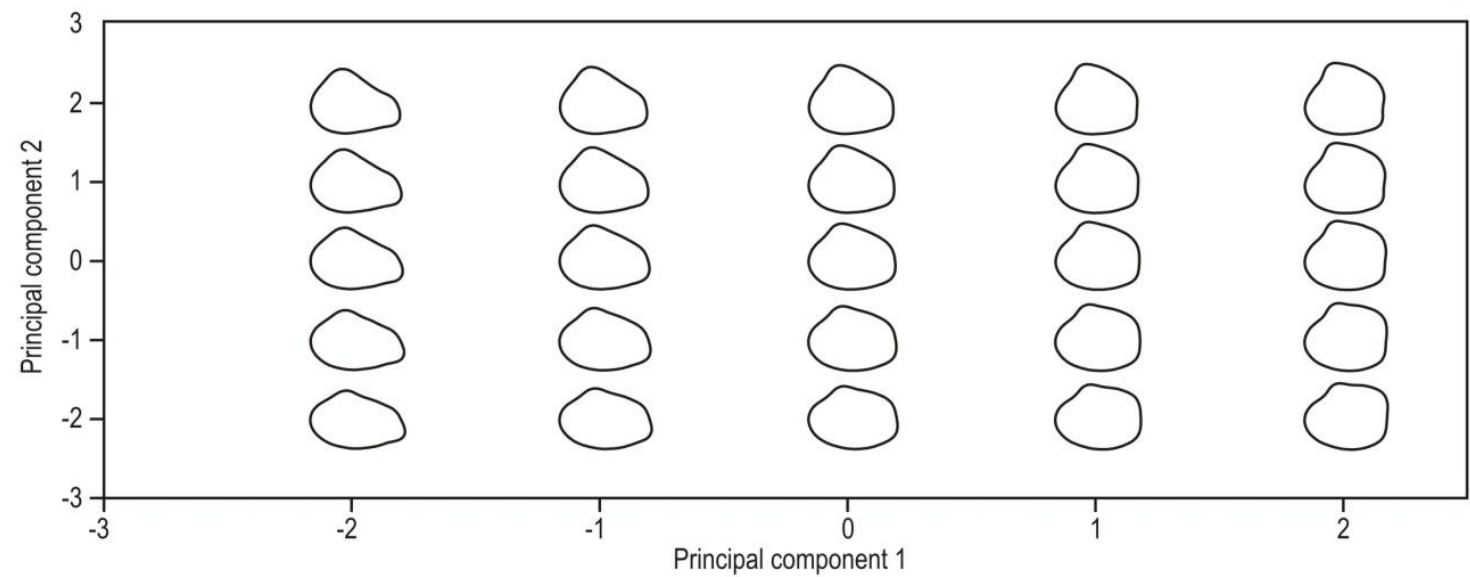

Figure 6.5: From Crampton \& Maxwell (2000). The first two principal component (PC) axes, with a suite of synthetic outline shapes generated using the inverse Fourier program Hcurve and the procedure outlined in Haines \&Crampton (2000), corresponding to unit standard deviation steps along each axis.

\begin{tabular}{lccc}
\hline Species & $\begin{array}{c}\text { Axial length } \\
\text { (5 largest) }\end{array}$ & $\begin{array}{c}\text { Age } \\
\text { (AL/growthrate) }\end{array}$ & $\begin{array}{c}\text { PC1 score } \\
\text { (from C\&M 2000) }\end{array}$ \\
\hline T. australis & 39 & 24 & -0.027 \\
S. maxwelli & 39 & 16 & -0.020 \\
S. acculta & 41 & 28 & -0.020 \\
S. & 40 & 14 & -0.024 \\
clifdenensis & 69 & 36 & -0.024 \\
E. ampla & 42 & 18 & -0.027 \\
S. trailli & 42 & 16 & -0.037 \\
E. & & & -0.047 \\
scopalveus & 41 & 23 & -0.042 \\
S. poroleda & & 25 & \\
E. subobesa & 51 & &
\end{tabular}

Table 6.2: Data for each species as used in clock models. Mean PC1 scores are of adult specimens and taken from Crampton\& Maxwell (2000). Axial lengths and ages are for the mean of the five largest adult specimens; PC1 scores are the mean of all adult specimens. 
We reproduce relevant ontogenetic trajectory figures of Crampton and Maxwell (2000) along with our clock models for each pair, modified to show only the taxa in question, in order to relate development in terms of occupancy of morphospace with the related changes in age and shape. Ontogenetic trajectories show the 'direction' of shapechange through ontogeny. Parallel trajectories are indicative of developmental similarities. Trajectories which are offset from each other indicate imperfect heterochrony - that is, that there is some other process affecting shape development and that changes are not purely heterochronically-driven. Clock models and ontogenetic trajectory plots are presented in stratigraphic order, oldest to youngest (Figure 6.7).

\begin{tabular}{lll}
\hline "Ancestral" taxon & "Descendant" taxon & Pair relationship \\
\hline T. australis & S. acculta & Lineage segment \\
T. australis & S. poroleda & Lineage segment \\
T. australis & S. maxwelli & Lineage segment \\
T. australis & E. subobesa & Lineage segment \\
T. australis & E. scopalveus & Lineage segment \\
T. australis & E. ampla & Lineage segment \\
S. acculta & S. poroleda & Sister-taxa \\
S. acculta & S. maxwelli & Lineage segment \\
S. maxwelli & S. trailli & Anagenetic \\
S. trailli & S. clifdenensis & Cladogenetic \\
E. subobesa & E. scopalveus & Lineage segment \\
E. scopalveus & E. ampla & Lineage segment \\
\hline
\end{tabular}

Table 6.3: Species pairs investigated for heterochronic relationships. 

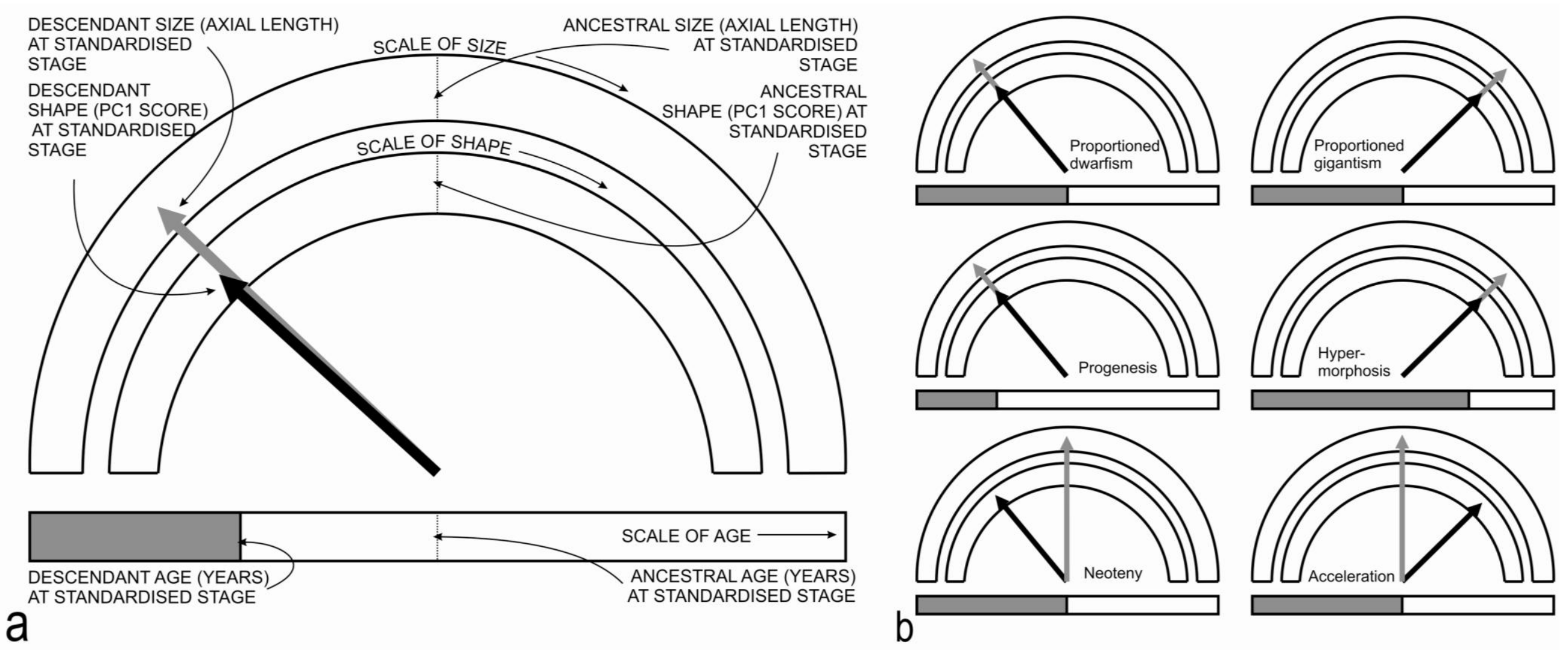

Figure 6.6: Clock models (redrawn from Gould, 1977) (a) The basic clock model: ancestral scores for age, shape and size are set at the midpoints of each axis, and the descendant scores are then plotted. Axes have been labelled (in brackets) with the appropriate measure of size, shape and age used in this study. (b) Example clock models to show dwarfism, gigantism and the four modes of true heterochrony. 


\subsection{Results}

T. australis (ancestral) - S. maxwelli (descendant)

a

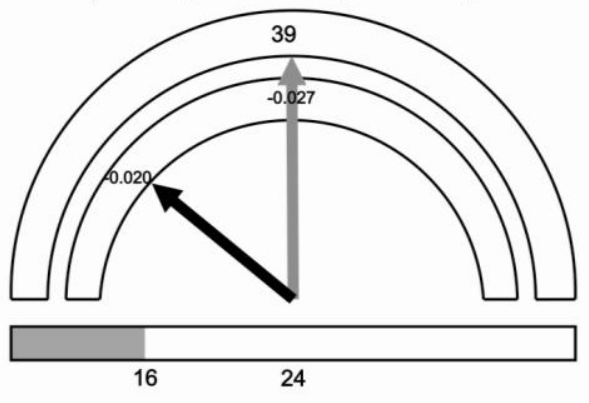

T. australis (ancestral) - S. poroleda (descendant)

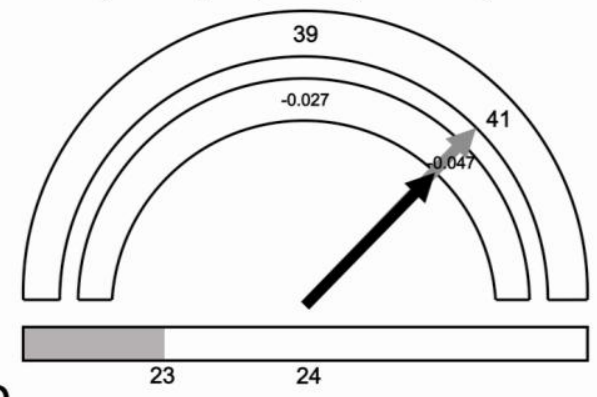

b

T. australis (ancestral) - S. acculta (descendant)

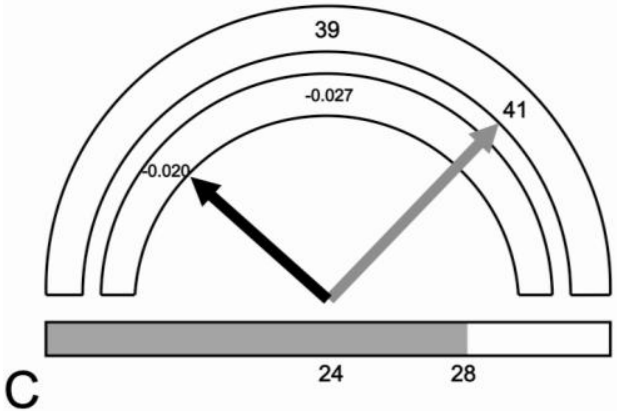

T. australis (ancestral) - E. subobesa (descendant)

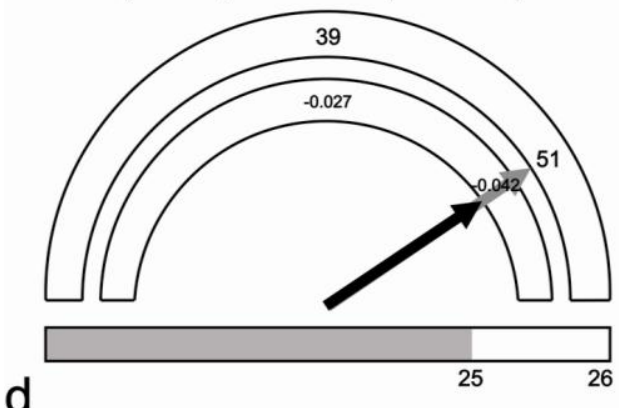

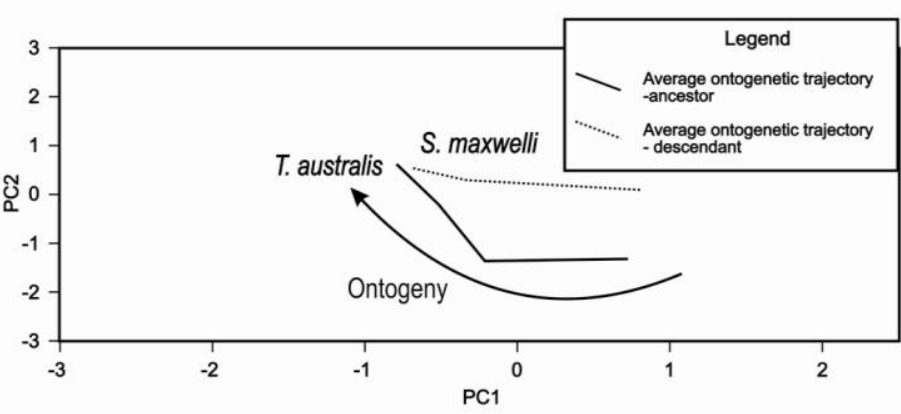
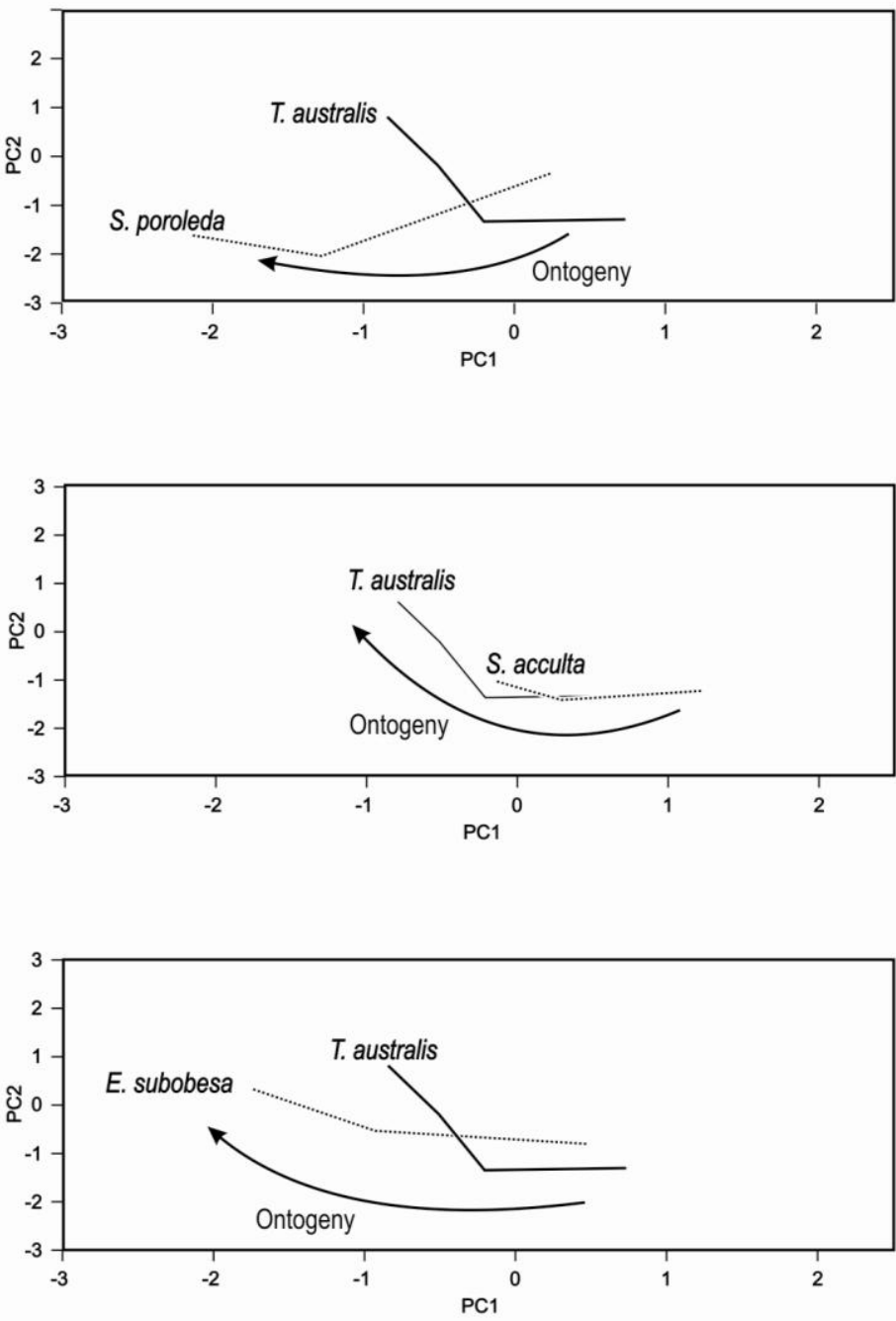

Figure 6.7a-d: (continued on subsequent pages) Clock models, and ontogenetic trajectory plots reproduced from Crampton\& Maxwell (2000), for the twelve pairs of species investigated in this study. 
Triplicitella australis is the oldest species studied here and is inferred as being the sister species to the Spissatella+ Eucrassatella clade. We have compared it in turn with each of the next-stratigraphically-youngest species that data is available for, to understand the net heterochronic change over each early lineage segment.

\section{Triplicitella australis - Spissatella maxwelli}

The relationship between these species is demonstrated by the clock model in Figure $6.7 \mathrm{a}$ to be paedomorphic, of uncertain mode (that is, assignable to neither progenesis or neoteny), with size and shape decoupled and development truncated by the shortened lifespan of $S$. maxwelli compared to T. australis. The early portions of their ontogenetic trajectories are subparallel and originate close to one an other on PC1, but are widely separated on PC2, which suggests that there is some significant component of nonheterochronic change in early ontogeny that differentiates S. maxwelli from Triplicitella, as with S. poroleda below.

Triplicitella australis - Spissatella poroleda

Compared to T. australis, $S$. poroleda is slightly shorter lived but also slightly larger, with shape and size being coupled and their development accelerated relative to age, leading to the appearance of hypermorphosis (Figure 6.7b). The ontogenetic trajectory plot shows that these species develop very differently, however, and it is highly likely that $S$. poroleda has not undergone heterochronic change relative to T. australis, but that some other form of developmental change gave rise to $S$. poroleda- this was suggested in Crampton and Maxwell (2000) and we support this interpretation.

\section{Triplicitella australis - Spissatella acculta}

The relationship between $T$. australis and $S$. acculta as demonstrated by the clock model in Figure $6.7 \mathrm{c}$ is neoteny. $S$. acculta's shape and size are decoupled, with shape being retarded and size increased relative to T. australis, over a longer period of growth. The accompanying ontogenetic trajectory plot shows that they develop very similarly in terms of shape. The 
early stages of their trajectories almost overlie one another, but $S$. acculta's trajectory is restricted to the area of the plot occupied typically by juvenile Triplicitella.
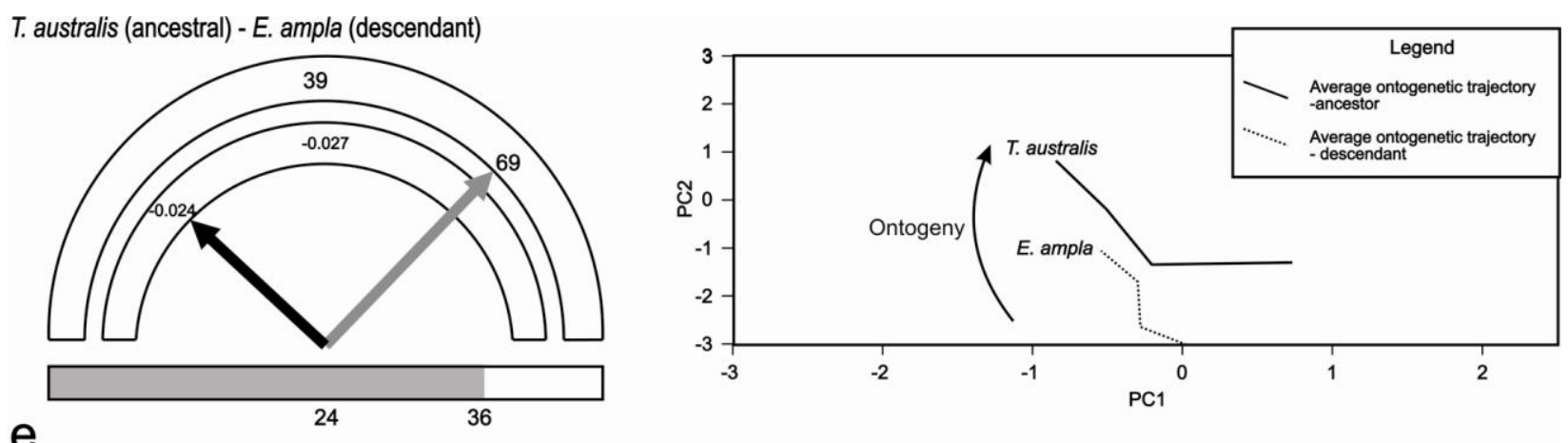

T. australis (ancestral) - E. scopalveus (descendant)
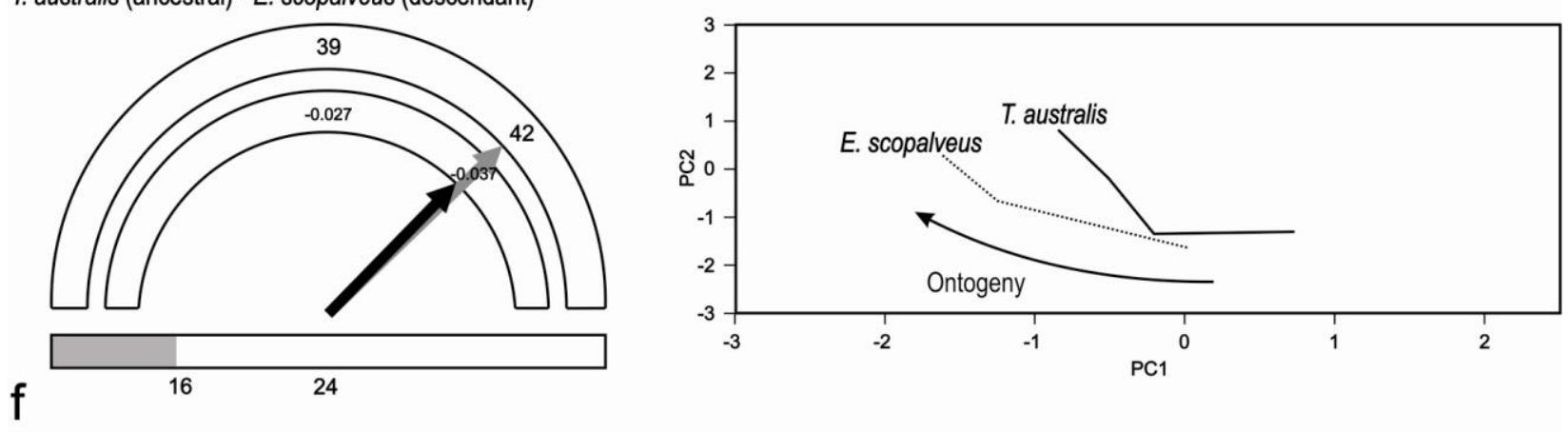

E. subobesa (ancestral) - E. scopalveus (descendant)
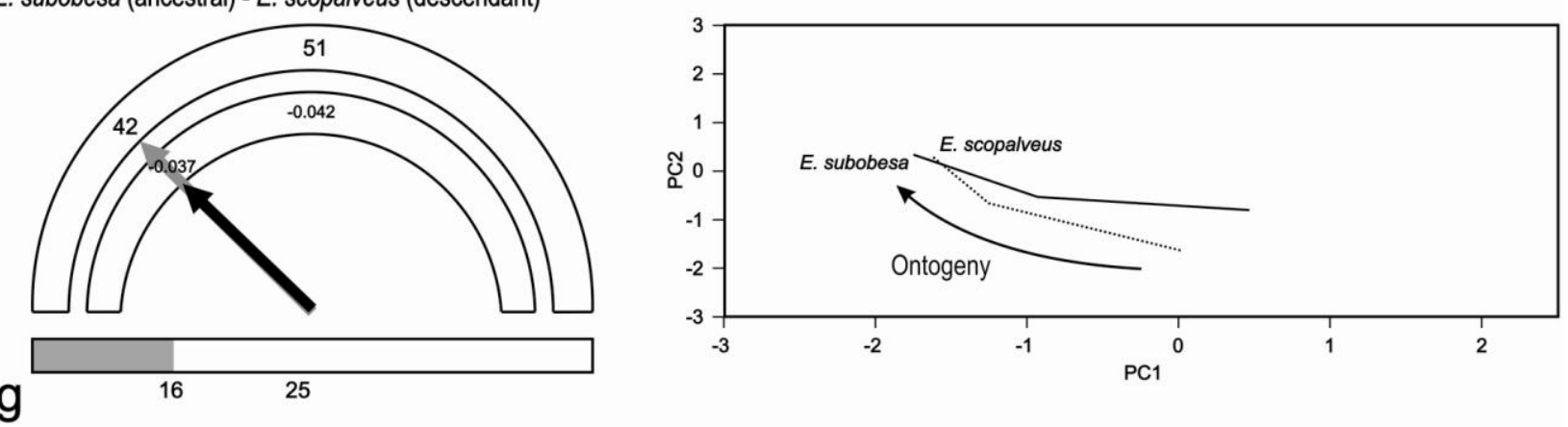

E. scopalveus (ancestral) - E. ampla (descendant)
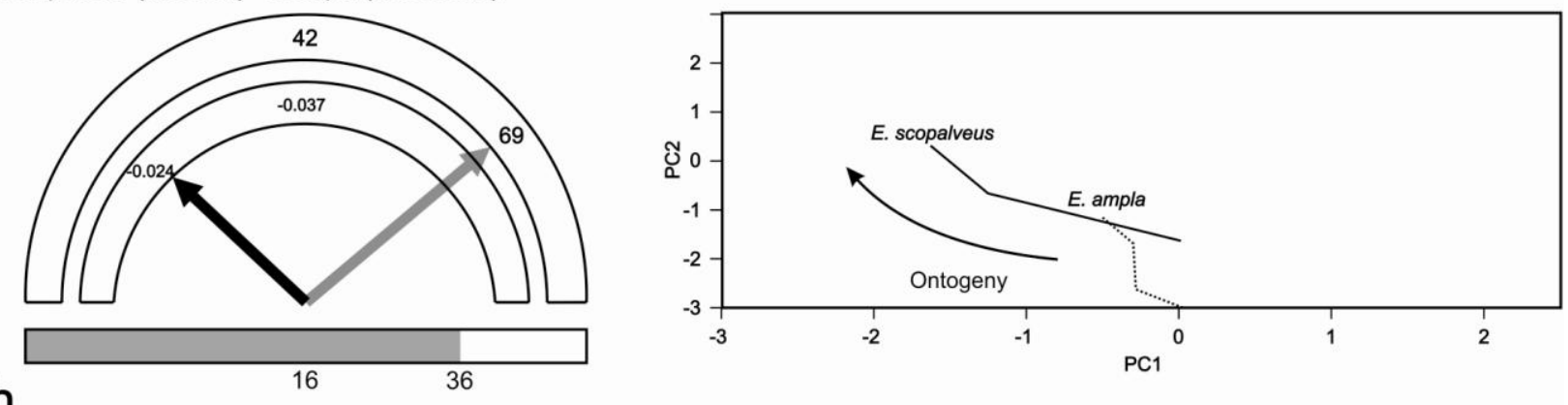

h

Figure 6.7e-h: (continuing from previous page, and on to next page) Clock models, and ontogenetic trajectory plots reproduced from Crampton\& Maxwell (2000), for the twelve pairs of species investigated in this study. 
Triplicitella australis - Eucrassatella subobesa

Figure $6.7 \mathrm{~d}$ demonstrates clearly that $T$. australis and E. subobesa are related by hypermorphosis - shape and size are coupled and extended by a longer period of growth. Their early ontogenetic trajectories are subparallel, and originate close together on both PC1 and PC2. Ontogenetically they diverge in morphospace at the 'immature' size class.

Triplicitella australis - Eucrassatella ampla

E. ampla has a considerably prolonged lifespan compared to T. australis, and correspondingly much increased size. However, in terms of shape E. ampla is much retarded compared to T. australis, and therefore the relationship is paedomorphosis by neoteny (Figure 6.7e). The ontogenetic trajectory plot shows that their early trajectories are broadly subparallel and that they both show a dramatic and similar change in PC2 score between 'immature' and 'adult' size classes.

Triplicitella australis - Eucrassatella scopalveus

E. scopalveus has a reduced lifespan but coupled, accelerated shape and size development, suggesting peramorphosis by acceleration (Figure 6.7f). The divergence of the early ontogenetic trajectories of these species indicates non-heterochronic influence on early ontogeny.

Eucrassatella subobesa - Eucrassatella scopalveus

E. scopalveus is neotenic compared to E. subobesa, attaining maturity later and with increased size, but retarded shape development as shown by PC1 score. The ontogenetic trajectories of these speciesare considerably offset on both PC1 and PC2 showing a nonheterochronic component of change. Notably, however, their adult shapes are convergent.

\section{Eucrassatella scopalveus - Eucrassatella ampla}

E. scopalveus is the sister species to the group E. amplat other Eucrassatella, and on the basis of morphology was placed in an ancestral position in the initial phylogenetic analysis, although this is not supportedstratigraphically. Figure 6.7h shows that E. ampla is neotenic 
relative to E. scopalveus, with reduced PC1 scores and a much longer lifespan and larger mature size. The earliest section of the E. ampla ontogenetic trajectory is sub-parallel with the earliest section of the E. scopalveus ontogenetic trajectory, but much shortened. It originates at the same point on PC1 but much further down PC2.
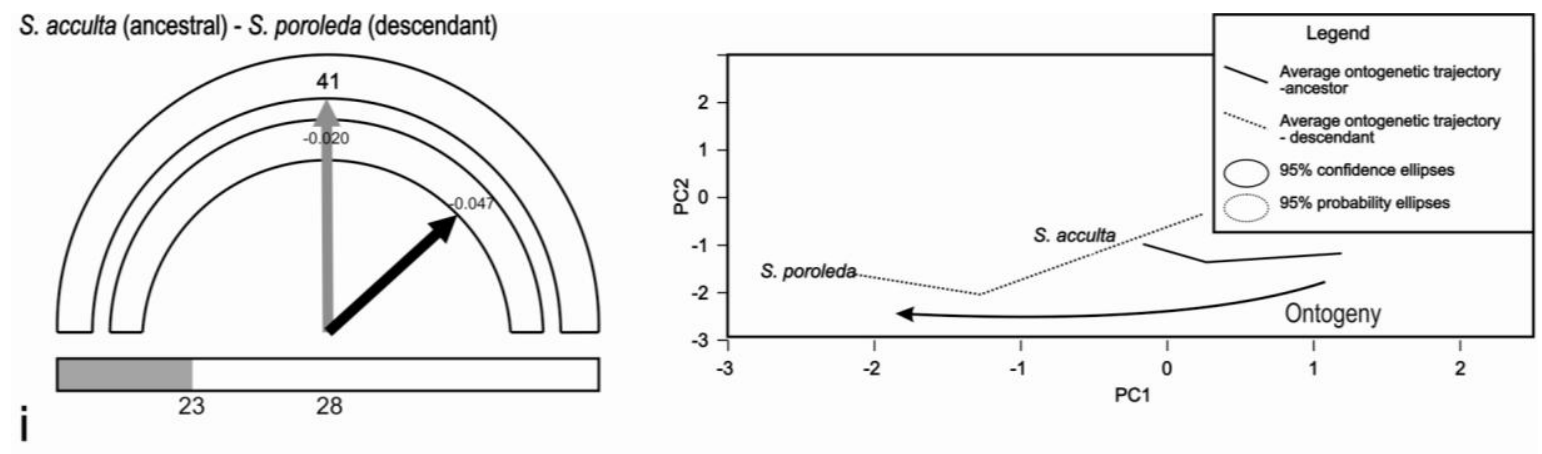

\section{S. acculta (ancestral) - S. maxwelli (descendant)}
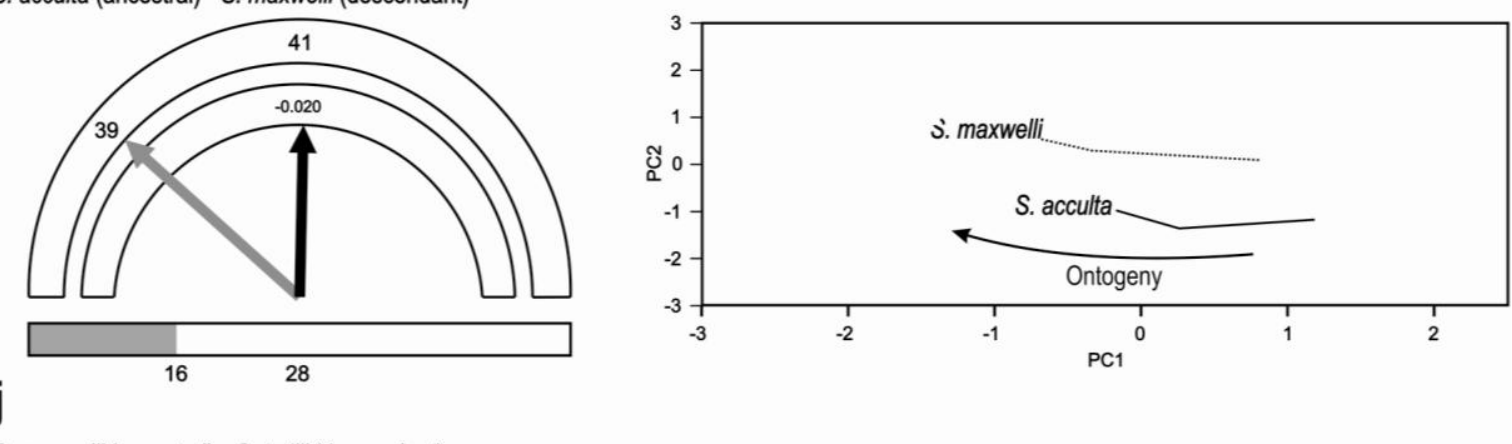

S. maxwelli (ancestral) - S. trailli (descendant)
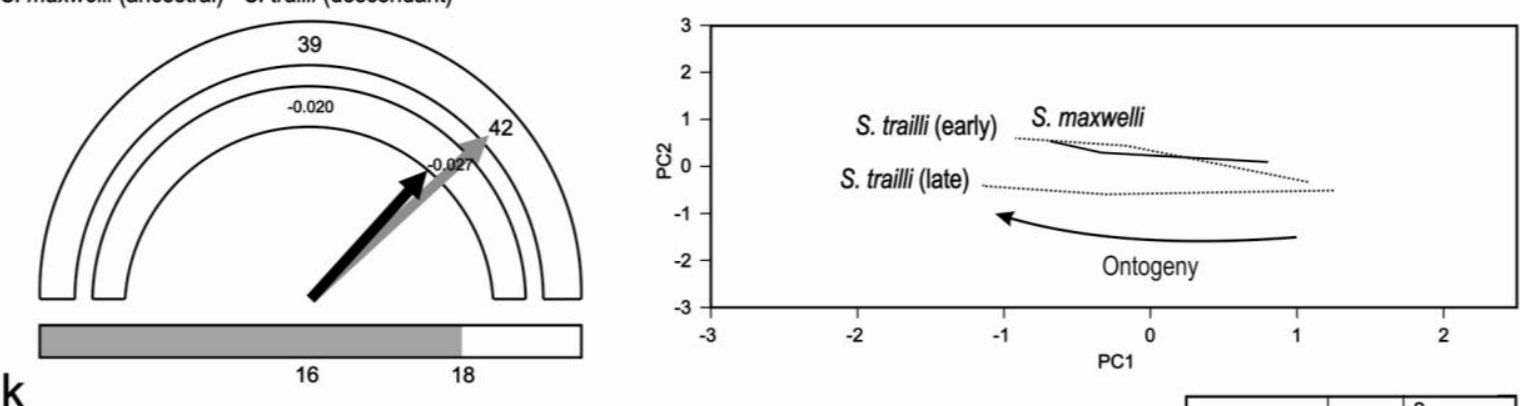

S. trailli (ancestral) - S. clifdenensis (descendant)
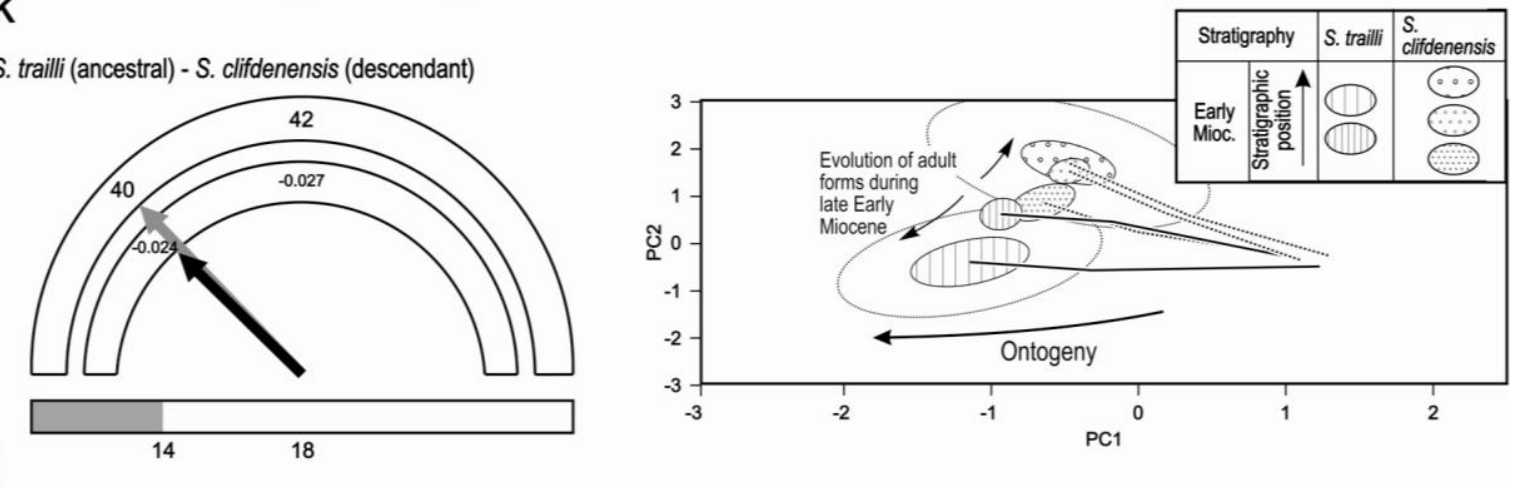

Figure 6.7i-l (continued from previous pages) Clock models, and ontogenetic trajectory plots reproduced from Crampton\& Maxwell (2000), for the twelve pairs of species investigated in this study. 


\section{Spissatella acculta - Spissatella poroleda}

S. poroleda attains maturity faster than $S$. acculta but at the same size (Fig. 6.7i) and with much accelerated shape development, displaying a peramorphic result that is not assignable to either acceleration or hypermorphosis. Ontogenetically they display a similar pattern of decreasing PC1 and PC2 scores between juvenile and immature shapes, followed by a further decrease in PC1 but increasing PC2 scores between immature and adult shapes, but there is considerably offset between their juvenile shapes and between the angles of their trajectories. Crampton and Maxwell (2000) inferred a non-heterochronic component in the relationship between S. poroleda and other Spissatella, and comparing this clock with other clocks including $S$. poroleda in this study we support this inference. $S$. poroleda shows few similarities in patterns of ontogenetic shape change with other taxa in this study group.

\section{Spissatella acculta - Spissatella maxwelli}

The clade $S$.acculta + S. poroleda is the sister to $S$. maxwelli, and is stratigraphically older. We select $S$. acculta as the 'ancestor' in this pair on the basis of its shape resemblance to $S$. media and because of its age. The clock model presented in Figure 6.7j shows that in S. maxwelli, relative to $S$. acculta, shape is accelerated relative to size and age, but that lifespan and size are truncated, leading paedomorphosis of uncertain mode. The ontogenetic trajectories of these species are sub-parallel, with that of $S$. maxwelli being longer and offset to a higher starting score on PC2.

\section{Spissatella maxwelli - Spissatella trailli; Spissatella trailli - Spissatella clifdenensis}

These three species are considered to constitute a single lineage of Spissatella, and are considered together here, although their relationships must be assessed pairwise given the structure of the clock model. $S$. maxwelli is inferred to be the direct ancestor by anagenesis of S. trailli (Crampton\& Maxwell, 2000). The clock model presented in Figure 6.7k demonstrates that $S$. trailli grows larger and reaches a higher PC1 score than $S$. 
maxwelli by extending its lifespan, indicating hypermorphosis. Their ontogenetic trajectories are sub-parallel, with the stratigraphically-older $S$. trailli having a trajectory that partially overlaps that of $S$. maxwelli and the trajectories of younger collections of $S$. trailli diverging further along PC2.

In turn, $S$. trailli is inferred to be the ancestor of $S$. clifdenensis by cladogenesis (Crampton \& Maxwell, 2000). Figure 6.71 shows that the heterochronic relationship between them is progenetic, where a truncated lifespan likewise truncates size and shape compared to the ancestral species. Ontogenetic trajectories plotted for collections of $S$. trailli and S. clifdenensis from Crampton and Maxwell (2000) demonstrate that stratigraphically-older S. trailli and S. clifdenensis are very similar in shape and development to each other (and to S. maxwelli), but that younger collections diverge along PC2.

Divergence along this axis corresponds to changes in the inflation of the umbonal region.

\subsection{Discussion}

A summary diagram of the distribution of heterochronic and related processes over the phylogenetic history of this clade is presented in Figure 6.8, with different line weights and styles representing the different processes identified as operating between species pairs. Although not all net interspecific changes between shape, size and age correspond ideally to a single class of heterochrony as categorised by Gould (1977), it can still be seen that there is no domination of the results by any single heterochronic mode or process.

The two genera Spissatella and Eucrassatella represent two different lineages that have coexisted for much of their lifespan, following a radiation in the latest Oligocene - earliest Miocene. The results presented here show that relative to Triplicitella australis, all categories of heterochrony sensu Gould (1977) are represented in the early history of the clade in terms of processes (acceleration and retardation of shape, size and lifespan relative to each 
other) and net change over lineages. The S. maxwelli-S. trailli - S. clifdenensis lineage appears to have originated as a smaller, shorter-lived descendant of earlier Spissatella (e.g., $S$. acculta) and then extended size and shape by prolonging lifespan (hypermorphosis) to produce a moderately-large, elongate shell shape $(S$. traill $)$. Following this, the youngest Spissatella, S. clifdenensis, which is a thick-shelled, relatively short species, descended from $S$. trailli by means of paedomorphosis by progenesis. Both of these classes of heterochrony involve change in lifespan rather than decoupling and changes in rate of either size or shape.

Relative to T. australis, the earliest Eucrassatella, E. subobesa, is hypermorphic. No direct ancestor-descendant relationships have been identified between species in this genus, but compared to both E. subobesa and E. scopalveus, E. ampla has an extended lifespan and increased shell size with a much more juvenile shell shape and is a massive, paedomorphic form. The three genera here studied are morphologically conservative, the principle differences between species being in terms of overall shape, shell thickness, and degree of coverage of sculpture over the shell disc. In his 1968 study, Stanley observed a decrease in generic diversity of non-siphonate, infaunal, suspension-feeding bivalves (including crassatellids) during the late Cretaceous and Cenozoic, possibly due to competition from siphonate taxa that appeared in the Mesozoic.

Crassatellids are infaunal but are constrained to remain at shallow depths within the substrate, which leaves them vulnerable to predation by crabs (Blundon \& Kennedy, 1982; Smith et al., 1999) and boring gastropods (Vermeij, 1983; Roopnarine \& Beussink, 1999). Deep-burial as an escape mechanism is not available to them due to their lack of siphons, and reburial speed after disinterment is sluggish due to their lack of a fused mantle. Therefore, their main defence against predation must then be to avoid disinterment in the first place by becoming more stable in the sediment, which can be achieved by increase in size (Stanley, 1970). 


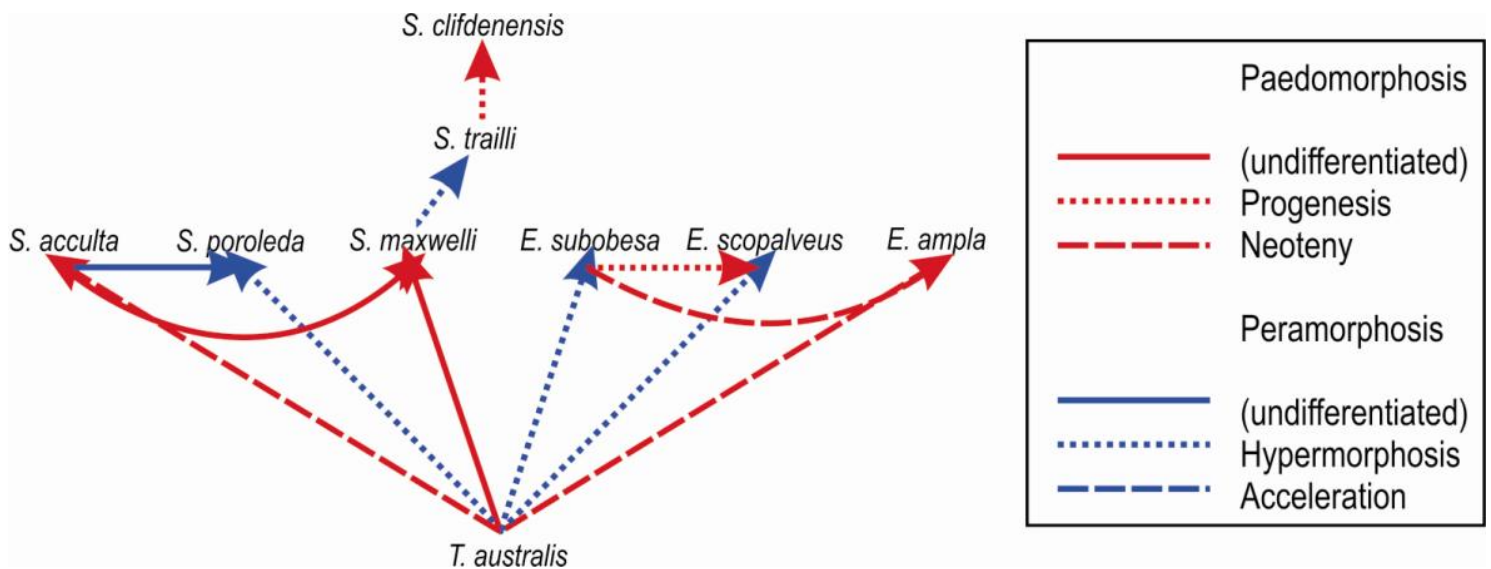

Figure 6.8: Distribution of modes of heterochrony within the study taxa.

The observation of all four categories of heterochrony in this clade suggests that these bivalves are not constrained in terms of the mechanism they employ to change shape - that is, they may either extend or truncate their lifespan, or accelerate or retard their growth in terms of shape and size - but that it is the morphological end result which is selected for. Overall, our findings are consistent with the assertion of Crampton and Maxwell (2000) that paedomorphosis and peramorphosis occur roughly equally within this group.

The constraints posed by the soft-part anatomy of crassatellids leave little morphological 'room' for them to diversify into in terms of shell form. The ontogenetic trajectories delineated by Crampton and Maxwell (2000) illustrate the directional 'channelling' of possible variance through morphospace for each species, and the addition of sclerochronological data has enabled us to further show that channelling may have operated in terms of selection for the elongate, heavy result rather than by constraining the mechanism by which that result is produced. 


\subsection{Conclusions}

- The lineage S. acculta-S. maxwelli-S. trailli-S. clifdenensis is dominated by changes in lifespan leading to speciation by hypermorphosis and progenesis.

- Younger Eucrassatella apparently achieved larger sizes by a combination of paedomorphosis (neoteny) and peramorphosis (hypermorphosis).

- Heterochronic responses to environmental pressure are not limited to any single heterochronic process (acceleration/retardation of growth or prolongation/truncation of lifespan) or result (paedomorphosis/peramorphosis).

- The variation of environmental conditions provides strong constraints on shell morphology. The restricted habitat available to these bivalves has channelled and limited their occupancy of morphospace without restricting the heterochronic processes involved. 


\section{7}

\section{Synthesis}

'"For the Snark's a peculiar creature, that won't

Be caught in a commonplace way.

Do all that you know, and try all that you don't:

Not a chance must be wasted to-day!"

For England expects - I forbear to proceed:

'Tis a maxim tremendous, but trite:

And you'd best be unpacking the things that you need

To rig yourselves out for the fight."'

- The Hunting of the Snark: Fit the Fourth - The Hunting 


\subsection{Conclusions of this study}

This thesis is concerned with the palaeobiology of a small and somewhat understudied fossil group, and approaches the problem from a phylogenetic standpoint, bringing several sources of data to bear upon the problem. Morphometric data provide the necessary characters for phylogenetic analysis, which provides the framework on which the taxonomic revision relies, and supplies ancestor-descendant relationship hypotheses in terms of which heterochronic inferences can be derived. Further morphometric data from Crampton \& Maxwell (2000) have allowed reconstruction of ontogeny and comparison of shape, leading to inferences of heterochrony.

The morphometric work in Chapter Three demonstrates that a landmark/semilandmark configuration that summarises both internal and external shape is preferred for use with the study group. Using this method, I have demonstrated that internal and external morphologies of these bivalves covary in shape, and supported the conclusion of Stasek (1963) and Stanley (1970) that the "Concept of Independant Entities" of Yonge (1953) is not supported, at least within the study group. The separation of Spissatella $\mathrm{n}$. sp. C from the variation of S. trailli and S. clifdenensis is confirmed, and the three taxa are shown to be separable in morphospace.

The phylogenetic analysis in Chapter Four drew on the results of the morphometrics to supply a suite of characters for stratocladistic use. The analysis produced a well-resolved, stratigraphically-supported phylogeny which was shown using Retention Indices to fit the data well. Furthermore, RIs demonstrated that addition of stratigraphic data improves the fit of tree to data overall. The analysis further revealed that Eucrassatella and Spissatella as previously defined were not monophyletic; i.e., are not composed of all species descended from a single common ancestor. It is recommended that two species assigned to Spissatella be reassigned to Eucrassatella on the basis of this phylogenetic analysis and a reexamination of shell characters, and that an alternative generic placement should 
be sought for "Eucrassatella" australis. A full revision of all species of 'larger' New Zealand Crassatellidae was undertaken in Chapter Five. Spissatella n. sp. C was described and named as Spissatella maxwelli $\mathrm{n}$. sp. and "Eucrassatella" australis was removed to a new genus Triplicitella. "Spissatella" subobesa and "Spissatella" maudensis were reassigned to Eucrassatella. Spissatella? cordiformis was declared a nomen dubium. Spissatella discrepans was synonymised with Spissatella acculta.

Chapter Six reports high-resolution oxygen isotope measurements taken from a small suite of specimens of Spissatella and Eucrassatella, and the presence of annual banding was confirmed for the first time in the Crassatellidae. This information allowed the shape and size data of Crampton and Maxwell (2000) to be recalibrated and re-examined in terms of heterochronic mechanisms of speciation and phyletic change through the evolution of the study clade. It was demonstrated that all categories of heterochrony sensu Gould (1977) have played some part in the history of this group, and that peramorphic and paedomorphic patterns are equally prevalent. No single process can be shown to dominate, and it is suggested that in this group, environmental and developmental constraints (e.g. the 'starting point' of juvenile morphology) have dictated end morphological results (adult morphology). The processes by which these results are attained are not restricted to either acceleration/retardation of growth or prolongation/truncation of lifespan alone.

\subsection{Functional morphological context and interpretation}

Form, specifically shell-form, is central to this palaeobiological investigation at all levels, and an infaunal bivalve's shell-form is strongly associated with life-habits and function. Like all crassatellids, Triplicitella, Spissatella and Eucrassatella are non-siphonate infaunal suspension feeders, similar to astartids, trigoniids and some carditiids (Stanley, 1968). This lack of siphons means that their posterior margin must remain in contact with the sediment/water interface in order to allow feeding, respiration and excretion. Stanley 
$(1968 ; 1970)$ noted that non-siphonate bivalves are, in general, sluggish burrowers because of their non-fused mantle, which prevents fast burrowing. They are, therefore, ill-equipped to live in high-energy environments with the threat of disinterment by wave action, which means that they are generally restricted to subtidal environments (Stanley, 1970). Inferences regarding the habitats of New Zealand taxa listed by Beu and Maxwell (1990) are generally in agreement with this interpretation; Spissatella is known from shelf and upper slope environments, Eucrassatella ampla is inferred as being primarily an inner-shelf dweller, and "Eucrassatella" (= Triplicitella) australis is known from inner or middle shelf assemblages (Beu \& Maxwell, 1990). Adaptations of shell form that confer greater stability within the sediment are likely to be selected for. Thick, heavy shells in infaunal bivalves have been observed by Stanley (1970) to increase the stability of the shell within the substrate and prevent disinterment. Thicker-shelled bivalves are also less vulnerable to predation by both crabs (Boulding, 1984) and boring naticid gastropods (Kitchell et al., 1981). Shell thickness in Spissatella and Eucrassatella increases in both lineages through geological time - the youngest New Zealand members of each genus (Spissatella clifdenensis, Eucrassatella ampla) are relatively thicker than earlier species.

Sculptural extent has not been thoroughly addressed in any study, but it does not appear to covary in the study group strictly with either size or shape. Spissatella and the other larger New Zealand crassatellids all bear the same type of commarginal ribbed sculpture and appear to have only been able to vary its coverage of the shell. In fact, most Crassatellidae have this simple commarginal sculpture (or no sculpture at all). Either they are in some way restricted to forming this kind of sculpture, or developing other sculptural variants did not provide enough of a benefit to outweigh the costs of doing so. Trigoniids bear a variety of complicated sculptural variants, which may act as an aid to burrowing and as a further adaptation to stability (Stanley, 1977). Trigoniids apparently utilised their spectacular variety of sculpture as a burrowing adaptation to overcome the obstacle of 
their being opisthogyrate and thus lacking the vital wedge-shaped, flattened lunule that ortho- and prosogyrous bivalves utilise for digging. Crassatellids, which are prosogyrous and do bear a flattened lunule, would have less need of complicated sculpture as an anchoring mechanism against the backwards component of their burrrowing sequence. Stanley (1970) listed commarginal ribbed sculpture as stabilising the shell in soft substrates, and being utilised as a juvenile anti-disinterment measure that may become obsolete as the animal ages and the shell grows larger. In Spissatella, the species of which are small to moderately-sized (up to $40 \mathrm{~mm}$ height), the sculpture typically (but not always) extends to the ventral margin. In the stratigraphically-older Eucrassatella (comparable in size to Spissatella) sculpture likewise extends to the ventral margin, but may be obsolete on the posterior area; whereas in the stratigraphically-younger, larger Eucrassatella (up to $100 \mathrm{~mm}$ height), sculpture is often restricted to the beaks or extends only to the centre of the shell disc.

A qualitative diagram of the sculpture/shell-shape morphospace is shown in Figure 7.1. Sculpture extending to the ventral margins is generally associated with smaller shells that have squarely truncated posteriors $(S$. media, S. poroleda, S. acculta, S. trailli, S. clifdenensis, E. subobesa, E. maudensis). Spissatella maxwelli is similar in size to these species, but has a more rounded posterior and bears variable sculpture, usually only on the centre of the disc and almost never on the posterior margin. Larger, thicker shells such as T. australis, E. ampla and E. marshalli, which have very rounded posteriors, bear sculpture typically only on the juvenile portions of the shell, at the beak. Eucrassatella kingicola, however, which is similar in size and thickness to T. australis and E. marshalli, but has a squarely-truncated posterior, has sculpture that extends at least to the middle of the disc and sometimes to the ventral margins. 


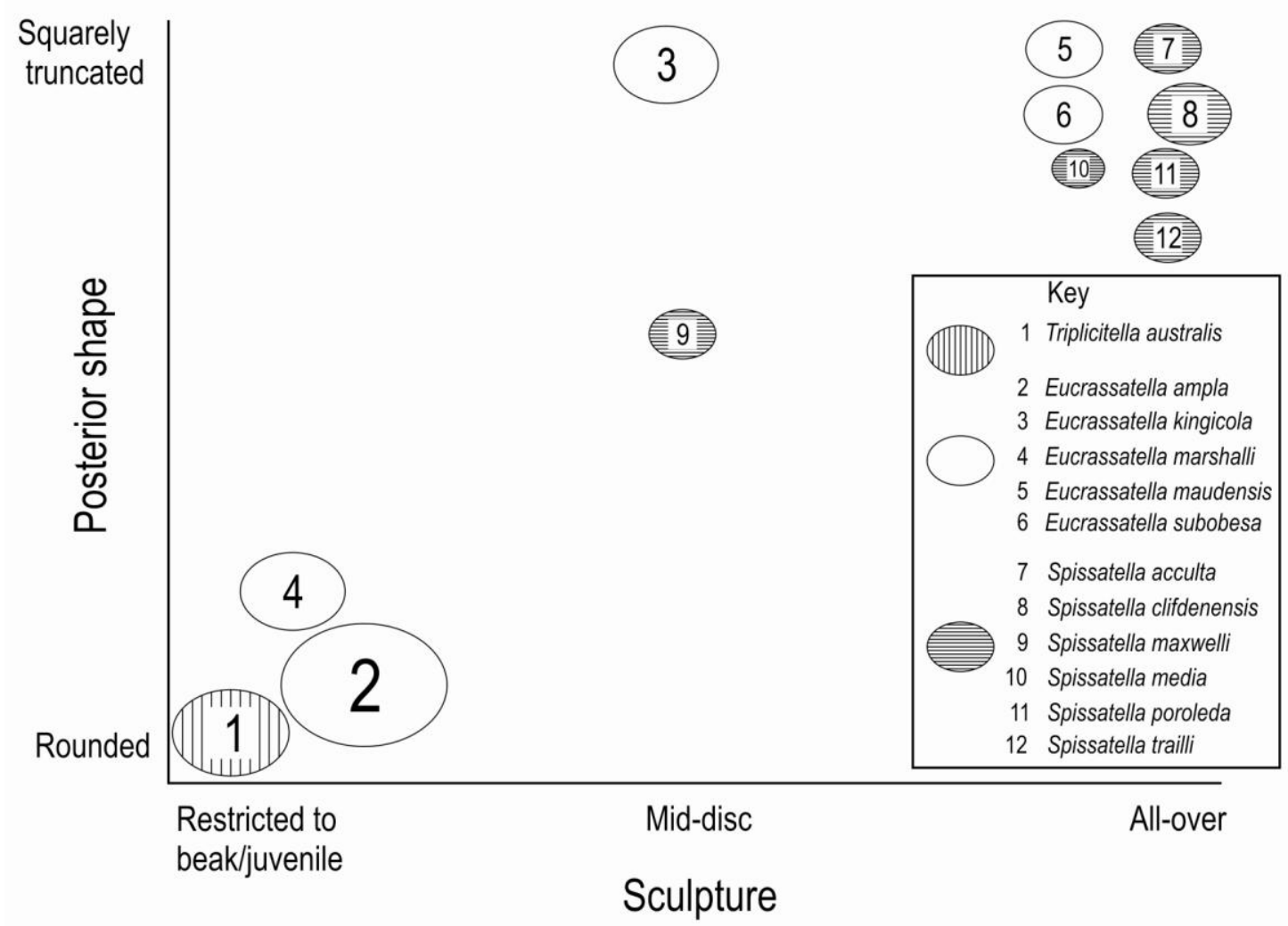

Figure 7.1: A qualitative morphospace showing the relationships of species based on their size, posterior shape and sculptural coverage of the shell disc. The axes are not to scale. Ellipse size indicates relative size of species. Eucrassatella scopalveus is omitted due to its pointed posterior shape being unique within the study group. Posterior shape is loosely equivalent to PC1 score, in which case if this axis were extended to include the 'pointed' shape state, E. scopalveus would plot at the extreme top left-hand corner.

Overall, shell form reflects historical, anatomical and environmental constraints, and can be regarded as the result of the interaction between these factors (Seilacher, 1970). Crassatellids such as Triplicitella, Spissatella and Eucrassatella are able, as demonstrated by this study, to modify overall shell shape by changes to developmental timing. This produces variation between elongate snorkel-like shells with extensive sculpture that allow relatively deep burial and sculptural anchoring, and short, heavy, axe-shaped shells that rely on weight and thickness to avoid both disinterment and predation. 


\subsection{Evolutionary trends in larger New Zealand Crassatellidae}

The interplay between evolutionary pressures on shape, size and sculpture has produced the variety of shell form that is observed in the species of New Zealand crassatellids. Each species has developed its own compromise between these factors to produce a shell that burrows efficiently and remains buried against the vagaries of water movement and predatory efforts. Tracing broad trends in shape-change over phylogeny, elongation and size increase develop independently a number of times. The earliest members of the clade studied here (the late Eocene Triplicitella australis and Spissatella media) are both very equilateral in shape. In the Oligocene, Spissatella began to become more elongate by a variety of means: $S$. acculta was of the same basic shape as $S$. media but much increased in size and with a correspondingly longer posterior region; S. poroleda was strongly elongate by virtue of having a smaller shell height for its shell length than its sister S. acculta; $S$. trailli developed as a giant form of $S$. maxwelli, and from this stock $S$. clifdenensis developed by arresting its shape development to produce a large but overall more "juvenile" in shape, less-elongate shell.

During the early Oligocene, Eucrassatella originated from a Spissatella-like or Triplicitella-like ancestor. The earliest Eucrassatella are very elongate and thick compared to contemporaneous Spissatella, and grew much larger. Eucrassatella is less speciose than Spissatella in New Zealand, but longer-lived as a clade (and still extant in Australia). The greatest diversity of crassatellid bivalves in New Zealand is observed in the Duntroonian Stage (late Oligocene, 27.2 - 25.3 Ma), coinciding broadly with the time of greatest inundation of the Zealandia landmass (the Oligocene; 33.7 - 23.8 Ma; King et al., 1999), which presumably provided the greatest amount of shelf habitat for exploitation. Two species of Spissatella and two species of Eucrassatella coexisted during this time period. Diversity decreased over the early Miocene, and by the late Miocene, only Eucrassatella ampla remained. E. marshalli appeared briefly in the Wanganui Series (Plio-Pleistocene), but was 
short-lived and did not survive until the Recent. Given its phylogenetic placement and morphological affinities, it is possible that E. marshalli represents a brief recolonisation of New Zealand by crassatellids, across the Tasman from Australia, and that E. ampla is the last representative of the New Zealand lineage.

Tashiro and Matsude (1988), in their study of trigoniids, suggest that the diversity of that group in the Cretaceous may have been triggered by competition with siphonate corbiculoids. Trigoniids developed extremely elongate posteriors with a median 'siphon groove' that separated their inhalant and exhalant currents, and acted as a snorkel, similar to the siphons of other bivalves. The inference is that their low diversity today (a single genus of trigoniids - Neotrigonia - still inhabits Australian waters) is due in large part to inability to compete successfully with truly siphonate bivalves such as corbiculoids and venerids. Crassatellids would have been subject to similar competition pressure from other coexisting burrowing bivalves, such as Neilo (Malletiidae), Dosinia (Veneridae; Dosiniinae), Circomphalus (Veneridae; Chioninae), Notocallista (Veneridae; Pitarinae), and Mactra (Mactridae), which would have benefited from the expansion of available habitat caused by the flooding of Zealandia as much as the crassatellids. It should be noted that all of these siphonate genera are still extant in New Zealand.

Overall, the low diversity of New Zealand's larger crassatellid genera would seem to be due, in some part, to the strong anatomical 'starting condition' constraints on their development, including most notably their non-siphonate condition and lack of sculptural variation. Shell form in bivalves is strongly controlled by physical requirements of habitat, there are strict limits to the seafloor habitats that non-siphonate bivalves such as crassatellids can safely occupy, and they are more vulnerable to predation than species which can escape by deep burial. Competition from siphonate taxa coupled with this inability to innovate, constrained by environmental pressure, may have led to the decline of the larger crassatellids in New Zealand. 


\subsection{Directions for future work}

Further insight into crassatellid evolution in New Zealand could be achieved by the inclusion of the smaller crassatellid bivalves Talabrica, Salaputium and Chattonia into the framework established here. A logical extension would also be inclusion of Australian species of Eucrassatella, and South American Tertiary species such as Spissatella lyelli and Crassatellites longior (which has been questionably assigned to Spissatella (Beu, 1997)). Data on shell-thickness and ornamentation, using parameters developed by Stanley (1970), would allow further investigation of heterochronic processes unrelated to shape.

The integrated use of morphometric, phylogenetic and ontogenetic data applied here could be used on other bivalve groups, and, with some modification, on gastropods. Extant species could be included, and the routine use of molecular data in phylogenetics and the ability of cladistic programs such as MacClade to use different, disparate sources of data in analyses would allow yet more data to be incorporated into such an investigation. New Zealand's high proportion of endemic mollusc taxa (Spencer et al., 2009) could provide a number of useful test-cases of small datasets in which the sum total of diversity is known to be restricted to the New Zealand region.

Overall, this study has shown that a multidisciplinary, pragmatic approach, which integrates morphology with other data such as stratigraphy and ontogenetic information, may be utilised to draw meaningful evolutionary inferences from character-depauperate, poorly-speciose taxa. 


\section{REFERENCES}


Adams, A. (1854). Descriptions of new shells, from the Cumingian collection. Proceedings of the Zoological Society of London, 20, 90-92.

Adrain, J. M., \& Westrop, S. R. (2001). Stratigraphy, phylogeny, and species sampling in space and time. In J. M. Adrain, G. D. Edgecombe, \& B. S. Lieberman (Eds.), Fossils, Phylogeny and Form, an analytical approach (pp. 291-313). Kluwer Academic/Plenum Publishers, New York.

Aguirre, M. L., Perez, S. I., \& Sirch, Y. N. (2006). Morphological variability of Brachidontes Swainson (Bivalvia, Mytilidae) in the marine Quaternary of Argentina (SW Atlantic). Palaeogeography, Palaeoclimatology, Palaeoecology, 239(1-2), 100-125.

Almeida, M. T., \& Bisby, F. A. (1984). A Simple Method for Establishing Taxonomic Characters from Measurement Data. Taxon, 33(3), 405-409.

Alroy, J. (2002). Stratigraphy in phylogeny reconstruction - reply to Smith (2000). Journal of Paleontology, 76(4), 587-589.

Beesley, P. L., Ross, G. J. B., \& Wells, A. (Eds.). (1998). Mollusca: The Southern Synthesis Fauna of Australia Volume 5 (pp. 1-563). Melbourne: CSIRO Publishing.

Beu, A. G. (1995). Pliocene limestones and their scallops. Lithostratigraphy, pectinid biostratigraphy and paleogeography of eastern North Island late Neogene limestone. Institute of Geological and Nuclear Sciences Monograph, 10, 1-243.

Beu, A. G. (2006). Marine Mollusca of oxygen isotope stages of the last 2 million years in New Zealand. Part 2 - Biostratigraphically useful and new Pliocene to Recent bivalves. Journal of the Royal Society of New Zealand, 36(4), 151-338.

Beu, A. G., Griffin, M., \& Maxwell, P. A. (1997). Opening of Drake Passage gateway and Late Miocene to Pleistocene cooling reflected in Southern Ocean molluscan dispersal: evidence from New Zealand and Argentina. Tectonophysics, 281, 83-97.

Beu, A. G., Maxwell, P. A., \& Brazier, R. C. (1990). Cenozoic Mollusca of New Zealand. New Zealand Geological Survey Palaeontological Bulletin, 58, 1-518.

Beu, A. G., Nolden, S., \& Darragh, T. A. (2012). Revision of New Zealand Cenozoic fossil Mollusca described by Zittel (1865) based on Hochstetter's collections from the Novara Expedition. Memoirs of the Association of Australasian Palaeontologists, 43, 1-69.

Beu, A. G., \& Raine, J. I. (2009). Revised Descriptions of New Zealand Cenozoic Mollusca from Beu and Maxwell (1990). GNS Science Miscellaneous Series, 27.

Bloch, J. I., Fisher, D. C., Rose, K. D., \& Gingerich, P. D. (2001). Stratocladistic analysis of Paleocene Carpolestidae (Mammalia , Plesiadapiformes) with description of a new Late Tiffanian genus. Journal of Vertebrate Paleontology, 21(1), 119-131.

Blundon, J. A., \& Kennedy, V. S. (1982). Refuges for infaunal bivalves from blue crab Callinectes sapidus (Rathbun) predation in Chesapeake Bay. Journal of Experimental Marine Biology and Ecology, 65, 67-81. 
Bodenbender, B. E., \& Fisher, D. C. (2001). Stratocladistic Analysis of Blastoid Phylogeny. Journal of Paleontology, 75(2), 351-369.

Bookstein, F. L. (1991). Morphometric Tools for Landmark Data: Geometry and Biology. Cambridge: Cambridge University Press.

Bookstein, F. L. (1997). Landmark methods for forms without landmarks: morphometrics of group differences in outline shape. Medical image analysis, 1(3), 225-43.

Boreham, A. U. E. (1965). A Revision of F. W. Hutton's Pelecypod Species Described in the Catalogue of Tertiary Mollusca and Echinodermata (1873). New Zealand Geological Survey Palaeontological Bulletin, 37, 1-125.

Bradshaw, M. A., \& McCartan, L. (1991). Palaeoecology and systematics of Early Devonian bivalves from the Horlick Formation, Ohio Range, Antarctica. Alcheringa 15(1), 1-42.

Carroll, L. (1898). The Hunting of the Snark: An Agony in Eight Fits. The MacMillan Company.

Clarke, E. (1904). The Fossils of the Waitemata and Papakura Series. Transactions of the New Zealand Institute 37, 413-421.

Clouse, R. M., De Bivort, B. L., \& Giribet, G. A. (2009). A phylogenetic analysis for the South-east Asian mite harvestman family Stylocellidae (Opiliones: Cyphophthalmi ) a combined analysis using morphometric and molecular data. Invertebrate Systematics, 23, $515-529$.

Clouse, R. M., De Bivort, B. L., \& Giribet, G. A. (2011). Phylogenetic signal in morphometric data. Cladistics, 27, 337-340.

Clyde, W. C., \& Fisher, D. C. (1997). Comparing the Fit of Stratigraphic and Morphologic Data in Phylogenetic Analysis. Paleobiology, 23(1), 1-19.

Cooper, R. A. (2004). The New Zealand Geological Timescale. Institute of Geological and Nuclear Sciences Monograph 22, 284p.

Crampton, J. S. (2006). Second-Order Sequence Stratigraphic Controls on the Quality of the Fossil Record at an Active Margin: New Zealand Eocene to Recent Shelf Molluscs. Palaios, 21(1), 86-105.

Crampton, J. S., \& Maxwell, P. A. (2000). Size: all it's shaped up to be? Evolution of shape through the lifespan of the Cenozoic bivalve Spissatella (Crassatellidae). Geological Society of London, Special Publications, 177, 399-423.

Crampton, J. S., Raine, J. I., Strong, P., \& Wilson, G. (2001). Integrated biostratigraphy of the Raukumara Series (Cenomanian-Coniacian) at Mangaotane Stream, Raukumara Peninsula , New Zealand. New Zealand Journal of Geology and Geophysics, 44(3), 365-389.

Dall, W. H. (1889). On the hinge of pelecypods and its development, with an attempt toward a better subdivision of the group. American Journal of Science, 38(3), 445-462. 
Darragh, T. A. (1965). Revision of the species of Eucrassatella and Spissatella in the Tertiary of Victoria and Tasmania. Proceedings of the Royal Society of Victoria New Series, 78(1), 95114.

Davis, G. M. (1982). Historical and Ecological Factors in the Evolution, Adaptive Radiation and Biogeography of Freshwater Mollusks. American Zoologist, 22, 375-395.

De Bivort, B. L., Clouse, R. M., \& Giribet, G. A. (2010). A morphometrics-based phylogeny of the temperate Gondwanan mite harvestmen (Opiliones, Cyphophthalmi, Pettalidae). Journal of Zoological Systematics and Evolutionary Research, 48(4), 294-309.

Deshayes, G. P. (1854). Descriptions of twenty new species of the genus Cardita from the collection of Hugh Cuming, Esq. Proceedings of the Zoological Society of London, 20, 100103.

Ferussac, A. E. de. (1822). Tableaux systematiques des animaux mollusques (p. 111). Paris and London.

Fink, W. L., \& Zelditch, M. L. (1995). Phylogenetic Analysis of Ontogenetic Shape Transformations: A Reassessment of the Piranha Genus Pygocentrus (Teleostei). Systematic Biology, 44(3), 343-360.

Finlay, H. J. (1926). New Shells from New Zealand Tertiary Beds: Part 2. Transactions and Proceedings of the New Zealand Institute, 56, 227-258.

Finlay, H. J., \& Marwick, J. (1937). The Wangaloan and Associated Molluscan Faunas of Kaitangata-Green Island Subdivision. New Zealand Geological Survey Palaeontological Bulletin, 15, 1-140.

Fisher, D. C. (1994). Stratocladistics: morphological and temporal patterns and their relation to phylogenetic process. In L. Grande \& O. Rieppel (Eds.), Interpreting the Hierarchy of Nature (pp. 133-171). San Diego: Academic Press.

Fisher, D. C. (2008). Stratocladistics: Integrating Temporal Data and Character Data in Phylogenetic Inference. Annual Review of Ecology, Evolution, and Systematics, 39(1), 365385.

Fisher, D. C., Foote, M., Fox, D. L., \& Leighton, L. R. (2002). Stratigraphy in phylogeny reconstruction - comment on Smith (2000). Journal of Paleontology, 76(4), 585-586.

Fleming, C. A. (1966). Marwick's Illustrations of New Zealand Shells, with a Checklist of New Zealand Cenozoic Mollusca. New Zealand Department of Scientific and Industrial Research Bulletin, 173, 456.

Foote, Mike, \& Miller, A. I. (2007). Principles of Paleontology (p. 354). New York: W. H. Freeman and Company.

Foote, Mike. (1989). Perimeter-based Fourier analysis: A new morphometric method applied to the trilobite cranidium. Journal of Paleontology, 63(6), 880-885. 
Fox, D. L., Fisher, D. C., \& Leighton, L. R. (1999). Reconstructing Phylogeny with and without Temporal Data. Science, 284, 1816-1819.

Gevirtz, J. L. (1976). Fourier analysis of bivalve outlines: Implications on evolution and autecology. Journal of the International Association for Mathematical Geology, 8(2), 151-163.

Giribet, G. A. (2008). Bivalvia. In W. F. Ponder \& D. R. Lindberg (Eds.), Pbylogeny and Evolution of the Mollusca (pp. 1-469). Berkeley, Los Angeles, London: University of California Press.

Goldberg, E. E., Roy, K., Lande, R., \& Jablonski, D. (2005). Diversity, endemism, and age distributions in macroevolutionary sources and sinks. The American naturalist, 165(6), 623-33.

Goloboff, P. A., Mattoni, C. I., \& Quinteros, A. S. (2006). Continuous characters analyzed as such. Cladistics, 22, 589-601.

Gould, S. J. (1977). Ontogeny and Phylogeny Cambridge, MA: Belknap Press. 501p.

Gould, S. J. (2002). The Structure of Evolutionary Theory (p. 1433). Cambridge, MA: Harvard University Press.

Griffin, M., \& Nielsen, S. N. (2008). A revision of the type specimens of Tertiary molluscs from Chile and Argentina described by d'Orbigny (1842), Sowerby (1846) and Hupé (1854). Journal of Systematic Palaeontology, 6(3), 251-316.

Gunz, P., Mitteroecker, P., \& Bookstein, F. L. (2005). Semilandmarks in Three Dimensions. In D. E. Slice (Ed.), Modern Morphometrics in Physical Anthropology (pp. 7398). Kluwer Academic/Plenum Publishers, New York.

Haines, A. J., \& Crampton, J. S. (2000). Improvements to the method of Fourier shape analysis as applied in morphometric studies. Palaeontology, 43(4), 765-783.

Hallmann, N., Schöne, B. R., Strom, A., \& Fiebig, J. (2008). An intractable climate archive - Sclerochronological and shell oxygen isotope analyses of the Pacific geoduck, Panopea abrupta (bivalve mollusk) from Protection Island (Washington State, USA). Palaeogeography, Palaeoclimatology, Palaeoecology, 269(1-2), 115-126.

Harris, G. F. (1897). Catalogue of Tertiary Mollusca in the Department of Geology, British Museum (Natural History). Part 1. The Australasian Tertiary Mollusca. London: British Museum (Natural History). 407p.

Hautmann, M., \& Nutzel, A. (2005). First record of a heterodont bivalve (Mollusca) from the early Triassic: Palaeoecological significance and implications for the "Lazarus Problem." Palaeontology, 48(6), 1131-1138.

Hector, J. (1886). Outline of the Geology of New Zealand. Wellington: Government Printers. $88 \mathrm{p}$.

Hendrixson, B. E., \& Bond, J. E. (2009). Evaluating the efficacy of continuous quantitative characters for reconstructing the phylogeny of a morphologically homogeneous spider 
taxon (Araneae, Mygalomorphae, Antrodiaetidae, Antrodiaetus). Molecular Phylogenetics and Evolution, 53, 300-313.

Humphries, C. J. (2002). Homology, characters and continuous variables. In N. MacLeod and P. L. Forey (Eds.), Morphology, Shape and Phylogeny (pp. 9-26). CRC Press.

Hutton, F. W. (1873). Catalogue of the Tertiary Mollusca and Echinodermata of New Zealand in the collection of the Colonial Museum. Colonial Museum and Geological Survey Department. $76 \mathrm{p}$.

Hutton, F. W. (1905). On Crassatellites trailli. Transactions and Proceedings of the New Zealand Institute, 38, 65-66.

Innes, D. J., \& Bates, J. A. (1999). Morphological variation of Mytilus edulis and Mytilus trossulus in eastern Newfoundland. Marine Biology, 133(4), 691-699.

Iredale, T. (1924). Results from Roy Bell's molluscan collections. Proceedings of the Linnean Society of New South Wales, 49(3), 179-278.

Ivany, L. C., Wilkinson, B. H., \& Jones, D. S. (2003). Using stable isotopic data to resolve rate and duration of growth throughtout ontogeny: An example from the surf clam Spisula solidissima. Palaios, 16, 126-137.

Jablonski, D. (1986). Background and mass extinctions: the alternation of macroevolutionary regimes. Science, 231(4734), 129-33.

Jablonski, D., \& Raup, D. M. (1995). Selectivity of end-Cretaceous Marine Bivalve Extinctions. Science, 268, 15-17.

Jackson, D. A. (1993). Stopping Rules in Principal Components Analysis: A Comparison of Heuristical and Statistical Approaches. Ecology, 74(8), 2204-2214.

Jaecks, G. S., \& Carlson, S. J. (2001). How Phylogenetic Inference can Shape our View of Heterochrony: Examples from Thecideide Brachiopods. Paleobiology, 27(2), 205-225.

Jones, D. S., \& Gould, S. J. (1999). Direct Measurement of Age in Fossil Gryphaea: The Solution to a Classic Problem in Heterochrony. Paleobiology, 25(2), 158-187.

Jones, D. S., Quitmyer, I. R., \& Andrus, C. F. T. (2005). Oxygen isotopic evidence for greater seasonality in Holocene shells of Donax variabilis from Florida. Palaeogeography, Palaeoclimatology, Palaeoecology, 228(1-2), 96-108.

Jones, D. S., Williams, D. F., Arthur, M. A., \& Krantz, D. E. (1984). Interpreting the paleoenvironmental, paleoclimatic and life history records in mollusc shells. Geobios, Memoire Special, 8, 333-339.

Kaesler, R. L., \& Waters, J. A. (1972). Fourier Analysis of the Ostracode Margin. Geological Society of America Bulletin, 83 (April), 1169-1178. 
Keyes, I. W. (1972). Biological Type Specimens in the New Zealand Geological Survey II. Cenozoic Bivalve and Scaphopod Mollusca. New Zealand Geological Survey Palaeontological Bulletin, 45, 1-113.

King, P. R., Naish, T. R., Browne, G. H., Field, B. D., \& Edbrooke, S. W. (1999). Cretaceous to Recent sedimentary patterns in New Zealand. Institute of Geological and Nuclear Sciences folio series, 1, 1-35.

Kirby, M. X. (2001). Differences in growth rate and environment between Tertiary and Quaternary Crassostrea oysters. Paleobiology, 27(1), 84-103.

Klingenberg, C. P., \& Gidaszewski, N. a. (2010). Testing and quantifying phylogenetic signals and homoplasy in morphometric data. Systematic Biology, 59(3), 245-61.

Kosnik, M. A., Jablonski, D., Lockwood, R., \& Novack-Gottshall, P. M. (2006). Quantifying Molluscan Body Size in Evolutionary and Ecological Analyses: Maximizing the Return on Data-Collection Efforts. Palaios, 21(6), 588-597.

Lamarck, J. B. de. (1805). Suite des mémoires sur les fossiles des environs de Paris. Annales Muséum National D'Histoire Naturelle, Paris, 6, 407-415.

Laws, C. R. (1935). New Eocene Mollusca from New Zealand. Transactions and Proceedings of the New Zealand Institute, 65, 23-29.

Lazier, A. V., Smith, J. E., Risk, M. J., \& Schwarcz, H. P. (1999). The skeletal structure of Desmophyllum cristagalli: the use of deep-water corals in sclerochronology. Lethaia, 32, 119-130.

Linnaeus, C. (1758). Systema Naturae per regna tria naturae ... editio decima, reformata. Tomus 1 Holmiae: Impensis Direct. Laurentii Salvii. 823p.

Lohmann, G. P. (1983). Eigenshape Analysis of Microfossils: A General Morphometric Procedure for Describing Changes in Shape. Mathematical Geology, 15(6), 659-672.

Lough, J. M., \& Barnes, D. J. (1990). Possible relationships between environmental variables and skeletal density in a coral colony from the central Great Barrier Reef. Journal of Experimental Marine Biology and Ecology, 134, 221-241.

Lutz, R. A., \& Rhoads, D. C. (1970). Growth Patterns within the Molluscan Shell: An Overview. In D. C. Rhoads \& R. A. Lutz (Eds.), Skeletal Growth of Aquatic Organisms: Biological Records of Environmental Change (pp. 203-248). New York and London: Plenum Press.

MacLeod, N. (1991). Punctuated Anagenesis and the Importance of Stratigraphy to Paleobiology. Paleobiology, 17(2), 167-188.

MacLeod, N. (1999). Generalizing and extending the eigenshape method of shape space visualization and analysis. Paleobiology, 25(1), 107-138.

MacLeod, N. (2002). Phylogenetic signals in morphometric data. In N. MacLeod and P. L. Forey (Eds.), Morphology, Shape and Phylogeny (pp. 100-138). CRC Press. 
Maddison, D. R., \& Maddison, W. P. (2005). MacClade 4: Analysis of phylogeny and character evolution. Retrieved from http://macclade.org

Marcot, J. D., \& Fox, D. L. (2008). StrataPhy: A new computer program for stratocladistic analysis. Palaeontologia Electronica, 11(1), 1-16.

Marshall, P., \& Murdoch, R. (1919). Some new fossil species of Mollusca. Transactions and Proceedings of the New Zealand Institute, 51, 253-258.

Marwick, J. (1926). Molluscan Fauna of the Waiarekan Stage of the Oamaru Series. Transactions and Proceedings of the New Zealand Institute, 56, 307-316.

Marwick, J. (1931). The Tertiary Mollusca of the Gisborne District. New Zealand Geological Survey Palaeontological Bulletin, 13, 1-177.

Marwick, J. (1960). Early Tertiary Mollusca from Otaio Gorge, South Canterbury. New Zealand Geological Survey Palaeontological Bulletin, 33, 1-32.

McGregor, H. V., \& Gagan, M. K. (2003) Diagenesis and geochemistry of Porites corals from Papua New Guinea: Implications for paleoclimate reconstruction. Geochimica et Cosmochimica Acta, 67, 2147-2156.

McNamara, K. J., \& McKinney, M. L. (2005). Heterochrony, disparity and macroveolution. Paleobiology, 31(2), 17-26.

Meesook, A., \& Grant-Mackie, J. A. (1995). Upper Jurassic stratigraphy, south Kawhia region, New Zealand. New Zealand Journal of Geology and Geophysics, 38(3), 361-373.

Monteiro, L. R., Beneditto, A. P. M. D., Guillermo, L. H., \& Rivera, L. a. (2005).

Allometric changes and shape differentiation of sagitta otoliths in sciaenid fishes. Fisheries Research, 74(1-3), 288-299.

Neumayr, M. (1884). Zur Morphologie des Bivalvenschlosses. Sitzungsberichte der Akademie der Wissenschaften, Wein, 88(1), 385-418.

Newell, N. D. (1956). Fossil Populations. The Species Concept in Palaeontology: Systematics Association Special Publication 2 (pp. 63-82). The Systematics Association.

Noé, S. U., Lembke-Jene, L., \& Dullo, W.-C. (2007). Varying growth rates in bamboo corals: sclerochronology and radiocarbon dating of a mid-Holocene deep-water gorgonian skeleton (Keratoisis sp.: Octocorallia) from Chatham Rise (New Zealand). Facies, 54(2), 151-166.

Perez, S. I., Bernal, V., \& Gonzalez, P. N. (2006). Differences between sliding semilandmark methods in geometric morphometrics, with an application to human craniofacial and dental variation. Journal of anatomy, 208(6), 769-84.

Pimental, R. A., \& Riggins, R. (1987). The Nature of Cladistic Data. Cladistics, 3, 201-209. 
Powell, A. W. B. (1931). Waitotaran faunules of the Wanganui System and descriptions of new species of Mollusca from the New Zealand Pliocene. Records of the Auckland Institute and Museum, 1, 85-112.

Powell, A. W. B. (1938). Tertiary Molluscan Faunules from the Waitemata Beds. Transactions and Proceedings of the New Zealand Institute, 68, 362-379.

Powell, A. W. B., \& Bartrum, J. A. (1929). The Tertiary (Waitematan) Molluscan Fauna of Oneroa, Waiheke Island. Transactions and Proceedings of the New Zealand Institute, 60, 395 447.

Pritchard, G. B. (1903). Lamellibranchs, Pt. 3. Contributions to the Palaeontology of the Older Tertiary of Victoria, 15, 87-103.

Raup, D. M., \& Jablonski, D. (1993). Geography of end-Cretaceous marine bivalve extinctions. Science (New York, N.Y.), 260, 971-3.

Richardson, C. A. (2001). Molluscs as archives of environmental change. Oceanography and Marine Biology: An Annual Review, 39, 103-164.

Rohlf, F. J. (1999). Shape Statistics: Procrustes Superimposition and Tangent Spaces. Journal of Classification, 16, 197-223.

Rohlf, F. J., \& Archie, J. W. (1984). A Comparison of Fourier Methods for the Description of Wing Shape in Mosquitoes (Diptera: Culicidae). Systematic Zoology, 33(3), 302-317.

Roopnarine, P. D., \& Beussink, A. (1999). Extinction and naticid predation of the bivalve Chione von Muhlfeld in the late Neogene of Florida. Palaeontologia Electronica, 1-24.

Savazzi, E. (1990). Biological aspects of theoretical shell morphology. Lethaia, 23, 195-212.

Seilacher, A. (1970) Arbeitskonzept zur konstruktions-Morphologie. Lethaia, 3, 393-396

Schatz, W. (2005). Palaeoecology of the Triassic black shale bivalve Daonella-new insights into an old controversy. Palaeogeography, Palaeoclimatology, Palaeoecology, 216(3-4), 189201.

Schneider, J. A. (2001). Bivalve systematics during the 20th century. Journal of Paleontology, 75(6), 1119-1127.

Scholz, H., \& Hartman, J. H. (2007). Fourier analysis and the extinction of unionoid bivalves near the Cretaceous-Tertiary boundary of the Western Interior, USA: Pattern, causes, and ecological significance. Palaeogeography, Palaeoclimatology, Palaeoecology, 255(1-2), 48-63.

Schöne, B. R., Fiebig, J., Pfeiffer, M., Gle $\beta$, R., Hickson, J., Johnson, A. L., Dreyer, W., et al. (2005). Climate records from a bivalved Methuselah (Arctica islandica, Mollusca; Iceland). Palaeogeography, Palaeoclimatology, Palaeoecology, 228(1-2), 130-148.

Scott, G. H. (1980). The value of outline processing in the biometry and systematics of fossils. Palaeontology, 23(4), 757-768. 
Seed, R. (1970). Shell Growth and Form in the Bivalvia. In D. C. Rhoads \& R. A. Lutz (Eds.), Skeletal Growth of Aquatic Organisms: Biological Records of Environmental Change (pp. 23-61). New York and London: Plenum Press.

Seilacher, A. (1984). Constructional morphology of bivalves: Evolutionary pathways in primary versus secondary soft-bottom dwellers. Palaeontology, 27(2), 207-237.

Skelton, P. W., Crame, J. A., Morris, N. J., \& Harper, E. M. (1990). Adaptive divergence and taxonomic radiation in post-Palaeozoic bivalves. In P. D. Taylor \& G. P. Larwood (Eds.), Major Evolutionary Radiations: Systematics Association Special Volume 42 (Vol. 42, pp. 91-11). Oxford: Clarendon Press.

Smith, A. B. (2000). Stratigraphy in phylogeny reconstruction. Journal of Paleontology, 74(5), 763-766.

Smith, T. E., Ydenberg, R. C., \& Elner, R. W. (1999). Foraging behaviour of an excavating predator, the red rock crab (Cancer productus Randall) on soft-shell clam (Mya arenaria L.). Journal of Experimental Marine Biology and Ecology, 238(2), 185-197.

Spencer, H. G., Marshall, B. A., Maxwell, P. A., Grant-Mackie, J. A., Stilwell, J. D., Willan, R. C., Campbell, H. J., et al. (2009). Phylum Mollusca. In D. P. Gordon (Ed.), New Zealand Inventory of Biodiversity: Volume 1. Kingdom Animalia: Radiata, Lophotrochozoa, Deuterostomia (pp. 161-254).

Stanley, S. M. (1968). Post-Paleozoic Adaptive Radiation of Infaunal Bivalve Molluscs: A Consequence of Mantle Fusion and Siphon Formation. Journal of Paleontology, 42(1), 214-229.

Stanley, S. M. (1970). Relation of Shell Form to Life Habits of the Bivalvia (Mollusca). Geological Society of America Memoir, 125, 1-296.

Stanley, S. M. (1975). Why Clams have the Shape they Have: An Experimental Analysis of Burrowing. Paleobiology, 1(1), 48-58.

Stasek, C. R. (1963). Orientation and form in the bivalved Mollusca. Journal of Morphology, $112(3), 195-214$.

Suter, H. (1914). Revision of the Tertiary Mollusca of New Zealand. New Zealand Geological Survey Palaeontological Bulletin, 2, 1-64.

Suter, H. (1917). Descriptions of new Tertiary Mollusca occurring in New Zealand, accompanied by a few notes on necessary changes in nomenclature, Part 1. New Zealand Geological Survey Palaeontological Bulletin, 5, 1-93.

Swiderski, D. L., Zelditch, M. L., \& Fink, W. L. (1998). Why Morphometrics is Not Special: Coding Quantitative Data for Phylogenetic Analysis. Systematic Biology, 47(3), 508-519.

Swiderski, D. L., Zelditch, M. L., \& Fink, W. L. (2002). Comparability, morphometrics and phylogenetic systematics. Morphology, Shape and Phylogeny (pp. 68-99). 
Taylor, J. D., Kennedy, W. J., \& Hall, A. (1973). The shell structure and mineralogy of the Bivalvia: Lucinacea-Clavagelllacea. Conclusions. Bulletin of the British Museum of Natural History (Zoology), 22, 254-294.

Thompson, D. W. (1942). On Growth and Form (p. 1116). London: Cambridge University Press.

Thorpe, R. S. (1984). Coding Morphometric Characters for Constructing Distance Wagner Networks. Evolution, 38(2), 244-255.

Vermeij, G. J. (1983). Traces and trends of predation, with special reference to bivalved animals. Palaeontology, 26(3), 455-465.

Wagner, P. J. (2002). Testing phylogenetic hypotheses with stratigraphy and morphology a comment on Smith (2000). Journal of Paleontology, 76(4), 590-593.

Webster, M., \& Sheets, H. D. (2010). A practical introduction to landmark-based geometric morphometrics. In J. Alroy \& G. Hunt (Eds.), Quantitative Methods in Paleobiology, Paleontological Society Papers, vol. 16 (pp. 163-188).

Wilson, E. O. (2004). Taxonomy as a fundamental discipline. Philosophical transactions of the Royal Society of London. Series B, Biological sciences, 359(1444), 739.

Yonge, C. M. (1953). The Monomyarian Condition in the Lamellibranchia. Transactions of the Royal Society of Edinburgh, 62(2), 443-478.

Young, G. C., \& Laurie, J. R. (Eds.). (1996). An Australian Phanerozoic Timescale (p. 279). Melbourne: Oxford University Press.

Zelditch, M. L., Bookstein, F. L., \& Lundrigan, B. L. (1992). Ontogeny of Integrated Skull Growth in the Cotton Rat Sigmodon fulviventer. Evolution, 46(4), 1164-1180.

Zelditch, M. L., Sheets, H. D., \& Fink, W. L. (2000). Spatiotemporal reorganization of growth rates in the evolution of ontogeny. Evolution; international journal of organic evolution, 54(4), 1363-71.

Zelditch, M. L., Swiderski, D. L., Sheets, H. D., \& Fink, W. L. (2004). Geometric Morphometrics for Biologists. Elsevier Ltd.

Zittel, K. A. von. (1863). Beitrage zur Palaontologie von Neuseeland. Nenes Jahrbuch fur Mineralogie, Geologie und Palaontologie 1863, 146-159.

Zittel, K. A. von. (1865). Fossile Mollusken und Echinodermen aus Neu-Seeland. Nebst Beitragen von den Herren Bergrath Franz Ritter v. Hauer und Professor Eduard Suess. Palaontologie von Neu-Seeland. Beitrage zur Kenntniss der fossilien Flora und Fauna der Provinzen Auckland und Nelson, von Prof. Dr. F. Unger, Prof. Dr. Karl Zittel, Prof. E. Suess, Felix Karrer, Dr. Ferdinand Stoliczkea, Dr. Guido Stache, Dr. Gustave Jaeg (pp. 15-68). 
Appendix 1:

Morphometrics 


\section{A1.1 Comparing morphometric methods for shape analysis of fossil bivalves}

We have compared four different morphometric datasets across a group of New

Zealand crassatellid bivalves, in order to select the method that offers the most discriminatory power with the greatest coverage of anatomy. These datasets are; (1) a seven-landmark/eighteen-semilandmark configuration summarising internal anatomy only; (2) external outlines captured by Fourier transform; (3) external outlines captured by (varying numbers of) semilandmarks; and (4) a seven landmark/thirty-eight semilandmark configuration that covers both internal anatomy and outline shape. Using jackknifed reassignment tests in canonical variates analysis (CVA), correct reassigment of specimens to their a priori groups were compared for each method, and using discriminant function analysis (DFA), degree of separation between a priori groups examined pairwise was likewise compared for each method.

\section{A1.1.1 Methods}

Dataset 1: Seven landmarks and twenty-eight semilandmarks which summarised the internal morphology of the shell were captured from a new set of digital photographs and subjected to Procrustes superimposition following the methods described in Webster \& Sheets (2010), using the Integrated Morphometrics Package (IMP) suite of programs (http://www3.canisius.edu/ sheets/morphsoft.html). DFA and CVA were performed in R (function 'lda', R Development Core Team, 2012).

Dataset 2: Fourier analysis (dataset 2) was performed using the method described in Crampton \& Maxwell (2000) on the "adult" (largest size-class) outlines from that study, using the programs Hangle, Htree and Hcurve (Haines \& Crampton, 2000). The starting point of the trace corresponds to the umbo of the shell. Starting points are normalised for in Htree according to properties of the entire dataset, matching most-similar outlines in a pairwise fashion to minimise root-mean-square differences between their tangent angle curves. This differs from the matching procedure of Hmatch (Haines \& Crampton, 2000) 
in that it starts by matching most-similar outlines instead of those that are most unlike each other. In this way the normalisation is relatively sensitive to outliers.

Dataset 3: Configurations of semilandmarks around the external outline were subsampled form 1024 uniformly-spaced coordinates generated from the Fourier dataset using 511 harmonics and the program Hshape (Haines \& Crampton, 2000). The subsampled points start at the umbo and are uniformly spaced except at the umbo. The sets of coordinates thus produced were then treated according to the methods for sliding semilandmarks, as explained in Webster \& Sheets (2010). In order to assess the effect that varying numbers of outline semilandmarks would have on the results, four different versions of this dataset were created, with 28, 100, 500 and 1024 points respectively. Twenty-eight represents the same number of points used for the pallial line in the internal-only dataset, 1024 is the same number of points as in the original Fourier dataset, and 100 and 500 were chosen as intermediate values between these extremes. The data captured by the four different versions are illustrated in Appendix Figure 1.1.

Dataset 4: Seven landmarks and thirty-eight semilandmarks summarising the interal morphology and outline shape of the shells were captured from a new set of digital photographs and subjected to Procrustes superimposition following the methods described in Webster \& Sheets (2010), using the Integrated Morphometrics Package (IMP) suite of programs (http://www3.canisius.edu/ sheets/morphsoft.html). DFA and CVA were performed in R (function 'lda', R Development Core Team, 2012).

\section{A1.1.2 Results}

CVA: A CVA was run for each dataset on all groups with $\mathrm{n}>5$. For dataset 3 , all four subsets were analysed. The results of the CVA jackknifed reassignment tests (see main text under Materials and Methods) for the variations on dataset 3 are summarised in Appendix Table 1.1. The best result is achieved by the 28 point dataset. Consequently, this is the 
version of dataset 3 that was used in subsequent interpretations. The same data $(\%$ correct jackknifed reassignments) for the 28 point Dataset 3 and the other three datasets are summarised in Appendix Table 1.2.
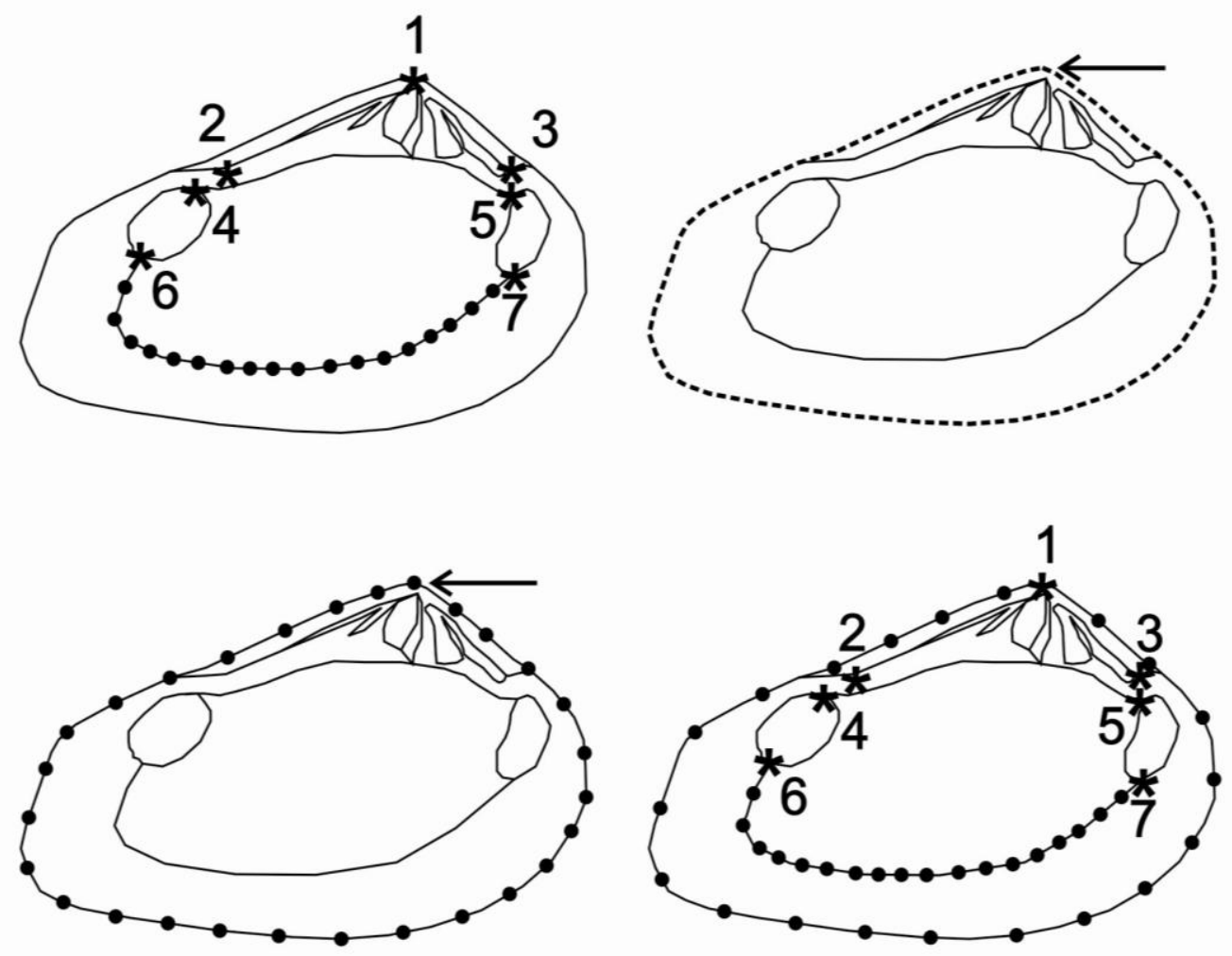

* (a) Landmark

- $\quad$ (b) Semilandmark

(c) Outline curve

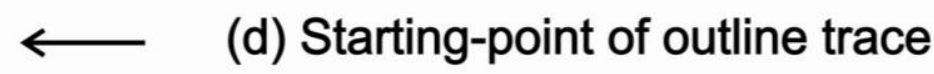

Appendix Figure 1.1: Diagrams of the four datasets used in this study: Dataset 1 (top left) (landmarks/semilandmarks of the internal anatomy); Dataset 2 (top right) (outlines captured using Fourier transform); Dataset 3 (bottom left) (outlines captured by semilandmarks subsampled from Fourier outlines); and Dataset 4 (bottom right) (landmarks/semilandmarks of the internal anatomy and outline shape). 'Starting point of trace' refers to the umbo, the location of which was standardised for using Htree (see text). 


\begin{tabular}{ccccc}
\hline OTU & 28 pts & 100 pts & 500 pts & 1024 pts \\
\hline 2 & 82 & 76 & 74 & 45 \\
3 & 71 & 63 & 67 & 46 \\
4 & 80 & 80 & 80 & 20 \\
5 & 73 & 82 & 82 & 82 \\
6 & 83 & 83 & 72 & 62 \\
7 & 90 & 80 & 60 & 60 \\
8 & 67 & 58 & 50 & 25 \\
9 & 64 & 45 & 55 & 18 \\
10 & 86 & 86 & 86 & 75 \\
13 & 80 & 60 & 47 & 47 \\
\hline Average \% correct & 77 & 71 & 67 & 48 \\
\hline Appendix Tab $11:$ Compars
\end{tabular}

Appendix Table 1.1: Comparison of \% correct reassignment of specimens to OTUs by jackknifed reassignment tests in CVA for four different variations on the subsampled semilandmark outline Dataset 3.

\begin{tabular}{ccccc}
\hline OTU & $\begin{array}{c}\text { Internal } \\
\text { only } \\
\text { (7 landmarks) }\end{array}$ & $\begin{array}{c}\text { Outline } \\
\text { (Fourier, 14 } \\
\text { harmonics) }\end{array}$ & $\begin{array}{c}\text { Outline } \\
\text { (Semilandmarks, } \\
28 \text { pts) }\end{array}$ & $\begin{array}{c}\text { Full shape } \\
\text { (Landmarks and } \\
\text { semilandmarks) }\end{array}$ \\
\hline 2 & 96 & 79 & 82 & 83 \\
3 & 92 & 63 & 71 & 83 \\
4 & 100 & 80 & 80 & 73 \\
5 & 100 & 91 & 73 & 86 \\
6 & 97 & 90 & 83 & 80 \\
7 & 100 & 100 & 90 & 88 \\
8 & 100 & 58 & 67 & 81 \\
9 & 91 & 73 & 64 & 71 \\
10 & 100 & 86 & 86 & 100 \\
13 & 100 & 93 & 80 & 83 \\
\hline Mean $\%$ correct & 98 & 81 & 77 & OTU
\end{tabular}

Appendix Table 1.2: Comparison of \% correct reassignment of specimens to OTUs by jackknifed reassignment tests in CVA for all four datasets.

DFA: DFA is a two-group CVA which collapses the multidimensional separation down to a single axis. Pairs of groups were chosen to illustrate a range of morphological relationships between 'very similar' and 'very disparate'. Groups with larger numbers of specimens were preferred. Figure 3 shows histograms produced by DFA, illustrating the greatest separation possible between the selected groups. For example, the third column of Appendix Figure 1.2 shows the results of DFA performed on each of the datasets for the pair of OTUs 3 and 9. These OTUs are shown to be separable by DFA on all four datasets. The greatest degree of separation is in the internal-only dataset, followed by the semilandmark outlines, 
and the least degree of separation is in the Fourier outlines, the full shape dataset being intermediate between these extremes.

\section{A1.1.3 Summary}

Based on the results presented here from all methods examined, we can draw the following conclusions:

- That internal anatomy discriminates OTUs to the greatest effect.

- That Fourier analysis performs slightly better than subsampled semilandmarks at discriminating OTUs, but not significantly.

- That a combined internal anatomy/outline shape approach performs better than outlines on their own.

Whereas it does not perform as well as the internal anatomy, a full-shape approach is preferrable for addressing questions of evolution and phylogenetics using morphometrics, as it takes into account as much variation, and as much of the anatomy, as possible. The outline of the bivalve, as discussed in the main text, is a vital component of its adaptation to its habitat, and should not be discarded. Furthermore, as this study is explicitly concerned in part with the relationship between internal and external morphology, including both in the landmark/semilandmark configuration is a requirement. However, if taxonomic discrimination is the ultimate goal of a given analysis, it may be that internal anatomy, which is less plastic than outline shape, would provide more reliable group assignments. 


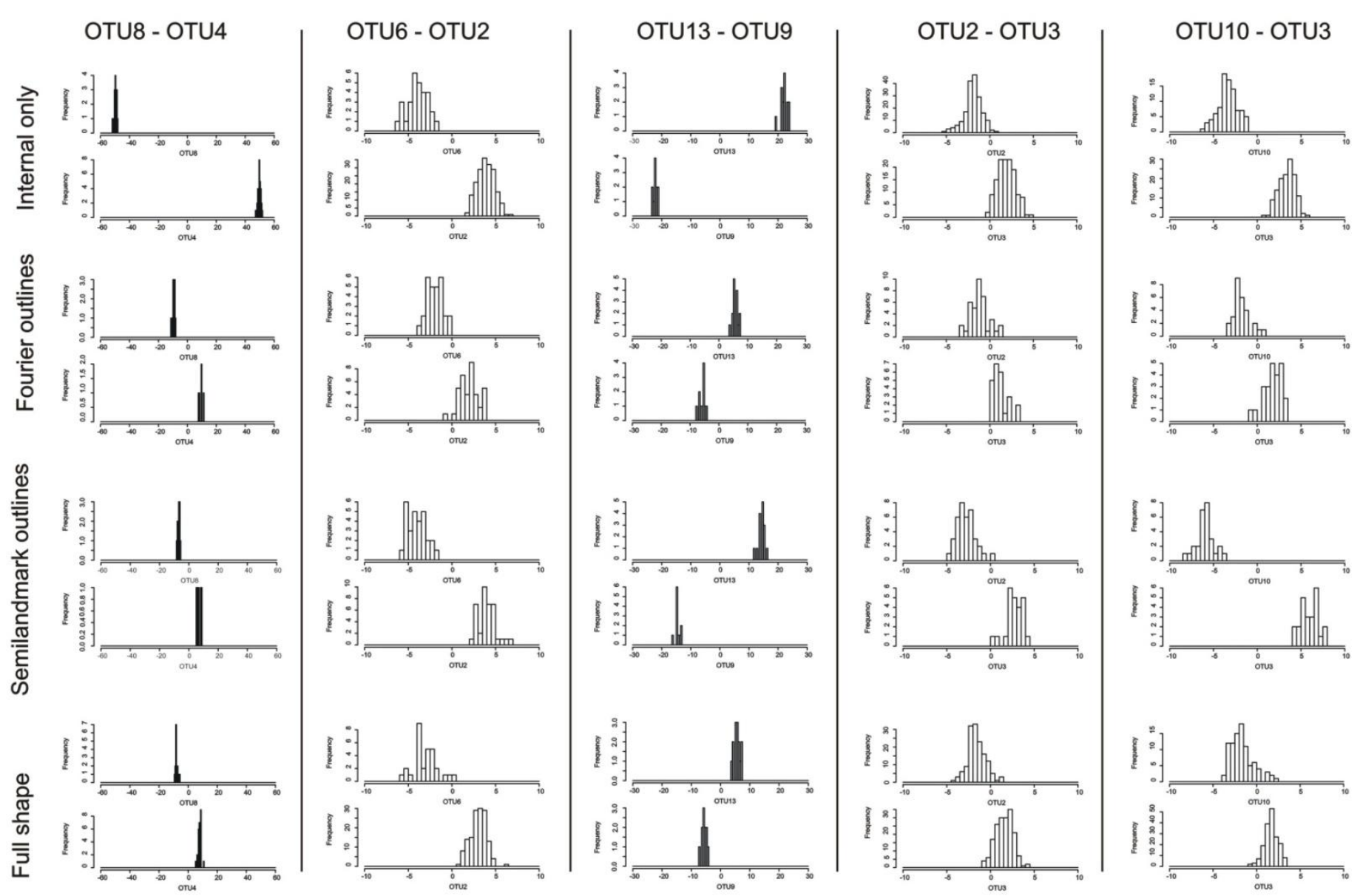

Appendix Figure 1.2: Stacked histograms of individual specimens scored by DFA. Columns are OTU pairs - rows are different datasets. Pairs were selected to cover a range of relationships between 'very similar' and 'very disparate'. 


\section{A1.2 Left vs. right valves}

In order to test for equivalveness of the taxa under investigation, a multivariate analysis of variance (MANOVA) was run on each OTU with $\mathrm{n}>15$, treating valve (left or right) as the grouping factor.

\begin{tabular}{cccccc}
\hline OTU & $\mathrm{n}$ & Df & Hotelling-Lawley & approx. $\mathrm{F}$ & $\operatorname{Pr}(>\mathrm{F})$ \\
\hline 2 & 144 & 1 & 0.0484 & 1.6830 & 0.1573 \\
3 & 179 & 1 & 0.0337 & 1.4680 & 0.2139 \\
4 & 30 & 1 & 0.1901 & 1.1881 & 0.3403 \\
6 & 30 & 1 & 0.0215 & 0.1344 & 0.9682 \\
8 & 16 & 1 & 0.8534 & 2.3468 & 0.1186 \\
10 & 91 & 1 & 0.2305 & 4.9556 & $0.0012^{* *}$ \\
\hline
\end{tabular}

Appendix Table 1.3: Left vs right valve MANOVA results for all OTUs with $\mathrm{n}>15$ (** indicates significance).

Only OTU 10 shows significant valve inquality. The degree of inequality is shown in Appendix Figure 1.3.
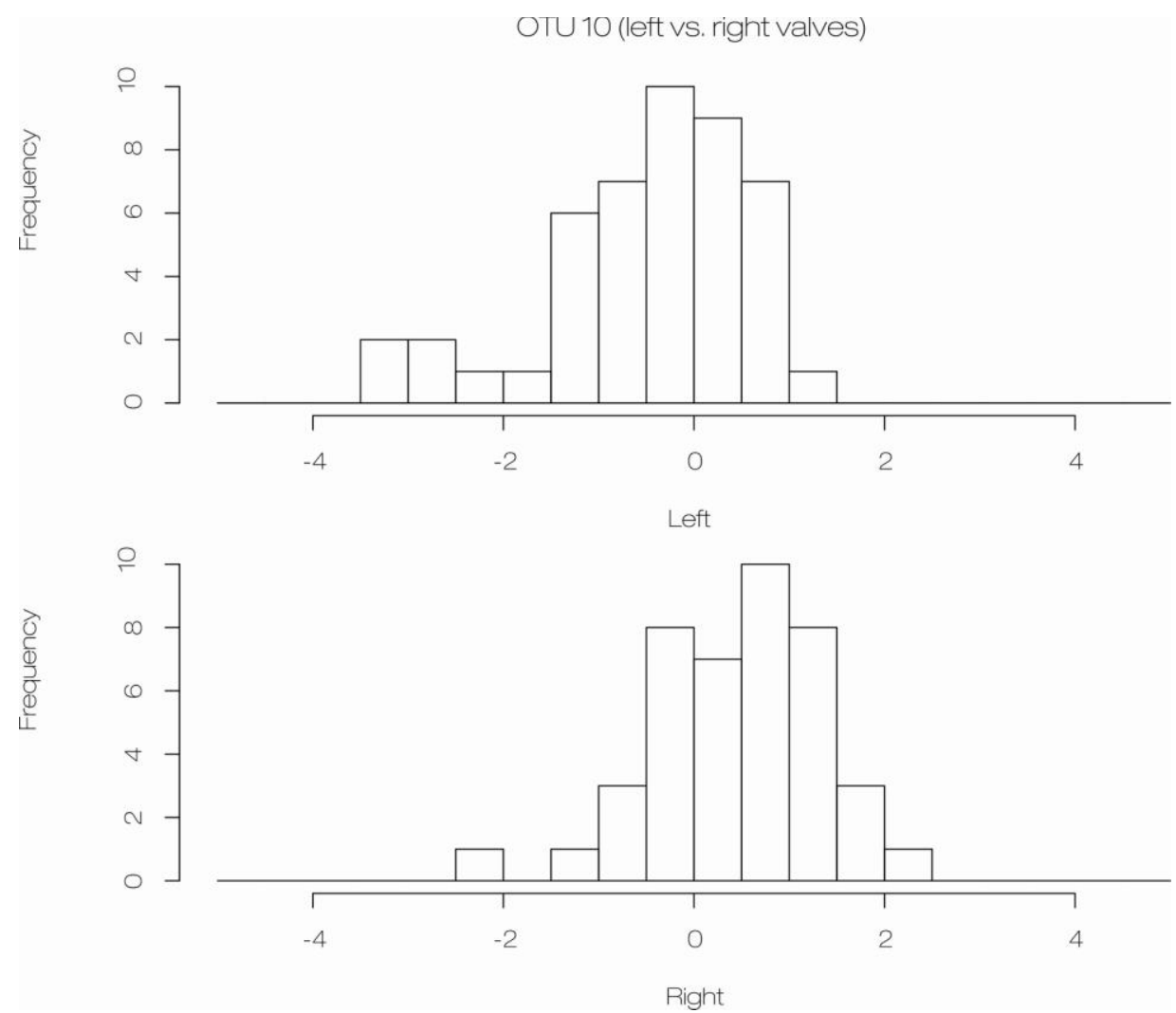

Appendix Figure 1.3: Left vs. right valve histograms for OTU 10 
To show the actual physical differences between the left and right valves of OTU 10, mean shapes are presented in Bookstein registration in Appendix Figure 1.4, with the baseline at landmarks 1 and 33 (corresponding to the axial length - see main text for explanation).

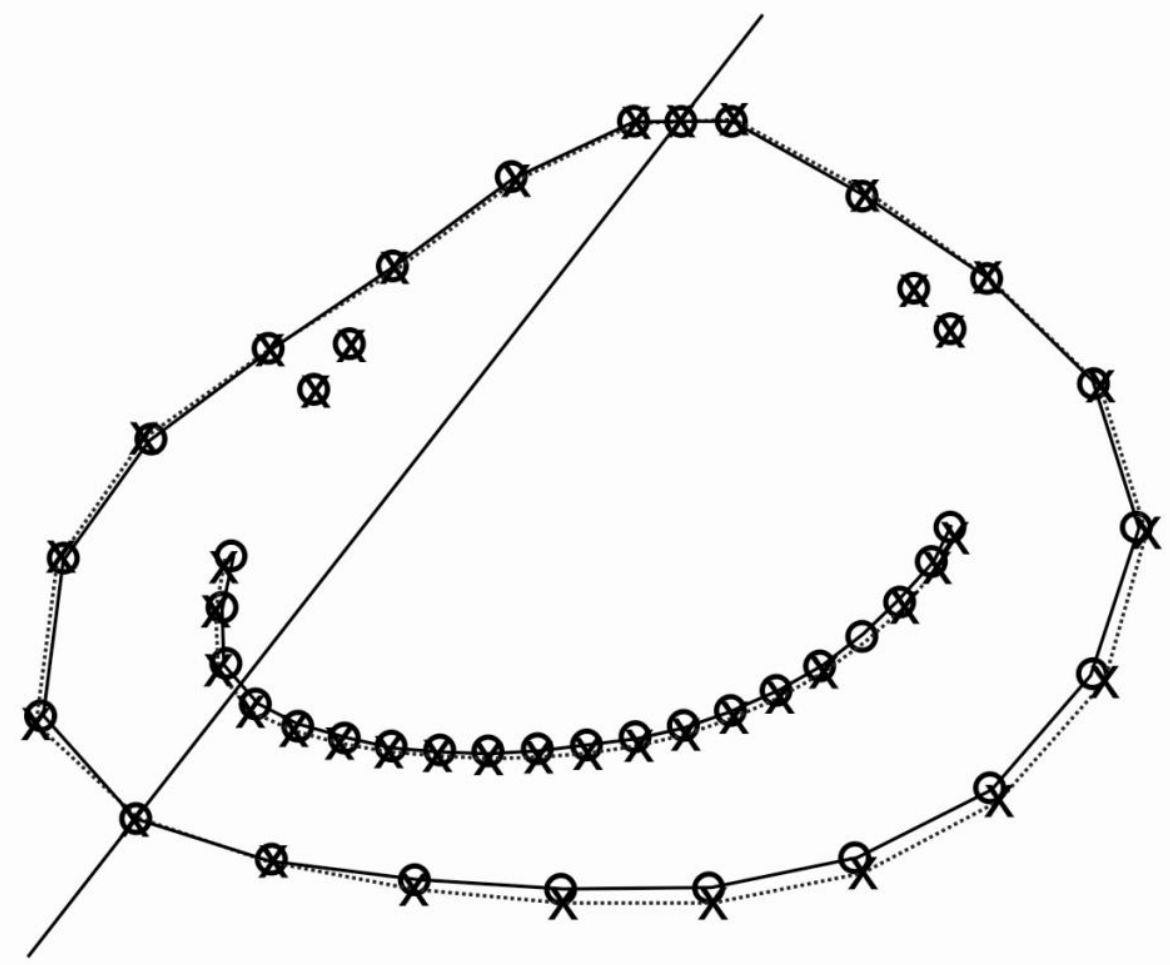

Appendix Figure 1.4: Mean left (circles) and right (crosses) valve shapes in Bookstein registration

\section{A1.2.1 Summary}

Although differences between the two valves are statistically significant, the observed inequality in valve shape is not great enough to warrant splitting left and right valves in analysis. 
Appendix 2:

\section{Phylogenetics}




\section{A2.1 Cladogram derived from discrete morphological and continuous morphometric data, without stratigraphic input}

To compare with the combined morphological, morphometric and stratigraphic tree shown in the main text, the same dataset was run in TNT (Goloboff et al., 2008), minus the stratigraphic character and with the morphometric data as ranges of standard error on the mean rather than binned using the boxplot method of Almeida and Bisby (1984).

Using implicit numeration methods in TNT, three shortest cladograms were found, and a strict consensus of these is presented in Figure 1.

Unsuprisingly, without the inclusion of stratigraphic data the cladogram is much less consistent with known stratigraphic order. Older taxa such as Eucrassatella australis and Spissatella media are nested in derived clades and many long 'ghost ranges' are required to fit this cladogram to the known stratigraphic ranges of included species.

The cladogram does recover a monophyletic Eucrassatella clade, which includes E. australis, and recovers a number of sister-group relationships also found by the phylogeny in Figure 3.4 in the main text $(S$. acculta + S. poroleda; S. subobesa + S. maudensis; E. marshalli + E. kingicola). However, it does not find the $S$. n. sp. C - S. trailli $-S$. clifdenensis lineage identified by previous authors and supported by morphometrics, which the stratocladistic phylogeny recovered. Overall, the purely morphological cladistic solution is less consistent with other data and with the fossil record than the stratocladistic solution. 

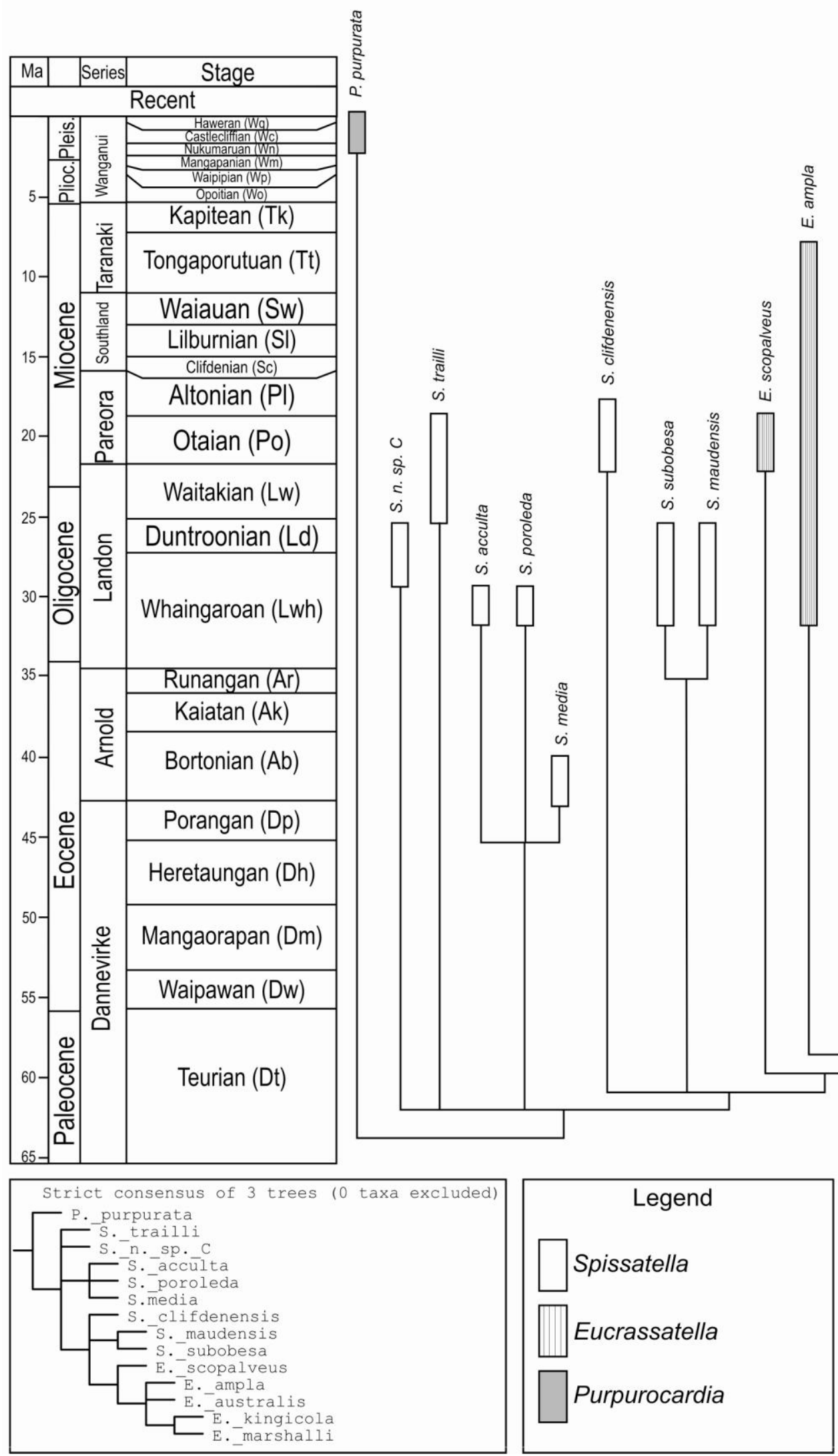

Appendix Figure 2.1: Cladogram derived from discrete morphological characters and continuous morphometric characters, using TNT (Goloboff et al., 2008). For the purposes of comparison with the phylogeny in the main text (Figure 3.4), this cladogram has been scaled to a geological timescale (original, unscaled cladogram in inset, bottom right). 


\section{Appendix 3:}

Estimating age jointly from band and isotope peak data

E. G. C. Smith 


\section{A3.1 Estimating age jointly from band and isotope peak data \\ E. G. C. Smith}

It is hypothesised that both bands and isotope peaks result from annual growth and annual environmental change respectively. Both quantities are uncertain. The average of the minimum and the maximum of each of the band and isotope peak counts is taken as an estimate of the mean for that specimen, and the separation between the minimum and the maximum is taken to be 4 standard deviations.

Call $\mathrm{B}$ the number of bands and $\mathrm{P}$ the number of peaks. In equations the hypothesis is

$$
\begin{aligned}
& \mathrm{B}_{\mathrm{j}}=\mathrm{Age}_{\mathrm{j}}+\text { scatter } \\
& \lambda \mathrm{P}_{\mathrm{j}}=\mathrm{Age}_{\mathrm{j}}+\text { scatter }
\end{aligned}
$$

where $j$ represents the $j^{\text {th }}$ specimen and the possibility of a systematic variation between peaks and bands is allowed for with the factor $\lambda$.

These equations are non-linear, but can be solved by linear-least squares after log transformation:

$$
\begin{aligned}
& \log B_{j}=\log A_{\mathrm{Ag}_{j}}+\text { scatter } \\
& \log \mathrm{P}_{\mathrm{j}}=\log \mathrm{Age}_{\mathrm{j}}-\log \lambda+\text { scatter }
\end{aligned}
$$

where $\log \lambda$ has been transferred to the RHS so that the set of $\log A g e_{j}$ and $\log \lambda$ are the parameters to be solved for.

One thousand random sets of $\mathrm{B}$ and $\mathrm{P}$ were made using the assumed means and standard deviations of the specimens, and assuming Gaussian distributions. Equations $2 \mathrm{a}$ and $\mathrm{b}$ were then solved by least squares for the $\log$ Ages and $\log \lambda$. A best estimate of $\log$ Age $_{j}$ was obtained by averaging the 1000 individual estimates, and 95\% confidence intervals for it were calculated from the spread of the log Ages. The means and 95\% limits were then exponentiated to give best Ages and $\lambda$, with corresponding 95\% confidence intervals. 